\title{
SCHOOL ACHIEVEMENT AND FAILURE IN PORTUGUESE AND SPANISH SPEAKING COUNTRIES
}

\section{EDITED BY: Edgar Galindo, Adelinda A. Candeias, Heldemerina S. Pires,}

and Miguel Ángel Carbonero

PUBLISHED IN: Frontiers in Psychology

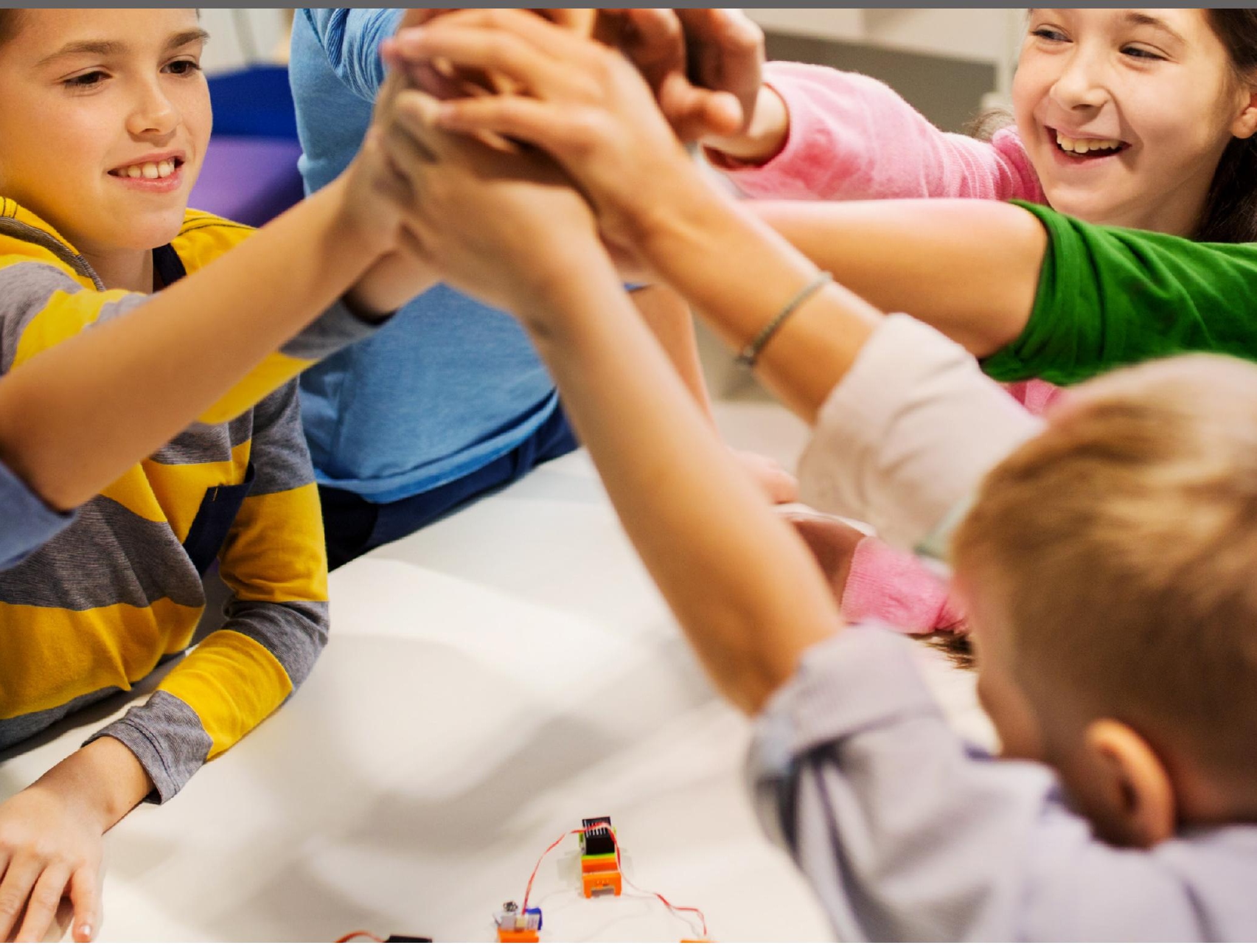

frontiers Research Topics 


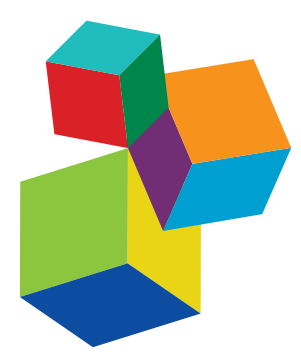

Frontiers Copyright Statement

C Copyright 2007-2018 Frontiers Media SA. All rights reserved.

All content included on this site, such as text, graphics, logos, button

icons, images, video/audio clips, downloads, data compilations and

software, is the property of or is

licensed to Frontiers Media SA

("Frontiers") or its licensees and/or subcontractors. The copyright in the text of individual articles is the property of their respective authors, subject to a license granted to Frontiers.

The compilation of articles constituting this e-book, wherever published, as well as the compilation of all other content on this site, is the exclusive property of Frontiers. For the

conditions for downloading and copying of e-books from Frontiers website, please see the Terms for Website Use. If purchasing Frontiers e-books from other websites or sources, the conditions of the website concerned apply.

Images and graphics not forming part of user-contributed materials may not be downloaded or copied without permission

Individual articles may be downloaded and reproduced in accordance with the principles of the CC-BY

licence subject to any copyright or other notices. They may not be re-sold as an e-book.

As author or other contributor you grant a CC-BY licence to others to reproduce your articles, including any graphics and third-party materials supplied by you, in accordance with the Conditions for Website Use and subject to any copyright notices which you include in connection with your articles and materials.

All copyright, and all rights therein, are protected by national and international copyright laws.

The above represents a summary only.

For the full conditions see the Conditions for Authors and the Conditions for Website Use.

ISSN 1664-8714

ISBN 978-2-88945-552-2

DOI $10.3389 / 978-2-88945-552-2$

\section{About Frontiers}

Frontiers is more than just an open-access publisher of scholarly articles: it is a pioneering approach to the world of academia, radically improving the way scholarly research is managed. The grand vision of Frontiers is a world where all people have an equal opportunity to seek, share and generate knowledge. Frontiers provides immediate and permanent online open access to all its publications, but this alone is not enough to realize our grand goals.

\section{Frontiers Journal Series}

The Frontiers Journal Series is a multi-tier and interdisciplinary set of open-access, online journals, promising a paradigm shift from the current review, selection and dissemination processes in academic publishing. All Frontiers journals are driven by researchers for researchers; therefore, they constitute a service to the scholarly community. At the same time, the Frontiers Journal Series operates on a revolutionary invention, the tiered publishing system, initially addressing specific communities of scholars, and gradually climbing up to broader public understanding, thus serving the interests of the lay society, too.

\section{Dedication to Quality}

Each Frontiers article is a landmark of the highest quality, thanks to genuinely collaborative interactions between authors and review editors, who include some of the world's best academicians. Research must be certified by peers before entering a stream of knowledge that may eventually reach the public - and shape society; therefore, Frontiers only applies the most rigorous and unbiased reviews.

Frontiers revolutionizes research publishing by freely delivering the most outstanding research, evaluated with no bias from both the academic and social point of view. By applying the most advanced information technologies, Frontiers is catapulting scholarly publishing into a new generation.

\section{What are Frontiers Research Topics?}

Frontiers Research Topics are very popular trademarks of the Frontiers Journals Series: they are collections of at least ten articles, all centered on a particular subject. With their unique mix of varied contributions from Original Research to Review Articles, Frontiers Research Topics unify the most influential researchers, the latest key findings and historical advances in a hot research area! Find out more on how to host your own Frontiers Research Topic or contribute to one as an author by contacting the Frontiers Editorial Office: researchtopics@frontiersin.org 


\section{SCHOOL ACHIEVEMENT AND FAILURE IN PORTUGUESE AND SPANISH SPEAKING COUNTRIES}

Topic Editors:

Edgar Galindo, University of Évora, Portugal

Adelinda A. Candeias, University of Évora, Portugal

Heldemerina S. Pires, University of Évora, Portugal

Miguel Ángel Carbonero, University of Valladolid, Spain

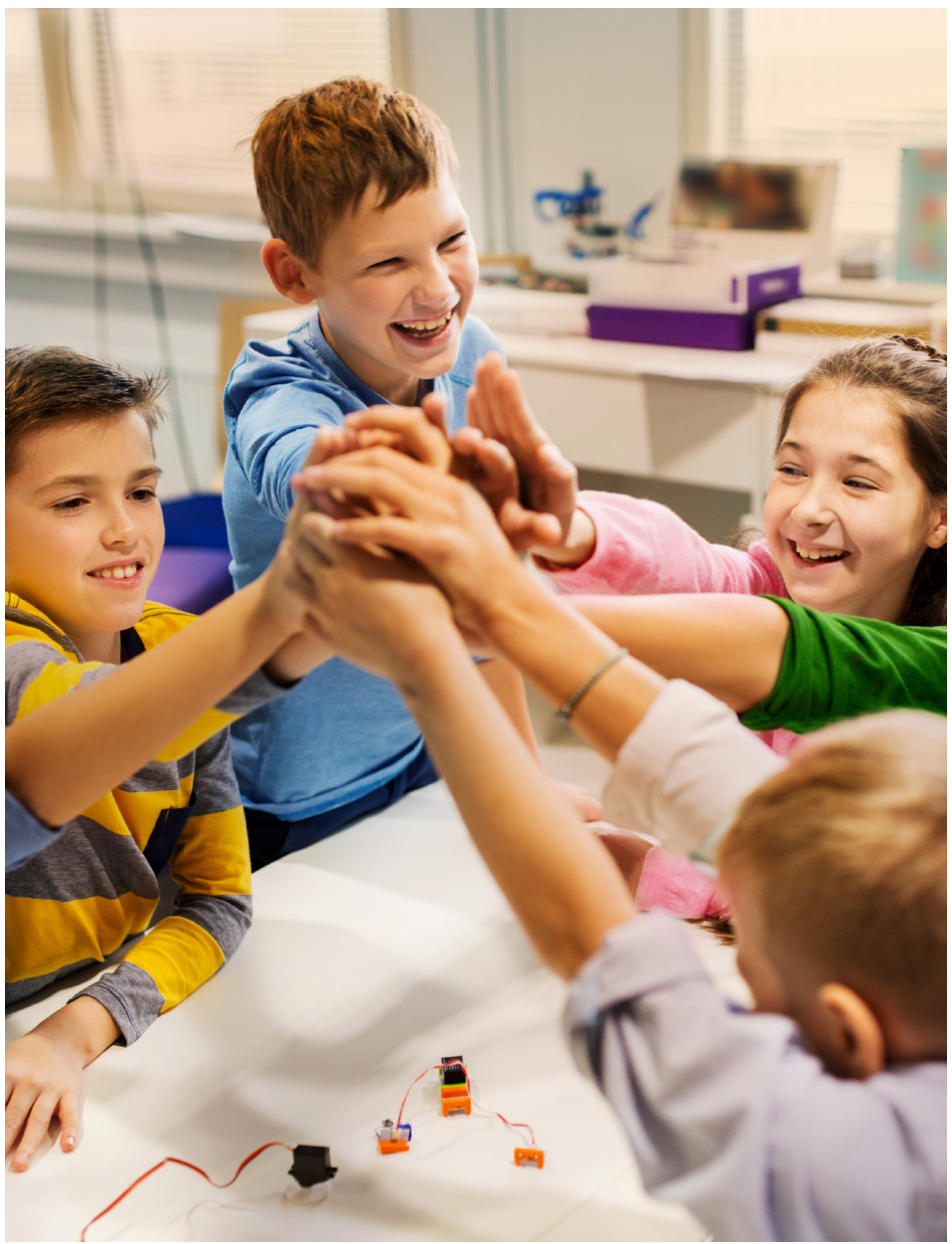

Cover image: Syda Productions/Shutterstock.com

This book is devoted to an increasingly important educational problem in the modern societies: school achievement and failure. School failure is presently a problem in developed as well as in developing countries. In the Spanish and Portuguese speaking countries in Europe and Latin America, school achievement and failure is consequently an important topic of political, social and scientific discussion. The following papers revise the latest research in the field, from the perspective of Psychology.

Citation: Galindo, E., Candeias, A. A., Pires, H. S., Carbonero, M. Á., eds. (2018). School Achievement and Failure in Portuguese and Spanish Speaking Countries. Lausanne: Frontiers Media. doi: 10.3389/978-2-88945-552-2 


\section{Table of Contents}

05 Editorial: School Achievement and Failure in Portuguese and Spanish Speaking Countries

Edgar Galindo, Adelinda A. Candeias, Heldemerina S. Pires and

Miguel Ángel Carbonero

\section{SECTION I}

\section{AN ANALYSIS OF VARIABLES}

08 The Role of Self-Control and Grit in Domains of School Success in Students of Primary and Secondary School

Xavier Oriol, Rafael Miranda, Juan C. Oyanedel and Javier Torres

17 Career Preparedness and School Achievement of Portuguese Children: Longitudinal Trend Articulations

Íris M. Oliveira, Maria do Céu Taveira and Erik J. Porfeli

30 Emotion Understanding, Social Competence and School Achievement in Children From Primary School in Portugal

Maria da Glória Franco, Maria J. Beja, Adelinda Candeias and Natalie Santos

45 School Achievement and Performance in Chilean High Schools: The Mediating Role of Subjective Wellbeing in School-Related Evaluations Verónica López, Juan C. Oyanedel, Marian Bilbao, Javier Torres, Denise Oyarzún, Macarena Morales, Paula Ascorra and Claudia Carrasco

60 Social and Emotional Learning and Academic Achievement in Portuguese Schools: A Bibliometric Study

Ana M. Cristóvão, Adelinda A. Candeias and José Verdasca

72 Predictive Relation Between Early Numerical Competencies and Mathematics Achievement in First Grade Portuguese Children

Lilia Marcelino, Óscar de Sousa and António Lopes

81 Academic Achievement in Physics-Chemistry: The Predictive Effect of Attitudes and Reasoning Abilities

Paulo N. Vilia, Adelinda A. Candeias, António S. Neto,

Maria Da Glória S. Franco and Madalena Melo

90 The Influence of Family Support According to Gender in the Portuguese Language Course Achievement

Heldemerina S. Pires, Adelinda A. Candeias, Luísa Grácio, Edgar Galindo and Madalena Melo

\section{SECTION II}

INTERVENTION STRATEGIES

98 Program to Promote Personal and Social Responsibility in the Secondary Classroom

Miguel A. Carbonero, Luis J. Martín-Antón, Lourdes Otero and

Eugenio Monsalvo 
110 Behavioral Skills Training in Portuguese Children With School Failure Problems

Edgar Galindo, Adelinda A. Candeias, Heldemerina S. Pires, Luísa Grácio and Marcus Stück

\section{SECTION III}

PREVENTION STRATEGIES

122 A National Early Intervention System as a Strategy to Promote Inclusion and Academic Achievement in Portugal

Vitor Franco, Madalena Melo, Graça Santos, Ana Apolónio and Leonor Amaral 
OPEN ACCESS

Edited by:

Puri Checa

Universidad de Granada, Spain

Reviewed by:

Antonio Valle,

University of A Coruña, Spain Alexandre Luiz De Oliveira Serpa, Hogrefe Publishing Group, Brazil

*Correspondence: Edgar Galindo edgar_galindo@hotmail.com

Specialty section:

This article was submitted to Educational Psychology, a section of the journal Frontiers in Psychology

Received: 27 April 2018 Accepted: 07 June 2018 Published: 25 June 2018

Citation:

Galindo E, Candeias AA, Pires HS and Carbonero MÁ (2018) Editorial: School Achievement and Failure in Portuguese and Spanish Speaking Countries. Front. Psychol. 9:1074 doi: 10.3389/fpsyg.2018.01074

\section{Editorial: School Achievement and Failure in Portuguese and Spanish Speaking Countries}

\author{
Edgar Galindo ${ }^{1 *}$, Adelinda A. Candeias ${ }^{1}$, Heldemerina S. Pires ${ }^{1}$ and \\ Miguel Ángelv Carbonero ${ }^{2}$
}

${ }^{1}$ Center for Research in Education and Psychology (CIEP), Psychology, Universidade de Évora, Évora, Portugal, ${ }^{2}$ Excellence Research Group GR179, Educational Psychology, University of Valladolid, Valladolid, Spain

Keywords: school achievement, school failure, academic achievement, educational psychology, applied psychology

\section{Editorial on the Research Topic}

\section{School Achievement and Failure in Portuguese and Spanish Speaking Countries}

School failure is an important social problem in the present world (Organization for Economic Co-operation Development, 2010). This seems to be especially true for Spanish and Portuguese speaking countries in Europe (Eurydice, 2011) and Latin America (Román, 2013). Consequently, school achievement and failure is an increasingly important topic of discussion and research. Psychology can make an important contribution to understanding these issues, emphasizing the individual perspective, i.e., defining academic and pre-academic skills for a good achievement and developing sound evaluation and intervention techniques for children with school failure problems. The following papers revise the latest developments in the field. The research covered tried to answer the most urgent questions on the topic: (1) Which variables are responsible for school achievement and failure? (2) Which intervention techniques can be used to help children with school failure problems?

All papers focused on children attending primary or secondary school, except one that dealt with prevention strategies for children at risk before schooling. Most sought correlations between determining variables and some measures of school achievement. Two studies applied intervention strategies designed to improve the academic performance of children with problems at school and systematically evaluated their results.

Oriol et al. observed the effect of self-control and grit on academic self-efficacy and satisfaction with school, using structural equation models. Both variables showed strong associations in both primary and secondary students. Grit is related to academic-self efficacy at both educational stages, but it is only correlated with satisfaction with school in secondary 
students. Self-control was only significantly related to school satisfaction in primary education. Oliveira et al. explored the links between career preparedness and academic development and how both varied across demographic characteristics during middle school years, employing gender and geographical location as potential moderators affecting the link between the domains of career and school. Results showed a longitudinal relationship between the school and work in youth.

Three studies focused on emotional variables. Franco et al. observed the relationship between emotion understanding and school achievement, considering age, gender, fluid intelligence, mother's educational level and social competence. A structural equation model revealed that the relationship between emotion understanding and school performance depended on a mediator variable designated as social competence. Mothers' educational level predicted social emotional competence and fluid intelligence was a predictor of emotion understanding, school achievement, and social emotional competence. A similar analysis was conducted by López et al. using structural equation modeling to observe the association of individual and school-related well-being variables with school achievement and performance in children who answered questionnaires assessing subjective wellbeing, social wellbeing at school, school climate, school social wellbeing and students' perceptions of teachers' wellbeing. Results showed that students' individual subjective wellbeing was associated with their achievement and performance in school. Cristóvão et al. reviewed the implementation in Portugal of programs to foster social and emotional learning (SEL), which was defined as the capacity to recognize and manage emotions, solve problems effectively, and establish positive relationships with others, and their results on academic achievement. After consulting several databases, they concluded that little such research is being produced in Portugal and what is carried out it scattered across many journals and authors.

Three more studies investigated the variables influencing academic success in specific subject matters. Marcelino et al. explored the role of early numerical competencies (ENC) (counting, number relations, and basic arithmetic operations) in early mathematics learning. Using a regression model, this study analyzed the relation between ENC and mathematics achievement in first-grade children. Results showed that children with low numerical competencies performed less well than those with moderate and high numerical competencies. Findings suggested that ENC are meaningful for predicting first-grade mathematics difficulties. Vilia et al. analyzed the impact of two variables on academic achievement in PhysicsChemistry, namely, student's attitudes toward the subject and reasoning abilities (measured respectively through the Attitude toward Physics-Chemistry Questionnaire/ATPCQ, and the Reasoning Test Battery/ RTB). An assessment using multiple regression stepwise analyses and standardized regression coefficients revealed ATPCQ and RTB to be significantly related to students' achievement in Physics and Chemistry. Pires et al. explored parental support as a variable determining success in a Portuguese language course. As expected, results showed a clear influence of parental support on academic achievement, but significant differences appeared according to gender, with girls being more sensitive to the affective dimension of parental support and boys to the instrumental one.

In his study of prevention measures applied in Portugal to children at risk, Franco et al. explained how the National System of Early Intervention contributed to promoting maximum development and the full inclusion of children up to 6 years of age, thus reducing the likelihood of school failure.

Last but not least, two studies applied psychology when implementing scientifically based intervention techniques for children with academic problems. Carbonero et al. carried out an intervention program based on Don Hellison's Positive Action Theory and Fishbein and Ajzen's Theory of the Reasoned Action, focusing on (a) teaching units on social responsibility, (b) student training in mediation processes, (c) teacher training, and (d) family training. Results showed that students schooled in social responsibility performed significantly better than those in a control group. Social responsibility seems to be related to commitment, self-discipline, and perseverance. Galindo et al. applied Behavioral Skills Training (BST), consisting of instructions, modeling, rehearsal, and feedback, to teach basic behavior (precurrents), academic behavior, or social behavior to a group of children with school failure problems, in two different studies. Results from the first study, using pre-test/post-test measures, showed an increase in academic achievement. A second study, using a multiple baseline design, showed few performance changes without training and academic improvement following BST. In both studies, comparable results occurred across students, demonstrating the positive effects of the intervention.

The approaches discussed in this Research Topic provide insight for teachers and psychologists so that they might better understand school achievement and failure, while it also serves as a source of potential tools for intervention in cases of school failure.

\section{AUTHOR CONTRIBUTIONS}

All authors listed made a substantial, direct and intellectual contribution to the work and approved it for publication.

\section{FUNDING}

This editorial was developed in the context of the Center for Investigation in Education and Psychology (Centro de Investigação em Educação e Psicologia), University of Evora, and the University of Valladolid. 


\section{REFERENCES}

Eurydice (2011). Grade Retention during Compulsory Education in Europe: Regulations and Statistics. Brussels: Education, Audiovisual and Culture Executive Agency.

Organization for Economic Co-operation and Development (2010). Overcoming Failure at School: Policies That Work. Paris: OECD.

Román C. M. (2013). Factores Asociados al Abandono y la Deserción Escolar en América Latina: una Mirada en Conjunto. REICE. Revista Iberoamericana sobre Calidad, Eficacia y Cambio en Educación. Available online at: http:// www.redalyc.org/articulo.oa?id=55127024002
Conflict of Interest Statement: The authors declare that the research was conducted in the absence of any commercial or financial relationships that could be construed as a potential conflict of interest.

Copyright $\odot 2018$ Galindo, Candeias, Pires and Carbonero. This is an open-access article distributed under the terms of the Creative Commons Attribution License (CC $B Y)$. The use, distribution or reproduction in other forums is permitted, provided the original author(s) and the copyright owner are credited and that the original publication in this journal is cited, in accordance with accepted academic practice. No use, distribution or reproduction is permitted which does not comply with these terms. 


\section{OPEN ACCESS}

Edited by: Adelinda Araujo Candeias, University of Évora, Portugal

Reviewed by: Maria Luísa Grácio, University of Évora, Portugal

Ana Couceiro Figueira, University of Coimbra, Portugal Jesús Nicasio García Sánchez,

Universidad de León, Spain

*Correspondence: Xavier Oriol xavier.orio/@unab.c

Specialty section:

This article was submitted to

Educational Psychology, a section of the journal

Frontiers in Psychology

Received: 28 November 2016 Accepted: 19 September 2017 Published: 11 October 2017

Citation:

Oriol X, Miranda R, Oyanedel JC and

Torres J (2017) The Role of

Self-control and Grit in Domains of School Success in Students of

Primary and Secondary School.

Front. Psychol. 8:1716.

doi: 10.3389/fpsyg.2017.01716

\section{The Role of Self-control and Grit in Domains of School Success in Students of Primary and Secondary School}

\author{
Xavier Oriol ${ }^{1 *}$, Rafael Miranda ${ }^{2}$, Juan C. Oyanedel ${ }^{1}$ and Javier Torres ${ }^{3}$ \\ ${ }^{1}$ Facultad de Educación, Universidad Andres Bello, Santiago de Chile, Chile, ${ }^{2}$ Departamento de Psicología, Universidad \\ Continental, Huancayo, Peru, ${ }^{3}$ Universidad Tecnológica de Chile INACAP, Santiago, Chile
}

Objective: Self-control and grit have become two of the most important variables that explain success in different aspects of people's daily life (Duckworth and Gross, 2014). Self-control promotes delayed gratification and directly influences thoughts, emotions, and impulses. On the other hand, grit enhances the achievement of goals through perseverance even before extreme external circumstances. Since both constructs are related, examining them together is compelling, as long as the different nuances that characterize each are taken into account. Two structural equation models (SEM) were conducted to observe the effect of self-control and grit on a more specific indicator of academic success (academic self-efficacy) and a more general indicator of school experience (satisfaction with school).

Methods: The first model comprises 5,681 primary students $(M=9.05$; $S D=0.79$, and the second 10,017 secondary students $(M=14.20 ; S D=1.04)$ from Lima, Peru. In both models, the influence of grit and self-control on school satisfaction was observed when taking self-efficacy as a mediator variable.

Results: The results show that grit and self-control have strong associations in both primary and secondary students. When estimating the covariance of both constructs, grit is related with academic-self efficacy at both educational stages, but only to satisfaction with school in secondary students. On the contrary, self-control shows a significant relationship with school satisfaction only in primary education. In turn, self-efficacy shows a mediating effect between grit and school satisfaction. After calculating the invariance of the models, differences are observed by gender in the relationships between variables.

Conclusion: The results indicate that both constructs are strongly interrelated. Regarding the associations with the indicators of academic success, a need for timely interventions specific to each educational stage is observed.

Keywords: Self-control, grit, academic self-efficacy, primary and secondary school 


\section{INTRODUCTION}

The most recent academics studies demonstrated that selfcontrol and grit have become two of the most important variables that explain success in different aspects of people's daily life (Duckworth and Gross, 2014). Since both constructs are related, examining them together is compelling, as long as the different nuances that characterize each are taken into account (Duckworth and Gross, 2014; Galla and Duckworth, 2015).

Both self-control and grit have been related to willpower. Specifically, self-control appears to promote delayed gratification and directly influences thoughts, emotions and impulses (Mischel, 2014); while grit is produced by keeping willpower constant and enhances the achievement of goals even before extreme external circumstances (Duckworth et al., 2007; Singh and Jha, 2008).

The experimental studies carried out by Mischel et al. (1989) and Mischel (2014) using the "marshmallow test" have been fundamental to understand the concept of self-control at present. These experiments allowed demonstrating the capacity of human beings for delaying gratification; and evidenced the importance of working on willpower from early ages (Mischel, 2014). The research conducted by Baumeister et al. (1998); Baumeister (2014) contributed to this perspective by finding that the human being frequently has to deal with daily life activities that rely heavily on self-control, which may drain willpower. However, it was also observed that positive states of mind induced after these exhausting tasks could relieve such exhaustion (Muraven, 2012).

The daily life of human beings is full on conflicts in which the temptation for immediate desires of higher order needs to be solved or satisfied immediately (Duckworth and Gross, 2014). Therefore, the development of a high capacity of regulation from early ages seems to product a long-term effect, since it promotes the resistance to higher order desires and allows directing behavior toward the achievement of goals (Hofmann et al., 2012). In this sense, the most recent longitudinal studies have also focused on identifying the effects of self-control in the long term, thus concluding that learning to delay gratification during the early ages predicts academic performance in further stages (Duckworth and Carlson, 2013; Duckworth and Gross, 2014; Mischel, 2014). Other studies have underscored that interventions to enhance self-regulation help students to feel less anxiety and tiredness as well as to focus on their studies avoiding external distractors (Oaten and Cheng, 2006; Cranwell et al., 2014). After the onset of adolescence, self-control also enable adolescents who are capable of regulating actions and emotions in the short term to set more long-term goals (Demetriou, 2000; Moilanen, 2007).

In this sense, the development of grit is related to more long-lasting goals that sometimes require years of effort to be attained (Duckworth et al., 2007; Duckworth and Gross, 2014). This non-cognitive personality trait is composed of a mixture between consistency in the interests and perseverance, and has been found a predictor of academic success in previous studies (Duckworth et al., 2007; Duckworth and Quinn, 2009), after controlling for educational aspirations and former achievements (Strayhorn, 2013). Nevertheless, a study recently conducted by
Ivcevic and Brackett (2014) showed that some indicators of academic success, namely rule violation, behavior recognitions, academic honors, and point average, were predicted by the big five trait "conscientiousness" and the emotion regulation ability, while grit did not much contribute to incremental validity.

The above suggests that much more research conducted to demonstrate the effects of grit on different variables of academic success, bearing in mind the changes that take place during the different educational stages. During secondary education, dramatic cognitive, and emotional changes occur, which influence information processing and decision-making (Blakemore and Robbins, 2012; Lerner et al., 2015). Some authors propose that adolescence is a stage of more emotional reactivity, especially due to the changes implied by puberty (Forbes and Dahl, 2010; Forbes et al., 2011). However, during this stage, adolescents also develop the capacity of establishing plans or preparing events that are more distant in time, in contrast to children, whose capacity is more limited to close events (Barkley, 1997). This capacity depends on the functions of the prefrontal cortex, which oversees the orientation to future and experiences, an important maturation process that occurs during adolescence (Blakemore et al., 2007; Burghy et al., 2012).

As for differences by gender in both constructs, the literature on this subject is ambiguous, and thus more studies are needed. Some studies conducted over the last few years have not found differences in self-control between boys and girls (e.g., Jonason and Tost, 2010), whereas others have concluded that men show lower self-control scores than women (Winfree et al., 2006; Weis et al., 2013). These differences may be due to the type of instrument used and the effect of age, which need to be controlled for.

In the case of grit, many studies conducted by Duckworth et al. (2007) did not find differences by gender; however, in other more recent study, women scored higher than men (Christensen and Knezek, 2014).

\section{Present Study}

For many researchers, one of the key aspects to explore nowadays is how self-control and grit behave before other variables in the different stages of the life cycle to promote their development (e.g., Vohs and Baumeister, 2004, 2013; Duckworth and Gross, 2014; Mischel, 2014). Overall, there seems to be a significant relationship between both constructs, but people with high levels of self-control are not necessarily gritty and vice versa (Duckworth, 2016).

In this sense, this study intends to observe how more stable patterns such as self-control and grit relate to one another and contribute to different domains of academic success. On the one hand, an outcome variable like self-efficacy is considered an indicator of academic success. This concept refers to the beliefs about the own capacities to learn and successfully perform the academic tasks or a performance in a specific domain (Bandura, 1986, 1997; Høigaard et al., 2015), and has been related to academic engagement, motivation for academic tasks and achievement (Salanova et al., 2011; Oriol-Granado et al., 2017). On the other hand, indicators like school satisfaction have been deemed more global. The concept of school satisfaction alludes 
to a specific quality of the life domain present in the educational environment, which is defined as the student's evaluation of the positivity of his or her school experiences "as a whole" (Huebner, 2004; Baker and Maupin, 2009; Oriol et al., 2017).

Both grit and self-control are expected to promote selfefficacy for solving academic tasks. However, this variable is also expected to act as a mediator between the patterns of grit and self-control, and as a more global indicator like school satisfaction. Furthermore, it is especially interesting to observe these relationships at ages corresponding to the different educational stages such as primary and secondary education.

To this end, two SEM models are presented, one for primary and other for secondary education, with the purpose of testing the following hypothesis: (1) a strong relationship is expected between self-control and grit in both primary and secondary students (2) Grit and self-control will be predictors of self-efficacy and school satisfaction in students from both educational stages. (3) Academic self-efficacy (which implies efficacy beliefs about specific tasks) would act as a mediator variable between selfcontrol and grit, and as a more global indicator of academic success, like school satisfaction. Finally, (4) differences by gender are expected between the models when comparing the primary and secondary stage.

\section{MATERIALS AND METHODS}

\section{Participants and Procedure}

The participants of this study took part in the impact assessment of the project "Escuela Amiga" of Peru's Ministry of Education (MINEDU). The data used for the present article corresponds to the base line of the same. The ethical considerations of the project were approved by MINEDU and endorsed by the ethics committee of the Innovation for Poverty Action (IPA), organization that provided technical assistance to MINEDU in the elaboration of written informed consents for parents and school principals, and written informed assents for students that were verbally explained prior to proceeding data collection. In this sense, the objective of the project was informed prior to the application of the questionnaire and students were informed that they were free not to answer the questionnaire in case they do not want.

In addition, as part of the ethical considerations proposed, IPA and MINEDU created protocols for monitoring data collection. Regarding the application protocol, the Ministry of Education and NGO IPA trained the interviewers on the application of the instrument and the implementation of an emotional containment protocol in case a student was affected by the content of the questionnaire. According to this protocol, in the event that a student experiences a situation affecting his emotional well-being, the survey supervisor should approach to his or her desk and asks her or him how he or she feels. In case of detecting any situation of emotional discomfort, the student is immediately referred to the psychologist or guardian, who is in a space different from the classroom where the survey is applied.

The instrument was applied to 15,825 students in 99 public educational institutions located in Lima Metropolitana. The sample was divided into 10,044 primary students $(63.5 \%)$ and 5,781 secondary students $(36.5 \%)$.

The mean age of the primary school sample was 9.05 years $(D E=0.81)$, with men's participation $(50.1 \%)$ being similar to women's $(49.9 \%)$. In the case of secondary students, the mean age was $14.2(D E=1.00)$ and, just as the primary education students, the distribution according sex was similar between men (49.5\%) and women $(50.5 \%)$.

\section{Measures}

\section{Self-control}

This scale was based on Moilanen's self-regulatory inventory (Moilanen, 2007). This scale is composed of four items on the short-term regulation dimension, with items related with impulse, attentional and emotional regulation toward immediate objectives, for example "When I'm sad, I can usually start doing something that will make me feel better," "After I'm interrupted or distracted, I can easily continue working where I left off." The Likert scale used contained five points. The Cronbach's alpha of this sample was 0.60 for secondary and 0.59 primary education.

\section{Grit}

Based on the GRIT Scale (Duckworth and Quinn, 2009). This scale was adapted to the instrument used for assessing the project "Escuela Amiga," denominated Single School Well-being Questionnaire (in Spanish, Cuestionario Único de Bienestar Escolar CUBE), and psychometrically validated (MINEDU, 2013, 2014). This scale is composed of eight items, such as "New ideas and projects distract me from the projects that I already undertook," "Difficulties (when something takes too long or doesn't work) don't get me down." The Likert scale used contained five points. The Cronbach's alpha of this sample was 0.55 for secondary and 0.61 for primary students.

\section{Academic Self-efficacy}

The scale was adapted from the instrument applied by Roeser et al. (1996). This dimension was assessed via three items, for instance, "If I have enough time, I can do well all my homework." The Likert scale used contained five points. The Cronbach's alpha was 0.68 and 0.66 for secondary and primary education, respectively-

\section{School Satisfaction}

This scale was adapted from Long et al. (2012) and translated into Spanish for Peru by Merino Soto (2013). It assesses subjective well-being in school through five items, e.g., "I learn quite a lot in school," "In general, I always want to go to school." The Likert scale used contained five points. The Cronbach's alpha was 0.85 for secondary education and 0.80 for primary education.

\section{RESULTS}

\section{Data Analysis}

Descriptive analysis and correlations were calculated for each dimension by means of the software SPSS v.24. Confirmatory factor analyses, mediations, structural equation models (SEM) and multigroup analysis were computed using the statistical package AMOS 22.0. These analyses were conducted using 
Maximum Likelihood-since this statistical descriptor has low sensitivity to the non-compliance of the multivariate normality assumption (West et al., 1995) — and Bootstrapping.

To verify the adequate fit of the model, the following robustness indices were used: Comparative Fit Index (CFI) and Tucker-Lewis Index(TLI) - for which values above 0.95 indicate a good fit and, and above 0.90 and acceptable fit (Medsker et al., 1994); Akaike Information Criterion (AIC) - where the lower value indicates the highest parsimony; and the Root Mean Square Error of Approximation (RMSEA) - for which it has been suggested that values below 0.05 are a good fit, while values between 0.05 and 0.08 indicate an acceptable fit (Browne and Cudeck, 1992).

\section{Descriptive Analyses}

Demographic characteristics of the sample are shown in Table $\mathbf{1 .}$ As well, The descriptive statistics for the analyzed variables present significant differences by educational stage and sex (see Table 2). In the primary stage, the means of the variables exceed those of the secondary stage. Regarding differences by sex, academic self-efficacy and school satisfaction are statistically higher in boys, while self-regulation and grit are statistically higher in girls.

The correlations were calculated among all variables at a general level, and by educational stage. As shown in Table 3, all correlations were significant $(\mathrm{p}<0.05)$. Likewise, all of them show a coefficient equal to or above 0.30 .

\section{Structural Equation Modeling Analysis}

Prior to the calculation of the SEM, the measurement model was calculated at a general level and according to educational stage. The three measurements presented adequate model adjustments, except from the $\chi^{2} / g . l$ coefficient, whose value was over 5, thus only indicating an acceptable fit ( $\mathrm{Hu}$ and Bentler, 1999).

In the case of the adjustments of the general measurement model, the adjustment statistics are acceptable (Bentler and Bonett, 1980; Hu and Bentler, 1999; Hair et al., 2007). The assessed indexes are $\left(\chi^{2}=7,105.33, \chi^{2} /\right.$ g.l. $=38.82$; TLI $=0.90$, CFI $=0.91$, RMSEA $=0.049)$. The model adjustment is also adequate for primary students $\left(\chi^{2}=3393.14, \chi^{2} /\right.$ g.l. $=18.54$; $\mathrm{TLI}=0.91$, CFI $=0.92$, RMSEA $=0.042)$, and the results of secondary education maintain the same trend $\left(\chi^{2}=3,832.12\right.$, $\chi^{2} /$ g.l. $=20.94$; TLI $\left.=0.85, \mathrm{CFI}=0.87, \mathrm{RMSEA}=0.059\right)$.

With respect to the factor loading analyzed in the adjustment model, some items of the grit variable have factor loadings below 0.4 in the three models (general, primary y secondary). Therefore, these items were eliminated from the latent variable (García Berumen González et al., 2012), thus forming a new grit variable composed of four items: (1) "Difficulties (when something takes too long or doesn't work) don't get me down," (2) "I'm persevering, I work hard when I do things," (3) "I always finish what I start" $\mathrm{y}$ (4) "I'm dedicated and careful." In the case of the self-regulation variable, the item "After I'm interrupted or distracted, I can easily continue working where I left off" was removed.

After eliminating these items, the indexes of the adjustment model improve at a general level $\left(\chi^{2}=2646.44, \chi^{2} /\right.$ g.l. $=27.00$;
TABLE 1 | Demographic characteristics of the sample.

\begin{tabular}{|c|c|c|c|c|}
\hline & & istics & $N$ & $\%$ \\
\hline \multirow[t]{13}{*}{ Primary } & Age & & & \\
\hline & & 7 & 21 & $0.2 \%$ \\
\hline & & 8 & 1,815 & $18.1 \%$ \\
\hline & & 9 & 6,31 & $62.8 \%$ \\
\hline & & 10 & 1,109 & $11 \%$ \\
\hline & & 11 & 347 & $3.5 \%$ \\
\hline & & 12 & 99 & $1.0 \%$ \\
\hline & & 13 & 59 & $0.6 \%$ \\
\hline & & 14 & 7 & $0.1 \%$ \\
\hline & & Lost & 211 & $2.8 \%$ \\
\hline & Sex & & & \\
\hline & & Man & 4,961 & $50.1 \%$ \\
\hline & & Woman & 4,935 & $49.9 \%$ \\
\hline \multirow[t]{12}{*}{ Secondary } & Age & & & \\
\hline & & 12 & 25 & 0.4 \\
\hline & & 13 & 1266 & 21.9 \\
\hline & & 14 & 2759 & 47.7 \\
\hline & & 15 & 1044 & 18.1 \\
\hline & & 16 & 423 & 7.3 \\
\hline & & 17 & 130 & 2.2 \\
\hline & & 18 & 26 & 0.4 \\
\hline & & Lost & 100 & 1.7 \\
\hline & Sex & & & \\
\hline & & Man & 2,781 & $49.5 \%$ \\
\hline & & Woman & 2,842 & $50.5 \%$ \\
\hline
\end{tabular}

TLI $=0.96$, CFI $=0.96$, RMSEA $=0.041)$. The same is true for the primary level $\left(\chi^{2}=1110.88, \chi^{2} /\right.$ g.l. $=11.33$; TLI $=0.97$, $\mathrm{CFI}=0.97$, RMSEA $=0.032)$ and secondary level $\left(\chi^{2}=1786.78\right.$, $\chi^{2} /$ g.l. $=18.23 ;$ TLI $\left.=0.92, \mathrm{CFI}=0.93, \mathrm{RMSEA}=0.055\right)$.

Subsequently, two SEM were conducted according to the educational level of the sample. The proposed model considers self-regulation and grit to be predictor variables of school satisfaction and academic self-efficacy. In turn, academic selfefficacy is a mediator variable between the predictor variables of school satisfaction.

The SEM for primary students detailed in Figure 1 shows an adequate fit: $\chi^{2} / \mathrm{df}=11.34$, df $=98 ; p<0.001$; CFI $=0.97$; $\mathrm{TLI}=0.97$; RMSEA $=0.032$.

The direct effects are specified in Table 4. The relationship between self-control and academic self-efficacy, together with grit over school satisfaction are not significant $(p>0.05)$. As for the relationship between grit and school satisfaction mediated by academic self-efficacy, there is a total mediation [IC $=(0.21$, $0.33) ; p<0.001]$. The indirect effect between self-control and school satisfaction through academic self-efficacy turns out to be non-significant $[\mathrm{IC}=(-0.06,0.09) ; p>0.05]$.

The SEM for secondary education detailed in Figure 2 shows an adequate adjustment: $\chi^{2} / \mathrm{df}=18.23$, df $=98 ; p<0.001$; $\mathrm{CFI}=0.93$; $\mathrm{TLI}=0.92$; $\mathrm{RMSEA}=0.055$.

Regarding the direct effects of the model, it is observed that the relationship between self-control, and school satisfaction and academic self-efficacy is not significant $(p>0.05)$. The 
TABLE 2 | Descriptive statistics.

\begin{tabular}{|c|c|c|c|c|c|c|c|c|c|c|}
\hline & \multicolumn{2}{|c|}{ Total } & \multicolumn{2}{|c|}{ Primary } & \multicolumn{2}{|c|}{ Secondary } & \multicolumn{2}{|c|}{ Men } & \multicolumn{2}{|c|}{ Women } \\
\hline & $M$ & $D E$ & $M$ & $D E$ & $M$ & $D E$ & $M$ & $D E$ & $M$ & $D E$ \\
\hline Academic self-efficacy & 3.44 & 0.61 & $3.56^{\star \star \star}$ & 0.58 & $3.21^{\star \star \star}$ & 0.60 & $2.59^{\star \star \star}$ & 0.67 & $2.62^{\star \star \star}$ & 0.68 \\
\hline Self-regulation & 2.82 & 0.77 & $2.97^{\star \star \star}$ & 0.78 & $2.58^{\star \star \star}$ & 0.69 & $3.41^{\star *}$ & 0.63 & $3.46^{\star \star}$ & 0.60 \\
\hline School satisfaction & 3.37 & 0.67 & $3.53^{\star \star \star}$ & 0.61 & $3.08^{\star \star \star}$ & 0.68 & $2.85^{\star \star}$ & 0.75 & $2.80^{\star \star}$ & 0.79 \\
\hline Grit & 2.60 & 0.67 & $2.82^{\star \star \star}$ & 0.68 & $2.24^{\star \star \star}$ & 0.51 & $3.31^{\star \star}$ & 0.70 & $3.43^{\star \star}$ & 0.64 \\
\hline
\end{tabular}

${ }^{\star *} p<0.01 ;{ }^{* * *} p<0.001$.

TABLE 3 | Correlations between variables at a general level and by educational level.

\begin{tabular}{|c|c|c|c|c|c|}
\hline & Variable & 1 & 2 & 3 & 4 \\
\hline \multirow[t]{4}{*}{ General } & 1. Grit & - & & & \\
\hline & 2. Academic self-efficacy & $0.44^{\star \star \star}$ & - & & \\
\hline & 3. Self-regulation & $0.48^{\star \star \star}$ & $0.44^{\star \star \star}$ & - & \\
\hline & 4.School satisfaction & $0.42^{\star \star \star}$ & $0.56^{\star \star \star}$ & $0.42^{\star \star \star}$ & - \\
\hline \multirow[t]{4}{*}{ Primary } & 1. Grit & - & & & \\
\hline & 2. Academic self-efficacy & $0.41^{\star \star \star}$ & - & & \\
\hline & 3. Self-regulation & $0.46^{\star \star \star}$ & $0.43^{\star \star \star}$ & - & \\
\hline & 4.School satisfaction & $0.36^{\star \star \star}$ & $0.53^{\star \star \star}$ & $0.41^{\star \star \star}$ & - \\
\hline \multirow[t]{4}{*}{ Secondary } & 1. Grit & - & & & \\
\hline & 2. Academic self-efficacy & $0.32^{\star \star \star}$ & - & & \\
\hline & 3. Self-regulation & $0.35^{\star \star \star}$ & $0.33^{\star \star \star}$ & - & \\
\hline & 4.School satisfaction & $0.30^{\star \star \star}$ & $0.49^{\star \star \star}$ & $0.30^{\star \star \star}$ & - \\
\hline
\end{tabular}

${ }^{\star \star \star} p<0.001$

TABLE 4 | Indirect effects of the structural equation model for primary students.

\begin{tabular}{llllc}
\hline Dependent variable & & Independent variable & Estimator & IC \\
\hline Academic self-efficacy & $<-$ & Self-control & 0.07 & {$[-0.13,0.22]$} \\
Academic self-efficacy & $<-$ & Grit & $0.76^{\star \star \star}$ & {$[0.61,0.95]$} \\
School satisfaction & $<-$ & Academic self-efficacy & $0.55^{\star \star \star}$ & {$[0.46,0.65]$} \\
School satisfaction & $<-$ & Grit & 0.05 & {$[-0.14,0.21]$} \\
School satisfaction & $<-$ & Self-control & $0.19^{\star \star}$ & {$[0.06,0.33]$} \\
\hline
\end{tabular}

${ }^{*} p<0.05 ;{ }^{* \star} p<0.01 ;{ }^{* \star \star} p<0.001$.

95\% confidence interval between brackets.

rest of the effects was significant (see Table 5). With respect to the indirect effects, an effect mediated by academic self-efficacy was found between grit and school satisfaction, [IC $=(0.21$, $0.33) ; p<0.001$ ]. Lastly, the mediating effect in the relationship between self-control and school satisfaction mediated by academic self-efficacy was not significant $[\mathrm{IC}=(-0.01,0.06)$; $p>0.05]$.

\section{Invariance Analysis}

Invariance was calculated by sex for each of the educational stages proposed in the model. The direct effects are presented in Table 6 for each of the educational stages and according sex. In the case of primary education students, the relationship between self-control and school satisfaction is significant for women $(p<0.05)$ and non-significant for men $(p>0.05)$. In the case of secondary education students, the effect of grit on school satisfaction is also significant for women $(p<0.05)$, but not for men $(p<0.05)$.

Table 7 shows significant differences by $\operatorname{sex}(p<0.05)$ between the proposed invariance models. In the case of the primary stage, there are no significant differences between the unconstrained model and the measurement weight model, and between the structural weight model and measurement weight model. Nevertheless, significant differences exist between the structural covariance model and the structural weights model. In the secondary stage, significant differences were identified between the unconstrained and the measurement weight model $(p<0.05)$.

\section{DISCUSSION}

First, one of the aspects that arises more interest nowadays is the relationship existing between grit and self-control at the different educational stages. In this sense, we observe high scores between these two constructs in both the correlations and the covariance value. In both self-control and grit, primary students show higher scores than secondary students. These data might seem surprising, since adolescents appear to have an increased maturation of the prefrontal cortex and to be more capable of setting goals and long-term plans (Blakemore et al., 2007). However, in some cases adolescents set goals such as "study to improve their marks" more induced by extrinsic motivation caused by social pressure than by other intrinsic motivation processes (Wong and Csikszentmihalyi, 1991). When this occurs, tedious and sometimes frustrating feelings may arise. During periods of transition to puberty, adolescents have a lot of trouble trying to control their impulses and to make adequate decisions when their objective involves emotional components (Bell and McBride, 2010). When confronted with these frustrating situations, adolescents may behave more impulsively than children and adults, and may feel depressed when not meeting their objectives (Casey and Caudle, 2013). Previous studies show that, during adolescence, intrinsic motivation declines as age increases (Lepper et al., 2005; Corpus et al., 2009) and this could be directly related to the differences in grit and selfcontrol found between children and adolescents. In this sense, developing superordinate goals that compel personal significance and intrinsic motivation in childhood could increase the capacity 


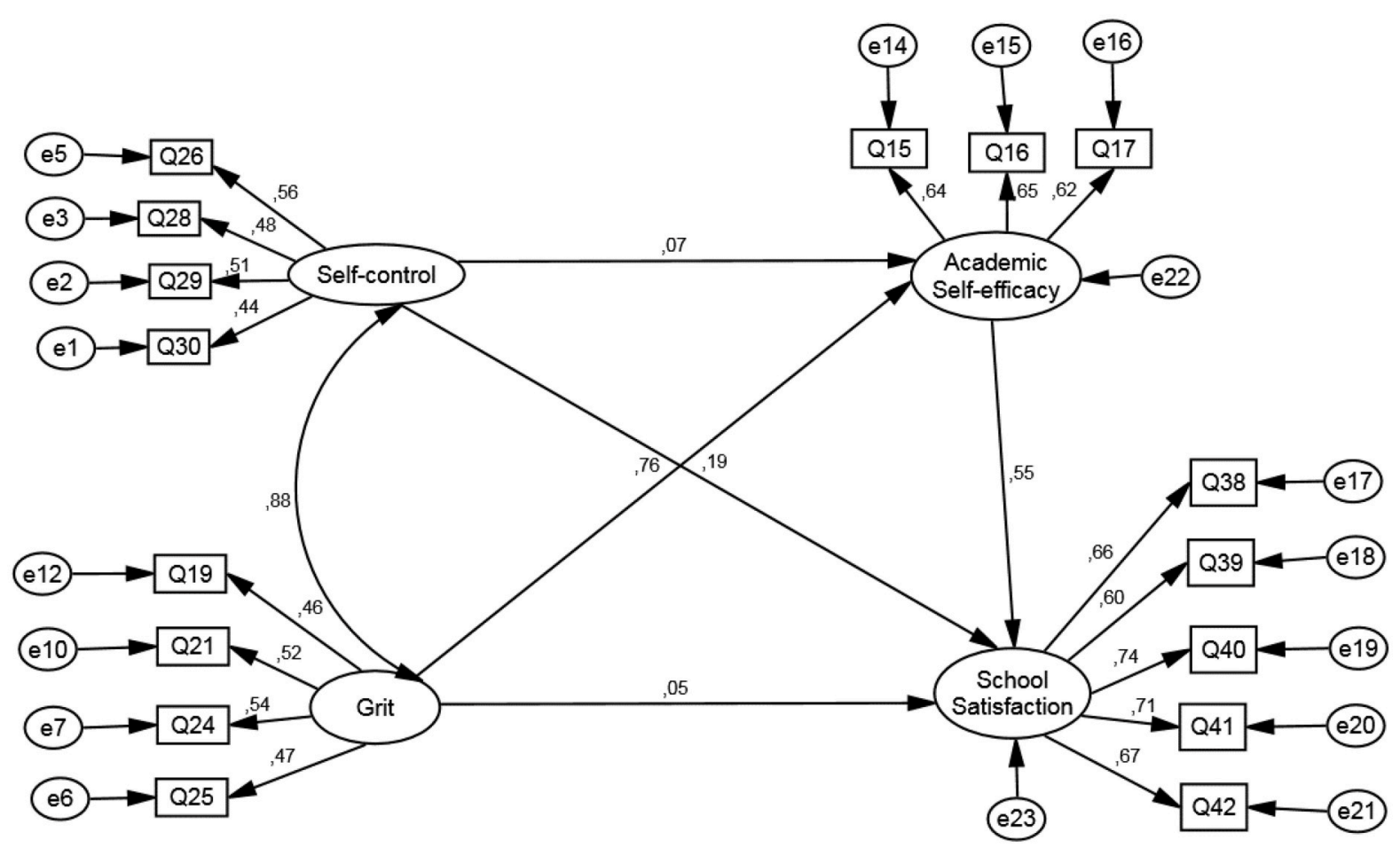

FIGURE 1 | Structural equation modeling for primary students.

TABLE 5 | Indirect effects of the structural equation model for secondary students.

\begin{tabular}{|c|c|c|c|c|}
\hline Dependent variable & & Independent variable & Estimator & IC \\
\hline Academic self-efficacy & $<-$ & Self-control & 0.06 & {$[-0.04,0.15]$} \\
\hline Academic self-efficacy & $<-$ & Grit & $0.65^{\star \star \star}$ & {$[0.56,0.74]$} \\
\hline School satisfaction & $<-$ & Academic self- efficacy & $0.44^{\star \star \star}$ & {$[0.38,0.50]$} \\
\hline School satisfaction & $<-$ & Grit & $0.21^{\star \star}$ & {$[0.11,0.31]$} \\
\hline School satisfaction & $<-$ & Self-control & 0.04 & {$[-0.03,0.12]$} \\
\hline
\end{tabular}

${ }^{*} p<0.05 ;{ }^{* *} p<0.01 ;{ }^{* \star *} p<0.001$.

95\% confidence interval between brackets.

to manage the innumerable mistakes and frustrations of daily life, especially during adolescence (Duckworth and Gross, 2014).

The second hypothesis proposed that grit and self-control would be predictors of both self-efficacy and school satisfaction at both educational stages. The results show that, calculating the covariance between both constructs, self-control stops relating with the indicators of academic success during adolescents, but it does predict school satisfaction in primary students. These data would be consistent with a recent study conducted by Hofmann et al. (2014), in which it was observed that people with more self-control traits would be happier and more satisfied with their life in general, due to the proactive control of their daily lives. In primary students, grit is related to academic self-efficacy and not with school satisfaction. This construct promotes perseverance in students and might be more useful than self-control to motivational systems. However, it must be noted that perseverance boosted by an extrinsic motivation may generate an obsessive passion than may become maladaptive for the individual in the long term (Vallerand, 2008). In this sense, as previously discussed, it would be better if students experience the type of satisfaction with learning that favors intrinsic motivation mechanisms in these early school stages.

During adolescence, grit does show a significant effect on school satisfaction, albeit with less intensity than academic selfefficacy. At this stage, adolescents orient their lives more to the future, and their cognitive development resembles adults'. This might imply that achieving long-term objectives becomes especially important for adolescence, since these attainments contribute to more global indicators of perceived well-being. Furthermore, studies on well-being report that perseverance in the achievement of objectives promotes a more positive life and constantly high levels of subjective well-being (Huebner, 2004; Hoyle, 2006; Magen and Gross, 2010).

The results of the third hypothesis show a mediating effect between grit and school satisfaction in primary and secondary students, and, on the contrary, the absence of mediation with selfcontrol. As stated above, self-control does not relate to beliefs of academic self-efficacy in the SEM models, and thus no mediating effect is observed. This might be due to the strong effect of the covariance between grit and self-control in both primary and secondary stages.

In the last hypothesis, we expected to find differences by sex between models. In the first place, the descriptive statistics show 


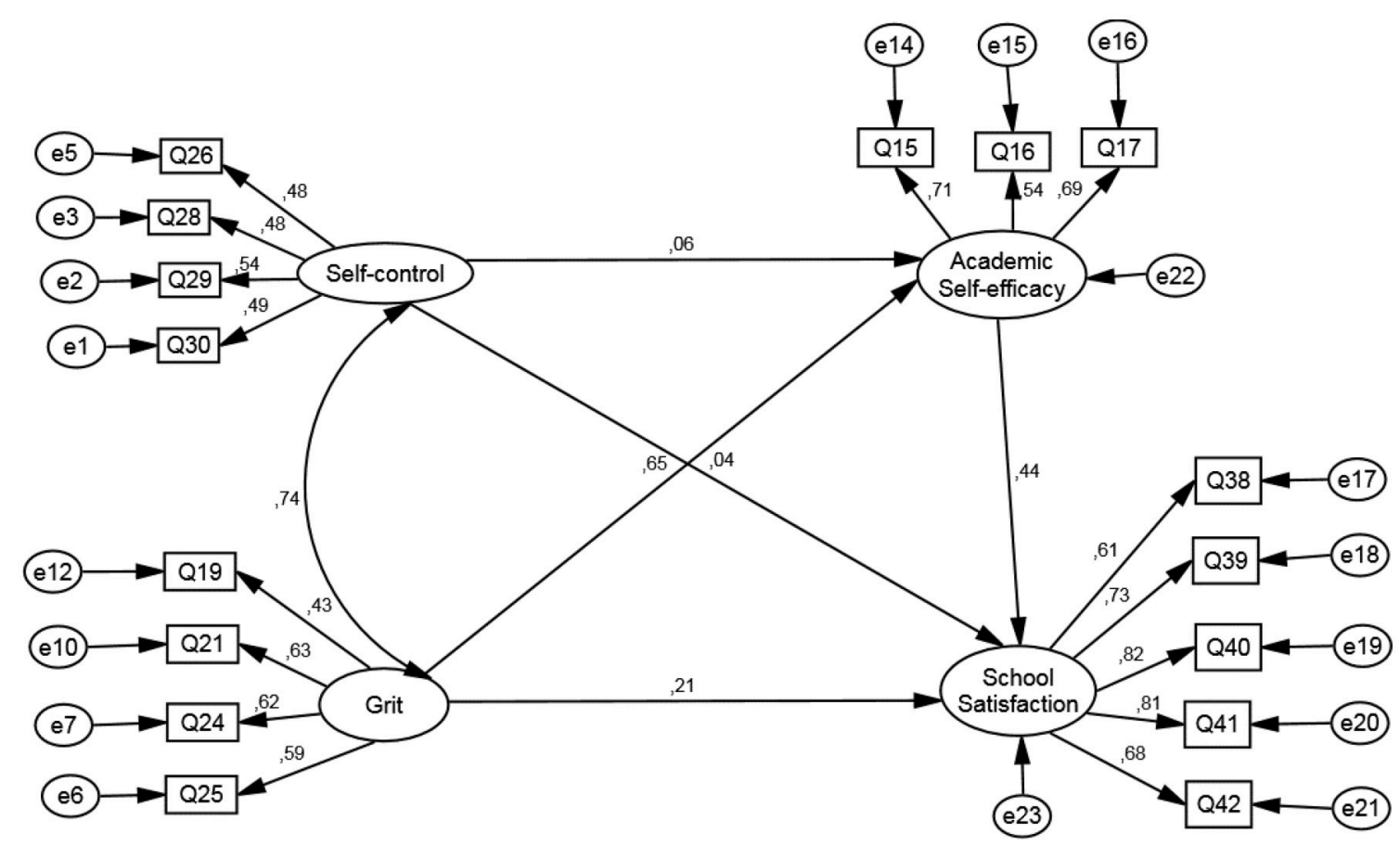

FIGURE 2 | Structural equation model for secondary students.

TABLE 6 | Direct effects according sex for primary and secondary students.

\begin{tabular}{lllll}
\hline & & & Man & Woman \\
\hline PRIMARY STUDENTS & & & & \\
Academic self-efficacy & $<-$ & Self-control & $0.86^{\star \star \star}$ & $0.69^{\star \star *}$ \\
Academic self-efficacy & $<-$ & Grit & -0.03 & $0.15^{\star}$ \\
School satisfaction & $<-$ & Academic self-efficacy & $0.60^{\star \star}$ & $0.50^{\star *}$ \\
School satisfaction & $<-$ & Grit & -0.04 & 0.06 \\
School satisfaction & $<-$ & Self-control & $0.21^{\star \star}$ & $0.23^{\star \star}$ \\
SECONDARY STUDENTS & & & \\
Academic self-efficacy & $<-$ & Self-control & $0.62^{\star \star \star}$ & $0.67^{\star \star}$ \\
Academic self-efficacy & $<-$ & Grit & 0.10 & 0.03 \\
School satisfaction & $<-$ & Academic self-efficacy & $0.51^{\star * \star}$ & $0.38^{\star *}$ \\
School satisfaction & $<-$ & Grit & $0.13^{*}$ & $0.22^{\star *}$ \\
School satisfaction & $<-$ & Self-control & 0.08 & 0.09 \\
\hline
\end{tabular}

${ }^{*} p<0.05 ;{ }^{* \star} p<0.01$ and ${ }^{* \star *} p<0.001$ (bilateral).

higher scores for girls in both self-control and grit. These results confirm the findings of some studies where higher scores in girls were observed in both constructs (Weis et al., 2013; Christensen and Knezek, 2014). After calculating invariance between the models, differences are not observed in the unconstrained model for primary students, but they are present in the other three models calculated. With respect to direct effects, it may be seen that grit predicts academic self-efficacy more strongly in boys, while a significant effect of self-control over self-efficacy may be observed only in girls. Girls also show higher scores in the relationship between self-control and school satisfaction.
TABLE 7 | Invariance of models between men and women according to educational stage.

\begin{tabular}{|c|c|c|c|c|c|c|c|c|}
\hline Models & $x^{2}$ & df & $\chi^{2 / d f}$ & $\Delta \chi^{2}$ & $\Delta \mathrm{df}$ & CFI & TLI & RMSEA \\
\hline \multicolumn{9}{|c|}{ PRIMARY } \\
\hline Model 1 & 1,275 & 196 & - & - & - & 0.97 & 0.96 & 0.02 \\
\hline Model 2 & 1,286 & 208 & 6.18 & 11 & 12 & 0.97 & 0.97 & 0.02 \\
\hline Model 3 & 1,292 & 213 & 6.07 & 6 & 5 & 0.97 & 0.97 & 0.02 \\
\hline Model 4 & 1,308 & 216 & 6.06 & $16^{\star \star}$ & 3 & 0.97 & 0.97 & 0.02 \\
\hline Model 5 & 1,344 & 218 & 6.17 & $36^{\star \star \star}$ & 2 & 0.97 & 0.97 & 0.02 \\
\hline Model 6 & 2,147 & 234 & 9.18 & $803^{\star \star \star}$ & 16 & 0.95 & 0.95 & 0.03 \\
\hline \multicolumn{9}{|c|}{ SECONDARY } \\
\hline Model 1 & 1,783 & 196 & - & - & - & 0.94 & 0.92 & 0.04 \\
\hline Model 2 & 1,825 & 208 & 8.78 & $42^{\star \star \star}$ & 12 & 0.94 & 0.93 & 0.04 \\
\hline Model 3 & 1,840 & 213 & 8.64 & $15^{\star \star}$ & 5 & 0.93 & 0.93 & 0.04 \\
\hline Model 4 & 1,857 & 216 & 8.60 & $17^{\star \star}$ & 3 & 0.93 & 0.93 & 0.04 \\
\hline Model 5 & 1,858 & 218 & 8.52 & 1 & 2 & 0.93 & 0.93 & 0.04 \\
\hline Model 6 & 2,128 & 234 & 9.09 & $270^{\star \star \star}$ & 16 & 0.92 & 0.92 & 0.04 \\
\hline
\end{tabular}

${ }^{* *} p<0.01 ;{ }^{* \star *} p<0.001$. Model 1, Unconstrained; Model 2, Measurement weights; Model 3, Structural weights; Model 4, Structural covariance; Model 5: Structural residuals; Model 6: Measurement residuals.

Furthermore, significant differences are found between the models for secondary students; therefore, there is no invariance between them. Girls show higher grit scores for both the relationship with self-efficacy and with school satisfaction. No significant relationships are determined between self-control and the outcome variables. 
Finally, it should be considered that one of the limitations of this study is its cross sectional instead of longitudinal nature. It would be very interesting that further research be conducted to follow the evolution of these constructs in the same individuals.

\section{CONCLUSION}

Grit and self-control are considered stable patterns or traits, yet this does not imply that they cannot be nurtured during the early ages by means of some strategies. Both constructs are strongly related to each other, and also to more specific performance indicators like self-efficacy as well as to more global indicators like school satisfaction. Nevertheless, it is observed that the effect of both variables varies according to age and success indicator. This indicates that specific strategies should be developed to work on: (1) more immediate impulse control; and (2) perseverance and passion for studying more in the long term, with the aim

\section{REFERENCES}

Baker, J. A., and Maupin, A. N. (2009). "School satisfaction and children's positive school adjustment," in Handbook of Positive Psychology in Schools, eds R. Gilman, E. S. Huebner, and M. J. Furlong (New York, NY: Routledge), 189-196.

Bandura, A. (1986). Social Foundations of Thought and Action: A Social Cognitive Theory. New York, NY: Prentice-Hall.

Bandura, A. (1997). Self-Efficacy: The Exercise of Control. New York, NY: Freeman.

Barkley, R. A. (1997). Behavioral inhibition, sustained attention, and executive functions: constructing a unifying theory of ADHD. Psychol. Bull. 121:65. doi: 10.1037/0033-2909.121.1.65

Baumeister, R. F. (2014). Self-regulation, ego depletion, and inhibition. Neuropsychologia 65, 313-319. doi: 10.1016/j.neuropsychologia.2014.08.012

Baumeister, R. F., Bratslavsky, E., Muraven, M., and Tice, D. M. (1998). Ego depletion: is the active self a limited resource? J. Pers. Soc. Psychol. 74, 1252-1265. doi: 10.1037/0022-3514.74.5.1252

Bell, C. C., and McBride, D. F. (2010). Affect regulation and prevention of risky behaviors. JAMA 304, 565-566. doi: 10.1001/jama.2010.1058

Bentler, P. M., and Bonett, D. G. (1980). Significance tests and goodness of fit in the analysis of covariance structures. Psychol. Bull. 88:588. doi: 10.1037/0033-2909.88.3.588

Blakemore, S. J., den Ouden, H., Choudhury, S., and Frith, C. (2007). Adolescent development of the neural circuitry for thinking about intentions. Soc. Cogn. Affect. Neurosci. 2, 130-139. doi: 10.1093/scan/nsm009

Blakemore, S. J., and Robbins, T. W. (2012). Decision-making in the adolescent brain. Nat. Neurosci. 15, 1184-1191. doi: 10.1038/nn.3177

Browne, M. W., and Cudeck, R. (1992). Alternative ways of assessing model fit. Sociol. Methods Res. 21, 230-258. doi: 10.1177/00491241920210 02005

Burghy, C. A., Stodola, D. E., Ruttle, P. L., Molloy, E. K., Armstrong, J. M., Oler, J. A., et al. (2012). Developmental pathways to amygdala-prefrontal function and internalizing symptoms in adolescence. Nat. Neurosci. 15, 1736-1741. doi: $10.1038 / \mathrm{nn} .3257$

Casey, B., and Caudle, K. (2013). The teenage brain self-control. Curr. Dir. Psychol. Sci. 22, 82-87. doi: 10.1177/0963721413480170

Christensen, R., and Knezek, G. (2014). Comparative measures of grit, tenacity and perseverance. Int. J. Learn. Teach. Educ. Res. 8, 16-30.

Corpus, J. H., McClintic-Gilbert, M. S., and Hayenga, A. O. (2009). Withinyear changes in children's intrinsic and extrinsic motivational orientations: contextual predictors and academic outcomes. Contemp. Educ. Psychol. 34, 154-166. doi: 10.1016/j.cedpsych.2009.01.001 of potentiating intrinsic motivation and self-learning in students (Franco et al., 2016). This should also take into account the massive cognitive and emotional changes that occur during the different educational stages.

\section{AUTHOR CONTRIBUTIONS}

XO: Introduction, data analyses, results, and discussion. RM: Data collection and analyses. JO: Review of the literature and results. JT: Review of the literature and references.

\section{ACKNOWLEDGMENTS}

This research was supported by the Ministry of Education of Peru (MINEDU). The data used for this study were shared by MINEDU with the aim of promoting the publication of research articles that contribute to generate evidence on the education matter in Peru.

Cranwell, J., Benford, S., Houghton, R. J., Golembewksi, M., Fischer, J. E., and Hagger, M. S. (2014). Increasing self-regulatory energy using an Internet-based training application delivered by smartphone technology. Cyberpsychol. Behav. Soc. Netw. 17, 181-186. doi: 10.1089/cyber.2013.0105

Demetriou, A. (2000). "Organization and development of self-understanding and self-regulation," in Handbook of Self-regulation, ed M. Zeidner (San Diego, CA: Academic Press), 209-251.

Duckworth, A. (2016). Grit: Passion, Perseverance and The Science of Success. London: Ebury Publishing.

Duckworth, A., and Gross, J. J. (2014). Self-control and grit related but separable determinants of success. Curr. Dir. Psychol. Sci. 23, 319-325. doi: 10.1177/0963721414541462

Duckworth, A. L., and Carlson, S. M. (2013). "Self-regulation and school success," in Self-Regulation and Autonomy: Social and Developmental Dimensions of Human Conduct, Vol. 40, eds B. W. Sokol, F. M. E. Grouzet, and U. Müller (New York, NY: Cambridge University Press), 208-230.

Duckworth, A. L., Peterson, C., Matthews, M. D., and Kelly, D. R. (2007). Grit: perseverance and passion for long-term goals. J. Pers. Soc. Psychol. 92, 1087-1011. doi: 10.1037/0022-3514.92.6.1087

Duckworth, A. L., and Quinn, P. D. (2009). Development and validation of the Short Grit Scale (GRIT-S). J. Pers. Assess. 91, 166-174. doi: $10.1080 / 00223890802634290$

Forbes, E. E., and Dahl, R. E. (2010). Pubertal development and behavior: hormonal activation of social and motivational tendencies. Brain Cogn. 72, 66-72. doi: 10.1016/j.bandc.2009.10.007

Forbes, E. E., Phillips, M. L., Silk, J. S., Ryan, N. D., and Dahl, R. E. (2011). Neural systems of threat processing in adolescents: role of pubertal maturation and relation to measures of negative affect. Dev. Neuropsychol. 36, 429-452. doi: 10.1080/87565641.2010.550178

Franco, C., Amutio, A., López-González, L., Oriol, X., and Martínez-Taboada, C. (2016). Effect of a mindfulness training program on the impulsivity and aggression levels of adolescents with behavioral problems in the classroom. Front. Psychol. 7:1385. doi: 10.3389/fpsyg.2016.01385

Galla, B. M., and Duckworth, A. L. (2015). More than resisting temptation: beneficial habits mediate the relationship between self-control and positive life outcomes. J. Pers. Soc. Psychol. 109:508. doi: 10.1037/pspp00 00026

García Berumen González, J., García Soto, P., and Domenge Mu-oz, R. (2012). Determinantes de la estructura de capital en la peque-a y mediana empresa familiar en México. Contaduría Admin. 57, 67-96.

Hair, J. F., Money, A. H., Samouel, P., and Page, M. (2007). Research Methods for Business. John Wiley and Sons. 
Hofmann, W., Baumeister, R. F., Förster, G., and Vohs, K. D. (2012). Everyday temptations: an experience sampling study of desire, conflict, and self-control. J. Pers. Soc. Psychol. 102, 1318. doi: 10.1037/a0026545

Hofmann, W., Luhmann, M., Fisher, R. R., Vohs, K. D., and Baumeister, R. F. (2014). Yes, but are they happy? Effects of trait self-control on affective well-being and life satisfaction. J. Pers. 82, 265-277. doi: 10.1111/jopy.12050

Høigaard, R., Kovac, V. B., Øverby, N. C., and Haugen, T. (2015). Academic self-efficacy mediates the effects of school psychological climate on academic achievement. Sch. Psychol. Q. 30, 64-74. doi: 10.1037/spq0000056

Hoyle, R. H. (2006). Personality and self-regulation: trait and information processing perspectives. J. Pers. 74, 1507-1526. doi: 10.1111/ j.1467-6494.2006.00418.x

Hu, L. T., and Bentler, P. M. (1999). Cutoff criteria for fit indexes in covariance structure analysis: conventional criteria versus new alternatives. Struct. Equat. Model. A Multidiscip. J. 6, 1-55. doi: 10.1080/10705519909540118

Huebner, E. S. (2004). Research on assessment of life satisfaction of children and adolescents. Soc. Indic. Res. 66, 3-33. doi: 10.1007/978-1-4020-2312-5_2

Ivcevic, Z., and Brackett, M. (2014). Predicting school success: comparing conscientiousness, grit, and emotion regulation ability. J. Res. Pers. 52, 29-36. doi: 10.1016/j.jrp.2014.06.005

Jonason, P. K., and Tost, J. (2010). I just cannot control myself: the dark triad and self-control. Pers. Individ. Dif. 49, 611-615. doi: 10.1016/j.paid.2010.05.031

Lepper, M. R., Corpus, J. H., and Iyengar, S. S. (2005). Intrinsic and extrinsic motivational orientations in the classroom: age differences and academic correlates. J. Educ. Psychol. 97, 184-196. doi: 10.1037/0022-0663.97.2.184

Lerner, J. S., Li, Y., Valdesolo, P., and Kassam, K. S. (2015). Emotion and decision making. Annu. Rev. Psychol. 66, 799-823. doi: 10.1146/annurev-psych-010213-115043

Long, R. F., Huebner, E. S., Wedell, D. H., and Hills, K. J. (2012). Measuring school-related subjective well-being in adolescents. Am. J. Orthopsychiatry 82, 50. doi: 10.1111/j.1939-0025.2011.01130.x

Magen, E., and Gross, J. J. (2010). "Getting our act together: toward a general model of self-control," in Self-Control in Society, Mind, and Brain, eds R. Hassin, K. Ochsner, and Y. Trope (New York, NY: Oxford University Press), 335-353.

Medsker, G. J., Williams, L. J., and Holahan, P. J. (1994). A review of current practices for evaluating causal models in organizational behavior and human resources management research. J. Manage. 20, 439-464. doi: $10.1177 / 014920639402000207$

Merino Soto, C. (2013). Análisis factorial de grupo múltiple de una versión muy breve del cuestionario revisado de personalidad de Eysenck (EPQR-BV). Int. J. Psychol. Res. 6, 79-88. doi: 10.21500/20112084.689

Ministerio de Educación del Perú (MINEDU) (2013). Análisis Psicométrico del Cuestionario de Bienestar Escolar de Primaria y Secundaria - Estudio Piloto 2013. Lima, CH: MINEDU.

Ministerio de Educación del Perú (MINEDU). (2014). Análisis Psicométrico del Cuestionario de Bienestar Escolar de Primaria y Secundaria-Estudio 2014. Lima, CH: MINEDU.

Mischel, W., Shoda, Y., Rodriguez, M. I. (1989). Delay of gratification in children. Science 244, 933-938. doi: 10.1126/science.2658056

Mischel, W. (2014). The Marshmallow Test: Mastering Self-Control. New York, NY: Little, Brown.

Moilanen, K. L. (2007). The adolescent self-regulatory inventory: the development and validation of a questionnaire of short-term and longterm self-regulation. J. Youth Adolesc. 36, 835-848. doi: 10.1007/s10964-0069107-9

Muraven, M. (2012). "Ego depletion: theory and evidence," in The Oxford Handbook of Human Motivation, ed R. M. Ryan (New York, NY: Oxford University Press), 111-126.

Oaten, M., and Cheng, K. (2006). Improved self-control: the benefits of a regular program of academic study. Basic Appl. Soc. Psychol. 28, 1-16. doi: $10.1207 /$ s15324834basp2801_1
Oriol-Granado, X., Mendoza-Lira, M., Covarrubias-Apablaza, C. G., and Molina-López, V. M. (2017). Positive emotions, autonomy support and academic performance of university students: the mediating role of academic engagement and self-efficacy. Revista de Psicodidáctica 22, 45-53. doi: $10.1387 /$ RevPsicodidact. 14280

Oriol, X., Torres, J., Miranda, R., Bilbao, M., and Ortúzar, H. (2017). Comparing family, friends and satisfaction with school experience as predictors of SWB in children who have and have not made the transition to middle school in different countries. Child. Youth Serv. Rev. 80, 149-156. doi: 10.1016/j.childyouth.2017.06.053

Roeser, R. W., Midgley, C., and Urdan, T. C. (1996). Perceptions of the school psychological environment and early adolescents' psychological and behavioral functioning in school: the mediating role of goals and belonging. J. Educ. Psychol. 88:408. doi: 10.1037/0022-0663.88.3.408

Salanova, M., Lorente, L., Chambel, M. J., and Martínez, I. M. (2011). Linking transformational leadership to nurses' extra-role performance: the mediating role of self-efficacy and work engagement. J. Adv. Nurs. 67, 2256-2266. doi: 10.1111/j.1365-2648.2011.05652.x

Singh, K., and Jha, S. D. (2008). Positive and negative affect, and grit as predictors of happiness and life satisfaction. J. Indian Acad. Appl. Psychol. 34, 40-45.

Strayhorn, T. L. (2013). What role does grit play in the academic success of black male collegians at predominantly white institutions? J. Afr. Am. Stud. 18, 1-10. doi: $10.1007 / \mathrm{s} 12111-012-9243-0$

Vallerand, R. J. (2008). On the psychology of passion: In search of what makes people's lives most worth living. Can. Psychol. 49, 1-13. doi: 10.1037/0708-5591.49.1.1

Vohs, K. D., and Baumeister, R. (2013). "Ego depletion, self-control, and choice," in Handbook of Experimental Existential Psychology, eds J. Greenberg, S. L. Koole, and T. Pyszczynski (New York, NY: Guilford Press), 398-410.

Vohs, K. D., and Baumeister, R. F. (2004). "Understanding self-regulation: an introduction," in Handbook of Self-Regulation: Research, Theory, and Application, eds R. F. Baumeister and K. D. Vohs (New York, NY: Guilford Press), 3-10.

Weis, M., Heikamp, T., and Trommsdorff, G. (2013). Gender differences in school achievement: the role of self-regulation. Front. Psychol. 4:442. doi: $10.3389 /$ fpsyg.2013.00442

West, S. G., Finch, J. F., and Curran, P. J. (1995). "Structural equation models with nonnormal variables: problems and remedies," in Structural Equation Modeling: Concepts, Issues and Applications, ed R. Hoyle (Newbury Park, CA: Sage), 56-75.

Winfree, L. T., Taylor, T. J., He, N., and Esbensen, F. A. (2006). Self-control and variability over time: multivariate results using a 5-year, multisite panel of youths. Crime Delinq. 52, 253-286. doi: 10.1177/0011128705278012

Wong, M. M., and Csikszentmihalyi, M. (1991). Motivation and academic achievement: the effects of personality traits and the quality of experience. J. Pers. 59, 539-574. doi: 10.1111/j.1467-6494.1991.tb00259.x

Conflict of Interest Statement: The authors declare that the research was conducted in the absence of any commercial or financial relationships that could be construed as a potential conflict of interest.

The reviewer MG and handling Editor declared their shared affiliation, and the handling Editor states that the process nevertheless met the standards of a fair and objective review.

Copyright (c) 2017 Oriol, Miranda, Oyanedel and Torres. This is an open-access article distributed under the terms of the Creative Commons Attribution License (CC $B Y)$. The use, distribution or reproduction in other forums is permitted, provided the original author(s) or licensor are credited and that the original publication in this journal is cited, in accordance with accepted academic practice. No use, distribution or reproduction is permitted which does not comply with these terms. 
OPEN ACCESS

Edited by:

Carbonero Martín Miguel Angel, University of Valladolid, Spain

Reviewed by: Edgar Galindo, University of Évora, Portugal Annamaria Di Fabio, University of Florence, Italy

Claudio Longobardi,

University of Turin, Italy

*Correspondence: Maria do Céu Taveira ceuta@psi.uminho.pt

Specialty section: This article was submitted to Educational Psychology, a section of the journa Frontiers in Psychology

Received: 31 January 2017 Accepted: 04 April 2017 Published: 24 April 2017

Citation:

Oliveira I'M, Taveira MC and Porfeli EJ (2017) Career Preparedness and School Achievement of Portuguese Children: Longitudinal Trend Articulations. Front. Psychol. 8:618. doi: 10.3389/fpsyg.2017.00618

\section{Career Preparedness and School Achievement of Portuguese Children: Longitudinal Trend Articulations}

\author{
Íris M. Oliveira ${ }^{1}$, Maria do Céu Taveira ${ }^{1 *}$ and Erik J. Porfeli ${ }^{2}$ \\ ${ }^{1}$ Department of Applied Psychology, School of Psychology, University of Minho, Braga, Portugal, ${ }^{2}$ College of Medicine, \\ Family and Community Medicine, Northeast Ohio Medical University, Rootstown, OH, USA
}

Social Cognitive Career Theory suggests that students' preparedness for the school-to-work transition is a developmental process. Middle school children explore various careers, obtain feedback about their academic progress, and develop career self-efficacy and outcome expectations. These processes advance provisional educational/occupational goals. The literature has suggested articulations between career and academic development and how both vary across demographic characteristics, but longitudinal studies linking these processes are scarce. This study tested articulations between career preparedness and academic achievement during middle school years and employed gender and geographical location as potential moderators affecting the linkage between career and school domains. Participants included 429 children $(47.8 \%$ girls) from northern $(69.5 \%)$ and central Portugal (30.5\%) followed across four occasions of measurement ( $M_{\text {ageWave1 }}=10.23$, $S D=0.50$ ). Data was collected with school records, the Multidimensional Scales of Perceived Self-Efficacy, Career Exploratory Outcome Expectations Scale, Childhood Career Exploration Inventory and Childhood Career Development Scale. Average and orthnormalized linear, quadratic and cubic trends were computed. Pearson correlation coefficients suggested positive and statistically significant associations between career exploratory outcome expectations and academic achievement average trends. Career planning and self-efficacy expectations were negatively associated with academic achievement quadratic trends. Multiple linear regression models suggested that career exploratory outcome expectations and career planning were respectively statistically significant predictors of the average and quadratic trends of academic achievement. Gender moderated the association between the career variables and academic achievement linear trends as well as the relation of career planning and self-efficacy with academic achievement cubic trends. Additionally, the geographical location moderated the association between the average trend of career exploratory outcome expectations and academic achievement as well as tended to moderate the relation between the career variables and academic achievement quadratic trends. Future research could seek to explore the role of context in shaping the trajectories and linkages between career and academic progress with a more representative sample of participants from a 
broader array of geographical locations. This study advances extant literature by affirming the longitudinal relationship between the school and work domains in youth, which might sustain practices aimed at fostering students' career preparedness and academic achievement.

Keywords: career preparedness, career development, school achievement, childhood, trend

\section{INTRODUCTION}

Career development can be conceived as the sequence of life roles performed by an individual over his/her life-course (Super, 1994). The student role is of major importance in childhood (until the 14 years of age), as it sustains the development of work attitudes and routines as well as the awareness of one's abilities and preferences (Super, 1994; Araújo and Taveira, 2009). Their academic path promotes children's development of a sense of industry and identification with teachers who they may perceive as supportive and knowledgeable classroom managers who are concerned with their wellbeing (Erikson, 1963; Di Fabio and Kenny, 2015; Chávez, 2016; Longobardi et al., 2016). In addition, while performing the student role and being subject to its inherent social expectations and formal functioning (Super, 1980), children acquire literacy and numeric skills as well as identify social clues of one's gender, prestige, and capabilities, which are encapsulated in an emerging sense of self (Gottfredson, 1981).

Although career and academic development have been often separately considered, calls have been made to acknowledge their joint articulations (e.g., Watson et al., 2015). In consonance with such calls, theoretical perspectives articulating these processes have been advanced. Both career and academic literatures have moved from initial perspectives conceiving one's educational path and quality of teaching as the basis to acquire skills and sustain later occupational attainment (Dunkin and Biddle, 1974; Lombardi et al., 2011) to an integrative perspective assuming the complementarity among career and academic processes throughout the lifespan (Kuijpers and Meijers, 2012).

Aligned with such a complementary position, the Social Cognitive Career Theory (SCCT; Lent et al., 1999) offered further articulation between career and academic development. SCCT asserts that preparedness for career transitions is a lifelong process that can be facilitated over the school years. The SCCT posits that, during the elementary and middle school years, children develop more realistic career self-efficacy and outcome expectations as well as construct provisional preferences and academic/occupational aspirations (Lent, 2004). These acquisitions highly rely on children's increased career exploration and social learning experiences, which can include teachers' feedback on the student's performance or one's perceived academic capabilities and psychophysiological reactions to the contents and tasks covered in academic and out-of-school settings. The SCCT is aligned with literature positing the need for children and youth to develop internal and external resources that help them cope with unstable environments (Di Fabio and Kenny, 2015). In addition, career and academic processes seem to jointly influence children's perseverance to overcome barriers and to attain goals, assignment of meaning to school and success in the later school-to-work transition (Bandura et al., 2001).

Empirical support to the complementary view of career and academic processes has been found. On the one hand, the academic experiences offer "a source of learning realistic occupational information" (Watson and McMahon, 2005, p. 124) and potentially afford the possibility for children to experience responsive, consistent and quality relationships with teachers as well as to engage in instrumental behaviors and advance career planning, exploration, aspirations, reasoning, agency, decidedness, cooperation and self-perceived employability (Howard et al., 2009, 2015; Veiga et al., 2014; Di Fabio and Kenny, 2015; Longobardi et al., 2016). On the other hand, career development advances students' learning self-regulation, construction of meaning about one-self, school engagement, achievement and satisfaction (Peetsma and van der Veen, 2011; Paradnikè and Bandzevičienè, 2016; Hartung, 2017; Rudolph et al., 2017).

Career and academic processes impact psychosocial outcomes later in life. Children's career exploration precedes career adaptability and identity later in adolescence and adulthood (Schmitt-Rodermund and Vondracek, 1999; Guan et al., 2015). Children's favorable career self-efficacy expectations promote career-choice readiness in adolescence (Hirschi, 2011). Evidence has additionally indicated that children's academic achievement is positively related with adult educational level and employment (Ek et al., 2005). Still, childhood literacy and numeracy learning difficulties have been shown to contribute, among other factors, to lower self-esteem, weak vocational identity and long-term unemployment (Anyadike-Danes and McVicar, 2005; Pasta et al., 2013; Chávez, 2016). School behavioral problems, weak academic achievement and learning disabilities during childhood seem also to increase the likelihood of school dropout and career indecision in adolescence and long-term unemployment in adulthood (Rojewski, 1996; Wiesner et al., 2003; Anyadike-Danes and McVicar, 2005; Ferreira et al., 2007). Still, factors such as the quality of the teacher-child relationship might protect students from such unfavorable trajectories (Pasta et al., 2013; Longobardi et al., 2016).

It is, therefore, important to theoretically and empirically acknowledge the linkages among career and academic processes to more deeply understand their mutual dynamics. The literature has suggested that career interventions implemented since the childhood period of the lifespan and systematically carried out over the school years positively affect students' academic achievement, school motivation, career exploration and awareness (Whiston et al., 2011; Choi et al., 2015). Career interventions may, therefore, benefit from theory and research 
that more deeply address the articulations among career and academic development.

Empirical findings to date have relied on longitudinal studies spanning middle school to adolescence or during the emerging adulthood period. Regarding the former, evidence suggested that a favorable future time perspective is associated with gains in academic achievement, which in turn has been shown to be a predictor and outcome of career planning (Peetsma and van der Veen, 2011; Negru-Subtirica and Pop, 2016). As for the latter, findings derived from emerging adults indicated that career selfefficacy expectations seem to be positively related with college persistence and academic achievement, which in turn impacts one's occupational choices by age 30 (Wright et al., 2012; Wang et al., 2015).

Prior research has also identified variations in career and academic processes across demographic characteristics. In general, girls demonstrate more favorable academic and career progress than boys (e.g., Bandura et al., 2001; Ferreira et al., 2007; Peetsma and van der Veen, 2011; Weis et al., 2013). The literature has also indicated that gender seems to moderate the child-in-context experiences and resulting career paths (Araújo and Taveira, 2009). On the other hand, the geographic location of children, although less addressed in the literature, has been shown to predict differences in life styles, income, occupational and employment opportunities (Rafecas, 2013), which in turn might contribute to differences in children's career preparedness and academic achievement (e.g., Howard et al., 2009). Previous exploratory studies in Portugal have also indicated that northern children are more motivated to solve social conflicts than their central peers (Pereira, 2014).

This study aims to further explore the linkages among career and academic development during the childhood period with a specific focus on articulations between career preparedness constructs (i.e., career self-efficacy, outcome expectations, exploration and planning) and academic achievement during middle school years. A four-wave longitudinal research design was employed. Gender and geographic location were tested as potential moderators affecting the articulation between career and school trends. Based on the reviewed literature and adopting a complementary position between career and academic processes, the following research hypotheses were tested:

Hypothesis 1: There will be positive associations between the career variables and academic achievement trends over time. Hypothesis 2: Gender will moderate the association between the career and academic achievement trends over time.

Hypothesis 3: Geographic location will moderate the association between the career and academic achievement trends over time.

\section{MATERIALS AND METHODS}

\section{Participants}

Data from the four-wave longitudinal research project "Trajectories of childhood career development: A study with middle school children" (FCT-SFRH/BD/84162/2012) was employed to test the association between longitudinal trajectories of career and academic preparation. A non-probabilistic intentional sampling method was used to recruit participants aged 9 to 13 years old attending fifth-grade ${ }^{1}$ at the first occurrence of measurement through sixth-grade at the fourth occurrence of measurement. Portuguese fifth- and sixth-grades are aligned with level 2 of the International Standard Classification of Education (ISCED)-lower secondary education (OECD, European Union, UNESCO Institute for Statistics, 2015).

A total of four schools from northern and central Portugal collaborated in this project. Northern and central Portugal were defined according to a legal document approved by the European Union (i.e., Regulamento UE 868/2014) ${ }^{2}$. which organizes Portuguese regions from broader to more specific Nomenclatures of Territorial Units for Statistical Purposes. The initial sample included 446 children, 213 (47.8\%) girls, and 233 (52.2\%) boys, 314 (70.4\%) from northern and 132 (29.6\%) from central Portugal $\left(M_{\text {age Wave1 }}=10.23, S D=0.49\right)$. Attrition was found for 17 cases due to health problems, emigration, or failure to be promoted to the sixth-grade. Attrition was found to be missing at random, presenting no associations with demographic, career or academic variables. This study included participants with complete data across the four occurrences of measurement. The final sample included 429 children, 207 (48.3\%) girls, and 222 (51.7\%) boys, 298 (69.5\%) from northern and 131 (30.5\%) from central Portugal $\left(M_{\text {age Wavel }}=10.23, S D=0.50\right)$. Most children were Portuguese-native (99.5\%), except for two cases who were Chinese and Brazilian. Participants mostly derived from medium-low social economic status $(52.4 \%)$, followed by low $(28.2 \%)$ and medium-high statuses $(18.6 \%)^{3}$.

\section{Measures}

\section{Career Development}

Children's self-efficacy expectations for academic, leisure and extracurricular activities were measured with the Portuguese version of the Multidimensional Scales of Perceived Self-Efficacy (MSPSE; Bandura, 1990; adapted by Teixeira and Carmo, 2004). Twenty-six items (e.g., "How easily do you plan your schoolwork") were answered with a five-point Likert-type scale ranging from 1 "Not easy at all" to 5 "Very easy." Higher scores reflected more favorable self-efficacy expectations for academic, leisure and extracurricular activities. Previous validity evidence of

\footnotetext{
${ }^{1}$ The Portuguese educational system includes four compulsory cycles of study. The first cycle of study (i.e., ISCED level 1 primary education) ranges from the first- to the fourth-grade and usually includes children aged six to 10. The second cycle of study includes the fifth- and sixth-grade and is usually attended by children aged 10 to 11 . The third cycle of study comprises seventh-, eighth- and ninth-grade, usually including students aged 11 to 14 . The Portuguese second and third cycles of study both correspond to the ISCED level 2 lower secondary education. The fourth cycle of study (i.e., ISCED level 3 upper secondary education) spins from tenth- through twelfth-grade and is usually attended by students aged 14 to 17 .

${ }^{2}$ Regulamento UE n. ${ }^{\circ} 868$ da Comissão (2014).

${ }^{3}$ Social economic statuses relied on the caregivers' educational level and occupation, following the Portuguese Classification of Occupations (Instituto Nacional de Estatística, 2011). A low social economic status was coded when caregivers did not complete Portuguese compulsory education and held unqualified jobs. A medium-low status was coded when at least one caregiver completed the Portuguese compulsory education and held a semi-qualified job. A medium-high status was coded when at least one of the caregivers had a college degree and held a qualified job.
} 
the Portuguese MSPSE version supported its hierarchical factor structure and theoretically predicted positive associations with academic achievement, career exploration and interests (e.g., Teixeira and Carmo, 2004; Oliveira, 2016). Reliability estimates in this sample ranged from 0.93 to 0.94 across the four occurrences of measurement.

Students' career exploratory outcome expectations were assessed with the Career Exploratory Outcome Expectations Scale (CEOES; Oliveira et al., 2016). This self-report measure includes 15 items (e.g., "Asking questions about the world of work at home, school and my friends will help me learn more about careers") answered in a four-point Likert-type scale ranging from 1 "Very low or low probability" to 4 "Very high probability." Higher scores reflected more favorable career exploratory outcome expectations. Extant validity results supported the CEOES one-dimensional structure, measurement invariance across both genders and positive association with career self-efficacy expectations (Oliveira et al., 2016). The estimates of internal consistency reliability in the current sample ranged from 0.80 to 0.91 over time.

Children's career exploration was assessed with the Childhood Career Exploration Inventory (CCEI; Oliveira, 2016). The CCEI is a self-report measure, which includes 12 items (e.g., "I like to ask my parents about their jobs") answered in a five-point Likerttype scale ranging from 1 "Strongly disagree" to 5 "Strongly agree." Higher scores indicated higher career exploration levels. Previous validity evidence supported the CCEI hierarchical factor structure, measurement invariance across genders during fifthand sixth-grade as well as positive associations with self-concept and locus of control (Oliveira, 2016). Internal consistency reliability ranged from 0.79 to 0.86 in the current sample followed over time.

Career planning was measured with the Portuguese Childhood Career Development Scale version (CCDS; Schultheiss and Stead, 2004; adapted by Oliveira and Taveira, 2014). Eight items (e.g., "It is important for me to plan for a project") were answered in a five-point Likert-type scale ranging from 1 "Strongly disagree" to 5 "Strongly agree." Previous research with the Portuguese CCDS version suggested that career planning is positively associated with career exploration and locus of control (Oliveira and Taveira, 2014; Oliveira, 2016). Internal consistency reliability in this sample ranged from 0.88 to 0.91 across the four occurrences of measurement.

\section{Academic Achievement}

Academic achievement was assessed through school records of the students' grades in each course at each occurrence of measurement. Average grades at each occurrence of measurement were computed. Higher average scores indicated higher school achievement.

\section{Ethical Considerations and Research Procedures}

This study followed Portuguese governmental regulatory standards to conduct research projects with children and youths at the school setting (Despacho, 15847/2007) ${ }^{4}$. This project was approved by the Portuguese Directorate General of Education, Ministry of Education and Science, through the monitoring system of school surveys (reference 0355100001). After obtaining such a legal approval, written consent to pursue the research project and recruit students from schools was obtained from institutional principals, teachers and school psychologists. The schools' principals and psychologists selected the classroom groups to which the project was introduced. All students from the classroom groups were invited to participate. Conforming with the Portuguese ethical standards of Psychology (Regulamento 258/2011) ${ }^{5}$, this study respected people's dignity and human rights, only including students who offered their assent for voluntary participation and whose caregivers signed a written consent form for their children's participation, acknowledging the research project's goals, procedures, confidentiality assurance and voluntary participation.

Data was collected from February 2013 to May 2014 by $\mathrm{PhD}$ and MSD Psychology students as well as school psychologists. Data at the first and second occurrences of measurement were collected 3 months apart. Six months elapsed between the second and third and between the third and fourth occasions. The MSPSE, CEOES, CCEI, and CCDS scales were group-administrated in the classroom setting. Researchers accessed school records to collect children's average grades at each occurrence of measurement. Taking the Portuguese ethical standards of Psychology and the longitudinal research demands into account, several strategies were employed to offer feedback to participants and to minimize attrition. These included offering make-up survey sessions for absent student, frequent school personal, e-mail and phone contacts, distribution of a newsletter informing caregivers of activities to advance their children's career development and academic achievement, as well as summaries of the main descriptive results from the study. Confidentiality was assured throughout this project.

\section{Data Analyses}

The Statistical Package for the Social Sciences (IBM SPSS, version 22.0 for Windows) was used to conduct the data analyses. A maximum $1.1 \%$ of missing values was found across the constructs at each occurrence of measurement. Results from the Little MCAR test suggested a completely at random pattern of missingness. An exception was only found for the planning items at the third occurrence of measurement. This exception was due to one case who did not complete the scale's items, whereby this participant's data was filtered from the analyses. The expectation-maximization method was used to treat the remaining missing values, due to their low frequency and random pattern (Tabachnick and Fidell, 2013).

Average and orthnormalized linear, quadratic and cubic trends of each career variable and school achievement $(x)$ were

\footnotetext{
${ }^{4}$ Despacho Ministério da Educação Diário da República Portuguesa n. 15847 (2007).

${ }^{5}$ Regulamento Portuguese Order of Psychologists n. ${ }^{\circ} 258$ (2011).
} 
computed, based on the following equations:

$$
\begin{aligned}
& \text { Linear trend }(x)=\frac{\left(\begin{array}{c}
\left(-3 x_{[\text {Wave } 1]}\right)+\left(-1 x_{[\text {Wave }]}\right) \\
\left(1 x_{[\text {Wave } 3]}\right)+\left(3 x_{[\text {Wave }]}\right)
\end{array}\right)+}{\sqrt{-3^{2}+\left(-1^{2}\right)+1^{2}+3^{2}}} \\
& \text { Quadratic trend }(x)=\frac{\left(-1 x_{[\text {Wave } 1]}\right)+\left(-1 x_{[\text {Wave } 3]}\right)+\left(1 x_{[\text {Wave } 4]}\right)}{\sqrt{1^{2}+\left(-1^{2}\right)+\left(-1^{2}\right)+1^{2}}} \\
& \text { Cubic trend }(x)=\frac{\left(-1 x_{[\text {Wave } 1]}\right)+\left(3 x_{[\text {Wave } 2]}\right)+}{\sqrt{-1^{2}+3^{2}+\left(-3^{2}\right)+1^{2}}}
\end{aligned}
$$

The associations between the career variables and academic achievement trends were tested. Due to evidence of nonnormality of the sampling distribution, parametric (i.e., Pearson) and non-parametric (i.e., Spearman) correlation coefficients were computed. When both tests were consistent, parametric results were reported; otherwise, non-parametric results were presented (Fife-Schaw, 2006). Multiple simultaneous linear regression models were computed to test the predictive role of the career constructs on academic achievement trends. The Durbin-Watson statistics suggested that residuals were uncorrelated. Based on the Cook's Distance measure and the range of the standardized residuals, multivariate outliers were identified and filtered from the regression analyses to prevent their biases on the estimated models (Field, 2009). The gender and the geographic location moderator effects were investigated by adding interaction terms into the regression models of each trend (see Figure 1). Variables were centralized before computing the interaction terms (Aiken and West, 1991).

\section{RESULTS}

The correlational results suggested a positive and statistically significant association among children's career exploratory outcome expectations and academic achievement average trends, $r=0.28, p<0.001$. Overall, children who reported favorable career exploratory outcome expectation presented significantly high academic achievement. In turn, a negative and statistically significant correlation between career planning and academic achievement quadratic trends was found, $r=-0.10$, $p=0.04$. Changes in career planning were inversely associated with changes in academic achievement. Career self-efficacy expectations and academic achievement quadratic trends also demonstrated a negative and statistically marginally significant association, $r=-0.09, p=0.07$. Children's shifts from favorable to unfavorable self-efficacy expectations tended to be associated with shifts from lower to higher academic achievement (see Table 1).

The multiple linear regression model testing the predictive role of the career variables on academic achievement average trends explained $8.7 \%$ of the variance $\left(R^{2}\right.$ Adj. $\left.=0.08\right)$ and was statistically significant, $F_{(4,424)}=10.11, p<0.001$. Career exploratory outcome expectations constituted a statistically significant predictor of academic achievement average trends, $\beta=0.29, t=6.12, p<0.001$. Children's overall favorable career exploratory outcome expectations were related with high academic achievement.

In addition, the linear regression model testing academic achievement regressed onto the career variables quadratic trends explained $2.7 \%$ of the variance $\left(R^{2}\right.$ Adj. $\left.=0.02\right)$ and was statistically significant, $F_{(4,417)}=2.86, p=0.02$. Career planning was a statistically significant predictor of academic achievement quadratic trends, $\beta=-0.11, t=-2.23, p=0.03$. However, the constructs' progress trends were inversely related, as career planning gains and losses were significantly associated with losses and gains in academic achievement (see Table 2).

Tables 3, 4 summarize the results from the multiple linear regression models testing the gender and geographic location moderator effects in the linkages among career and academic trends.

Results suggested that gender was a statistically significant moderator of the association between career variables and academic achievement linear trends, $\beta=-0.12, t=-2.50$, $p=0.01$. While girls presented a positive association among the constructs, boys presented a negative association (see Figure 2).

Gender also moderated the association between career selfefficacy and academic achievement, $\beta=0.10, t=1.96, p=$ 0.05 , as well as among career planning and academic achievement cubic trends, $\beta=-0.14, t=-2.66, p=0.008$. The positive association was more pronounced for boys than girls (see Figure 3). In addition, the career planning cubic trend was negatively associated with the academic achievement cubic trend for both genders, but was stronger for boys than girls (see Figure 4).

Additionally, geographic location of the children moderated the association between career exploratory outcome expectations and academic achievement average trends, $\beta=-0.29, t=$ $-6.14, p<0.001$. Children from both geographical areas presented a positive association among the overall career exploratory outcome expectations and academic achievement trends. More favorable career exploratory outcome expectations were associated with higher academic achievement over time. However, this trend was more pronounced for northern Portuguese children than for their central Portuguese peers (see Figure 5).

The relationships between the career variables and academic achievement quadratic trends were positively related and moderated by the geographic location, $\beta=0.09, t=1.71, p=$ 0.09 . The positive association tended to be slightly stronger for central Portuguese children than northern Portuguese children (see Figure 6).

\section{DISCUSSION}

This study examined longitudinal trends between career preparedness constructs and academic achievement with Portuguese middle school children. The results support the need to acknowledge the joint linkages among career and academic dynamics, as several statistically significant relations and predictive models among the constructs were found. 

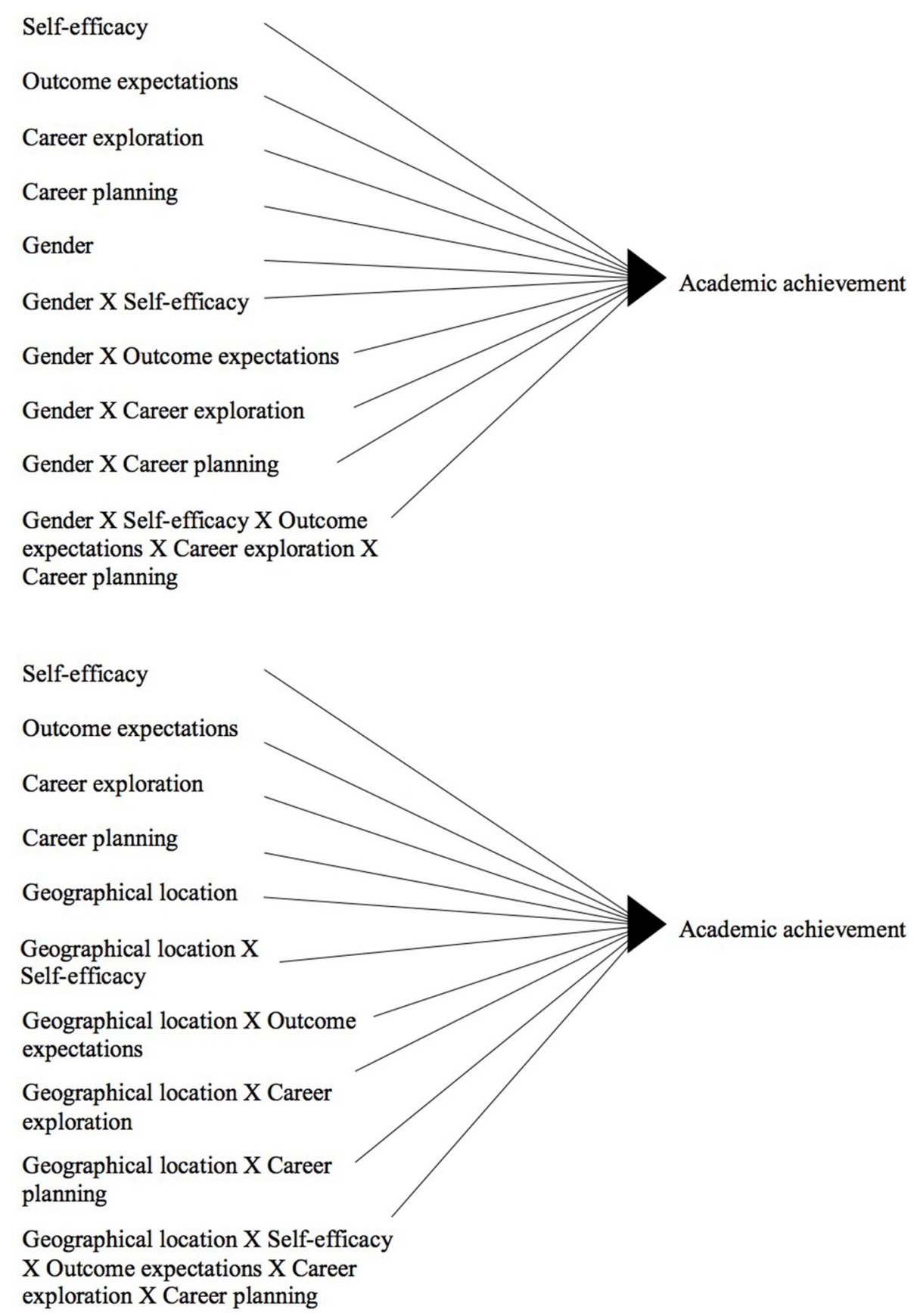

FIGURE 1 | Schematic representation of the regression models testing the gender and geographic area moderator effects on the linkage between career preparedness and school achievement.

H1 was partially supported. A positive association between career exploratory outcome expectations and academic achievement average trends was suggested by both correlational and regression results. The association among these constructs is aligned with literature suggesting that during childhood, students are expected to assign meaning to school and acknowledge the importance of academic achievement for their future careers (Super, 1994; Hartung, 2017). As children engage in instrumental behaviors and adapt to school social expectations (Chávez,
2016), they might set the goal of attaining good grades. This goal might foster a virtuous cycle of children's academic success and enhance their academic confidence in the future. The combination of positive performance and confidence may foster more active/meaningful learning, as well as the development of a sense of industry and establishment of a close teacherstudent relationship (Erikson, 1963; Lent et al., 1999; Lent, 2004; Longobardi et al., 2016; Oliveira et al., 2016). On the contrary, accumulated experiences of school failure might foster a vicious 
TABLE 1 | Correlations between the career variables and academic achievement trends.

\begin{tabular}{lcc}
\hline Variables & $\begin{array}{c}\text { Self- } \\
\text { efficacy }\end{array}$ & $\begin{array}{c}\text { Outcome } \\
\text { expectations }\end{array}$ \\
\hline
\end{tabular}

\begin{tabular}{|c|c|c|c|c|c|}
\hline \multicolumn{6}{|c|}{ AVERAGE TREND } \\
\hline Self-efficacy & - & & & & \\
\hline $\begin{array}{l}\text { Outcome } \\
\text { expectations }\end{array}$ & 0.07 & - & & & \\
\hline Exploration & $0.40^{\star \star \star}$ & 0.04 & - & & \\
\hline Planning & $0.47^{\star \star \star}$ & $0.10^{*}$ & $0.55^{\star \star \star}$ & - & \\
\hline Achievement & -0.05 & $0.28^{\star \star \star}$ & -0.08 & -0.05 & - \\
\hline \multicolumn{6}{|c|}{ LINEAR TREND } \\
\hline Self-efficacy & - & & & & \\
\hline $\begin{array}{l}\text { Outcome } \\
\text { expectations }\end{array}$ & 0.004 & - & & & \\
\hline Exploration & $0.28^{\star \star \star}$ & -0.05 & - & & \\
\hline Planning & $0.32^{\star \star \star}$ & -0.05 & $0.45^{\star \star \star}$ & - & \\
\hline Achievement & -0.05 & -0.01 & 0.08 & 0.02 & - \\
\hline \multicolumn{6}{|c|}{ QUADRATIC TREND } \\
\hline Self-efficacy & - & & & & \\
\hline $\begin{array}{l}\text { Outcome } \\
\text { expectations }\end{array}$ & $-0.08 \dagger$ & - & & & \\
\hline Exploration & $0.21^{\star \star \star}$ & 0.04 & - & & \\
\hline Planning & $0.23^{\star \star \star}$ & -0.04 & $0.27^{\star \star \star}$ & - & \\
\hline Achievement & $-0.09+$ & 0.08 & -0.004 & $-0.10^{\star}$ & - \\
\hline \multicolumn{6}{|c|}{ CUBIC TREND } \\
\hline Self-efficacy & - & & & & \\
\hline $\begin{array}{l}\text { Outcome } \\
\text { expectations }\end{array}$ & 0.01 & - & & & \\
\hline Exploration & $0.20^{\star \star \star}$ & 0.02 & - & & \\
\hline Planning & $0.23^{\star \star \star}$ & -0.02 & $0.22^{\star \star \star}$ & - & \\
\hline Achievement & 0.01 & -0.04 & -0.03 & -0.001 & - \\
\hline
\end{tabular}

${ }^{\star} p<0.05 .{ }^{\star \star \star} p<0.001 .{ }^{\dagger} p<0.10$.

cycle of future failure and diminished academic confidence, thus increasing the likelihood to avoid school-related tasks and to develop a sense of inferiority if no protective psychoeducational strategies are set in motion (Erikson, 1963; Anyadike-Danes and McVicar, 2005; Ferreira et al., 2007). Future research could examine how children's academic achievement might sustain and/or be sustained by optimism and favorable expectations to attain valued outcomes from career exploration.

Contrary to our hypothesis, academic achievement presented negative correlations with career self-efficacy and career planning quadratic trends, with the latter being similarly verified in regression analysis. These findings are surprising considering extant evidence pointing to a positive association among the constructs (e.g., Peetsma and van der Veen, 2011; Wright et al., 2012; Negru-Subtirica and Pop, 2016). The negative association between career self-efficacy expectations and academic achievement quadratic trends suggest that a high academic achievement peak was linked to an unfavorable self-efficacy valley. It is worth emphasizing that the MSPSE offers a global estimate of self-efficacy for academic, leisure and extracurricular activities, which might have influenced these
TABLE 2 | Multiple linear regressions testing academic achievement regressed onto career variables trends.

\begin{tabular}{|c|c|c|c|c|}
\hline Predictors & $R^{2}\left(R^{2} \mathrm{Adj}.\right)$ & $\boldsymbol{F}$ & $\beta$ & $t$ \\
\hline \multicolumn{5}{|l|}{ AVERAGE TREND } \\
\hline Self-efficacy & $0.09(0.08)$ & $10.11^{\star \star \star}$ & -0.03 & -0.56 \\
\hline Outcome expectations & & & 0.29 & $6.12^{\star \star \star}$ \\
\hline Exploration & & & -0.06 & -1.04 \\
\hline Planning & & & -0.04 & -0.59 \\
\hline \multicolumn{5}{|l|}{ LINEAR TREND } \\
\hline Self-efficacy & $0.01(0.004)$ & 1.40 & -0.05 & -1.05 \\
\hline Outcome expectations & & & -0.004 & -0.09 \\
\hline Exploration & & & 0.12 & $2.20^{*}$ \\
\hline Planning & & & -0.01 & -0.25 \\
\hline \multicolumn{5}{|l|}{ QUADRATIC TREND } \\
\hline Self-efficacy & $0.03(0.02)$ & $2.86^{\star}$ & -0.06 & -1.24 \\
\hline Outcome expectations & & & 0.08 & 1.66 \\
\hline Exploration & & & 0.03 & 0.62 \\
\hline Planning & & & -0.11 & $-2.23^{\star}$ \\
\hline \multicolumn{5}{|l|}{ CUBIC TREND } \\
\hline Self-efficacy & $0.008(-0.002)$ & 0.79 & 0.05 & 0.96 \\
\hline Outcome expectations & & & -0.05 & -0.95 \\
\hline Exploration & & & -0.06 & -1.26 \\
\hline Planning & & & -0.01 & -0.24 \\
\hline
\end{tabular}

${ }^{\star} p<0.05 .{ }^{* \star *} p<0.001$.

findings. Despite temporal variations in academic achievement, a child's attainment of high academic achievement might foster stronger engagement in academic pursuits, which in turn, might constrain his/her availability to engage in extracurricular and leisure activities. Oppositely, a child's weak academic achievement might source from reduced engagement in academic activities and more engagement in extracurricular and leisure activities, thus increasing one's confidence in out-of-school activities and possibly inflating those self-efficacy scores. To clarify these findings, future research could address the importance of extracurricular and leisure activities in children's career and academic progress trends and how these various activities might mutually influence each other (Super, 1994; Araújo and Taveira, 2009; Hartung, 2017).

By a similar token, as students' academic achievement gains might spring from a great amount of time and effort devoted to academic activities, which might diminish the time available to consider their future. In turn, children demonstrating poorer academic achievement, might invest less time in academic pursuits and more time engaging in other pursuits (Veiga et al., 2014). It might also be the case that as children perform the student role (Super, 1994; Araújo and Taveira, 2009), their planning becomes more focused on academic tasks and management of student responsibilities than on planning for future roles. Hence, future studies employing both career and academic planning measures could help clarify this result. In addition, future studies could rely on mixed-method research designs to bring complementary qualitative evidence 
TABLE 3 | Gender moderator role in the association among career variables and academic achievement trends.

\begin{tabular}{|c|c|c|c|c|}
\hline Predictors & $R^{2}\left(R^{2} \mathrm{Adj}.\right)$ & $\boldsymbol{F}$ & $\beta$ & $t$ \\
\hline \multicolumn{5}{|l|}{ AVERAGE TREND } \\
\hline Self-efficacy & $0.10(0.08)$ & $4.77^{\star \star \star}$ & -0.04 & -0.69 \\
\hline Outcome expectations & & & 0.30 & $5.90^{\star \star \star}$ \\
\hline Exploration & & & -0.07 & -1.27 \\
\hline Planning & & & -0.02 & -0.38 \\
\hline Gender & & & -0.07 & -1.41 \\
\hline Gender X self-efficacy & & & 0.08 & 1.40 \\
\hline Gender $\times$ outcome expectations & & & -0.06 & -1.19 \\
\hline Gender $\times$ exploration & & & -0.01 & -0.25 \\
\hline Gender × planning & & & -0.06 & -1.06 \\
\hline $\begin{array}{l}\text { Gender } \times \text { self-efficacy } \times \text { outcome } \\
\text { expectations } \times \text { exploration } \times \text { planning }\end{array}$ & & & 0.06 & 1.22 \\
\hline \multicolumn{5}{|l|}{ LINEAR TREND } \\
\hline Self-efficacy & $0.03(0.01)$ & 1.46 & -0.04 & -0.84 \\
\hline Outcome expectations & & & -0.02 & -0.32 \\
\hline Exploration & & & 0.12 & $2.07^{\star}$ \\
\hline Planning & & & -0.01 & -0.15 \\
\hline Gender & & & -0.02 & -0.31 \\
\hline Gender $\times$ self-efficacy & & & -0.01 & -0.15 \\
\hline Gender $\times$ outcome expectations & & & -0.01 & -0.26 \\
\hline Gender $\times$ exploration & & & 0.08 & 1.49 \\
\hline Gender $\times$ Planning & & & -0.07 & -1.20 \\
\hline $\begin{array}{l}\text { Gender } \times \text { self-efficacy } \times \text { outcome } \\
\text { expectations } \times \text { exploration } \times \text { planning }\end{array}$ & & & -0.12 & $-2.50^{\star \star}$ \\
\hline \multicolumn{5}{|l|}{ QUADRATIC TREND } \\
\hline Self-efficacy & $-0.04(0.01)$ & 1.60 & -0.07 & -1.38 \\
\hline Outcome expectations & & & 0.09 & $1.75 \dagger$ \\
\hline Exploration & & & 0.03 & 0.64 \\
\hline Planning & & & -0.10 & $-1.94^{*}$ \\
\hline Gender & & & 0.002 & 0.04 \\
\hline Gender $\times$ self-efficacy & & & -0.04 & -0.69 \\
\hline Gender $\times$ outcome expectations & & & 0.01 & 0.19 \\
\hline Gender $\times$ exploration & & & 0.002 & 0.03 \\
\hline Gender $\times$ planning & & & -0.09 & -1.70 \\
\hline $\begin{array}{l}\text { Gender } \times \text { self-efficacy } \times \text { outcome } \\
\text { expectations } \times \text { exploration } \times \text { Planning }\end{array}$ & & & 0.02 & 0.46 \\
\hline \multicolumn{5}{|l|}{ CUBIC TREND } \\
\hline Self-efficacy & $0.04(0.01)$ & 1.49 & 0.04 & 0.85 \\
\hline Outcome expectations & & & -0.02 & -0.40 \\
\hline Exploration & & & -0.06 & -1.12 \\
\hline Planning & & & -0.02 & -0.35 \\
\hline Gender & & & -0.06 & -1.24 \\
\hline Gender $\times$ self-efficacy & & & 0.10 & $1.96^{\star}$ \\
\hline Gender $\times$ outcome expectations & & & 0.04 & 0.79 \\
\hline Gender $\times$ exploration & & & -0.003 & -0.06 \\
\hline Gender × planning & & & -0.14 & $-2.66^{\star \star}$ \\
\hline $\begin{array}{l}\text { Gender } \times \text { self-efficacy } \times \text { outcome } \\
\text { expectations } \times \text { exploration } \times \text { planning }\end{array}$ & & & -0.04 & -0.77 \\
\hline
\end{tabular}

${ }^{\dagger} p<0.10 .{ }^{*} p<0.05 .{ }^{* \star} p<0.01 .{ }^{* \star *} p<0.001$.

on the students' career-related reasoning (Howard et al., 2015; Watson et al., 2015) and examine its impact on the career planning-academic achievement association.
TABLE 4 | Geographic location moderator role in the association among career variables and academic achievement trends.

\begin{tabular}{|c|c|c|c|c|}
\hline Predictors & $R^{2}$ ( $\left.R^{2} \mathrm{Adj}.\right)$ & $\boldsymbol{F}$ & $\beta$ & $t$ \\
\hline \multicolumn{5}{|l|}{ AVERAGE TREND } \\
\hline Self-efficacy & $0.18(0.16) \quad 9$ & $9.21^{\star \star \star}$ & -0.08 & -1.51 \\
\hline Outcome expectations & & & 0.30 & $7.91^{\star \star \star}$ \\
\hline Exploration & & & 0.01 & 0.25 \\
\hline Planning & & & 0.02 & 0.36 \\
\hline Geographic location & & & 0.16 & $2.86^{\star \star}$ \\
\hline Geo $\times$ self-efficacy & & & 0.04 & 0.83 \\
\hline Geo $\times$ outcome expectations & & & -0.29 & $-6.14^{\star \star \star}$ \\
\hline Geo $\times$ exploration & & & -0.04 & -0.77 \\
\hline Geo $\times$ planning & & & 0.05 & 0.79 \\
\hline $\begin{array}{l}\text { Geo } \times \text { self-efficacy } \times \text { outcome } \\
\text { expectations } \times \text { exploration } \times \text { planning }\end{array}$ & & & -0.03 & -0.52 \\
\hline \multicolumn{5}{|l|}{ LINEAR TREND } \\
\hline Self-efficacy & $0.02(-0.001) 0$ & 0.94 & -0.06 & -1.19 \\
\hline Outcome expectations & & & -0.008 & -0.17 \\
\hline Exploration & & & 0.13 & $2.34^{\star}$ \\
\hline Planning & & & -0.02 & -0.35 \\
\hline Geographic location & & & -0.04 & -0.77 \\
\hline Geo $\times$ self-efficacy & & & -0.07 & -1.42 \\
\hline Geo $\times$ outcome expectations & & & 0.01 & 0.14 \\
\hline Geo $\times$ exploration & & & -0.04 & -0.64 \\
\hline Geo $\times$ planning & & & 0.03 & 0.50 \\
\hline Geo $\times$ self-efficacy $\times$ outcome & & & -0.02 & -0.35 \\
\hline
\end{tabular}

expectations $\times$ exploration $\times$ planning

\section{QUADRATIC TREND}

\begin{tabular}{|c|c|c|c|c|}
\hline Self-efficacy & $0.07(0.04)$ & $2.90^{\star \star}$ & -0.05 & -1.09 \\
\hline Outcome expectations & & & 0.06 & 1.26 \\
\hline Exploration & & & 0.04 & 0.71 \\
\hline Planning & & & -0.05 & -0.90 \\
\hline Geographic location & & & -0.16 & $-3.06^{* \star}$ \\
\hline Geo $\times$ self-efficacy & & & 0.07 & 1.33 \\
\hline Geo $\times$ outcome expectations & & & 0.03 & 0.52 \\
\hline Geo $\times$ exploration & & & 0.00 & -0.008 \\
\hline Geo $\times$ planning & & & -0.08 & -1.50 \\
\hline Geo $\times$ self-efficacy $\times$ outcome & & & 0.09 & $1.72 \dagger$ \\
\hline
\end{tabular}

expectations $\times$ exploration $\times$ planning

$\begin{array}{lrr}\text { CUBIC TREND } & 0.02(-0.01) & 0.69 \\ \text { Self-efficacy } & 0.01 & 0.09 \\ \text { Outcome expectations } & -0.05 & -0.93 \\ \text { Exploration } & -0.03 & -0.63 \\ \text { Planning } & 0.01 & 0.15 \\ \text { Geographic location } & -0.06 & -1.15 \\ \text { Geo } \times \text { self-efficacy } & -0.06 & -1.09 \\ \text { Geo } \times \text { outcome expectations } & 0.01 & 13 \\ \text { Geo } \times \text { exploration } & 0.06 & 1.14 \\ \text { Geo } \times \text { planning } & 07 & 1.25 \\ \text { Geo } \times \text { self-efficacy } \times \text { Outcome } & -0.05 & -0.96 \\ \text { expectations } \times \text { exploration } \times \text { planning } & & \end{array}$

${ }^{\dagger} p<0.10 .{ }^{*} p<0.05 .{ }^{* *} p<0.01 .{ }^{* * *} p<0.001$.

Both the correlational and regression analyses found no association between career exploration and academic achievement trends, which was misaligned with our initial 
hypothesis. Still, this finding seems consistent with literature acknowledging that the school setting may not sufficiently stimulate children's inquisitive behavior, reflexivity and career exploration (Kuijpers and Meijers, 2012; Negru-Subtirica and Pop, 2016). We, therefore, highlight extant calls to investigate career exploration in extracurricular and outof-school activities as well as its associations with academic processes, such as engagement in school or academic adjustment (e.g., Araújo and Taveira, 2009; Oliveira, 2016; Paradnikè and Bandzevičienè, 2016). Moreover, future studies could assess academic achievement as perceived by the child rather than his/her recorded grades at the school setting. In previous studies, children perceived achievement has been shown to play a greater role in career and academic development than their actual grades (e.g., Bandura et al., 2001).

Taking the demographic characteristics into account, H2 was supported. Gender moderated the relationships between the career and academic achievement linear trends, with girls demonstrating a positive relationship and boys demonstrating the reverse. This finding is consistent with previous evidence suggesting that girls demonstrate more advanced career development and academic achievement than boys (e.g., Bandura et al., 2001; Ferreira et al., 2007; Weis et al., 2013). However, this study brings complementary longitudinal evidence to this topic by suggesting that boys' academic success might come with a cost of less advanced career development. This might suggest that, during middle school years, boys may not yet comprehend the role of school and academic achievement for their future, contrary to what would be expected from the literature (Super, 1980; Bandura, 1990; Peetsma and van der Veen, 2011). This possible explanation may similarly be applied to the results indicating opposite cubic trends between career planning and academic achievement, with such a relationship being more pronounced for boys than girls. Children's greater focus on academic demands may deviate their attention from future career prospects. This might be more evident for boys, as they seem to not yet articulate linkages between career and academic processes. Further studies employing mixed-method designs could clarify these results by addressing girls' and boys' discourse when talking about their role as a student and its links to the future.

Results also indicated similar associations among self-efficacy expectations and academic achievement cubic trends, although such a relation was more pronounced for boys compared to girls. This finding is aligned with literature highlighting the importance of self-efficacy expectations for academic achievement in childhood (Lent, 2004). The more pronounced results for boys compared to girls might suggest that boys' overall confidence in academic, extracurricular and leisure activities is central to their favorable academic achievement. Boys' academic success might, therefore, be facilitated when one acknowledges their multiple life roles, offers opportunities to learn how to manage time and enjoy both school and out-of-school activities, and recognizes their achievements in academic, extracurricular and leisure tasks. Although this seems also to be the case for girls, perhaps their confidence in leisure and extracurricular activities might be reduced and masked by the general self-efficacy measure used in this study. Future research should clarify the importance of extracurricular and leisure activities for children's career development and academic processes, taking differences for gender into consideration (Bandura et al., 2001).

H3 was also supported. Despite both geographic areas presenting a positive association among career exploratory outcome expectations and academic achievement average trends, such an association was more evident for northern than central Portugal. This finding might reflect the Portuguese social-economic regional asymmetries and the fact that the northern area typically offers increased educational and work opportunities than the central area (Rafecas, 2013). On the one hand, northern Portuguese children may benefit from greater opportunities to explore academic domains and related jobs, thus promoting academic achievement because of the more favorable career outcomes available in this region (Oliveira et al., 2016). On the other hand, the academic achievement of central Portuguese children seems not to be as facilitated by career exploratory outcome expectations. This might be due the economic disadvantageous situation of the central area (Rafecas, 2013), which might embolden children' efforts to be successful at school to increase the likelihood of future career attainment within a more difficult labor market. This possibility seems aligned with the additional result suggesting that central Portuguese children presented a slightly stronger positive association between the career constructs and academic achievement quadratic trends than their northern peers. The latter finding might suggest that central Portuguese children may articulate career and academic processes and eventually engage in academic activities as a strategy to succeed in the future more so than their northern peers do.

The results regarding the geographic moderator effects are, therefore, consistent with international evidence suggesting variations in career and academic variables for children's geographic areas (Howard et al., 2009). They are also aligned with calls to acknowledge contextual influences on a person's career development and school attainment (Lent et al., 1999; Lent, 2004). Future research could clarify the similarities and differences between northern and central Portuguese schools, acknowledging for example their learning environment, quality of teacher-student relationships and leadership features. Such a detailed description of northern and central Portuguese schools would afford the possibility to examine their impact on students' career and academic development, thus enlightening our findings.

This study relied on a sample with an unbalanced distribution of children from northern and central Portugal. Hence, caution is advised when generalizing the geographic location moderator results. To overcome such a limitation, future studies could be conducted with a larger sample of Portuguese middle school children and include a balanced number of participants per geographic location. Moreover, the geographic location could be expanded in future studies, recruiting children from the continent and isles of Portugal (Regulamento UE 868/2014) ${ }^{6}$ and examining the career and academic particularities of

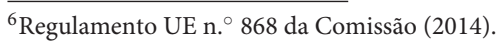




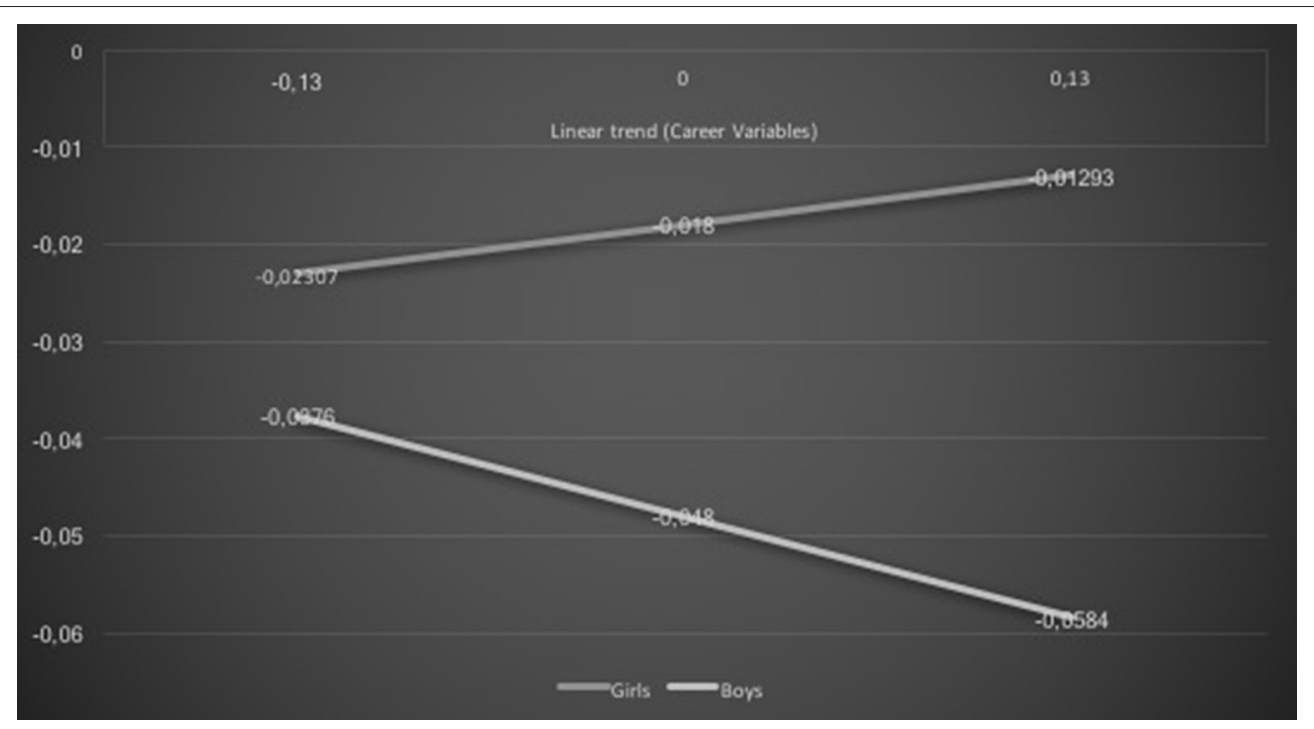

FIGURE 2 | Gender and career variables interaction effect on academic achievement: linear trends.

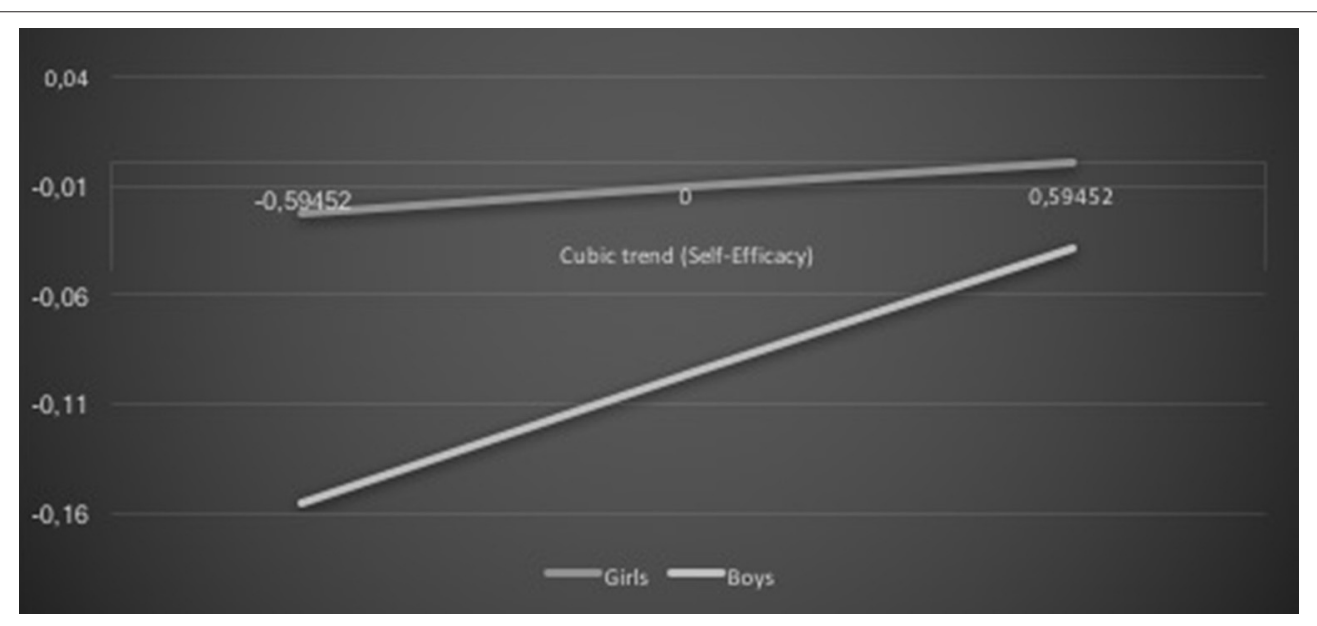

FIGURE 3 | Gender and self-efficacy interaction effect on academic achievement: cubic trends.

children from rural, urban and semi-urban settings. Following a multidisciplinary and collaborative approach (Watson et al., 2015), it would be important for career development researchers to establish partnerships with colleagues in the education, economy and sociology domains to examine the impact of the Portuguese regional asymmetries in children's career and academic processes as well as to jointly seek strategies to reduce such inequalities. It could also be relevant to conduct cross-cultural studies examining children's career and academic development trends in different countries. For example, research partnerships could be strengthened with other Portuguesespeaking countries in America (Brazil), Asia (Macau, East Timor), and Africa (Angola, Cape Verde, and Mozambique).

In conclusion, this study advanced an emerging body of literature assessing the linkages among career and academic processes (Watson et al., 2015; Negru-Subtirica and Pop, 2016).
Relying on a longitudinal research design, this study highlighted the articulation between children's career preparedness and academic achievement, thus calling for additional efforts to address the linkages among these processes throughout the lifespan. This work might stimulate future research and program interventions. Regarding research, the complementary view of career and academic processes (Kuijpers and Meijers, 2012) grounding this study might trigger future multidisciplinary research efforts (Watson et al., 2015). Such efforts would be useful to deepen the scientific knowledge of career and academic processes and to continue investigating their mutual dynamics with longitudinal designs (Negru-Subtirica and Pop, 2016). Moreover, multidisciplinary research could identify common internal and external resources that facilitate students' positive development and psychosocial functioning (Erikson, 1963; Gottfredson, 1981; Di Fabio and Kenny, 2015; Chávez, 


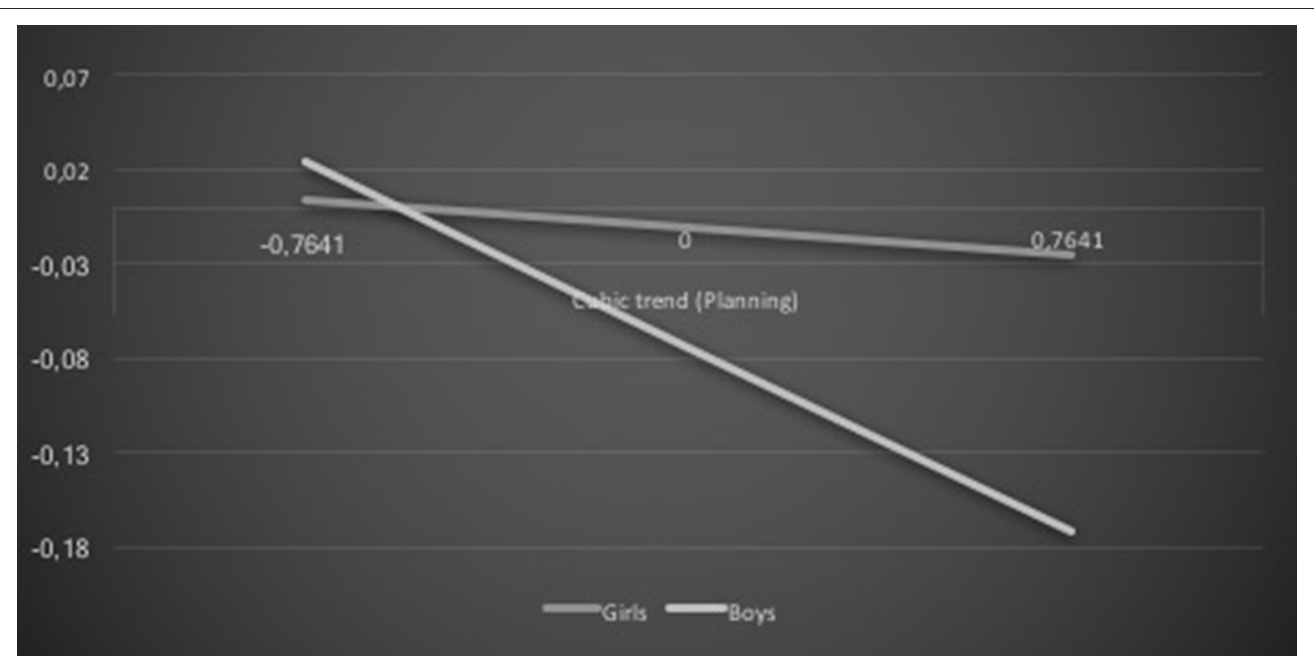

FIGURE 4 | Gender and career planning interaction effect on academic achievement: cubic trends.

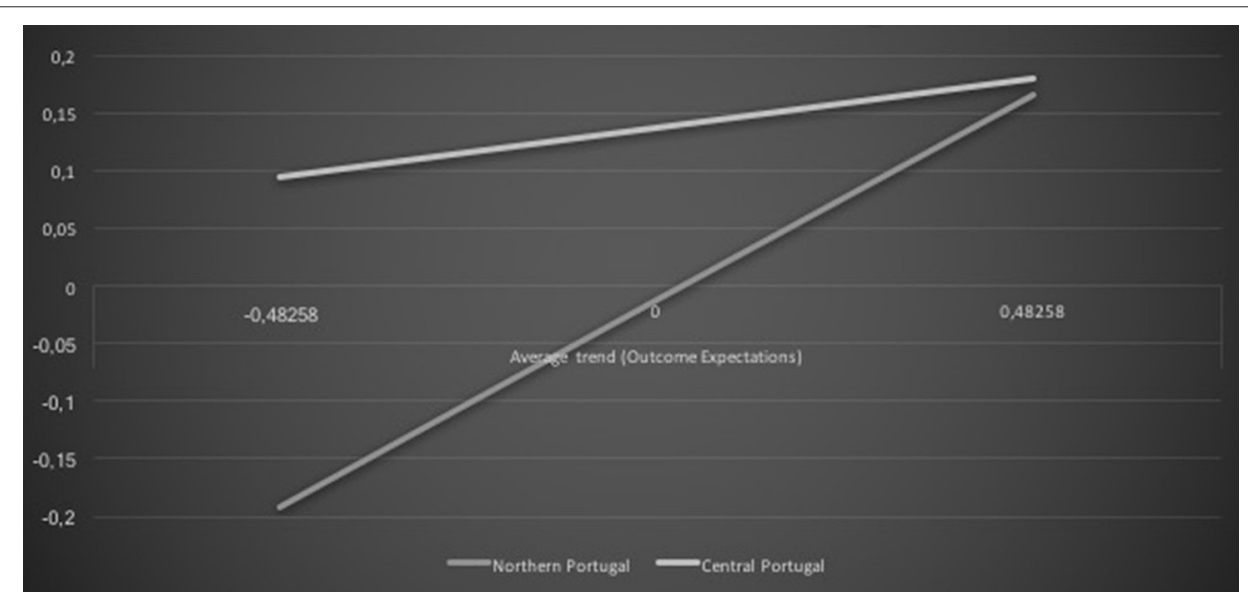

FIGURE 5 | Geographic location and outcome expectations interaction effect on academic achievement: average trends.

2016). Research comparing the career and academic processes of children with and without records of school behavioral problems or diagnosed learning disabilities could also be useful to discern their career and academic needs and to inform psychoeducational practices (Rojewski, 1996; Pasta et al., 2013). As for intervention, this study affirms the need for career practitioners to recognize the importance of the student role (Super, 1994) during the childhood period. This study affirms the potential value of jointly fostering career preparedness and academic achievement during the childhood period of the lifespan. To enhance career preparedness and academic achievement, career interventions could (a) help students identify and manage life roles; (b) create opportunities for students to observe behaviors and activities from their peers and adult practitioners, (c) stimulate mastery and performance experiences in school and out-of-school settings, and (d) help students identify and activate their social support networks (e.g., Bandura et al., 2001; Lent, 2004; Howard et al., 2009; Di
Fabio and Kenny, 2015; Oliveira et al., 2016; Paradnikè and Bandzevičiene, 2016). Taking the importance of demographic factors into account, career practitioners could also develop interventions with educational agents (e.g., teachers, parents) to acknowledge the impact of their quality relationships, and affirm their vital role in transmitting gender and prestige balanced messages (Gottfredson, 1981; Pasta et al., 2013; Longobardi et al., 2016). These educational efforts could also encourage further collaboration between teachers, parents, and the workforce to facilitate children's overall positive career and academic development (Araújo and Taveira, 2009; Watson et al., 2015).

\section{ETHICS STATEMENT}

This study was carried out in accordance with the Portuguese Ethical Standards of Psychology and the Portuguese Directorate General of Education. All participants' caregivers gave written informed consent in accordance with the Declaration of Helsinki. 


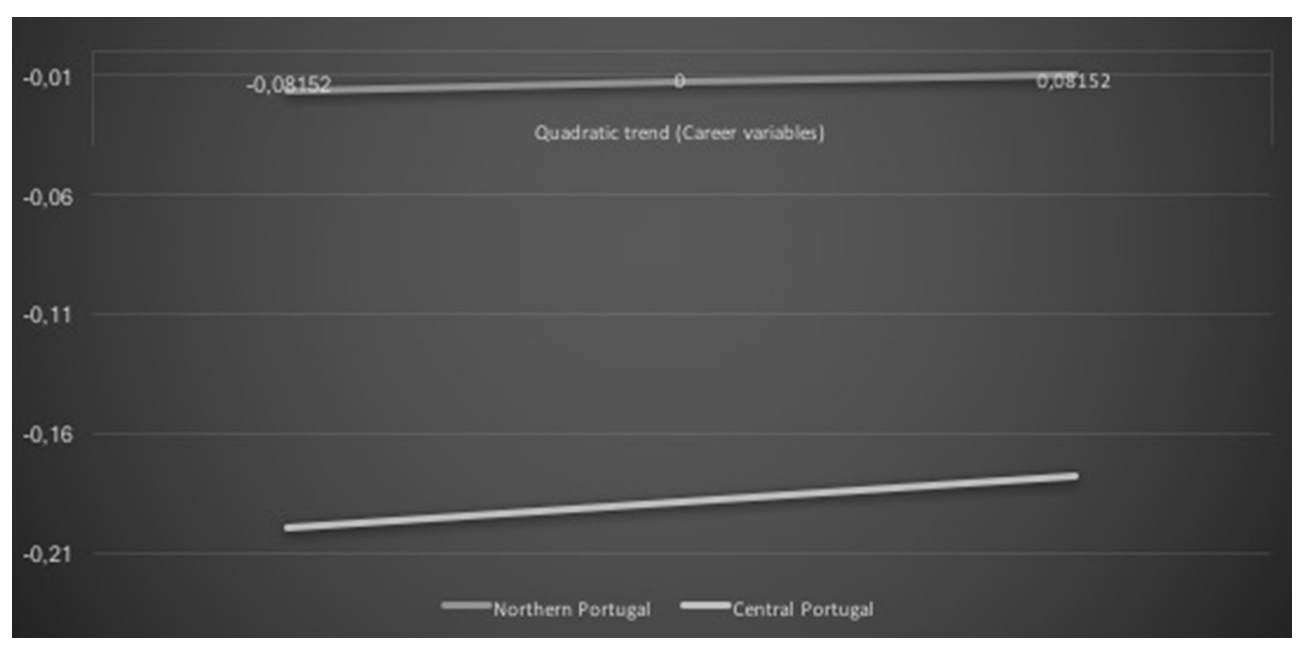

FIGURE 6 | Geographic location career variables interaction effect on academic achievement: quadratic trends.

The data collection protocol was approved by the Portuguese Monitoring System of school surveys.

\section{AUTHOR CONTRIBUTIONS}

IO Contributed to the conception and draft of the manuscript. MT and EP Contributed for its design and critical review. All authors revised and approved the manuscript's version to be submitted and assured the integrity and accuracy of the entire work.

\section{FUNDING}

This study was funded by the Portuguese Foundation for Science and Technology through a Doctoral grant (SFRH/BD/84162/2012), supported by national funds of

\section{REFERENCES}

Aiken, L. S., and West, S. G. (1991). Multiple Regression: Testing and Interpreting Interactions. Newbury Park, CA: Sage Publications.

Anyadike-Danes, M., and McVicar, D. (2005). You'll never walk alone: childhood influences and male career path clusters. Labour Econ. 12, 511-530. doi: 10.1016/j.labeco.2005.05.008

Araújo, A., and Taveira, M. C. (2009). Study of career development in children from a developmental-contextual perspective. Euro. J. Educ. Psychol. 2, 49-67. doi: 10.1989/ejep.v2i1.19

Bandura, A. (1990). Multidimensional Scales of Perceived Academic Efficacy. Stanford, CA: Stanford University.

Bandura, A., Barbaranelli, C., Caprara, G. V., and Pastorelli, C. (2001). Self-efficacy beliefs as shapers of children's aspirations and career trajectories. Child Dev. 72, 187-206. doi: 10.1111/1467-8624.00273

Chávez, R. (2016). Psychosocial development factors associated with occupational and vocational identity between infancy and adolescence. Adolesc. Res. Rev. 1, 307-327. doi: 10.1007/s40894-016-0027-y

Choi, Y., Kim, J., and Kim, S. (2015). Career development and school success in adolescents: the role of career interventions. Career Dev. Q. 63, 171-186. doi: $10.1002 /$ cdq. 12012 the Portuguese Ministry of Education and Science and the European Social Fund through the Human Capital Operational Program. This study was conducted at the Psychology Research Centre (UID/PSI/01662/2013), University of Minho, which is supported by the Portuguese Foundation for Science and Technology and the Portuguese Ministry of Education and Science through national funds and co-financed by FEDER through COMPETE2020 under the PT2020 Partnership Agreement (POCI-01-0145-FEDER-007653).

\section{ACKNOWLEDGMENTS}

We acknowledge Dr. Adelinda Candeias, Department of Psychology, University of Évora, Portugal for the support provided during the conception of this work and for the raised challenge to disclosure it in the scientific community.

Di Fabio, A., and Kenny, M. E. (2015). The contributions of emotional intelligence and social support for adaptive career progress among Italian youth. J. Career Dev. 42, 48-59. doi: 10.1177/0894845314533420

Dunkin, M., and Biddle, B. (1974). The Study of Teaching. New York, NY: Holt, Rinehart, and Winston.

Ek, E., Sovio, U., Remes, J., and Järvelin, M. (2005). Social predictors of unsuccessful entrance into the labour market: a socialization process perspective. J. Vocat. Behav. 66, 471-486. doi: 10.1016/j.jvb.2004.02.002

Erikson, E. (1963). Childhood and Society. New York, NY: W.W. Norton.

Ferreira, J. A., Santos, E. J., Fonseca, A. C., and Haase, R. (2007). Early predictors of career development: a 10-year follow-up study. J. Vocat. Behav. 70, 61-77. doi: 10.1016/j.jvb.2006.04.006

Field, A. (2009). Discovering Statistics Using SPSS. London: Sage Publications.

Fife-Schaw, C. (2006). "Levels of measurement," in Research Methods in Psychology, eds G. M. Breakwell, S. Hammond, C. Fife-Schaw, and J. A. Smith (London: Sage), 50-63.

Gottfredson, L. S. (1981). Circumscription and compromise: a developmental theory of occupational aspirations. J. Couns. Psychol. 28, 545-579. doi: 10.1037/0022-0167.28.6.545

Guan, Y., Wang, F., Liu, H., Jua, X., Fang, Z., Li, Y., et al. (2015). Career-specific parental behaviors, career exploration and career adaptability: a three-wave 
investigation among Chinese undergraduates. J. Vocat. Behav. 86, 95-103. doi: 10.1016/j.jvb.2014.10.007

Hartung, P. J. (2017). "Childhood: career construction opening act," in Career Exploration and Development in Childhood: Perspectives from Theory, Practice and Research, eds M. Watson and M. McMahon (Abingdon: Routledge Books Taylor and Francis Group), 24-33.

Hirschi, A. (2011). Career-choice readiness in adolescence: developmental trajectories and individual differences. J. Vocat. Behav. 79, 340-348. doi: 10.1016/j.jvb.2011.05.005

Howard, K. A., Ferrari, L., Nota, L., Solberg, V. S., and Soresi, S. (2009). The relation of cultural context and social relationships to career development in middle school. J. Vocat. Behav. 75, 100-108. doi: 10.1016/j.jvb.2009.06.013

Howard, K. A., Flanagan, S., Castine, E., and Walsh, M. E. (2015). Perceived influences on the career choices of children and youth: an exploratory study. Int. J. Educ. Vocat. Guid. 15, 99-111. doi: 10.1007/s10775-015-9298-2

Kuijpers, M., and Meijers, F. (2012). Learning for now or later: career competencies among students in higher vocational education in the Netherlands. Stud. Higher Educ. 37, 449-467. doi: 10.1080/03075079.2010.523144

Lent, R. W. (2004). "Social cognitive career theory, career education, and schoolto-work transition: Building a theoretical framework for career preparation," in Desenvolvimento Vocacional ao Longo da Vida: Fundamentos, Princípios e Orientações, eds M. C. Taveira, H. Coelho, H. Oliveira, and J. Leonardo (Coimbra: Almedina), 13-23.

Lent, R. W., Hackett, G., and Brown, S. D. (1999). A social cognitive view of school-to-work transition. Career Dev. Q. 47, 297-311. doi: 10.1002/j.2161-0045.1999.tb00739.x

Lombardi, A., Seburn, M., and Conley, D. (2011). Development and initial validation of a measure of academic behaviors associated with college and career readiness. J. Career Assess. 19, 375-391. doi: 10.1177/1069072711409345

Longobardi, C., Prino, L. E., Marengo, D., and Settanni, M. (2016). Studentteacher relationships as a protective factor for school adjustment during the transition from middle to high school. Front. Psychol. 7:1988. doi: 10.3389/fpsyg.2016.01988

Negru-Subtirica, O., and Pop, E. (2016). Longitudinal links between career adaptability and academic achievement in adolescence. J. Vocat. Behav. 93, 163-170. doi: 10.1016/j.jvb.2016.02.006

OECD European Union, UNESCO Institute for Statistics (2015). Operational Manual: Guidelines for Classifying Education Programmes and Related Qualifications. Paris: OECD Publishing.

Oliveira, I. M. (2016). Construction and Validation of the Childhood Career Exploration Inventory. Doctoral. dissertation, University of Minho, Braga.

Oliveira, I. M., and Taveira, M. C. (2014). Avaliação do Desenvolvimento Vocacional na Infância: Versão portuguesa da Childhood Career Development Scale [Assessment of Childhood Career Development: The Portuguese Version of the Childhood Career Development Scale]. Saarbrucken: Novas Edições Académicas.

Oliveira, I. M., Taveira, M. C., Cadime, I., and Porfeli, E. J. (2016). Psychometric properties of a career exploratory outcome expectations measure. J. Career Assess. 24, 380-396. doi: 10.1177/1069072715580577

Paradnikè, K., and Bandzevičienè, R. (2016). Career construction in academic setting: links between career adaptability and study engagement. Int. J. Psychol. A. Biopsychosoc. Approach 18, 71-88. doi: 10.7220/2345-024x.18.4

Pasta, T., Mendola, M., Longobardi, C., Prino, L. E., and Gastaldi, F. G. (2013). Attributional style of children with and without specific learning disability. Electron. J. Res. Educ. Psychol. 11, 649-664. doi: 10.14204/ejrep.31.13064

Peetsma, T., and van der Veen, I. (2011). Relations between the development of future time perspective in three life domains, investment in learning, and academic achievement. Learn. Instr. 21, 481-494. doi: 10.1016/j.learninstruc. 2010.08 .001

Pereira, S. (2014). Inteligência Social em Jovens: Influência da Região de Residência [Social Intelligence in Adolescence: Influences of the Residential Area] Master's degree. thesis, University of Minho, Braga.

Rafecas, J. (2013). Income Inequality in Historical Perspective: Portugal 1890-2006. Doctoral. dissertation, University of Barcelona, Barcelona.
Rojewski, J. W. (1996). Occupational aspirations and early career-choice patterns of adolescents with and without learning disabilities. Learn. Disabil. Q. 16, 99-116. doi: 10.2307/1511251

Rudolph, C. W., Lavigne, K. N., and Zacher, H. (2017). Career adaptability: a meta-analysis of relationships with measures of adaptivity, adapting responses, and adaption results. J. Vocat. Behav. 98, 17-34. doi: 10.1016/j.jvb.2016. 09.002

Schmitt-Rodermund, E., and Vondracek, F. W. (1999). Breadth of interests, exploration, and identity development in adolescence. J. Vocat. Behav. 55, 298-317. doi: 10.1006/jvbe.1999.1683

Schultheiss, D., and Stead, G. B. (2004). Childhood career development scale: scale construction and psychometric properties. J. Career Assess. 12, 113-134. doi: $10.1177 / 1069072703257751$

Super, D. (1980). A life-span, life-space approach to career development. J. Vocat. Behav. 16, 282-298. doi: 10.1016/0001-8791(80)90056-1

Super, D. (1994). "A life span, life space perspective on convergence," in Convergence in Career Development Theories: Implications for Science and Practice, eds M. L. Savickas and R. W. Lent (Palo Alto, CA: CPP Books), 63-74.

Tabachnick, B. G., and Fidell, L. S. (2013). Using Multivariate Statistics, 6th Edn. Boston, MA: Allyn and Bacon.

Teixeira, M. O., and Carmo, A. M. (2004). "Estudos com a versão portuguesa da Escala Multidimensional da Autoeficácia Percebida de Bandura (MSPSE) [Studies with Portuguese version of Bandura's Multidimensional Scales of Perceived Self-Efficacy (MSPSE)]," in Avaliação Psicológica: Formas e Contextos, eds C. Machado, L. Almeida, M. Gonçalves, and V. Ramalho (Braga: Psiquilíbrios), 198-203.

Veiga, F. H., Oliveira, I. M., and Taveira, M. C. (2014). “Student's engagement in school, academic achievement, and career exploration of Portuguese adolescents," in Proceedings of the 8th International Technology, Education and Development Conference (Valencia: INTED), 7545-7553.

Wang, M., Degol, J., and Ye, F. (2015). Math achievement is important, but task values are critical too: examining the intellectual and motivational factors leading to gender disparities in stem careers. Front. Psychol. 17:36. doi: $10.3389 /$ fpsyg.2015.00036

Watson, M., and McMahon, M. (2005). Children's career development: a research review from a learning perspective. J. Vocat. Behav. 67, 119-132. doi: 10.1016/j.jvb.2004.08.011

Watson, M., Nota, L., and McMahon, M. (2015). Evolving stories of child career development. Int. J. Educ. Vocat. Guid. 15, 175-184. doi: 10.1007/s10775-015-9306-6

Weis, M., Heikamp, T., and Trommsdorff, G. (2013). Gender differences in school achievement: the role of self-regulation. Front. Psychol. 4:442. doi: 10.3389/fpsyg.2013.00442

Whiston, S. C., Tai, W. L., Rahardja, D., and Eder, K. (2011). School counseling outcome: a meta-analytic examination of interventions. J. Couns. Dev. 89, 37-55. doi: 10.1002/j.1556-6678.2011.tb00059.x

Wiesner, M., Vondracek, F. W., Capaldi, D. M., and Porfeli, E. J. (2003). Childhood and adolescent predictors of early adult career pathways. J. Vocat. Behav. 63, 305-328. doi: 10.1016/S0001-8791(03)00028-9

Wright, S. L., Jenkins-Guarnieri, M., and Murdock, J. L. (2012). Career development among first-year college students: college self-efficacy, student persistence and academic success. J. Career Dev. 40, 292-310. doi: $10.1177 / 0894845312455509$

Conflict of Interest Statement: The authors declare that the research was conducted in the absence of any commercial or financial relationships that could be construed as a potential conflict of interest.

Copyright (c) 2017 Oliveira, Taveira and Porfeli. This is an open-access article distributed under the terms of the Creative Commons Attribution License (CC BY). The use, distribution or reproduction in other forums is permitted, provided the original author(s) or licensor are credited and that the original publication in this journal is cited, in accordance with accepted academic practice. No use, distribution or reproduction is permitted which does not comply with these terms. 


\title{
Emotion Understanding, Social Competence and School Achievement in Children from Primary School in Portugal
}

\author{
Maria da Glória Franco ${ }^{*}$, Maria J. Beja ${ }^{1}$, Adelinda Candeias² and Natalie Santos ${ }^{1}$ \\ 'Department of Psychology, Faculty of Arts and Humanities, University of Madeira, Funchal, Portugal, ${ }^{2}$ Department of \\ Psychology, School of Social Sciences, University of Évora, Évora, Portugal
}

\section{OPEN ACCESS}

Edited by:

Jesus de la Fuente,

University of Almería, Spain

Reviewed by:

Claudio Longobardi,

University of Turin, Italy

Paola Verónica Paoloni,

Consejo Nacional de Investigaciones

Cientificas y Tecnológicas -

Universidad Nacional de Río Cuarto,

Argentina

${ }^{*}$ Correspondence: Maria da Glória Franco gloria@uma.pt

Specialty section:

This article was submitted to

Educational Psychology,

a section of the journal

Frontiers in Psychology

Received: 28 February 2017

Accepted: 28 July 2017

Published: 15 August 2017

Citation:

Franco MG, Beja MJ, Candeias A

and Santos N (2017) Emotion Understanding, Social Competence and School Achievement in Children

from Primary School in Portugal.

Front. Psychol. 8:1376.

doi: 10.3389/fpsyg.2017.01376
This study analyzes the relationship between emotion understanding and school achievement in children of primary school, considering age, gender, fluid intelligence, mother's educational level and social competence. In this study participated 406 children of primary school. The instruments used were the Test of Emotion Comprehension, Colored Progressive Matrices of Raven, Socially Action and Interpersonal Problem Solving Scale. The structural equation model showed the relationship between the emotion understanding and school performance depends on a mediator variable that in the context of the study was designated social competence. Age appear as an explanatory factor of the differences found, the mother's educational level only predicts significantly social emotional competence, fluid intelligence is a predictor of emotion understanding, school achievement and social emotional competence. Regarding the influence of sex, emotional understanding does not emerge as a significant predictor of social emotional competence in girls or boys. Multiple relationships between the various factors associated with school achievement and social emotional competence are discussed as well as their implications in promoting child development and school success.

Keywords: emotion understanding, social emotional competence, school achievement, elementary school, structural equational model

\section{INTRODUCTION}

The importance emotions have, in understanding the learning process and in the manner how individuals successfully complete their learning, is a topic that has commenced many studies. Learning is a complex individual process, but also a social one. Social interaction is one of it's key components, that allows cognitive growth thanks to the guided learning that takes place in the proximal development area in which subjects move (Bruner, 1970/1998, Vygotsky, 1934/2008). In social interactions in the classroom, Social competences provide positive relationships between the individual and other social agents involved (Del Prette and Del Prette, 2005; Elijah and Madeira, 2013).

In this socio-constructivist approach, Saarni (1990) defends that emotions play a central role in social interaction. By understanding his emotions and feelings, the subject can decide, based on them, the most adequate behavior for each context, contributing to a constructive social and 
personal interaction, adapting conduct to context and situations. This ability to express, identify, understand and regulate emotions, as well as the ability to understand others' emotions and feelings, is what the author defines as emotional competence (Saarni, 2000).

The concept of emotional competence emerges associated to different processes and abilities, having present the multitude of concepts that are studied as analogs to this one, such as emotional knowledge, emotional comprehension, emotional intelligence and emotional regulation (Bridges et al., 2004; Garner, 2010; Franco and Santos, 2015; McCormick et al., 2015; Roazzi et al., 2015; Djambazova-Popordanoska, 2016), and also taking into account the number of measuring instruments used in its assessment, such as observation, self-assessment or hetero-assessment (Djambazova-Popordanoska, 2016). On the other hand, the most studied abilities can be grouped into three components: emotional expression, emotional regulation and emotion understanding (Denham et al., 2003; Denham, 2006). As Saarni (1990) states, when we speak of emotional competence, "We are talking about how [children] can respond emotionally, yet simultaneously and strategically apply their knowledge about emotions and their expression to relationships with others, so that they can negotiate interpersonal exchanges and regulate their emotional experiences" (p. 116).

Being one of emotional competence's components, emotion understanding has been studied within this context, but also outside of it, which gives place to great conceptual inconsistency (Franco and Santos, 2015). Despite the great diversity of definitions, emotion understanding can be defined as a set of abilities, which include understanding the relationship between emotions and other mental states, the knowledge of emotion regulating strategies and the understanding of ambivalent emotional responses (Pons et al., 2004). In detail, nine abilities make up for emotion understanding during childhood: (I) Recognition of emotions on the basis of facial expression; (II) Understanding of external causes of emotions; (III) Understanding of desire-based emotions; (IV) of beliefbased emotions; (V) Understanding the influence of a reminder on a present emotional state; (VI) Understanding of the regulation of an experienced emotion; (VII) Understanding of the possibility of hiding an underlying or true emotional state; (VIII) Understanding of mixed emotions; and (IX) Understanding of moral emotions (Pons et al., 2004). These abilities don't all occur at the same age, but develop with age, starting with the most elementary abilities to the more complex. They coexist throughout development and makeup for each other's pillars as new abilities are acquired. Research shows that with age there is a greater performance in each of the abilities (Pons and Harris, 2005; Santos, 2012; Silva, 2012). Cognitive development also influences the development of emotional understanding, facilitating the manifestation of new abilities (Albanese et al., 2010; De Stasio et al., 2014).

The development of emotion understanding goes through three phases: the external phase, the mental phase and the reflexive phase (Pons et al., 2004; Tenenbaum et al., 2004; Pons and Harris, 2005). During the external phase, between ages three and six, children are able to identify different emotional expressions, to understand external situational factors that may trigger emotions and understand that the recollection of a past event may trigger an emotional reaction, in other words, recognize emotions, understand the external causes, desires and recollections. The mental phase, between ages five and nine, embraces the fact that children understand that emotions depend on beliefs and awakened desires, and that not always the experienced emotions are the expressed ones, for there is a difference between apparent emotions and real emotions (e.g., a child can seem apparently calm because he is in a party of his best friend but inside he can be very sad because he lost is favorite toy). Lastly the reflexive phase, from ages eight and twelve, involves the ability to understand composite emotions, these are emotions that may occur simultaneously, that sometimes may be contradictory. The ability to understand that certain emotions are associated to moral values in their life context and the aptitude to regulate emotions in order to adapt them to that very same context, are also a characteristic of this phase.

Numerous studies have related emotional competence to school achievement, from preschool to higher education, not forgetting primary school. These studies are very heterogeneous, not only because of the diversity of the emotional competences that are approached (emotional knowledge, emotional regulation, emotional understanding, emotional intelligence), as well as because of the manner in which academic achievement is tested. Sometimes, through learning outcomes (final grades of the school year or of specific subjects, most commonly mathematics and the mother tongue), other times through adjustment skills or adaption to school context. Despite the dispersion of studies, that disturbs the true understanding of the connection between these two variables, as we will later come across, their contributions indicate the existence of a relation between these two variables, either directly or mediated by different variables.

The research on the influence of emotional competence in school achievement in primary education is scarce, but the review of the existing studies regarding preschool education is a relative contribution in two aspects, understanding the importance that development of these competences has in attending primary school successfully: (a) in the preparation of certain cognitive skills for school learning; (b) the development of the necessary requirements for transitioning school level. Note the studies on emotion understanding that demonstrate it is related to important cognitive processes that affect learning, such as language competence (Cutting and Dunn, 1999; Colwell and Hart, 2006), attention processes among them, focusing and sustaining attention in a classroom capacity (Nelson et al., 1999).

The research on emotional regulation proof it's relation to "readiness to learn," "teachability" (Denham, 2006), "school readiness" (Raver, 2002, 2003; Raver and Knitzer, 2002), productivity in the classroom (Graziano et al., 2007), success in mathematics and reading ability (Blair and Razza, 2007; Graziano et al., 2007), which is also mediated by factors such as attention (Izard et al., 2001; Trentacosta and Izard, 2007) and behavioral self-regulation (Howse et al., 2003). Regarding school adjustment, both in the research on emotion understanding (Shields et al., 2001) as well as in the studies on emotional regulation (Denham et al., 2012b, 2014; Herndon et al., 2013) 
there is a positive relation with the first. Research describes the implementation socio-emotional competence development programs in preschool (e.g., SEL Programs, Curriculum PATH) and also reveals that the participation in these programs, with consequent improvement in these skills, leads the individual to better his capacity to adapt to school and is predictive of greater academic results (Bierman et al., 2008; Denham and Brown, 2010; Denham et al., 2012b, 2014; Low et al., 2015).

Rhoades et al. (2011) developmental study of the transition to primary school demonstrates the impact that promotion of emotional competences has in primary school. These authors followed 341 disadvantaged children from public schools in a district of Northeastern United States, for 3 years, from preschool to first grade, that were submitted to an emotional competence program in preschool, under the Head Start program, and tried to understand through the analysis of structural equations, how emotion knowledge is related to attention skills and academic competence. The results may be summarized in the following way: (a) preschool emotion knowledge is a significant predictor of later academic achievement; (b) attention skills are one mediator of this relationship; (c) children's emotion knowledge and attention skills are two key components for improving academic competence in the early school years.

There is very little research in this area at Primary School level. Trentacosta et al. (2006) showed that: (a) emotion knowledge predicted attentional competence while controlling for age, gender, verbal ability, and initial levels of attentional competence; (b) Emotion knowledge also mediated the relation between verbal ability and attentional competence; (c) Emotion knowledge may provide children with the satisfactory peer and teacher relations that foster achievement motivation and attention to academic tasks to a level commensurate with their general cognitive ability. The study of McKown et al. (2016), which used structural equation models, supports the relation between socio-emotional skills and academic outcomes. It also shows that the relation between socio-emotional skills and reading is measured by social behavior (socially skilled behavior). But the measuring of social behaviors, in the relation between socio-emotional competences and the grades in mathematics, are not demonstrated, for they only appear in one of the studied samples.

In Portugal we found two studies that relate emotion understanding to academic achievement in elementary school (Silva, 2012; Rocha, 2016). Both studies use as an instrument the Test of Emotional Comprehension- TEC (Pons and Harris, 2000; Pons et al., 2004; Rocha et al., 2015) and measure Academic Achievement through grades obtained in Portuguese and Mathematics. In both studies (Silva, 2012; Rocha, 2016), the results suggest some relation between emotion understanding and the grades obtained in Portuguese and Mathematics. However, and according to the studies carried out by Rocha (2016) emotion understanding does not directly predict academic achievement, but this influence is measured by social competence. On the contrary, social competence is a direct predictor of school achievement.

Various models have been developed to explain the link between emotional competences, social competences and academic achievement. Eisenberg et al. (2005) suggest that children's emotional regulation (influenced by language skills as well as emotion knowledge and emotional understanding) affects their academic achievement, not only directly, but also through the measure of social competences. These authors also consider that there may be direct effects of emotion understanding and language skills on academic achievement and social competence. This model is sustained on research that approaches social competence, demonstrating that children that apply their emotion understanding in emotionally charged situations have better relationships with peers: these students are more prosocial, are considered more socially skilled by the teachers and are identified as being more pleasant by peers. This data has been confirmed in longitudinal studies (Izard et al., 2001; Denham et al., 2003, 2013; Ensor et al., 2011).

Various researchers have demonstrated the validity of this model, including the influence of other variables such as age, gender, parents' academic level and socioeconomic level. Montroy et al. (2014) confirmed, through the analysis of structural equations, that the relation between children's self-regulation in preschool and their reading ability, was measured by social functioning, social competences and behavioral problems, and that this relation was similar in both boys and girls. Valiente et al. (2011) confirmed, in a longitudinal study, that there is an effect of emotional regulating competences on academic achievement in children, when measured in ages from 4 to 8 , which is later mediated by social competences, when measured in the same children 2 years later ( 6 and 8 years old). The socioeconomic level, age and gender affect academic achievement, but only children's socioeconomic level affected their regulating competences. Neither these competences, nor children's social competences, are affected by gender or age.

Nonetheless, studies by (Denham et al., 2012a,b, 2013) confirm the link between emotion understanding and academic achievement, mediated by social competences in preschool children. These authors also determined that preschool children's emotion understanding was a predictor of the perception teachers had of their social competences and academic adjustment. In these studies, a child's age, the mother's academic level and the child's self-regulating ability presented effects on emotion understanding: emotion understanding was greater in older children, with higher levels of self-regulation and with mothers who had higher academic levels.

In the research carried out by Rocha (2016) the link between emotion understanding and academic achievement, facilitated by social competence, in children of the 3rd and 4th grade of school, was confirmed. The mothers' academic level was a predictor of their social competence and their academic achievement, but not of their emotion understanding, age and gender not having a significant influence on the model.

The present study aims to further study the model presented by Rocha (2016) using a more comprehensive model and including fluid intelligence, following de Spearman's theory of cognitive capacity ( $g$ factor, Simões, 1995; McCallum et al., 2001), since cognitive skills are considered better predictors of academic achievement (Colom and Flores-Mendoza, 2007; Di Fabio and Palazzeschi, 2009, 2015; Downey et al., 2014). 
Therefore, our objective is to determine the relation between fluid intelligence, mother's educational level, age, gender, emotion understanding and social competence as predictors of children's academic achievement in the first 4 years of primary school. The following hypothesis were defined:

H1: Children's emotion understanding predicts school achievement

$\mathrm{H} 2$ : Social competence is a mediating factor in the relationship between emotion understanding and school achievement

H3: Children's fluid intelligence predicts children's emotion understanding, social competence and school achievement

H4: Children's age predicts emotion understanding and social competence

H5: Mother's educational level predicts children's emotion understanding, social competence and school achievement H6: Children's gender predicts differently the structural model

As a starting point to test our hypothesis and being based on various studies, the different relations to be established were synthesized in Figure 1. The relations were tested through the analysis of Structural Equations.

\section{MATERIALS AND METHODS}

\section{Participants}

Data collection was carried out in four primary schools of the Autonomous Region of Madeira, which resulted in a sample of 406 students, 196 female and 210 male, aged between 6 and 11 $(M=7.93, S D=1.43)$ from grades 1 st to 4 th.

Several parents and six teachers, of six different classes (one 1st grade class, two 2 nd grade classes, two 3 rd grade classes and one 4 th grade class) of one of the schools participated in the study. Teachers assessed the social behavior of 108 students $(26.61 \%$ of the sample), ages ranged between 6 and $11(M=7.63, S D=1.12)$. The parents of 86 children (20.44\% of the sample) assessed the social behavior of their children, whose ages ranged between 6 and 10 years $(M=7.58, S D=1.09)$. In Table 1 the characteristics of different samples are presented in greater detail.

\section{Instruments}

To assess the student's performance on emotional competence, the computerized Portuguese version translated by Roazzi et al. (2008) of the Test of Emotion Comprehension (TEC), of Pons et al. (2004), was used. This instrument assesses the level of nine components of emotional understanding, where a point is attributed to each correctly answered component. Each child can obtain a minimum of zero and a maximum of nine points. Using the Kuder-Richardson coefficient as a measure of reliability, acceptable levels of internal consistency have been found (KR-20- = 0.72).

To assess the students' social competence were used two different measures: (a) Social Competence Assessment Scales [SCAS (7-11) by Candeias, 2008]; (b) Problem solving in social situations index (PRI) of the Social Intelligence Cognitive Test (PCIS, Candeias, 2007). The SCAS is a 360-degree instrument that evaluates, from the perspective of students, parents and teachers, the degree of competence and the difficulty level facing five different social situations, through a three-point Likert scale. Each child can obtain a minimum of 10 points and a maximum of 30 points. In this study, adequate internal consistency levels were found, both in students' scales $(\alpha=0.73)$ as well as in parents' scales $(\alpha=0.87)$ and teachers' scales $(\alpha=0.97)$. The PCIS is an ability instrument and measures several skills involved in the resolution of social problems, regarding the quality of the components of the process (process dimension) as well as the level of interpersonal knowledge that the individual displays (contents dimension). Facing three different images containing social situations, the child has to identify the social problem, the best solution to it and the best strategies to achieve it. In this index, each child may obtain a minimum of 0 points and a maximum of 63 points. Adequate levels of internal consistency were found $(\alpha=0.86)$.

In order to evaluate the students' fluid intelligence, the adapted Portuguese version of the Colored Progressive Matrices (CPM, Simões, 2000) was used.

To assess school achievement, the average marks in the following subjects, Portuguese and mathematics, were calculated at the end of the semester where the emotional and social competence tests were applied.

The school grades go according to the following scale: 1 - unsatisfactory, 2 - marginally satisfactory, 3 - satisfactory, 4 very satisfactory, 5 - very good or excellent.

\section{Procedure}

Data collection took place at the school attended by the children, with the required written consent and authorization granted by the parents, school board as well as the children, following the ethical principles of scientific research. In order to ensure that reading skills did not affect the results, experienced psychologists applied the assessment scales, individually, reading each question, taking between 30 and $45 \mathrm{~min}$. The instruments were applied in the following order: TEC, CPM, SACS and PRI. The questionnaires were handed to the teachers in a closed envelope and were completed and returned in the time space of 1 week. Parents completed the questionnaires during a parents meeting that took place to explain the objectives of the study.

\section{Data Analysis}

Following collection, data was input to the SPSS software, version 23.0 for Windows. Descriptive statistics and Pearson correlation coefficients were calculated, along with structural equation analysis of the causal model of school achievement. It was evaluated with the AMOS software (version 23.0) as described by Maroco (2014) using the maximum likelihood model, the most adequate for small samples (200-500 subjects). In an adjustment to the model, a two-step strategy was used: in the 1 st step, the measurement model was adjusted and in the 2nd step, the structural model was adjusted.

Due to the presence of missing in the sample, the averages and intersections were estimated. Data analysis took place to reveal the presence of cases of univariate and multivariate outliers. No participants with outlier values were found. The normality of the variables was determined by the measures 

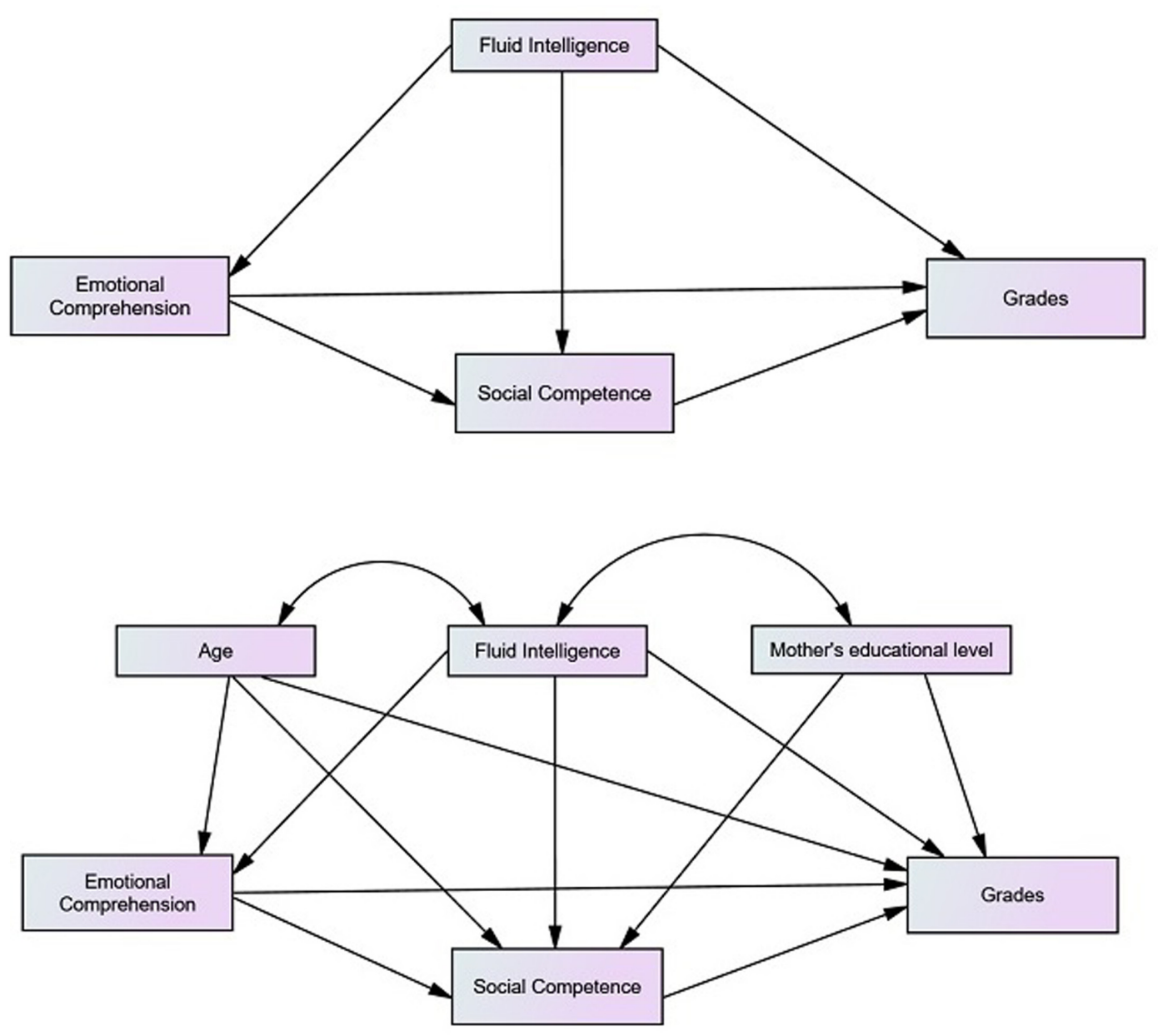

FIGURE 1 | Proposed model of predictors of school achievement.

of skewness $(s k)$ and univariate Kurtosis $(k u)$, presented in Table 2. None of the variables presented values of $s k$ or $K u$ that were indicators of severe violations to normal distribution $(|s k|<3$ and $|k u|<7-10$, refer to Maroco, 2014).

The quality of the adjustment of the model was determined according to quality adjustment indexes and respective reference values according to Maroco (2014) in which: $X^{2} / d f<2-3$, CFI e TLI $>0.90$. The RMSEA was also utilized, with a confidence interval (CI) of $90 \%$ and the probability of the RMSEA $\leq 0.05$. A CI of $90 \%$ with an upper confidence bound less than 0.10 and $p$ [RMSEA] $\geq 0.05$ was considered a reasonable adjustment indicator, based on the belief that when the RMSEA value is less than 0.05 , the adjustment is very good. In order to compare models, the AIC was used, being the best model, the one that presents lower values in this index. The quality of the local adjustment of the model was determined by factor weights and individual reliability of the items. The significance of the structural coefficients was evaluated with a $Z$-test produced by the AMOS software (Critial Ratio and $p$-value). The significance of the direct, indirect and total effects was determined by the Sobel test, as described by Maroco (2014).

Lastly, to test gender differences in the final model, path analysis with the same predictors and trajectories was done on both boys and girls. The invariance of the measuring model was tested in both groups, by comparison of the random model (with factorial weights and variances/covariances of the arbitrary factors) with the constrict model, where factorial weights and the variances and covariances of both groups were set. Lastly, the invariance of the structural model was determined by comparison of the model with free structural coefficients versus the model with fixed structural coefficients and equal in both groups. The statistical significance of the difference between both models was verified by the Chi-square test.

\section{RESULTS}

\section{Preliminary Analysis}

The descriptive statistics and correlations between variables are presented on Table 2. Emotion understanding tested with TEC 
TABLE 1 | Participants description.

\begin{tabular}{|c|c|c|c|c|c|c|c|}
\hline \multirow[t]{2}{*}{ Variable } & \multirow[t]{2}{*}{ Level } & \multicolumn{2}{|c|}{$\begin{array}{l}\text { Participants (Total) } \\
\quad(n=406)\end{array}$} & \multicolumn{2}{|c|}{$\begin{array}{l}\text { Participants assess by teachers } \\
\qquad(n=108)\end{array}$} & \multicolumn{2}{|c|}{$\begin{array}{l}\text { Participants assess by parents } \\
\qquad(n=86)\end{array}$} \\
\hline & & $f$ & $\%$ & $f$ & $\%$ & $f$ & $\%$ \\
\hline \multirow[t]{2}{*}{ Gender } & Females & 196 & 48.3 & 56 & 51.9 & 49 & 57.0 \\
\hline & Males & 210 & 51.7 & 52 & 48.01 & 37 & 43.0 \\
\hline \multirow[t]{2}{*}{ School year } & 1st year & 104 & 25.6 & 15 & 13.9 & 12 & 14.0 \\
\hline & 4th year & 120 & 29.6 & 22 & 20.4 & 17 & 19.8 \\
\hline \multirow[t]{4}{*}{ Mother's educational level } & 1st cicle $\mathrm{a}^{\mathrm{a}}$ & 52 & 16.3 & 12 & 13.2 & 8 & 11.1 \\
\hline & 2nd Cicleb & 95 & 29.8 & 19 & 20.9 & 17 & 23.6 \\
\hline & 3rd cicle ${ }^{c}$ & 77 & 24.1 & 32 & 35.2 & 24 & 33.3 \\
\hline & High schoold $^{d}$ & 70 & 21.9 & 28 & 20.9 & 19 & 26.4 \\
\hline
\end{tabular}

${ }^{\mathrm{a}}$ First four grades of Portuguese educational system; ${ }^{\mathrm{b}} 5$ th and 6 th grades of Portuguese educational system; ${ }^{\mathrm{c}} 7$ th to 9 th grade of Portuguese educational system; ${ }^{\mathrm{d}} 10$ th to 12 th grade of Portuguese educational system; e University education.

TABLE 2 | Correlation matrix and descriptive statistics of variables collected.

\begin{tabular}{|c|c|c|c|c|c|c|c|c|c|}
\hline & 1 & 2 & 3 & 4 & 5 & 6 & 7 & 8 & 9 \\
\hline (2) Mother's educational level & -0.10 & 1 & & & & & & & \\
\hline $\begin{array}{l}\text { (4) Social Competence } \\
\text { Assessment Scale - Self } \\
\text { (SCAS-S) }\end{array}$ & $-0.24^{* *}$ & 0.02 & 0.00 & 1 & & & & & \\
\hline $\begin{array}{l}\text { (6) Social Competence } \\
\text { Assessment Scale - Teachers } \\
\text { (SCAS-T) }\end{array}$ & 0.05 & 0.14 & $0.27^{* *}$ & 0.00 & $0.49^{* *}$ & 1 & & & \\
\hline $\begin{array}{l}\text { (7) Test of Emotional } \\
\text { Comprehension }\end{array}$ & $0.42^{* *}$ & 0.07 & $0.21^{* *}$ & $-0.14^{* *}$ & 0.06 & $0.32^{* *}$ & 1 & & \\
\hline$n$ & 406 & 319 & 272 & 402 & 86 & 108 & 406 & 406 & 406 \\
\hline Mean & 7.93 & 2.75 & 20.87 & 24.27 & 22.94 & 18.75 & 5.28 & 23.82 & 3.20 \\
\hline SD & 1.43 & 1.19 & 7.44 & 3.85 & 4.27 & 7.09 & 1.68 & 6.04 & 1.05 \\
\hline Minimum & 6 & 1 & 5.00 & 13.00 & 10.00 & 10.00 & 1.00 & 7.00 & 1.00 \\
\hline Maximum & 11 & 5 & 49.00 & 30.00 & 30.00 & 30.00 & 9.00 & 36.00 & 5.00 \\
\hline Skewness & 0.34 & 0.19 & 0.40 & -0.33 & -0.59 & 0.22 & -0.16 & -0.23 & 0.02 \\
\hline Kurtosis & -0.81 & -0.93 & 0.31 & -0.46 & 0.21 & -1.29 & -0.54 & -0.59 & -0.58 \\
\hline
\end{tabular}

**Correlation is significant at the 0.01 level (two-tailed). *Correlation is significant at the 0.05 level (two-tailed).

presents weak positive correlations with school marks $(p=0.001)$ and with the index of social problem solving $(p=0.001)$, indicating some relation between child's emotion understanding, school achievements and the capacity to solve problems of social nature. Moderate positive correlations were also found with social competence, when evaluated by the teachers $(p<0.001)$ and with age $(p<0.001)$. On the opposite, poor negative correlations were found between emotion understanding and social competence when self-assessed by the children (SCAS-S) $(p=0.006)$, suggesting that better emotion awareness children have, the less positive their self-assessment will be regarding their social competences.

The connections between the instruments that assess social competence and school achievement were also significant and positive. These correlations are weak with the PRI $(p=0.028)$ and with the SCAS-S $(p=0.047)$, moderate with the SCAS when 
evaluated by the parents (SCAS-P) $(p=0.004)$ and strong with the SCAS when assessed by the teachers (SCAS-T) $(p<0.001)$. There are no correlations between the instruments that test social competence and the mother's educational level. There are only poor correlations between age and the SCAS-S $(p<0.001)$ and the PRI $(p<0.001)$.

Moderate positive correlations were found between fluid intelligence, evaluated by Raven's Colored Progressive Matrices, and children's school marks $(p<0.001)$. Fluid intelligence is also related to emotion understanding $(p<0.001)$ and to social competence when assessed by the PRI $(p<0.001)$, by the SCAS-S $(p=0.001)$ and by the teachers SCAS $(p=0.004)$. Age $(p<0.001)$ and the mother's educational level $(p=0.005)$ are also correlated to fluid intelligence.

Lastly, we found moderate positive correlations between school grades and mothers' educational levels $(p<0.001)$ and poor negative correlations between school grades and the child's age $(p=0.011)$.

\section{Measuring Model}

Before testing our theoretic model, the adjustment indexes of the reference model were calculated, in order to determine if the instruments used (SACS in its three versions and PRI) could be grouped in one latent variable that describes student's social competence. Although all adjustment indexes are adequate, $\left(X^{2} / d f=0.006\right.$; CFI $=1.000$; TLI $=1.477$; $\mathrm{RMSEA}=0.000$, IC at 90\%[0.00;0.00], $p[$ RMSEA $]=0.998 ;$ AIC $=24.012)$, the factorial weight $(0.00)$ and reliability values $(0.00)$ were very low in SACS, in the child's self-assessment version. The results for this version of the SACS scale were excluded from the measuring model, because it doesn't seem to saturate the social competence factor.

\section{Structural Model}

According to Rocha (2016), a causal model of emotion understanding of academic achievement was evaluated, mediated by social competence. The fit indexes for each of the models are represented in Table 3.

In model 1 , the variables that consistently contribute to the explanation of our endogenous variable, academic achievement, were included as exogenous variables, age, mother's educational level and fluid intelligence assessed by CPM.

The adjustment indexes of model 1 are low. All trajectories are significant, being the explained variance of academic achievement in this model $20.8 \%$, the greatest predictor of fluid intelligence (Table 4). Age and academic level are significant predictors of academic achievement.

In model 2, emotion understanding was included as a predictor of academic achievement, with direct trajectories for age, mother's educational level and fluid intelligence as predictors of emotion understanding. Once again, the model presents minor adjustment indexes, explaining $22.0 \%$ of the variance. Fluid intelligence is the best predictor of academic achievement, as well as emotion understanding, followed by age. Mother's educational level continues to be a predictor for academic achievement, along with emotion understanding as significant predictor too. Mother's educational level is not a significant predictor of emotion understanding, excluding this trajectory therefore in the following models (Table 4).

Finally, in model 3, represented in Figure 2, the complete model was tested, with direct trajectories of fluid intelligence and of age for emotion understanding; mother's academic level, fluid intelligence and age for social competence; and of emotion understanding, mother's educational level and fluid intelligence for academic achievement. Social competence was considered as a mediator, between emotion understanding and academic achievement.

Model 3 presented adequate adjustment levels, explaining $52.6 \%$ of the variance regarding academic achievement. It was found that the trajectory for emotion understanding $\rightarrow$ academic achievement was no longer significant in this model, social competence becoming the mediator of the relationship between these two variables. We observed yet that mother's educational level and age are not significant predictors of social competence. Therefore, these trajectories were removed from the final and 4th model, represented in Figure 3.

In model 4, the trajectories are significant (Table 4) demonstrating a bettering in the quality of the model comparatively to model 3 , and maintaining the same percentage of variance regarding academic achievement (52.6\%). It was also found that social competence has a very important direct effect in the explanation of emotion understanding. Emotion understanding presents only one indirect relation with academic achievement, mediated by social competence, and confirmed by the Sobel test $(b=0.014, \beta=0.134, Z=3.334, p=0.001)$. Fluid intelligence determined by TEC $(b=0.069, \beta=0.070$, $Z=2.799, p=0.005)$ presents significant indirect effects on social competence, and significant indirect effects on academic achievement through social competence $(b=0.016, \beta=0.152$, $Z=2.034, p=0.042)$. The total standardized effects indicate that highest predictor is social competence $(\beta=0.591)$, followed by fluid intelligence $(\beta=0.356)$, mother's educational level ( $\beta=0.193)$ and emotion understanding $(\beta=0.134)$.

Lastly, to determine the differences between gender in model 4, path analysis was applied for boys and girls. Figure 4 illustrates the estimates of the factorial weights and of individual reliability of the items of the model. The quality indexes for the multigroup model were significant: $\left(X^{2} / d f=1.359, \mathrm{CFI}=0.974, \mathrm{TLI}=0.936\right.$, RMSEA $=0.030$, IC a 90\% $[0.000 ; 0.051]$, p rmsea $]=0.940$, AIC $=156.775)$, proving that the proposed factorial model presents a good adjustment, simultaneously for both boys and girls, demonstrating the configurational invariance of the measuring model. The constrict model, with fixed factorial weights, did not present a significantly worse adjustment levels to the model with arbitrary parameters $\left(\Delta X_{\lambda}^{2}(3)=6.983\right.$, $p=0.072$ ), in which we may conclude that the measuring model presents low invariance levels, where factorial weights do not differ significantly between boys and girls.

Once the invariance of the measuring model had been settled, it was shown the model that has fixed factorial weights and structural coefficients did not differ significantly to the model with free structural coefficients and fixed factorial 
TABLE 3 | Fit indices of tested models.

\begin{tabular}{|c|c|c|c|c|c|c|c|}
\hline \multirow[t]{2}{*}{ Model } & \multirow[t]{2}{*}{$X^{2} / g l$} & \multirow[t]{2}{*}{ CFI } & \multirow[t]{2}{*}{ TLI } & \multicolumn{3}{|c|}{ RMSEA } & \multirow[t]{2}{*}{ AIC } \\
\hline & & & & RMSEA & $90 \% \mathrm{Cl}$ & $p$ & \\
\hline Model 1 & 3.302 & 0.987 & 0.874 & 0.075 & [0.000;0.172] & 0.211 & 29.302 \\
\hline Model 2 & 3.256 & 0.993 & 0.892 & 0.075 & [0.000;0.171] & 0.215 & 41.256 \\
\hline Model 3 & 2.207 & 0.965 & 0.894 & 0.055 & [0.026;0.083] & 0.356 & 90.489 \\
\hline
\end{tabular}

TABLE 4 | Summary of covariate regression weights for structural equation models

\begin{tabular}{|c|c|c|c|c|c|c|}
\hline Model & Direct effects & & & $b$ & $\beta$ & $p$ \\
\hline & Grades & $<-$ & Mother's educational level & 0.192 & 0.218 & $<0.001$ \\
\hline \multirow[t]{6}{*}{ Model $2\left(R^{2}\right.$ Grades $=0.220 ; R^{2}$ TEC $\left.=0.281\right)$} & TEC & $<-$ & CPM & 0.093 & 0.335 & $<0.001$ \\
\hline & TEC & $<-$ & Mother's educational level & 0.060 & 0.042 & 0.382 \\
\hline & TEC & $<-$ & Age & 0.332 & 0.281 & $<0.001$ \\
\hline & Grades & $<-$ & CPM & 0.058 & 0.337 & $<0.001$ \\
\hline & Grades & $<-$ & Mother's educational level & 0.187 & 0.213 & $<0.001$ \\
\hline & Grades & $<-$ & Age & -0.224 & -0.306 & $<0.001$ \\
\hline \multirow[t]{8}{*}{ Model $3\left(R^{2}\right.$ Grades $=0.526 ; R^{2}$ TEC $=0.277 ; R^{2}$ social $\left.=0.176\right)$} & TEC & $<-$ & CPM & 0.096 & 0.346 & $<0.001$ \\
\hline & TEC & $<-$ & Age & 0.323 & 0.273 & $<0.001$ \\
\hline & Social Competence & $<-$ & TEC & 1.160 & 0.285 & 0.002 \\
\hline & Grades & $<-$ & TEC & -0.027 & -0.044 & 0.531 \\
\hline & Grades & $<-$ & CPM & 0.035 & 0.203 & 0.003 \\
\hline & Grades & $<-$ & Mother's educational level & 0.128 & 0.145 & 0.015 \\
\hline & Grades & $<-$ & Social Competence & 0.093 & 0.611 & $<0.001$ \\
\hline & Grades & $<-$ & Age & -0.172 & -0.235 & $<0.001$ \\
\hline \multirow[t]{6}{*}{ Model $4\left(R^{2}\right.$ Grades $=0.526 ; R^{2}$ TEC $=0.277 ; R^{2}$ SocialC $\left.=0.146\right)$} & TEC & $<-$ & CPM & 0.096 & 0.346 & $<0.001$ \\
\hline & TEC & $<-$ & Age & 0.323 & 0.273 & $<0.001$ \\
\hline & Social Competence & $<-$ & TEC & 0.931 & 0.233 & 0.002 \\
\hline & Social Competence & $<-$ & CPM & 0.236 & 0.213 & 0.014 \\
\hline & Grades & $<-$ & Social Competence & 0.094 & 0.607 & $<0.001$ \\
\hline & Grades & $<-$ & CPM & 0.035 & 0.204 & 0.002 \\
\hline
\end{tabular}

weights $\left(\Delta X_{\lambda}^{2}(7)=10.014, p=0.188\right)$. Consequently, the causal model is invariant in both groups, not having been found any evidence of significant differences between boys and girls.

\section{DISCUSSION}

As suggested in the accumulated research in the past years (Izard et al., 2001; Trentacosta and Izard, 2007; Zins et al., 2007; Rhoades et al., 2011; Torres et al., 2015) in this study we found evidence that emotion understanding is a poor predictor of academic achievement. The addition of emotion understanding to the model merely adds to the explained variance value by $1.2 \%$, a modest increase that is consistent with other studies carried out in high school students (Agnoli et al., 2012; Qualter et al., 2012; Downey et al., 2014). Barchard (2007) suggests that is not enough to determine whether emotional competences predict academic achievement, but it's also necessary to determine whether it betters it's prediction and if it is worth including emotional competence measurements in existing assessment batteries. 


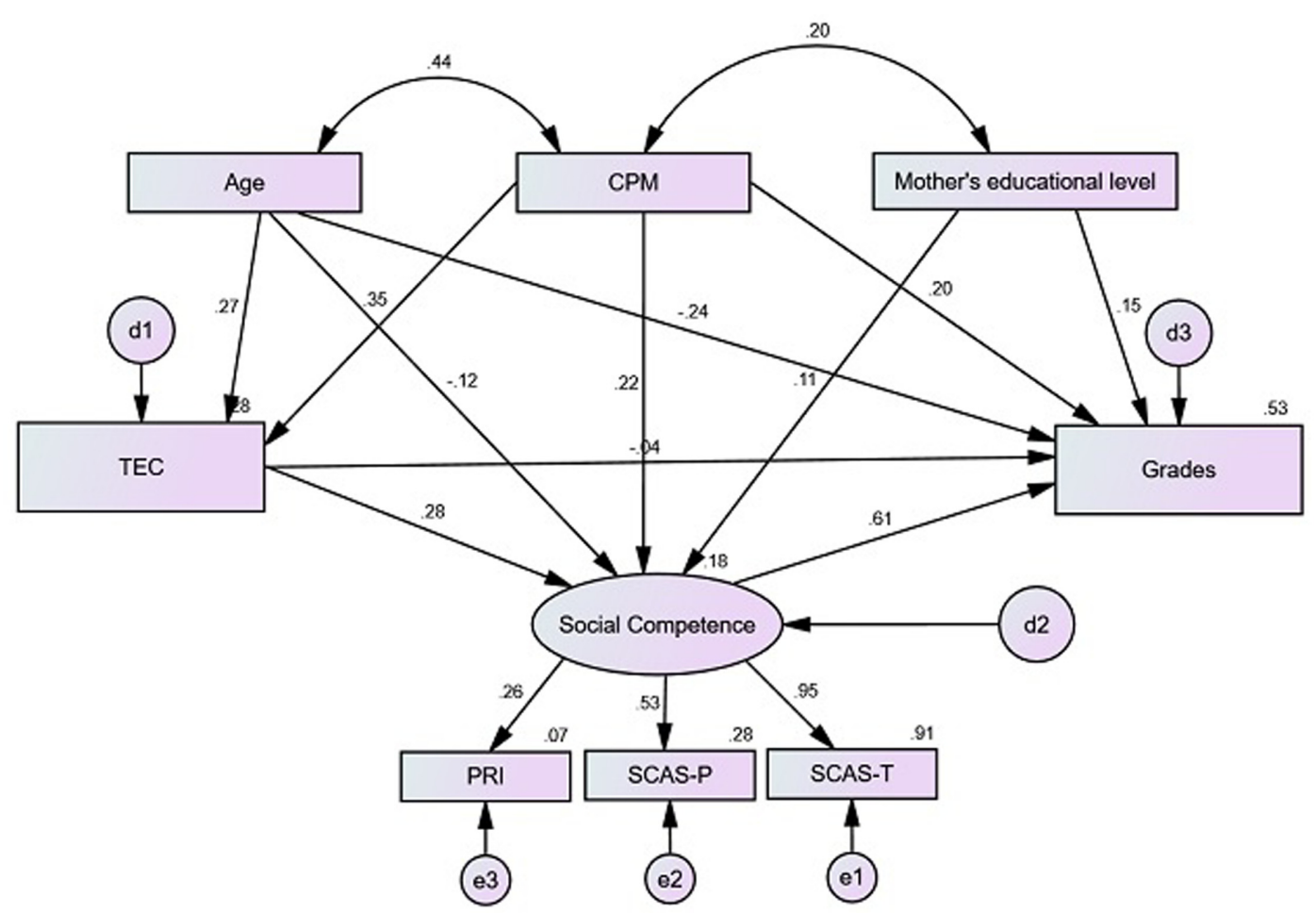

FIGURE 2 | Structural model 3 of emotion understanding for academic achievement, mediated by social competence, with estimates for structural coefficients, factorials loads and standardized individual reliability $\left(X^{2} / d f=2.207, \mathrm{CFI}=0.965, \mathrm{RMSEA}=0.055, \mathrm{AIC}=90.489\right)$.

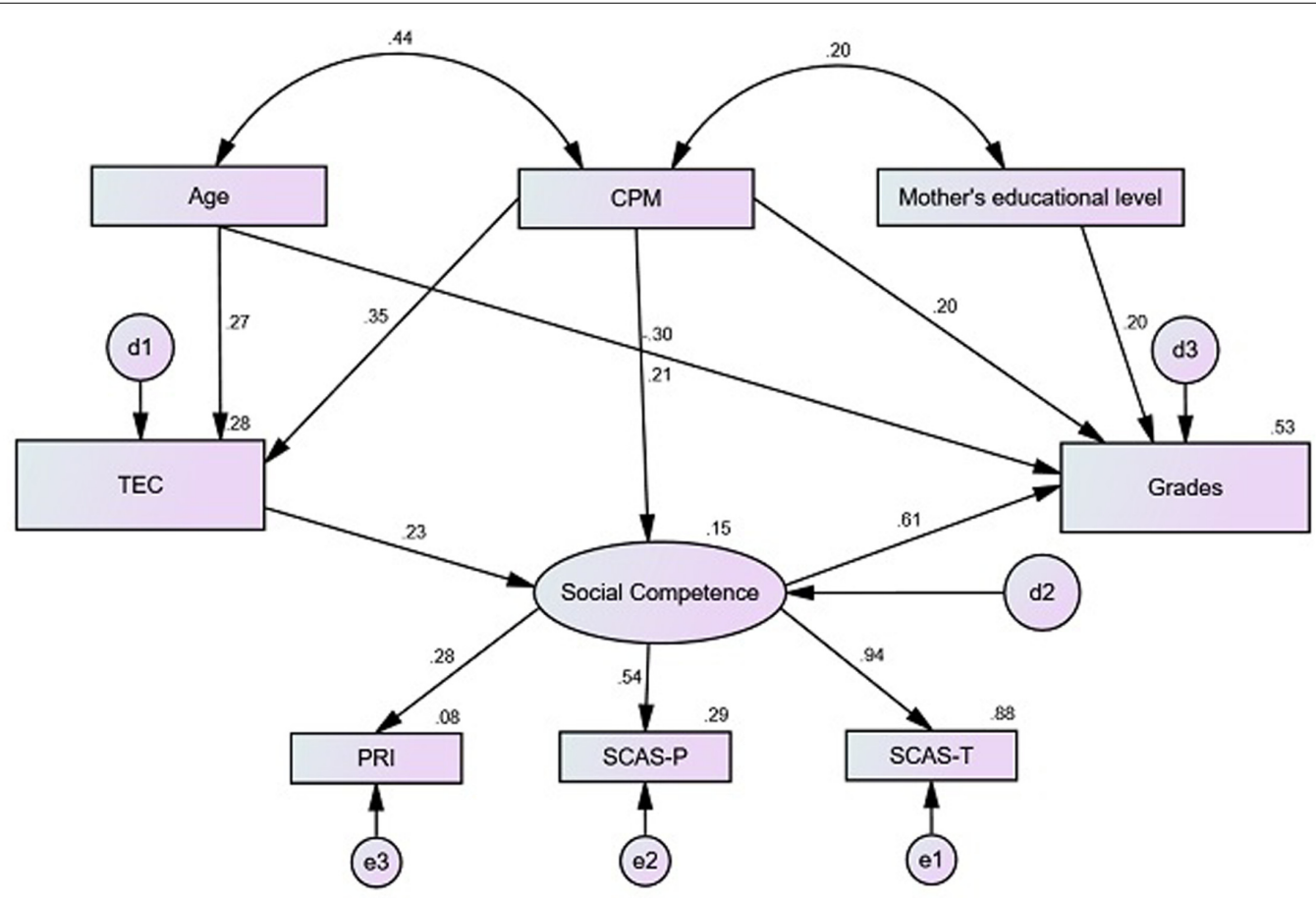

FIGURE 3 | Structural model 4 of emotion understanding for academic achievement, mediated by social competence, with estimates for structural coefficients, factorials loads and standardized individual reliability $\left(X^{2} / d f=1.935, \mathrm{CFI}=0.966, \mathrm{RMSEA}=0.048, \mathrm{AIC}=87.030\right.$ ). 


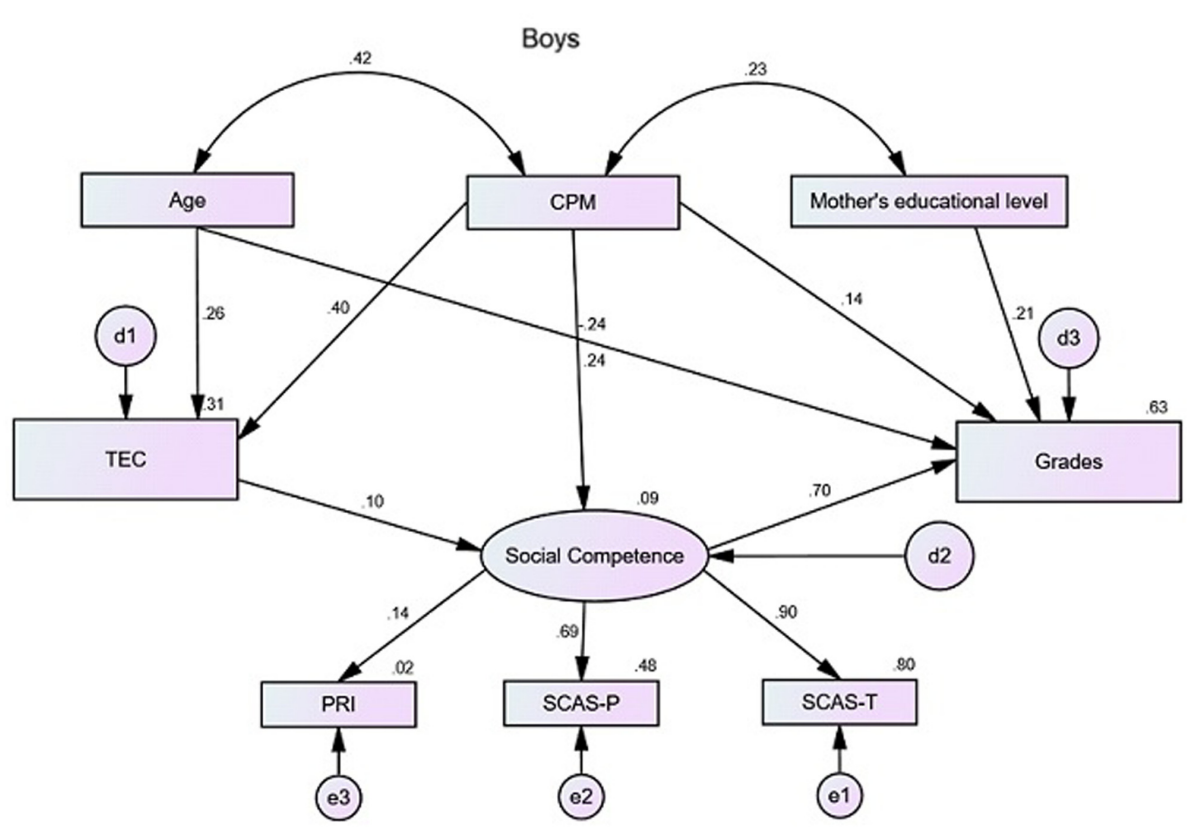

Girls

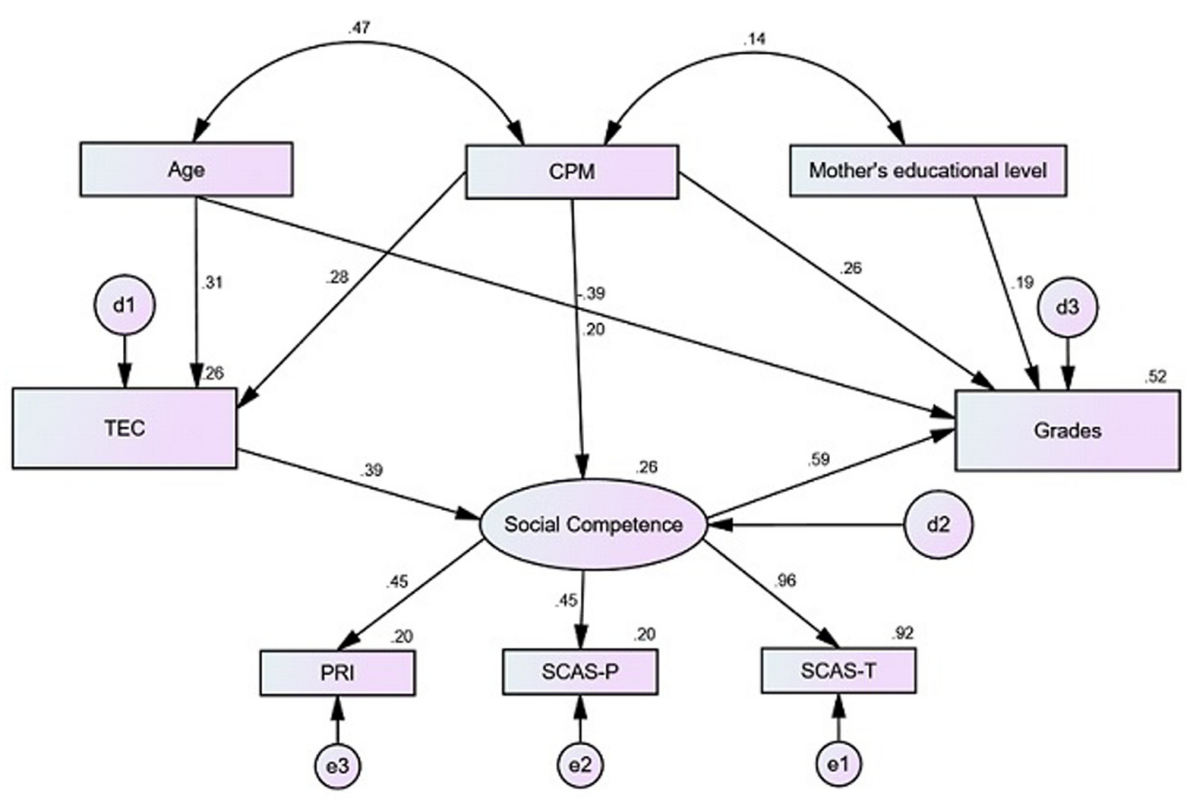

FIGURE 4 | Model 4, causal model of emotion understanding for academic achievement, mediated by social competence, in two student groups (boys and girls) with estimates for structural coefficients, factorials loads and standardized individual reliability $\left(X^{2} / d f=1.359, \mathrm{CFI}=0.974, \mathrm{RMSEA}=0.030, \mathrm{AIC}=156.775\right)$.

What the findings demonstrate is that there is an interaction between emotion understanding and social competence in the prediction of academic achievement, improving the variance explained by the model in $30.6 \%$ and contributing with new findings that establish a positive relationship between social and emotional competences and academic achievements (Caprara et al., 2000; Izard et al., 2001; Denham et al., 2012b;
Oberle et al., 2014). Social competence is a mediator of the relationship between emotion understanding and academic achievement, facilitating the relationship with others. In this manner, the predictive ability of social competences, and indirectly of emotion understanding, is significant, even when fluid intelligence and mother's educational level are monitored. 
Social information processing includes competences that require emotion understanding. The ability to understand emotions is related to the communication of the emotion, and when in scarcity, leads to inadequate or insufficient communication, jeopardizing social competence (Machado et al., 2008). Furthermore, the interpretation, modulation and implementation of emotion allow children to respond prosocially in social situations (Mostow et al., 2002; Belacchi and Farina, 2010). In this manner, social competence is set on a series of social, cognitive and emotional abilities of the individual to deal with interpersonal relations that occur in various contexts, encouraging healthier and more beneficial relationships with others (Del Prette and Del Prette, 2005). The ability to establish healthy relationships plays an essential role in human development in general and in particular in school activities, influencing the relationship with teachers, academic achievement and approval among peers (Carrilho, 2012). Social competences are important for efficient learning, according to Elijah and Madeira (2013), because they provide positive relationships between the individual and other social agents, benefitting the participation in classroom activities, for example: exchanging information, requesting orientation or correction, awaiting their turn to speak, follow rules and orientate oneself to the activity (Del Prette and Del Prette, 2005).

As in previous studies (Colom and Flores-Mendoza, 2007; Di Fabio and Palazzeschi, 2009, 2015, Downey et al., 2014) in this study, cognitive abilities significantly predict academic achievement, regardless of the mother's educational level. The findings also indicate that fluid intelligence predicts emotion understanding and social competences. According to the emotional intelligence ability model, it is expected that emotional competences be moderately correlated to intelligence levels (Garner, 2010; Agnoli et al., 2012; Djambazova-Popordanoska, 2016). In fact, of all emotional abilities, emotion understanding tends to have a stronger correlation with general cognitive functions, with similar values to those found in this study (between 0.40 and 0.60) (Brackett et al., 2011).

The relationship between social competence and fluid intelligence was also expected. Social abilities require some flexibility of thought and of behavior in order to approach and deal with the various social and emotional stimulants. In the processing of social information, emotions and cognitions work together to allow the child to understand and precisely interpret social clues, clarify social objectives, select and implement socially appropriate responses (Mostow et al., 2002). At school, this will be reflected in the facility to transition from one activity to the next in the classroom, not to persist on the same task and try new strategies to complete school activities (Feitosa et al., 2012).

There is evidence that age is a significant predictor of emotion understanding, but not of social competence. In this study, the general scoring in emotion understanding increases regularly with age, as previously found in other studies carried out with TEC (Farina et al., 2007; Albanese et al., 2010; Santos, 2012; Silva, 2012; Franco and Santos, 2015). On the other hand, despite the fact that some studies indicate a connection between age and the development of social competences (Cecconello and
Koller, 2000; Major, 2011), in this study these relationships were not found. A possible explanation for these results can be related to the way social competence was assessed, because teachers and parents assess their children's social competences comparatively to other children of the same age, diluting the effect of age.

As expected, mother's educational level is a predictor of academic achievement, confirming other studies (Magnuson, 2007; Dubow et al., 2009; Rocha, 2016). In the same manner, no significant effects were found between the mother's educational level and emotional understanding (Gameiro, 2012; Rocha, 2016) and social competence. Nonetheless, in other studies these variables are related (Alves, 2006; Rhoades et al., 2011; Lima, 2012; Nunes, 2012; Denham et al., 2013; Rocha, 2016).

Lastly, no gender differences were found in the causal model of academic achievement. In some studies gender differences were found regarding academic achievement (Duckworth and Seligman, 2006; Mestre et al., 2006; Deary et al., 2007), emotional competences (Mathieson and Banerjee, 2011; Naghavi and Redzuan, 2011; Denham et al., 2013) and social competences (Denham et al., 2012b, 2013) when studied separately. When these variables were study together the gender differences diminished (Trentacosta and Izard, 2007; Montroy et al., 2014; Rocha, 2016).

In our sample, there is no evidence that gender influences the way social competences mediate the relationship between emotion understanding and academic achievement. A possible explanation suggested by Montroy et al. (2014) is that gender differences tend to appear in older children, of middle and high school. Gender differences in the first years of primary school aren't always documented (Albanese et al., 2007; Farina et al., 2007; Gustafson, 2009; Matthews et al., 2009; Belacchi and Farina, 2010) but increase in magnitude with age (Montroy et al., 2014). Research carried out with adolescents find greater levels of emotion understanding and social skills among girls than among boys (Welsh et al., 2001; Brackett et al., 2004; Oberle et al., 2014). This may be because as children grow up, intergrupal processes may contribute to the development of preconception and discrimination based on gender (Leaper, 2011). Recent studies show that restrictive gender roles have consequences on girls' academic achievements (Brown and Leaper, 2010) and on boy's socioemotional development (Oransky and Fisher, 2009).

In summary, the present study examines the relationship between fluid intelligence, mother's educational level, gender emotion understanding and social competence as predictors of academic achievement. These findings contribute to the current understanding of the influence of academic achievement, with significant implications to education support and suggest orientations for future studies. Aiding primary school children to achieve academic success it is important not only to promote academic abilities, as well as social and emotional skills (Greenberg et al., 2003; Fleming et al., 2005; Payton et al., 2008; Durlak et al., 2011; Collaborative for Academic, Social, and Emotional Learning [CASEL], 2012).

One of the limitations of this study was the use of grades attributed by the teachers as a measure of academic achievement, because if grades are of easy access through teachers or school 
archives, their reliability may be limited by the criteria differences among teachers (McMillan, 2001; Oberle et al., 2014). A way to overcome this particular limitation would be to consider different indexes of academic performance simultaneously, and more objective, standardized tests (Di Fabio and Palazzeschi, 2009; Oberle et al., 2014).

In the same manner, personality characteristics were not taken into consideration, which could have been important, seeing that some authors defend that intelligence and personality are better predictors of academic achievement than emotional and social competences (e.g., Barchard, 2007).

Another variable that could be analyzed in future studies is teacher-child relationships. Different studies reveal that teacherchild relationships as well as affective relation between them (Franco, 2012) are important to the comprehension of school achievement (Hamre and Pianta, 2001; Pianta and Stuhlman, 2004; Franco and Beja, 2010; Pasta et al., 2013), school adjustment (Pianta and Steinberg, 1992; Baker, 2006) and the development of social and emotional competences (Birch and Ladd, 1998; Zhang and Nurmi, 2012; Sette et al., 2014; Skalická et al., 2015).

\section{REFERENCES}

Agnoli, S., Mancini, G., Pozzoli, T., Baldaro, B., Russo, P. M., and Surcinelli, P. (2012). The interaction between emotional intelligence and cognitive ability in predicting scholastic performance in school-aged children. Pers. Individ. Dif. 53, 660-665. doi: 10.1016/j.paid.2012.05.020

Albanese, O., De Stasio, S., Di Chiacchio, C., Fiorilli, C., and Pons, F. (2010). Emotion comprehension: the impact of nonverbal intelligence. J. Genet. Psychol. 171, 101-115. doi: 10.1080/00221320903548084

Albanese, O., Molina, P., Gavazzi, I., De Stasio, S., Farina, E., Fiorilli, C., et al. (2007). "The assessment of emotion understanding: the Italian standardization of the test of emotion comprehension (TEC)," in Giornata di Studio Sulle Emozioni, eds V. Zammuner and C. Galli (Padua: CLEUP), 44-47.

Alves, D. (2006). O Emocional e o Social na Idade Escolar. Uma Abordagem dos Preditores da Aceitação Pelos Pares. Master's dissertation, University of Porto, Porto.

Baker, J. A. (2006). Contributions of teacher-child relationships to positive school adjustment during elementary school. J. Sch. Psychol. 44, 211-229. doi: 10.1016/ j.jsp.2006.02.002

Barchard, K. A. (2007). Does emotional intelligence assist in the prediction of academic success? Educ. Psychol. Meas. 63, 840-858. doi: 10.1177/ 0013164403251333

Belacchi, C., and Farina, E. (2010). Prosocial/hostile roles and emotion comprehension in preschoolers. Aggress. Behav. 36, 371-389. doi: 10.1002/ab. 20361

Bierman, K. L., Domitrovich, C. E., Nix, R. L., Gest, S. D., Welsh, J. A., Greenberg, M. T., et al. (2008). Promoting academic and social-emotional school readiness: the head start REDI program. Child Dev. 79, 1802-1817. doi: 10.1111/j.14678624.2008.01227.x

Birch, S. H., and Ladd, G. W. (1998). Children's interpersonal behaviors and the teacher-child relationship. Dev. Psychol. 34, 934-946. doi: 10.1037/0012-1649. 34.5.934

Blair, C., and Razza, R. P. (2007). Relating effortful control, executive function, and false belief understanding to emerging math and literacy ability in Kindergarten. Child Dev. 78, 647-663. doi: 10.1111/j.1467-8624.2007. 01019.x

Brackett, M. A., Mayer, J. D., and Warner, R. M. (2004). Emotional intelligence and its relation to everyday behaviour. Pers. Individ. Dif. 36, 1387-1402. doi: 10.1016/S0191-8869(03)00236-8

Brackett, M. A., Rivers, S. E., and Salovey, P. (2011). Emotional intelligence: implications for personal, social, academic, and workplace success. Soc. Pers. Psychol. Compass 5, 88-103. doi: 10.1111/j.1751-9004.2010.00334.x
It would also be important to carry out longitudinal studies that look into the predictive role of social and emotional aspects in academic results, during different periods of development (Hawkins et al., 2008; Oberle et al., 2014).

\section{ETHICS STATEMENT}

This study was carried out in accordance with the recommendations of Portuguese Psychologists Bar with written informed consent from all subjects. All subjects gave written informed consent in accordance with the Declaration of Helsinki.

\section{AUTHOR CONTRIBUTIONS}

Conceptualization: MF, NS, and MB; Methodology: MF and NS; Formal Analysis: MF, MB, and AC; Investigation: MF and NS; Writing-Review and Editing: MF, NS, and MB; Supervision: MF, $\mathrm{MB}$, and $\mathrm{AC}$.

Bridges, L. J., Denham, S. A., and Ganiban, J. M. (2004). Definitional issues in emotion regulation research. Child Dev. 75, 340-345. doi: 10.1111/j.1467-8624. 2004.00675.x

Brown, C. S., and Leaper, C. (2010). Latina and European American girls' experiences with academic sexism and their self-concepts in mathematics and science during adolescence. Sex Roles 63, 860-870. doi: 10.1007/s11199-0109856-5

Bruner, J. S. (1970/1998). O Processo da Educação [The Process of Education]. Lisbon: Edições 70.

Candeias, A. (2007). PCIS - Prova Cognitiva de Inteligência Social [CTSI - Cognitive Test of Social Intelligence]. Lisbon: CEGOC-TEA, Lda.

Candeias, A. (2008). Prova de Avaliação de Competência Social PACS [Social Competence Assessment Scales - SCAS]. Manual Experimental. Lisbon: CEGOCTEA, Lda.

Caprara, G. V., Barbaranelli, C., Pastorelli, C., Bandura, A., and Zimbardo, P. G. (2000). Prosocial foundations of children's academic achievement. Psychol. Sci. 11, 302-306. doi: 10.1111/1467-9280.00260

Carrilho, G. P. C. (2012). A Interacção Familiar, Autoconceito, Competências Sociais e Sua Relação com o Desempenho Académico em Adolescentes. Master's dissertation, University of Algarve, Faro.

Cecconello, A. M., and Koller, S. H. (2000). Competência social E empatia: um estudo sobre resiliência com crianças em situação de pobreza. Estud. Psicol. 5, 71-93. doi: 10.1590/S1413-294X2000000100005

Collaborative for Academic, Social, and Emotional Learning [CASEL] (2012). Effective Social and Emotional Learning Programs. Preschool and Elementary School Edition. Chicago, IL: Collaborative for Academic, Social, and Emotional Learning.

Colom, R., and Flores-Mendoza, C. E. (2007). Intelligence predicts scholastic achievement irrespective of SES factors: evidence from Brazil. Intelligence 35, 243-251. doi: 10.1016/j.intell.2006.07.008

Colwell, M. J., and Hart, S. (2006). Emotion framing: does it relate to children's emotion knowledge and social behavior. Early Child Dev. Care 176, 591-603. doi: 10.1080/03004430500147367

Cutting, A. L., and Dunn, J. (1999). Theory of mind, emotion understanding, language, and family background: individual differences and interrelations. Child Dev. 70, 853-865. doi: 10.1111/1467-8624.00061

De Stasio, S., Fiorilli, C., and Di Chiacchio, C. (2014). Effects of verbal ability and fluid intelligence on children's emotion understanding. Int. J. Psychol. 49, 409-414. doi: 10.1002/ijop.12032

Deary, I. J., Strand, S., Smith, P., and Fernandes, C. (2007). Intelligence and educational achievement. Intelligence 35, 13-21. doi: 10.1016/j.intell.2006. 02.001 
Del Prette, A., and Del Prette, Z. A. P. (2005). Psicologia das Habilidades Sociais na Infância: Teoria e Prática [Psychology of Social Skills in Childhood: Theory and Practice]. Petrópolis: Vozes.

Denham, S. A. (2006). Social relationships and school readiness. Early Educ. Dev. 17, 151-176. doi: 10.1207/s15566935eed1701

Denham, S. A., Bassett, H. H., Brown, C., Way, E., and Steed, J. (2013). I know how you feel': preschoolers' emotion knowledge contributes to early school success. J. Early Child. Res. 13, 252-262. doi: 10.1177/1476718X13497354

Denham, S. A., Bassett, H. H., Thayer, S. K., Mincic, M. S., Sirotkin, Y. S., and Zinsser, K. (2012a). Observing preschoolers' social-emotional behavior: structure, foundations, and prediction of early school success. J. Genet. Psychol. 173, 246-278. doi: 10.1080/00221325.2013.869534

Denham, S. A., Bassett, H. H., Way, E., Mincic, M., Zinsser, K., and Graling, K. (2012b). Preschoolers' emotion knowledge: self-regulatory foundations, and predictions of early school success. Cogn. Emot. 26, 667-679. doi: 10.1080/ 02699931.2011.602049

Denham, S. A., Bassett, H. H., Zinsser, K., and Wyatt, T. M. (2014). How preschoolers' social-emotional learning predicts their early school success: developing theory-promoting, competency-based assessments. Infant Child Dev. 23, 426-454. doi: 10.1002/icd.1840

Denham, S. A., Blair, K. A., DeMulder, E., Levitas, J., Sawyer, K., AuerbachMajor, S., et al. (2003). Preschool emotional competence: pathway to social competence? Child Dev. 74, 238-256. doi: 10.1111/1467-8624. 00533

Denham, S. A., and Brown, C. (2010). Plays nice with others': social - emotional learning and academic success. Early Educ. Dev. 21, 652-680. doi: 10.1080/ 10409289.2010.497450

Di Fabio, A., and Palazzeschi, L. (2009). An in-depth look at scholastic success: fluid intelligence, personality traits or emotional intelligence? Pers. Ind. Dif. 46, 581-585. doi: 10.1016/j.paid.2008.12.012

Di Fabio, A., and Palazzeschi, L. (2015). Beyond fluid intelligence and personality traits in scholastic success: trait emotional intelligence. Learn. Individ. Differ. 40, 121-126. doi: 10.1016/j.lindif.2015.04.001

Djambazova-Popordanoska, S. (2016). Implications of emotion regulation on young children's emotional wellbeing and educational achievement. Educ. Rev. 68, 497-515. doi: 10.1080/00131911.2016.1144559

Downey, L. A., Lomas, J., Billings, C., Hansen, K., and Stough, C. (2014). Scholastic success: fluid intelligence, personality, and emotional intelligence. Can. J. Sch. Psychol. 29, 40-53. doi: 10.1177/0829573513505411

Dubow, E. F., Boxer, P., and Huesmann, L. R. (2009). Long-term effects of parents' education on children's educational and occupational success: mediation by family interactions, child aggression, and teenage aspirations. Merrill Palmer Q. 55, 224-249. doi: $10.1353 / \mathrm{mpq} \cdot 0.0030$

Duckworth, A. L., and Seligman, M. E. P. (2006). Self-discipline gives girls the edge: gender in self-discipline, grades, and achievement test scores. J. Educ. Psychol. 98, 198-208. doi: 10.1037/0022-0663.98.1.198

Durlak, J. A., Weissberg, R. P., Dymnicki, A. B., Taylor, R. D., and Schellinger, K. B. (2011). The impact of enhancing students' social and emotional learning: a meta-analysis of school-based universal interventions. Child Dev. 82, 405-432. doi: $10.1111 / j .1467-8624.2010 .01564 . x$

Eisenberg, N., Sadovsky, A., and Spinrad, T. L. (2005). Associations of emotionrelated regulation with language skills, emotion knowledge, and academic outcomes. New Dir. Child Adolesc. Dev. 109, 109-118. doi: 10.2964/jsik. kuni0223

Elijah, D. W., and Madeira, J. M. (2013). Efeitos da intervenção social cognitiva para a melhoria da competência social e do sucesso escolar em alunos de escola primária inglesa: estudo de caso?. Saber Educar 18, 94-105. doi: 10.17346/se. vol18.54

Ensor, R., Spencer, D., and Hughes, C. (2011). 'You feel sad?' Emotion understanding mediates effects of verbal ability and mother-child mutuality on prosocial behaviors: findings from 2 years to 4 years. Soc. Dev. 20, 93-110. doi: $10.1111 / j .1467-9507.2009 .00572 . x$

Farina, E., Albanese, O., and Pons, F. (2007). Making inferences and individual differences. Psychol. Lang. Commun. 11, 3-19.

Feitosa, F. B., Del Prette, Z. A. P., and Del Prette, A. (2012). Social skills and academic achievement: the mediating function of cognitive competence. Temas Em Psicol. 20, 61-70.
Fleming, C. B., Haggerty, K. P., Catalano, R. F., Harachi, T. W., Mazza, J. J., and Gruman, D. H. (2005). Do social and behavioral characteristics targeted by preventive interventions predict standardized test scores and grades? J. Sch. Health 75, 342-349. doi: 10.1111/j.1746-1561.2005.00048.x

Franco, G. (2012). A Representação dos Alunos do $1^{\circ}$ ciclo das Características Afectivas dos Seus Professores: Um Estudo na RAM; Portugal [Representations of 1st Grade Students of the Affective Characteristics of their Teachers: A Study in the RAM; Portugal]. VIII Colóquio CIE- UMa: O Futuro da Escola Pública [VIII Colloquium CIE-UMa: The Future of Public School]. Funchal: Universidade da Madeira.

Franco, G., and Beja, M. J. (2010). Os Aspectos Afectivos dos Professores, Autoconceito e Rendimento Escolar dos Alunos [Affective Aspects of Teachers, Selfconcept and School Achievement of their Students]. Seminário Internacional Contributos da Psicologia em Contexto Educativo [International Seminar Contributions of Psychology in Educational Contexts]. Braga: Universidade do Minho.

Franco, M. G., and Santos, N. N. (2015). Desenvolvimento da compreensão emocional. Psicol. Teor. Pesqui. 31, 339-348. doi: 10.1590/010237722015032099339348

Gameiro, S. S. (2012). A Compreensão das Emoções em Crianças dos 6 aos 8 anos Estudo de Adaptação Portuguesa do TEC. Master's dissertation, University of Coimbra, Coimbra.

Garner, P. W. (2010). Emotional competence and its influences on teaching and learning. Educ. Psychol. Rev. 22, 297-321. doi: 10.1007/s10648-010-9129-4

Graziano, P. A., Reavis, R. D., Keane, S. P., and Calkins, S. D. (2007). The role of emotion regulation and children's early academic success. J. Sch. Psychol. 45, 3-19. doi: $10.1016 /$ j.jsp.2006.09.002

Greenberg, M. T., Weissberg, R. P., O’Brien, M. U., Zins, J. E., Fredericks, L., Resnik, H., Elias, M. J., et al. (2003). Enhancing school-based prevention and youth development through coordinated social, emotional, and academic learning. Am. Psychol. 58, 466-474. doi: 10.1037/0003-066X.58.6-7.466

Gustafson, E. A. (2009). The Emotion Comprehenstion Test: Selected Psychometric Propterties of a New Measure of Emotion Understandign for Preschoolers. Master's dissertation, University of Maryland, College Park, MD.

Hamre, B., and Pianta, R. C. (2001). Early teacher-child relationships and the trajectory of children's school outcomes through eighth grade. Child Dev. 2, 625-638. doi: 10.1111/1467-8624.00301

Hawkins, J. D., Kosterman, R., Catalano, R. F., Hill, K. G., and Abbott, R. D. (2008). Effects of social development intervention in childhood 15 years later. Arch. Pediatr. Adolesc. Med. 162, 1133-1141. doi: 10.1001/archpedi.162.12.1133

Herndon, K. J., Bailey, C. S., Shewark, E. A., Denham, S. A., and Bassett, H. H. (2013). Preschoolers' emotion expression and regulation: relations with school adjustment. J. Genet. Psychol. 174, 642-663. doi: 10.1080/00221325.2012. 759525

Howse, R. B., Calkins, S. D., Anastopoulos, A. D., Keane, S. P., and Shelton, T. L. (2003). Regulatory contributors to children's kindergarten achievement. Early Educ. Dev. 14, 37-41. doi: 10.1207/s15566935eed1401_7

Izard, C., Fine, S., Schultz, D., Mostow, A., Ackerman, B., and Youngstrom, E. (2001). Emotion knowledge as a predictor of social behavior and academic competence in children at risk. Psychol. Sci. 12, 18-23. doi: 10.1111/1467-9280. 00304

Leaper, C. (2011). Research in developmental psychology on gender and relationships: reflections on the past and looking into the future. Br. J. Dev. Psychol. 29, 347-356. doi: 10.1111/j.2044-835X.2011.02035.x

Lima, A. C. (2012). A Compreensão das Emoções em Crianças dos 4 aos 5 anos Estudo de Adaptação Portuguesa do TEC. Master's dissertation, University of Coimbra, Coimbra.

Low, S., Cook, C. R., Smolkowski, K., and Buntain-Ricklefs, J. (2015). Promoting social-emotional competence: an evaluation of the elementary version of Second Step ${ }^{\circledR}$. J. Sch. Psychol. 53, 463-477. doi: 10.1016/j.jsp.2015.09.002

Machado, P., Veríssimo, M., Torres, N., Peceguina, M. I. D., Santos, A. J., and Rolão, T. (2008). Relações entre o conhecimento das emoções, as competências académicas, as competências sociais e a aceitação entre pares. Psicológica 3, 463-478.

Magnuson, K. (2007). Maternal education and children's academic achievement during middle childhood. Dev. Psychol. 43, 1497-1512. doi: 10.1037/0012-1649. 43.6.1497 
Major, S. (2011). Avaliação de Aptidões Sociais E Problemas de Comportamento Em Idade Pré- Escolar: Retrato Das Crianças Portuguesas. Coimbra: Universidade de Coimbra.

Maroco, J. (2014). Análise de Equações Estruturais: Fundamentos teóricos, Software \& Aplicações [Analysis of Structural Equation. Theoretical Fundamentals, Software and Applications]. Pêro Pinheiro: ReportNumber.

Mathieson, K., and Banerjee, R. (2011). Peer play, emotion understanding, and socio-moral explanation: the role of gender. Br. J. Dev. Psychol. 29, 188-196. doi: 10.1111/j.2044-835X.2010.02020.x

Matthews, J. S., Ponitz, C. C., and Morrison, F. J. (2009). Early gender differences in self-regulation and academic achievement. J. Educ. Psychol. 101, 689-704. doi: $10.1037 / \mathrm{a} 0014240$

McCallum, S., Bracken, B., and Wasserman, J. (2001). Essentials of Nonverbal Assessment. New York, NY: Wiley.

McCormick, M. P., Cappella, E., O'Connor, E. E., and McClowry, S. G. (2015). Social-emotional learning and academic achievement. AERA Open 1, 1-26. doi: $10.1177 / 2332858415603959$

McKown, C., Russo-Ponsaran, N. M., Allen, A., Johnson, J. K., and WarrenKhot, H. K. (2016). Social-emotional factors and academic outcomes among elementary-aged children. Infant Child Dev. 25, 119-136. doi: 10.1002/icd.1926

McMillan, J. H. (2001). Secondary teachers' classroom assessment and grading practices. Educ. Meas. Issues Pract. 20, 20-32. doi: 10.1111/j.1745-3992.2001. tb00055.x

Mestre, J. M., Guil, R., Lopes, P. N., Salovey, P., and Gil-Olarte, P. (2006). Emotional intelligence and social and academic adaptation to school. Psicothema 18(Suppl.), 112-117.

Montroy, J. J., Bowles, R. P., Skibbe, L. E., and Foster, T. D. (2014). Social skills and problem behaviors as mediators of the relationship between behavioral self-regulation and academic achievement. Early Child. Res. Q. 29, 298-309. doi: 10.1016/j.ecresq.2014.03.002

Mostow, A. J., Izard, C. E., Fine, S., and Trentacosta, C. J. (2002). Modeling emotional, cognitive, and behavioral predictors of peer acceptance. Child Dev. 73, 1775-1787. doi: 10.1111/1467-8624.00505

Naghavi, F., and Redzuan, M. (2011). The relationship between gender and emotional intelligence. World Appl. Sci. J. 15, 555-561.

Nelson, B., Martin, R. P., Hodge, S., Havill, V., and Kamphaus, R. (1999). Modeling the prediction of elementary school adjustment from preschool temperament. Pers. Individ. Dif. 26, 687-700. doi: 10.1016/S0191-8869(98) 00174-3

Nunes, J. (2012). A Compreensão das Emoções em Crianças dos 9 aos 11 anos Estudo de Adaptação Portuguesa do TEC. Master's thesis, University of Coimbra, Coimbra.

Oberle, E., Schonert-reichl, K. A., Hertzman, C., and Zumbo, B. D. (2014). Social emotional competencies make the grade: predicting academic success in early adolescence. J. Appl. Dev. Psychol. 35, 138-147. doi: 10.1016/j.appdev.2014. 02.004

Oransky, M., and Fisher, C. (2009). The development and validation of the meanings of adolescent masculinity scale. Psychol. Men Masc. 10, 57-72. doi: $10.1037 / \mathrm{a} 0013612$

Pasta, T., Mendola, M., Longobardi, C., Prino, L. E., Giovanna, F. G. M., et al. (2013). Attributional style of children with and without Specific Learning Disabilit. Electron. J. Res. Educ. Psychol. 11, 649-664. doi: 10.14204/ejrep.31. 13064

Payton, J., Weissberg, R. P., Durlak, J. A., Dymnicki, A. B., Taylor, R. D., Schellinger, K. B., et al. (2008). The Positive Impact of Social and Emotional Learning for Kindergarten to Eighth-Grade Students. Chicago, IL: Collaborative for Academic, Social, and Emotional Learning.

Pianta, R., and Steinberg, M. (1992). Teacher-child relationships and the process of adjusting to school. New Dir. Child Adolesc. Dev. 57, 61-80. doi: 10.1002/cd. 23219925706

Pianta, R. C., and Stuhlman, M. W. (2004). Mother-child relationships, teacherchild relationships, and school outcomes in preschool and kindergarten. Sch. Psychol. Rev. 33, 444-458. doi: 10.1016/S0885-2006(97)90003-X

Pons, F., and Harris, P. (2000). Test of Emotional Comprehension- TEC. Oxford: University of Oxford.

Pons, F., and Harris, P. (2005). Longitudinal change and longitudinal stability of individual differences in children's emotion understanding. Cogn. Emot. 19, 1158-1174. doi: 10.1080/02699930500282108
Pons, F., Harris, P. L., and De Rosnay, M. (2004). Emotion comprehension between 3 and 11 years: developmental periods and hierarchical organization. Eur. J. Dev. Psychol. 1, 127-152. doi: 10.1080/17405620344000022

Qualter, P., Gardner, K. J., Pope, D. J., Hutchinson, J. M., and Whiteley, H. E. (2012). Ability emotional intelligence, trait emotional intelligence, and academic success in British secondary schools: a 5year longitudinal study. Learn. Individ. Differ. 22, 83-91. doi: 10.1016/j.lindif.2011.11.007

Raver, C. C. (2002). Emotions matter: making the case for the role of young children's emotional development for early school readiness. Soc. Policy Rep. $16,3-18$.

Raver, C. C. (2003). Young Children's Emotional Development and School Readiness. Champaign, IL: ERIC Clearinghouse on Elementary and Early Childhood Education.

Raver, C. C., and Knitzer, J. (2002). Ready to Enter: What Research Tells Policymakers About Strategies to Promote Social and Emotional School Readiness Among Three- and Four-Year-Old Children. Promoting the Emotional WellBeing of Children and Families: Policy Paper No. 1. New York, NY: National Center for Children in Poverty.

Rhoades, B. L., Warren, H. K., Domitrovich, C. E., and Greenberg, M. T. (2011). Examining the link between preschool social-emotional competence and first grade academic achievement: the role of attention skills. Early Child. Res. Q. 26, 182-191. doi: 10.1016/j.ecresq.2010.07.003

Roazzi, A., Dias, M. B. B., Minervino, C. M., Roazzi, M., and Pons, F. (2008). "Compreensão das emoções em crianças: estudo transcultural sobre a validação do teste de compreensão da emoção TEC (test of emotion comprehension)," in Proceedings of the Actas Da XIII Conferência Internacional Avaliação Psicológica: Formas E Contextos, eds A. Noronha, C. Machado, L. Almeida, M. Gonçalves, S. Martins, and V. Ramalho (Braga: Psiquilibrios edições).

Roazzi, A., Rocha, A. A., Candeias, A. A., da Silva, A. L., Minervino, C. A., Roazzi, M. M., et al. (2015). "Social competence and emotional comprehension?: How are they related in children?," in Searching for Structure in Complex Social, Cultural and Psychological Phenomena, eds A. Roazzi, B. C. Souza, and W. Bilsky (Recife: Editora UFPE), 267-283. doi: 10.13140/RG.2.1.3374.9524

Rocha, A. A. (2016). Compreensão e Regulação das Emoções: suas Relações com a Eficácia na Interação Social em Crianças. Doctoral Dissertation, University of Coimbra, Coimbra.

Rocha, A. A., Roazzi, A., da Silva, A. L., Candeias, A. A., Minervino, C. A., Roazzi, M. M., et al. (2015). "Test of emotion comprehension?: exploring the underlying structure through confirmatory factor analysis and similarity structure analysis," in Fact Theory: Searching for Structure in Complex Social, Cultural and Psychological Phenomena, eds A. Roazzi, B. C. de Souza, and W. Bilsky (Recife: Editora UFPE), 66-84. doi: 10.13140/RG.2.1.2457. 4483

Saarni, C. (1990). "Emotional competence: how emotions and relationships become integrated," in Socioemotional Development: Nebraska symposium on Motivation, ed. R. A. Thompson (Lincoln, NE: University of Nebraska Press), $115-161$.

Saarni, C. (2000). "Emotional competence: a developmental perspective," in The Handbook of Emotional Intelligence: Theory, Development, Assessment, and Application at Home, School, and in the Workplace, eds R. Bar-On and J. D. A. Parker (San Francisco, CA: Jossey-Bass), 68-91.

Santos, N. N. (2012). Inteligência Emocional: A Compreensão das Emoções em Crianças do Pré-Escolar. Master's thesis, University of Madeira, Funchal.

Sette, S., Baumgartner, E., and Schneider, B. H. (2014). Shyness, childteacher relationships, and socio-emotional adjustment in a sample of Italian preschool-aged children. Infant Child Dev. 23, 323-332. doi: 10.1002/icd. 1859

Shields, A., Dickstein, S., Seife, R., Giusti, L., Magee, K. D., Spritz, B., et al. (2001). Emotional competence and early school adjustment: a study of preschoolers at risk. Early Educ. Dev. 12, 73-96. doi: 10.1207/s15566935eed1201_5

Silva, E. P. (2012). A Relação Entre Inteligência Emocional e o Rendimento Escolar em Crianças do $1^{\circ}$ Ciclo do Ensino Básico da R.A.M. Master's thesis, University of Madeira, Funchal.

Simões, M. (2000). Investigações no Âmbito da Aferição Nacional do Teste das Matrizes Progressivas Coloridas de Raven (MPCR). Lisboa: Fundação Calouste Gulbenkian.

Simões, M. R. (1995). "O teste das matrizes progressivas coloridas de raven [The raven coloured progressive matrices test (RCPM)]," in Provas Psicológicas em 
Portugal [Psychological Tests in Portugal], eds L. Almeida, M. Simões, and M. Gonçalves (Braga: Associação dos Psicólogos Portugueses), 1-18.

Skalická, V., Stenseng, F., and Wichstrom, L. (2015). Reciprocal relations between student-teacher conflict, children's social skills and externalizing behavior. Int. J. Behav. Dev. 39, 413-425. doi: 10.1177/0165025415584187

Tenenbaum, H., Visscher, P., Pons, F., and Harris, P. (2004). Emotional understanding in quechua children from an agro-pastoralist village. Int. J. Behav. Dev. 28, 471-478. doi: 10.1080/01650250444000225

Torres, M. M., Domitrovich, C. E., and Bierman, K. L. (2015). Preschool interpersonal relationships predict kindergarten achievement: mediated by gains in emotion knowledge. J. Appl. Dev. Psychol. 39, 44-52. doi: 10.1016/j. appdev.2015.04.008

Trentacosta, C. J., and Izard, C. E. (2007). Kindergarten children's emotion competence as a predictor of their academic competence in first grade. Emotion 7, 77-88. doi: 10.1037/1528-3542.7.1.77

Trentacosta, C. J., Izard, C. E., Mostow, A. J., and Fine, S. E. (2006). Children's emotional competence and attentional competence in early elementary school. Sch. Psychol. Q. 21, 148-170. doi: 10.1521/scpq.2006. 21.2.148

Valiente, C., Eisenberg, N., Haugen, R., Spinrad, T. L., Hofer, C., Liew, J., et al. (2011). Children's effortful control and academic achievement: mediation through social functioning. Early Educ. Dev. 22, 411-433. doi: 10.1080/ 10409289.2010.505259
Vygotsky, L. (1934/2008). Pensamento e Linguagem [Thought and language]. Lisboa: Relógio de água.

Welsh, M., Parke, R. D., Widaman, K., and O'Neil, R. (2001). Linkages between children's social and academic competence: a longitudinal analysis. J. Sch. Psychol. 39, 463-482. doi: 10.1016/S0022-4405(01)00084-X

Zhang, X., and Nurmi, J.-E. (2012). Teacher-child relationships and social competence: a two-year longitudinal study of Chinese preschoolers. J. Appl. Dev. Psychol. 33, 125-135. doi: 10.1016/j.appdev.2012.03.001

Zins, J. E., Payton, J. W., Weissberg, R. P., and O’Brien, M. U. (2007). “Social and emotional leaning and successful school performance," in The Science of Emotional Intelligence: Knowns and Unknowns, eds G. Matthews, M. Zeidner, and R. D. Roberts (New York, NY: Oxford University Press), 376-395.

Conflict of Interest Statement: The authors declare that the research was conducted in the absence of any commercial or financial relationships that could be construed as a potential conflict of interest.

Copyright $\odot 2017$ Franco, Beja, Candeias and Santos. This is an open-access article distributed under the terms of the Creative Commons Attribution License (CC BY). The use, distribution or reproduction in other forums is permitted, provided the original author(s) or licensor are credited and that the original publication in this journal is cited, in accordance with accepted academic practice. No use, distribution or reproduction is permitted which does not comply with these terms. 


\section{OPEN ACCESS}

Edited by:

Adelinda Araujo Candeias, University of Évora, Portugal

Reviewed by:

Claudio Longobardi, University of Turin, Italy Trude Nilsen,

University of Oslo, Norway

*Correspondence:

Verónica López

veronica.lopez@pucv.cl

Specialty section: This article was submitted to Educational Psychology, a section of the journal

Frontiers in Psychology

Received: 26 February 2017

Accepted: 29 June 2017

Published: 14 July 2017

Citation:

López V, Oyanedel JC, Bilbao M, Torres J, Oyarzún D, Morales M, Ascorra P and Carrasco C (2017)

School Achievement and Performance in Chilean High

Schools: The Mediating Role of Subjective Wellbeing in School-Related Evaluations.

Front. Psychol. 8:1189. doi: 10.3389/fpsyg.2017.01189

\section{School Achievement and Performance in Chilean High Schools: The Mediating Role of Subjective Wellbeing in School-Related Evaluations}

\author{
Verónica López ${ }^{1,2 *}$, Juan C. Oyanedel ${ }^{3}$, Marian Bilbao 4 , Javier Torres 1,5 , \\ Denise Oyarzún ${ }^{1}$, Macarena Morales ${ }^{1}$, Paula Ascorra ${ }^{1,2}$ and Claudia Carrasco ${ }^{1}$ \\ 'School of Psychology, Pontificia Universidad Católica de Valparaíso, Valparaíso, Chile, ${ }^{2}$ Centro de Investigación para la \\ Educación Inclusiva, Valparaíso, Chile, ${ }^{3}$ Faculty of Education, Universidad Andrés Bello, Santiago, Chile, ${ }^{4}$ School of \\ Psychology, Universidad de Santiago de Chile, Santiago, Chile, ${ }^{5}$ Universidad Tecnológica de Chile INACAP, Vitacura, Chile
}

School achievement gaps and school failure are problematic issues in Latin America, and are mainly explained by the socio-economic status (SES) of the students. What schools can do to improve school achievement and reduce school failure is a critical issue, both for school management and teacher training. In this study, we present the association of individual and school-related socio-emotional variables with school achievement and performance, controlling for the effects of SES. A probabilistic sample of 4,964 students, drawn from 191 schools enrolled in year 10 in urban areas of Chile, answered questionnaires assessing subjective wellbeing, social wellbeing in school, school climate, school social wellbeing and students' perceptions of teachers' wellbeing. Using structural equation modeling, and controlling for SES, we modeled subjective wellbeing as a mediator of the relationship between school-related variables, such as school climate and perception of teacher's wellbeing, and (a) school achievement, and (b) school performance. School achievement was computed as a product of (a) the probability of passing the school year, and (b) the percentage of yearly attendance at school. Data on school achievement was drawn from administrative registries from the Chilean Ministry of Education. School performance was computed as the estimated grade point average (GPA) at the end of the school year, based on the students' previous 5-year GPAs, and was also obtained through administrative data of the last 5 years. Findings reveal the mediating role of subjective wellbeing in the relationship between school-related evaluations (students' social wellbeing at school, their perception of teachers' wellibeing and school climate) and school achievement. For school achievement, two variables were mediated (students' social wellbeing at school and school climate). However, for school performance, no significant mediations were found. We conclude that, on the one hand, after controlling for SES, students' 
individual subjective wellbeing is associated with their achievement and performance in school. We discuss the importance of improving school experiences that may protect and promote students' subjective experience and school achievement and performance, and reduce the probability of school failure and dropout.

Keywords: school achievement, school failure, student wellbeing, school climate, social wellbeing, Latin America, high school, Chile

\section{INTRODUCTION}

School achievement gaps and school failure are problematic issues in Latin America. Although enrolment has increased and general dropout has decreased, graduation rates are low, and these indicators show important gaps regarding gender, regions within countries and socio-economic groups (Bassi et al., 2013).

In Chile, dropout rates are lower than in other Latin American countries reaching $5.4 \%$ in $2013^{1}$. However, this percentage hides a socio-economic gap, with $32.6 \%$ of students who drop out being from the lowest socio-economic status (SES) (CASEN, 2013). Research suggests that Chile has one of the most socio-economically segregated educational systems in the world (OECD, 2011; Valenzuela et al., 2014), raising the issue of what schools can do to improve school achievement and reduce school failure.

School dropout has consequences both for those leaving the school system and for society at large (Rumberger and Rotermund, 2012). Dropouts are less likely to find employment and are more likely to end up earning lower wages. There is also evidence that school dropout is a predictor of delinquency, violence and drug use during adolescence and early adulthood (Henry et al., 2012; Na, 2016).

Research has addressed causes of school dropout, highlighting among them violent behavior and unhealthy peer relationships (Finn and Rock, 1997), and low parental commitment to the education of their sons and daughters (Pölkki and Vornanen, 2015). Also, it has noted the role of low attachment to school and low subjective and psychological wellbeing (South et al., 2007).

Other factors highlighted by the literature include the SES of the family, and social vulnerability. There is usually marked by an early incorporation into labor, adolescent pregnancy, poor academic performance, lack of motivation to study, behavioral problems, high school and neighborhood mobility, and grade repetition (Cairns et al., 1989; Aguirre et al., 2009; Román, 2009; Tyler and Lofstrom, 2009; Gasper et al., 2012. In the case of Chile, see Herrera, 1999; García-Huidobro, 2000; CEPAL, 2002; Román, 2009; Espinoza et al., 2011; Espinoza et al., 2012; Espinoza-Díaz et al., 2014).

Grade repetition and school non-attendance have been pinpointed as specific and measurable indicators of estimated school dropout (Havik et al., 2015). Grade repetition, as well as school dropout, generates what is known as educational lag, which is defined as a gap between the educational level a student

\footnotetext{
${ }^{1}$ One of the policies that has contributed to this phenomenon is the promulgation in 2003 of the Law $N^{\circ} 19.876$, which establishes secondary education as compulsory and free in public schools.
}

has at a given age and the educational level which he or she is supposed to have according to the national normative standards.

School-related evaluations could have a strong impact on student achievement and behavior (school achievement). Nonetheless, it is important to consider the individual evaluation that adolescents do of their own lives and how it affects both their psychological, behavioral and educational outcomes. To assess their own appraisal of their lives it is worth to look at the literature of subjective wellbeing.

Subjective wellbeing is understood as "an umbrella term for different valuations that people make regarding their lives, the events happening to them, their bodies and minds, and the circumstances in which they live" (Diener, 2006, p. 400). Subjective wellbeing has proven to be critical to maintaining positive mental health. Among its determinants are also the social aspects that mark people's lives (Keyes and Lopez, 2005).

Current research on happiness and subjective wellbeing is characterized by three main perspectives: subjective wellbeing (Diener, 2006), psychological wellbeing (Ryff and Singer, 1998), and social wellbeing (Keyes, 1998, 2006; Keyes, 2013). All these perspectives offer an interesting dimension: the relationship of wellbeing with the concept of health, which has as its protagonist an active and socio-historical subject (Blanco and Valera, 2007).

Subjective wellbeing studies, according to the guidelines of OECD (2013), include three major aspects: affectivity (positive, negative, and balance of affects), overall life assessment (life satisfaction and life domains), and sense of life (perception of living a life with meaning and purpose, and good psychological and social functioning). The first two aspects have traditionally been developed by a hedonic perspective such as the studies of happiness, while aspects of the psychological functioning of life with meaning and purpose come from studies on the tradition of eudemonics (Vázquez and Hervás, 2008; OECD, 2013).

Keyes proposes the relevance of the evaluation of our social functioning, and our evaluative perception of society in general, as one of the pillars of positive mental health (Keyes, 1998; Keyes and Shapiro, 2004; Keyes and Lopez, 2005). Social wellbeing is a complementary pillar to psychological wellbeing, which contributes to the construction of life with meaning and purpose by enabling meaningful relationships with others. This leads to a feeling of relevance in the social world, which is intelligible, and has a history and future to which the person feels attached (Keyes, 2006).

Social wellbeing has been defined as "the evaluation we make of circumstances and functioning within society" (Keyes, 1998, p. 7). Social integration, social acceptance, social contribution, 
social updating, and social coherence are the key areas defining social wellbeing (Keyes, 1998; Keyes and Shapiro, 2004). Thus, social wellbeing evaluates the interpersonal aspects of mental health. Considering these dimensions, the measurement of social wellbeing has become increasingly important in recent years, mainly due to its relations with civic health and social capital (Putnam, 2001) and especially with mental health from a biopsychosocial perspective (Keyes and Shapiro, 2004; Keyes, 2013).

Studies also show that environmental circumstances can sometimes produce substantial and lasting differences in subjective wellbeing (Diener, 2006; Oyanedel et al., 2014). One of these areas is school experience. The school can be seen as a place where subjective wellbeing becomes greatly important in the formation of adolescents. It is at this stage that an important part of their future satisfaction with life is defined (Cárdenas et al., 2008), as well as the definition of their future projects, and their relational and self-perception frameworks. Thus, high school constitutes an important stage in the development of students' cognitive, social and emotional capacities. It is precisely at this stage of life that adolescents construct an image of themselves, get in touch with their peers and begin to experience and control a wide range of emotions (Ning et al., 2013).

Most research on adolescent life satisfaction has examined the roles of family functioning and intrapersonal variables, but few studies have investigated life satisfaction in relation to schooling (Suldo et al., 2006; Wit et al., 2011; Veltro et al., 2014). Existing research linking satisfaction with life and satisfaction with the school shows that the most relevant associations are found with achieving a good school performance (Huebner and Gilman, 2006; Dwyer, 2008; Kirkcaldy et al., 2009; Saab and Klinger, 2010; Diseth et al., 2012), with a good perception of the quality of education received (Cárdenas et al., 2008), with an increase in the perception of social opportunities through education (Ferrante, 2002), with the perceived support of the social context in which young people develop (Hirschi, 2009) and finally, with the objective measurement of school performance (Quinn and Duckworth, 2007).

Students' life satisfaction is negatively affected by poor school climate and instances of school violence. Research has shown significant relationships between low levels of satisfaction with life and greater violence (physical and psychological) received from the peer group members (Oyanedel and Bazan, 2011), and where aggressive behavior is used as a social recognition mechanism (Buelga et al., 2008).

This research advances the understanding of the subjective wellbeing of adolescents, as it also considers social wellbeing (Keyes, 1998) within the school world, from a social-ecological perspective (Bronfenbrenner, 1987; Bronfenbrenner and Morris, 2006; Espelage and Swearer, 2010). If schools can make a significant difference in the integral development of students by promoting subjective (psycho-socio-affective) variables related to their wellbeing, there may be an alternative to the structural determinism derived from the segregation (based on socioeconomic level) of the Chilean educational system.

The promotion by teachers and managers of healthy school environments favors the integral development of students within the framework of a school culture that cares about the quality of life of their community (Benbenishty and Astor, 2005; López et al., 2011). A healthy school environment should affect academic achievement, understood not only through the probability of obtaining a better academic performance but also as the likelihood of preventing school failure and dropout.

Assessing the relationship between subjective wellbeing and educational achievement requires the development of more sophisticated models to avoid two possible restrictions. The first is the effect of SES, which, as reported by previous research, shows significant association both with the dependent and independent variables. The second is associated with focusing only on associations, instead of disentangling the mechanisms behind these associations. In this study, we propose that, at least, two supplementary school-related factors could be involved in this relationship: the role of pedagogical support of teachers, and school climate.

Recently, studies about educational quality have highlighted the role of the school context among its determinants. From a socio-ecological perspective (Benbenishty and Astor, 2005; Bronfenbrenner and Morris, 2006; Espelage and Swearer, 2010), student learning outcomes should consider the interrelation between the different levels that operate in and through the school system. From this perspective (Bronfenbrenner, 1987; Khoury-Kassabri et al., 2004), phenomena such as school violence are the result of the interaction between different relevant subsystems, among them students, families, the school, and the general community. All play a determinant role in individual performance.

School climate corresponds to a multidimensional construct related to the perceptions, thoughts, and values that members of an educational establishment give to it, and the social relations taking place on it (Assael and Neumann, 1991; Benbenishty and Astor, 2005). It is a characteristic of educational establishments, produced by the perceptions of the students about certain variables which, in turn, generate perceptions about that school. It has a strong impact on students' behavior and academic results. School climate is a phenomenon different from bullying and school violence (Astor et al., 2006).

School climate appears to have a strong effect on both educational attainment and the development of psychological strenghts. Literature on school climate makes clear that, although broad, it is generally understood under four specific dimensions: academic, community, safety and, institutional (Wang and Degol, 2016). Even when in practice they overlap, each of these represents an specific area of analysis and intervention in school settings.

The academic dimension of school climate, is one of the most prominent areas of school climate, dealing mainly with the importance of teaching and learning activities inside the school, and one of the most widely studied (Thapa et al., 2013). The community level, referring to the role that relationships have inside the school has been also researched widely, both in terms of academic outcomes, as well as their role in promoting positive psychosocial adjustment, increasing connectedness and reducing disengagement. School engagement has been reported as a protective factor for school dropout and school failure (Fall 
and Roberts, 2012; Wang and Fredricks, 2014). Engagement also shows association with intrinsic motivation and high educational expectations (Fan and Wolters, 2012), as well as preventing depression and low self-efficacy in academic settings (Quiroga et al., 2013). Benbenishty and Astor (2005) have specified three elements involved in generating a favorable school climate: clear policies and standards (Johnson, 2010); positive and supportive relationships with adults (Dwyer et al., 2001), and subjective and social wellbeing of students, insofar as positive relationships favor trust and commitment to the school.

Creating a healthy school climate is then a key role of the management team and teachers. They are in charge of building a supportive environment for learning, not only from individual attitudes of respect for diversity, solidarity and good treatment but also by establishing management practices which make it possible to build and sustain these relationships over time (Wubbels, 2011; Wubbels et al., 2015). Managing school behavior, promoting a feeling of belonging to the school, and establishing a system of legitimate and fair rules requires an active management of coexistence. It also requires a democratic style of management, where the participation of the school community is valued and practices allowing this participation are generated and promoted (López et al., 2011).

Comparative research shows the relationship between school failure and negative school climate (McEvoy and Welker, 2000). In the United States, Werblow et al. (2010) show that a positive school climate predicts school retention and, therefore, prevents dropout. The SERCE (UNESCO, 2008) and TERCE studies (UNESCO, 2016), carried among students of primary schools in Latin American countries, also found this relationship to apply with achievement in language, mathematics, and science. Scherer and Nilsen (2016) report, using a large-scale comparative dataset, an association between positive school climate and students' academic achievement motivation in mathematics, although of lesser extend that the association between achievement and instructional quality.

Samdal et al. (1998) examined the relationship between school climate and school satisfaction using data for students aged 11, 13, and 15 in Finland, Latvia, Norway, and Slovakia. Among school climate factors (teacher support, student support, classroom disturbances, unreasonable job demands, school justice, school safety, harassment and loneliness during time between classes), the authors found that the strongest predictors of student satisfaction with school are organized into process factors (school justice and school safety) and teacher support. These are followed by student support and class disturbances.

Wentzel (1998), using a sample of 167 sixth graders in a suburban community in the United States, found that academic support from teachers and peers is related to interest in school. Natvig et al. (2003) explored the relationship between happiness and stress in school, as well as personal and social factors associated with them, among 887 Norwegian adolescents aged 10-15 years old. They found that teacher support and peer support were positively related to happiness and that the support of teachers seemed to be more important than the support of other students.
In summary, available research shows that academic achievement and school climate are associated with adolescent subjective wellbeing.

Those teachers who favor an environment in their classrooms centered on learning and who play a role as mediators of this learning process, tend to achieve better results in terms of student learning and school performance (Ascorra et al., 2003; Davis, 2003; Ascorra and Crespo, 2004; Quaas et al., 2005; Pianta et al., 2012). In Latin America, the second and third international comparative study on language, mathematics and associated factors developed by UNESCO (UNESCO, 2008, 2016) reported that students who obtain the best results come from classrooms where students do not bother each other, where there are few or no fights, and where most of them are friends. Both reports conclude that classroom climate affects the academic success of students, so it is a key factor to consider in interventions aimed at educational improvements.

Several authors have emphasized the relevance of classroom climate and school coexistence to facilitate a learning-centered environment (Fraser, 1996; Adelman and Taylor, 1997; Hamre and Pianta, 2006; López et al., 2012; Friedberg, 2015). Literature also focus on the student-teacher relationship, which can be understood as a dyadic system. This relationship involves both characteristics of the student as well as of the teacher (Prino et al., 2016). This relationship is embedded in the school culture, which can regulate and affect it. Recent research reports that the student-teacher relation can operate as a protective factor in transitional events, for instance in the integration of students to new school (Longobardi et al., 2016) as well as in the integration of students with special needs (Pasta et al., 2013).

Research on effective schools (Raczynski and Muñoz, 2005; Allen et al., 2013), emphasizes the role of teachers as key actors in the processes carried out in classrooms, highlighting the construction of a good coexistence and a classroom climate based on learning, and on the choice of cooperative methodologies. Understanding teachers as professionals capable of thinking and making decisions about the conditions under which learning is developed (López-Vargas and Basto-Torrado, 2010) opens a space for a better management of classroom climate. There may be a relationship between teachers behaviors and the development of a classroom climate capable of promoting learning. Furthermore, the existence of a positive classroom and school climate builds and maintains not only positive teacher-student relationships, but also a higher sense of wellbeing for teachers themselves (Allen et al., 2013). In this study, we propose that students can perceive their teachers' wellbeing and that this perception influences their school achievement and performance.

This study aims to understand the relationship between high school students' school social wellbeing, school climate, teachers' perceived wellbeing and academic outcomes. We hypothesize positive associations between these constructs. We also hypothesize that subjective wellbeing could act as a mediator of some of these relationships, meaning that for high school students, subjective wellbeing plays an important role for the interpretation and understanding of school-related phenomena. 


\section{MATERIALS AND METHODS}

\section{Participants and Procedure}

This study uses a probabilistic, stratified and two-stage (schoolclassroom) sample of students in regular high schools in urban zones of the three main regions of Chile (V, VIII, and the Metropolitan region of Santiago de Chile). The sampling framework used was the 2012 national school enrolment registry from the Chilean Ministry of Education, and these data were linked with the one of the National School Vulnerability Index (IVE-SINAE) to include SES of the school. In the first stage, schools teaching secondary education were stratified, and a random selection made within each stratum. Then, classrooms of second degree of secondary school were selected using Kish table.

Our selected sample was composed of 221 educational establishments. Asking for institutional consent, we received a rejection rate of $13.6 \%$ resulting in a final sample of 191 establishments (Table 1).

Fieldwork was carried out during August and September 2013. The estimated student sample was $5,367^{2}$, equating to a response rate of $92.4 \%$. The resulting sample consisted of 4,964 students. The sample size is associated with an observed maximum error of $\pm 1.4 \%$, assuming a maximum variance and a $95 \%$ confidence level. At the regional level, the absolute error is $\pm 2.4 \%$.

In this study, $51 \%$ of participants were men. Most respondents attended schools in the VIII Region (36.2\%), followed by the Metropolitan Region (35.9\%), and finally by the V Region (27.8\%). Most of the sample were voucher schools $(54.1 \%)$ [(Junta Nacional de Auxilio Escolar y Becas (JUNAEB)], while $30.7 \%$ were public schools, and $15.1 \%$ were private schools. Most schools in the sample belonged to the high socio-economic group (46\%), followed by middle-level (33.7\%), and low (20.3\%).

\section{Ethical Considerations}

We followed a two-stage consent process: First, school principals gave their consent for the adolescents participating in our study. Individual informed consent to take part in the research was also collected from the adolescents, along with written consent describing the nature and objective of the study following the ethical code of the Chilean National Commission for Science and Technology. The consent stated that data confidentiality would be assured and participation was voluntary. For the adolescents,

${ }^{2}$ Estimation based on the enrolment of the classrooms surveyed. representatives of each school parents' association were asked to sign a consent form to have their children participate in our study. An information document was sent to each student's parents explaining the research and including a clause allowing them to exclude their child from it. The study was approved by the IRB of the Pontifical Catholic University of Valparaíso.

\section{Measures}

Differencing school social wellbeing and students' subjective wellbeing is an important element of this research. Whereas subjective wellbeing focuses on individual experience, school wellbeing looks at the work of a school as a system. Subjective well-being refers to a person's cognitive and affective evaluations of his or her life, including both emotional reactions as well as cognitive judgments of satisfaction (Diener et al., 2002: 63). Similarly, child subjective wellbeing should be understood as an individual conviction of a young person about the degree of accomplishment of his/her living needs, approached regarding satisfaction, happiness, fears and apprehensions (Strózik et al., 2016). Subjective wellbeing is composed of both an emotional and cognitive dimension. While emotional wellbeing involves an excess of positive over negative feelings, personal psychological functioning involves the presence of more positive than negatively perceived self-attributes (Keyes, 1998: 122). On the other hand, School social wellbeing is an adaptation of the construct of social wellbeing (Keyes, 1998) to school settings. Social wellbeing highlights the role that social life and social roles play in the constitution of self and represents a more eudemonic measure of wellbeing. School social wellbeing is a measure of the social health of the school, as perceived by individual students. It is more linked to the "community level" in school climate research (Wang and Degol, 2016), in the way it relates to an appraisal of a system of relationships taking place in the school, considering dimensions associated with integration, acceptance, and contribution.

The following measures were used:

\section{Subjective Wellbeing}

Personal wellbeing index (Casas and Bello, 2012)

The Personal wellbeing index (PWI) was designed by Cummins et al. (2003). It initially included seven items related to satisfaction with different areas of life: health, the standard of living, achievements, safety, belonging groups, future security, and interpersonal relationships. It later incorporated school children's

TABLE 1 | Sample distribution by socio-economic status, administrative dependency, and region.

\begin{tabular}{|c|c|c|c|c|c|c|c|c|c|c|}
\hline \multirow[t]{3}{*}{ Sample } & \multicolumn{9}{|c|}{ Socio-economic status } & \multirow[b]{3}{*}{ Total } \\
\hline & \multicolumn{3}{|c|}{ High } & \multicolumn{3}{|c|}{ Medium } & \multicolumn{3}{|c|}{ Low } & \\
\hline & $\mathbf{v}$ & VIII & $\mathbf{R M}$ & $\mathbf{v}$ & VIII & RM & v & VIII & RM & \\
\hline Private & 13 & 11 & 13 & 0 & 0 & 0 & 0 & 0 & 0 & 37 \\
\hline Voucher & 13 & 15 & 13 & 13 & 12 & 10 & 4 & 5 & 11 & 96 \\
\hline Public & 0 & 1 & 7 & 6 & 11 & 6 & 8 & 12 & 7 & 58 \\
\hline Total & 26 & 27 & 33 & 19 & 23 & 16 & 12 & 17 & 18 & 191 \\
\hline
\end{tabular}


satisfaction with their situation, and with school life. This nineitem Likert scale, with a response range of 0 ("totally unsatisfied") to 10 ("fully satisfied"), has shown a good performance in adolescents (12 years old and older). The results of this scale in Chile were satisfactory, with an alpha for the total scale of 0.83 , forming a single factor that explains $44.5 \%$ of the variance (Bilbao et al., 2016). In our sample, factor analysis confirms the configuration of a single factor, with $\alpha=0.81$ for the nine items. For the construction of this index, the raw scores of the items were added.

\section{Brief multidimensional students' life satisfaction scale - BMSLSS - (Seligson et al., 2003)}

This brief scale assesses six areas of satisfaction: family life, friends, school experience, the students themselves, the place where the student live, and overall satisfaction with life. The responses ranges of items range from 1 ("very unsatisfied") to 7 ("very satisfied"). The scale showed a single factor with a reliability of $\alpha=0.80$. Raw scores were added to create the additive scale.

\section{Positive and negative affect schedule (Watson et al., 1988)}

This scale consists of 20 items measuring the occurrence of specific kinds of affect over the previous month. It is divided into two dimensions of ten items each, focusing on positive emotions (e.g., attentive, interested, proud), and on negative emotions (e.g., fearful, irritable, concerned). Items are on a 5-category Likert scale (where: $1=$ "nothing or very slightly" and $5=$ "extremely"). The reliability was $\alpha=0.80$ for the total scale, with a factorial structure for Negative $(\alpha=0.81)$ and Positive Affectivity $(\alpha=0.83)$. For the construction of these indices, the raw scores of the items were added and then averaged. After this, the "Balance of Affects" index was constructed, by subtracting the sum of the items showing Negative Affectivity from those showing Positive Affectivity.

\section{School Social Wellbeing}

To measure social wellbeing in school settings, we adapted Keyes' Social Wellbeing Scale (1998). The original scale seeks to know individuals' perceptions of the functioning of society, and their role in it. To estimate the level of wellbeing placed in a student context, the word "society" was changed to "school" and the language culturally adapted following expert advice and previous research experience. The scale showed a good psychometric behavior in school settings, with an $\alpha$ for the total scale of 0.88 , and concurrent validity with other instruments that evaluated complementary constructs such as classroom climate and school climate. Confirmatory factor analysis with primary school students presented an adequate structure with three dimensions: "Social Integration," "Social Acceptance," and "Social Contribution" (CFI $=0.93$; RMSEA $=0.046)$. The adaptation for adults, presented an adequate structure of the five dimensions, adding "Social cohesion" and "Social updating" (CFI $=0.91$; RMSEA $=0.075)$.

\section{School Climate}

The school climate scale [Benbenishty and Astor, 2005, adapted and validated by López et al. (2014)], measures three dimensions: "norms," "participation," and "teachers' support," showing good behavior in different school populations $(\alpha=0.87)$. Items range from 1 ("strongly disagree") to 5 ("strongly agree"). Confirmatory factor analysis showed a three-dimensional structure $(\mathrm{CFI}=0.946$; $\mathrm{RMSEA}=0.049)$ indicating a good fit of the model to the general population. For the construction of the indices, the raw scores of the items were added and were then averaged.

\section{Students' Perception of Teachers' Wellbeing}

This scale is an ad hoc measure constructed by the recommendation of expert judges who assessed the instruments used in this research. A brief scale was built on students' perceptions of teachers' wellbeing and welfare. This scale consists of five questions: "My teachers treat us well," "My teachers like their work," "My teachers are happy in this school," "The teachers of this school treat each other well," and "The teachers of this school have good working conditions." The reliability analysis showed good performance, with a single factor and $\alpha=0.82$. The response range of the items ranges from 1 ("strongly disagree") to 5 ("strongly agree"). For the construction of these indices, the raw scores of the items were added and then averaged.

\section{Student Achievement and Performance}

For the purposes of this research, achievement is understood as the probability of passing a class, as well as a general attendance to school. The main objective of this construct is to measure actual engagement with the school, reducing the probability of dropping out. A low achievement would lead to dropout (low probability of passing and low attendance). Performance is associated with the level of learning or success at school, and therefore is measured through a function of the grade point average (GPA). Low performance would lead to failing a class, or to mediocre educational outputs.

Student achievement was operationalized as the probability of course passing, estimated as (a) the student's 5-year pass rate for the 2008-2012 period, and (b) student attendance, operationalized as the average student attendance in the 5-year period 2008-2012.

Student performance was defined as the grades obtained by a student in his school during the 5-year period 2008-2012.

Data for both variables was obtained from the school performance datasets of the Ministry of Education for the period 2008-2012 per each participant individual.

To create these variables, we merged the public datasets from the National Student Registry, with the database of primary sources collected in this study. The identity of the participants was recorded using the National Identity Number. Data linkage was carried out by Ministry of Education officers in charge of managing the National Student Registry. The Ministry uses a system called MRUN system ${ }^{3}$, which consists of an algorithm that hides the identity of individuals but allows them to be internally identified by creating a different MRUN for each national identity number, which does not alter over time.

\footnotetext{
${ }^{3}$ Mask of the Unique Birth Registry number, Rol Único de Nacimiento, in Spanish.
} 
Students' performance was operationalized as a general academic score, measured through the yearly average marks obtained per student. The 5-year averages of this variable (2008-2012) were used to create a variable called "average grade estimation" using a linear model (OLS). This variable is defined for analytical purposes as "expected academic performance." This procedure provided information for a total of 1,723 total cases, with 296 cases excluded.

\section{Socio-Economic Measures: School Vulnerability Index}

To measure SES of the school, we used the School Vulnerability Index (IVE by its Spanish initials). IVE is an index created by the Government of Chile to measure the degree of socioeconomic vulnerability of students attending publicly funded schools, whether public or voucher. It is the official instrument for the assignation of school benefits across the country.

The IVE considers the children's family's socio-economic level, the educational level of the parents-tutors, the health condition of the student, the physical and emotional wellbeing of the student (using standardized tests) and the location of the school (urban or rural). On this basis, the IVE ranks schools according to how many of their students present a condition requiring special treatment and extra funding. IVE scores range from 0 to 100. Private schools are not included in the IVE scores; in these cases a value of 0 was assigned. IVE is updated yearly and classifies schools by the percentage of vulnerable children attended, which makes it a more sensitive measure than those based on averages.

Schools were classified as high (IVE $<10$ ), mid $(10>$ IVE $<60)$ or low $(60<$ IVE) SES. These variables were coded as high $=1$, mid $=2$, and low $=3$. All students inside a school share the same IVE.

Wang and Degol report that findings associated with SES at the school level are consistent, generally indicating that students attending schools with lower proportions of low SES children demonstrate not only higher levels of achievement but also greater growth in achievement over time (2006: 328). Therefore, a measure related to the proportion of vulnerable children attending the same school seems to be an adequate measure of the role of SES in achievement.

\section{Design and Analyses Imputation of Missing Cases}

To increase the number of cases for the variable "average grade estimation," a model of imputation of missing cases was used through linear regression estimation (OLS) for the averages. The estimation protocol was based on the following conditions: (i) cases to be imputed cannot have more than two missing values; therefore, all cases with more than two missing values were not estimated; (ii) the imputation model is MCO with at least three adjacent values, and (iii) imputation of the central value was replaced by the average of the available values.

This procedure allowed the recovery of a total of 223 records, leaving 73 cases without value in the dependent variable. The total sample is 1,946 cases.

\section{Data Analysis}

Correlations, analysis of variance and structural equation models were used. Correlations were used to determine the degree of association that the different scales have among them. The analyses of variance allowed us to verify the existence of statistically significant differences between means of different groups. This analysis is relevant when using a stratified sample, which is composed of different groups, to determine whether there are significant differences in the results of the same variable.

SEM modeling consists of a hypothesis test to estimate the potential interrelationships between different constructs based on a theoretical model, as well as their indicators and measurement levels. The following indexes and values of goodness of fit were considered: Square Chi (Chi-Square), Comparative Fit Index $(\mathrm{CFI})>0.91$; Root Mean Square Error of Approximation (RMSEA) < 0.05 (Byrne, 2009).

Analysis was done at individual level, with only SES measured at school level and used as a fixed variable for all students under the same school. All variables, except for SES are measured by student ratings.

Analysis was performed using SPSS Statistics 20 and SPSS Amos V.21.

\section{RESULTS}

\section{Descriptive and Correlational Analyses}

The descriptive analysis shows few differences between the total and the matched sample. From here onward we will make us of the latter for the multivariate analysis (Tables 2, 3).

All the values in the matched sample are in the expected range for the full sample, according to the minimum and maximum values. In Table 3, the probability of passing, attendance percentage, and performance estimation were included. The probability of passing is calculated on a percentage scale, with a mean of 0.96 , showing high probabilities of passing. The same applies with attendance percentage $(M=92.80)$. Performance estimation was calculated according to the grade average of students in the Chilean scale (1-7), showing a mean of 5.69 .

The correlational analysis shows that most variables show significant association. Nonetheless, school climate does not show a significant association with the performance estimation, nor with the probability of passing.

The strongest association is between PWI and BMSLSS. This is to be expected, considering that both are subjective wellbeing measures (Table 4).

\section{Analysis of Variance and Mediational Analyses \\ Academic Achievement}

Testing the hypothesis about a relationship between subjective wellbeing and academic achievement began with the dichotomization in high and low subjective wellbeing (based on the mean of the BMSLSS), to assess the existence of significant differences between these groups. A mean difference test shows 
TABLE 2 | Descriptive statistics full sample.

\begin{tabular}{|c|c|c|c|c|c|}
\hline & $N$ & Min. & Max. & Mean & Std. Dev. \\
\hline Age & 4620 & 14 & 27 & 15.6 & 0.78 \\
\hline Personal wellbeing index (averages) & 4725 & 0.33 & 10 & 7.72 & 1.36 \\
\hline Brief Multidimensional students' life satisfaction scale (averages) & 4822 & 1 & 7 & 5.58 & 1.01 \\
\hline School social wellbeing (averages) & 4597 & 1 & 5 & 3.53 & 0.61 \\
\hline School climate (averages) & 4610 & 1 & 5 & 3.45 & 0.71 \\
\hline Perception of teachers' wellbeing (averages) & 4867 & 1 & 5 & 3.81 & 0.7 \\
\hline Positive and negative affect schedule-positive affects (averages) & 4654 & 1 & 5 & 3.30 & 0.76 \\
\hline Positive and negative affect schedule-negative affects (averages) & 4572 & 1 & 5 & 2.47 & 0.77 \\
\hline Positive and negative affect schedule-balance of affects (averages) & 4472 & -3 & 3.7 & 0.83 & 1.04 \\
\hline
\end{tabular}

TABLE 3 | Descriptive statistics matched sample.

\begin{tabular}{|c|c|c|c|c|c|}
\hline & $N$ & Min. & Max. & Mean & Std. Dev. \\
\hline Age & 1930 & 14 & 20 & 15.58 & 0.74 \\
\hline Probability of passing & 1968 & 0.33 & 1 & 0.96 & 0.1 \\
\hline Attendance percentage & 1968 & 44 & 100 & 92.80 & 5.06 \\
\hline Performance estimation & 1946 & 3.86 & 7 & 5.69 & 0.588 \\
\hline Personal wellbeing index (averages) & 1939 & 1.11 & 10 & 7.73 & 1.35 \\
\hline Brief multidimensional students' life satisfaction scale (averages) & 1972 & 1 & 7 & 5.55 & 1.02 \\
\hline School social wellbeing (averages) & 1875 & 1.35 & 5 & 3.57 & 0.61 \\
\hline School climate (averages) & 1895 & 1 & 5 & 3.53 & 0.69 \\
\hline Perception of teachers' wellbeing (averages) & 1997 & 1 & 5 & 3.88 & 0.67 \\
\hline Positive and negative affect schedule-positive affects (averages) & 1920 & 1 & 5 & 3.35 & 0.74 \\
\hline Positive and negative affect schedule-negative affects (averages) & 1890 & 1 & 5 & 2.54 & 0.77 \\
\hline Positive and negative affect schedule-balance of affects (averages) & 1848 & -3 & 3.6 & 0.81 & 1.06 \\
\hline
\end{tabular}

TABLE 4 | Correlations ( $N=1968)$.

\begin{tabular}{|c|c|c|c|c|c|c|c|c|c|c|c|}
\hline & 1 & 2 & 3 & 4 & 5 & 6 & 7 & 8 & 9 & 10 & 11 \\
\hline (1) Performance estimation & - & & & & & & & & & & \\
\hline (2) Probability of passing & $0.42^{* *}$ & - & & & & & & & & & \\
\hline (3) Attendance percentage & $0.28 * *$ & $0.31 * *$ & - & & & & & & & & \\
\hline (4) Personal Wellbeing Index & $0.07^{* *}$ & $0.06^{* *}$ & $0.09 * *$ & - & & & & & & & \\
\hline $\begin{array}{l}\text { (5) Brief Multidimensional } \\
\text { students' life satisfaction scale }\end{array}$ & $0.05^{*}$ & $0.05^{*}$ & $0.08^{* *}$ & $0.68 * *$ & - & & & & & & \\
\hline (6) School social wellbeing & $0.14^{* *}$ & $0.09 * *$ & $0.09 * *$ & $0.40^{* *}$ & $0.46^{* *}$ & - & & & & & \\
\hline (7) School Climate & 0.042 & 0.045 & $0.09 * *$ & $0.35^{* *}$ & $0.39^{* *}$ & $0.62 * *$ & - & & & & \\
\hline (8) Perc. teachers' wellbeing & $0.09 * *$ & $0.09 * *$ & $0.13^{* *}$ & $0.29 * *$ & $0.32^{* *}$ & $0.49^{* *}$ & $0.67^{* *}$ & - & & & \\
\hline $\begin{array}{l}\text { (9) Positive and negative affect } \\
\text { schedule-positive affects }\end{array}$ & $0.05^{*}$ & -0.009 & 0.039 & $0.38^{* *}$ & $0.37^{* *}$ & $0.25^{* *}$ & $0.22^{* *}$ & $0.18^{* *}$ & - & & \\
\hline $\begin{array}{l}\text { (10) Positive and negative affect } \\
\text { schedule-negative affects }\end{array}$ & $-0.06^{* *}$ & $-0.09 * *$ & -0.038 & $-0.28^{* *}$ & $-0.32^{* *}$ & $-0.18^{* *}$ & $-0.10^{* *}$ & $-0.07^{* *}$ & 0.020 & - & \\
\hline $\begin{array}{l}\text { (11) Positive and negative affect } \\
\text { schedule-balance of affects }\end{array}$ & $0.08^{* *}$ & $0.06^{* *}$ & $0.06^{* *}$ & $0.47^{* *}$ & $0.48^{* *}$ & $0.31^{* *}$ & $0.23^{* *}$ & $0.17^{* *}$ & $0.69 * *$ & $-0.71^{* *}$ & - \\
\hline
\end{tabular}

$* p<0.05, * * p<0.01$.

that students with high levels of subjective wellbeing attend $(t=-2.395, p=0.017)$ and pass $(t=-2.749, p=0.006)$ significantly more than students with low levels.

For SEM analyses, the first step was to test subjective wellbeing as a predictor of academic achievement. We estimated a latent individual wellbeing variable expressed through the balance of affects (PANAS, PWI, and BMSLSS). This direct model shows that individual wellbeing predicts student achievement (0.15), controlling for the effect of SES. This model (Figure 1) shows a proper fit $(\mathrm{RMSEA}=0.059, \mathrm{CFI}=0.969)$.

Our second step was to assess the predicting values of school-related evaluations on student achievement. We tested these association in model 2 (Figure 2), which shows a proper fit $($ RMSEA $=0.057$, CFI $=0.983)$. Perceptions of teachers' wellbeing presents the higher coefficient $(0,16)$, while school climate presents a negative association $(-0,01)$. There are 


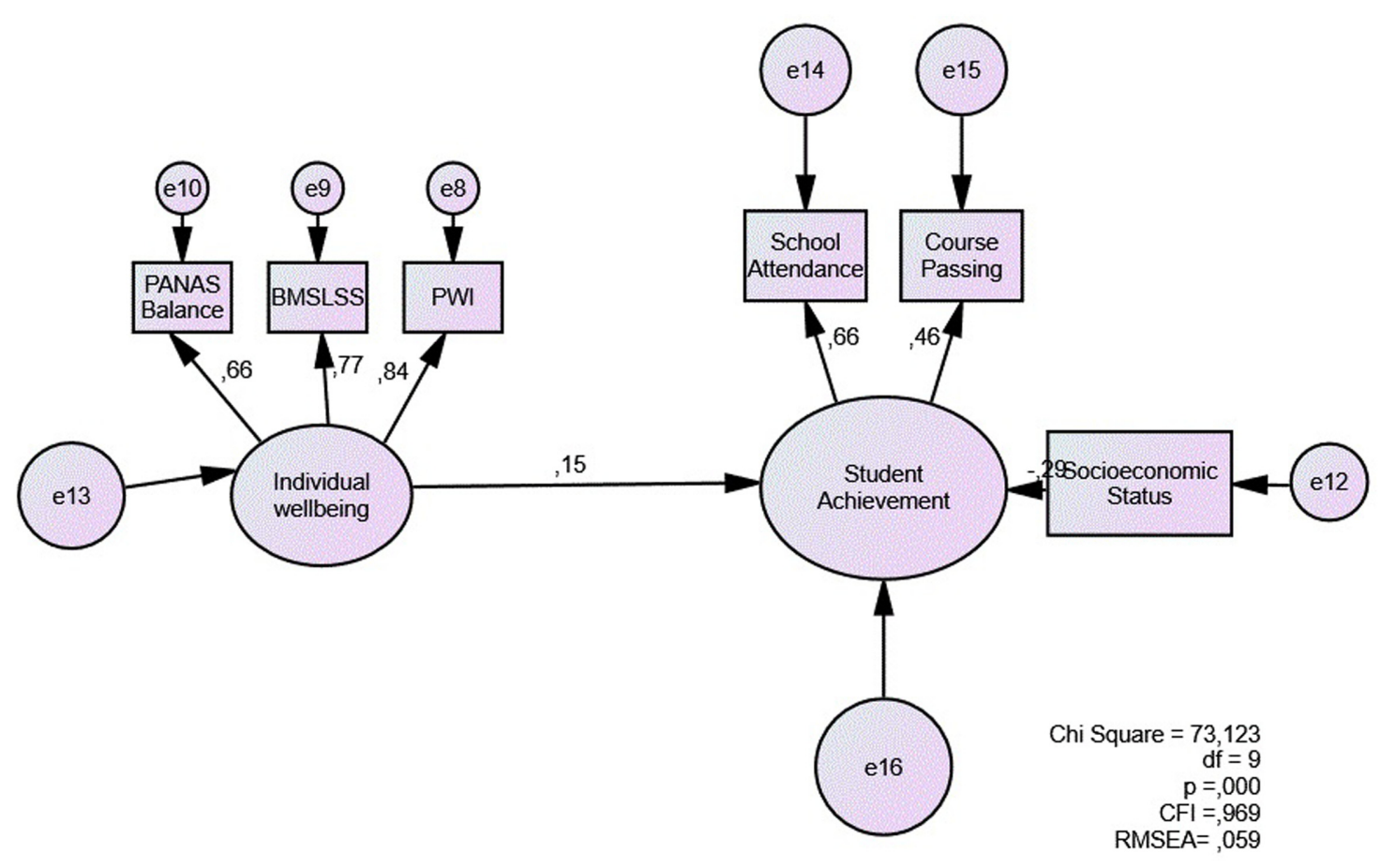

FIGURE 1 | Direct model of subjective wellbeing as a predictor of student achievement.

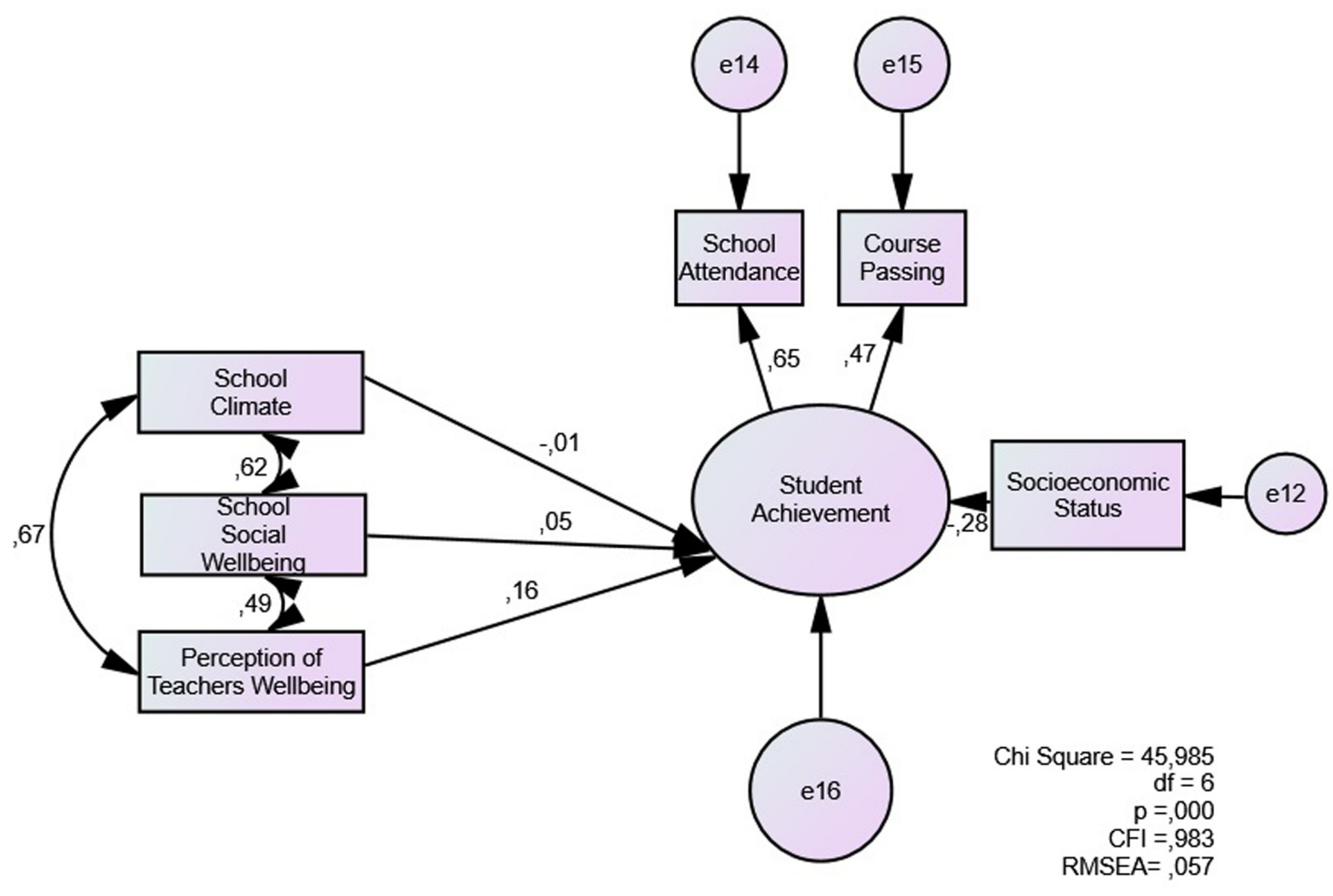

FIGURE 2 | Direct model of school-related evaluations as predictors of student achievement. 


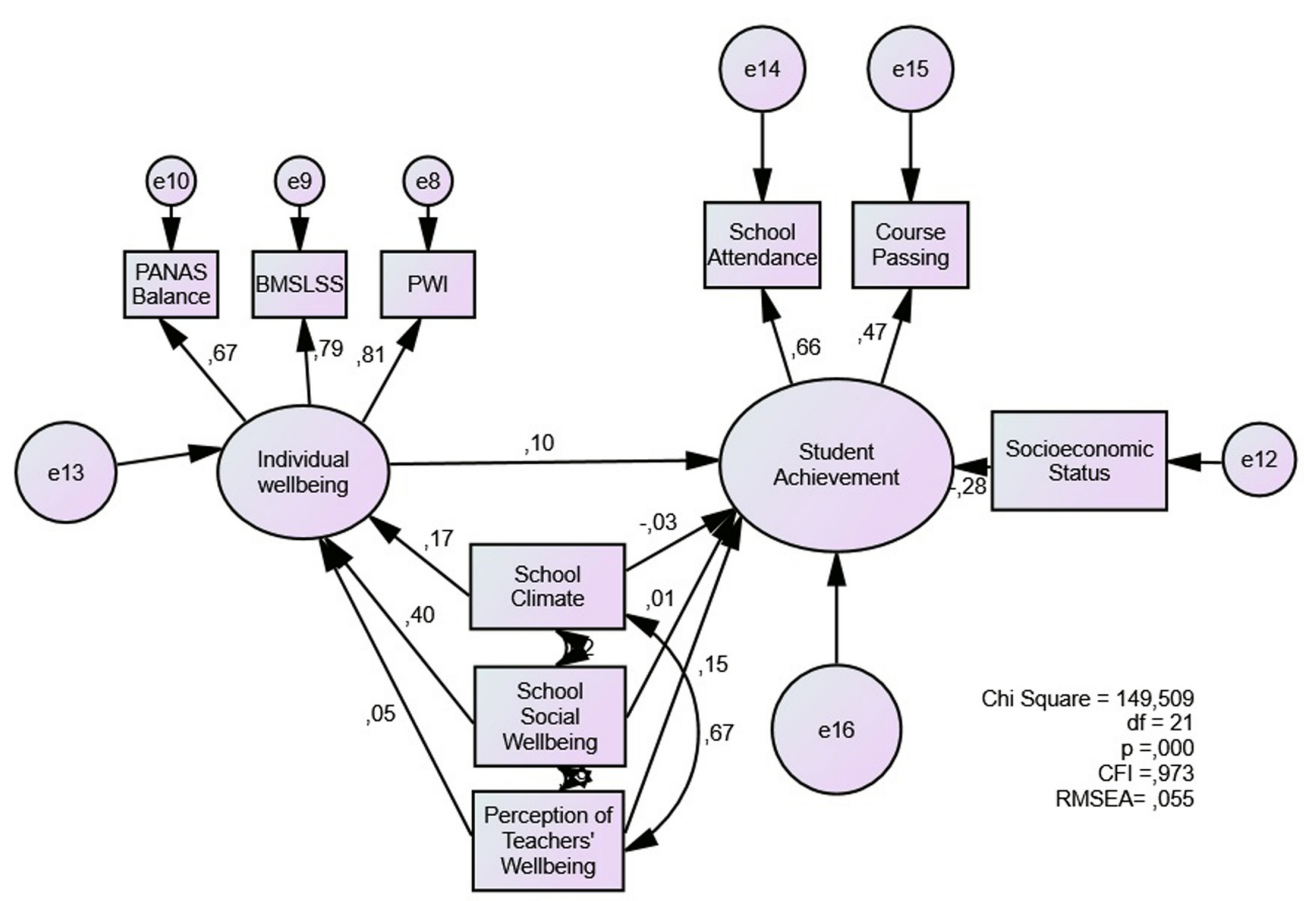

FIGURE 3 | Individual subjective wellbeing as a mediator of the association between school-related evaluations and student achievement.

high correlations between school climate and the other two concepts.

In Model 3 (Figure 3), we included individual subjective wellbeing as a mediating variable. The model shows an adequate fit $(\mathrm{RMSEA}=0.055$; CFI $=0.973)$. Individual wellbeing has a coefficient of (0.10), while the coefficients of the three schoolrelated evaluations are reduced, with school social wellbeing showing the biggest decrease. Mediation significance was determined by using Sobel test (Sobel, 1982; MacKinnon et al., 2002), the results show significant mediation for both school climate and school social wellbeing. Teachers' perception of wellbeing shows a direct association not mediated by individual wellbeing (Table 5).

\section{Academic Performance}

With academic performance as an outcome variable, the coefficient shown by individual wellbeing is lower than the one presented in Model 1 with student achievement (0.08) (Figure 4). Model fit is adequate (RMSEA $=0.076$; CFI $=0.964)$.

The next step was test the role of school-related evaluations on school performance (Figure 5). School social wellbeing shows the highest direct association with performance $(0,13)$, while school climate shows a negative association. School climate shows high correlations with the other two predictors. This step improved the model fit $(\mathrm{RMSEA}=0.079$; CFI $=0.984)$.

Model 6 (Figure 6) presents the results for the full model of student performance, including individual wellbeing as a mediating variable. Individual wellbeing shows a small predicting value $(0,03)$, while school social wellbeing has a higher direct association with performance (0.11). Model fit is acceptable $(\mathrm{CFI}=0.971, \mathrm{RMSEA}=0.066) . \mathrm{We}$ found no mediating role of individual wellbeing for the prediction of student performance (Table 6).

The results show that individual wellbeing has a direct effect on school performance: when subjective wellbeing increases

TABLE 5 | Mediation effects on achievement $(N=2019)$.

\begin{tabular}{|c|c|c|c|c|c|c|}
\hline \multirow[t]{2}{*}{ Variable } & \multicolumn{3}{|c|}{ Direct effects } & \multirow{2}{*}{$\begin{array}{l}\text { Indirect effect } \\
\beta 1 \times \beta 2 \text { (SE) }\end{array}$} & \multirow{2}{*}{$\begin{array}{l}P \text {-value for mediation } \\
\qquad p=z 1 \times z 2\end{array}$} & \multirow[b]{2}{*}{ Association type } \\
\hline & $\beta 1$ (SE) & $\beta 2$ (SE) & $\beta 3$ (SE) & & & \\
\hline School social wellbeing & $0,505(0,037)^{*}$ & $0,442(0,186)^{*}$ & $0,062(0,245)$ & $0,223(0,095)^{*}$ & 0,019 & Mediated \\
\hline School climate & $0,189(0,038)^{*}$ & $0,442(0,186)^{*}$ & $-0,141(0,235)$ & $0,084(0,039)^{*}$ & 0,032 & Mediated \\
\hline $\begin{array}{l}\text { Teacher's wellbeing } \\
\text { perception }\end{array}$ & $0,056(0,035)$ & $0,442(0,186)^{*}$ & $0,757(0,214)^{*}$ & $0,025(0,019)$ & 0,184 & $\begin{array}{l}\text { Significant but } \\
\text { disconnected association }\end{array}$ \\
\hline
\end{tabular}

${ }^{*} p<0.05$. 
TABLE 6 | Mediation effects on performance $(N=2019)$.

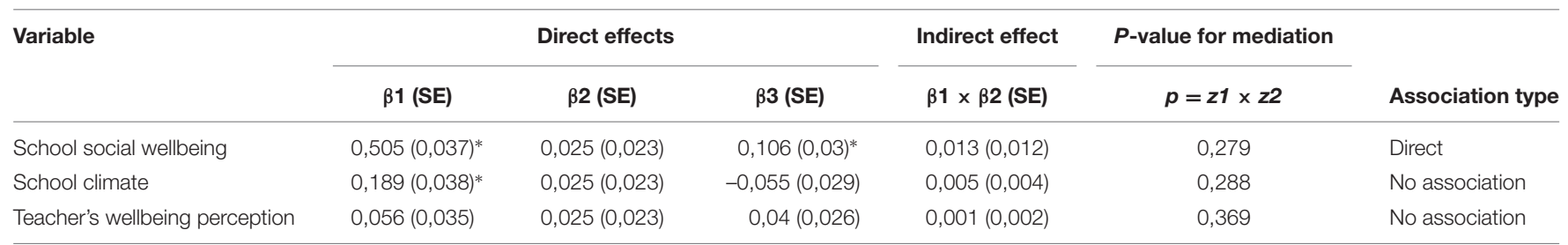

${ }^{*} p<0.05$.
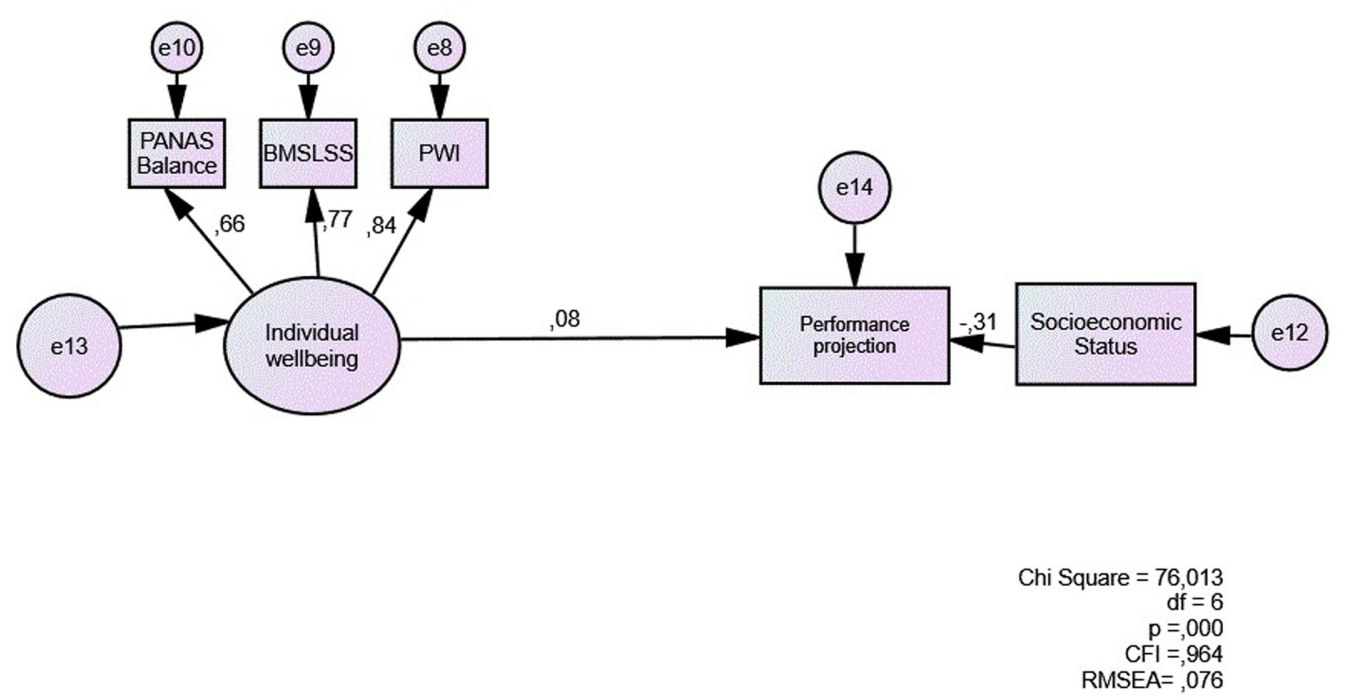

FIGURE 4 | Direct model of subjective wellbeing as a predictor of student academic performance.
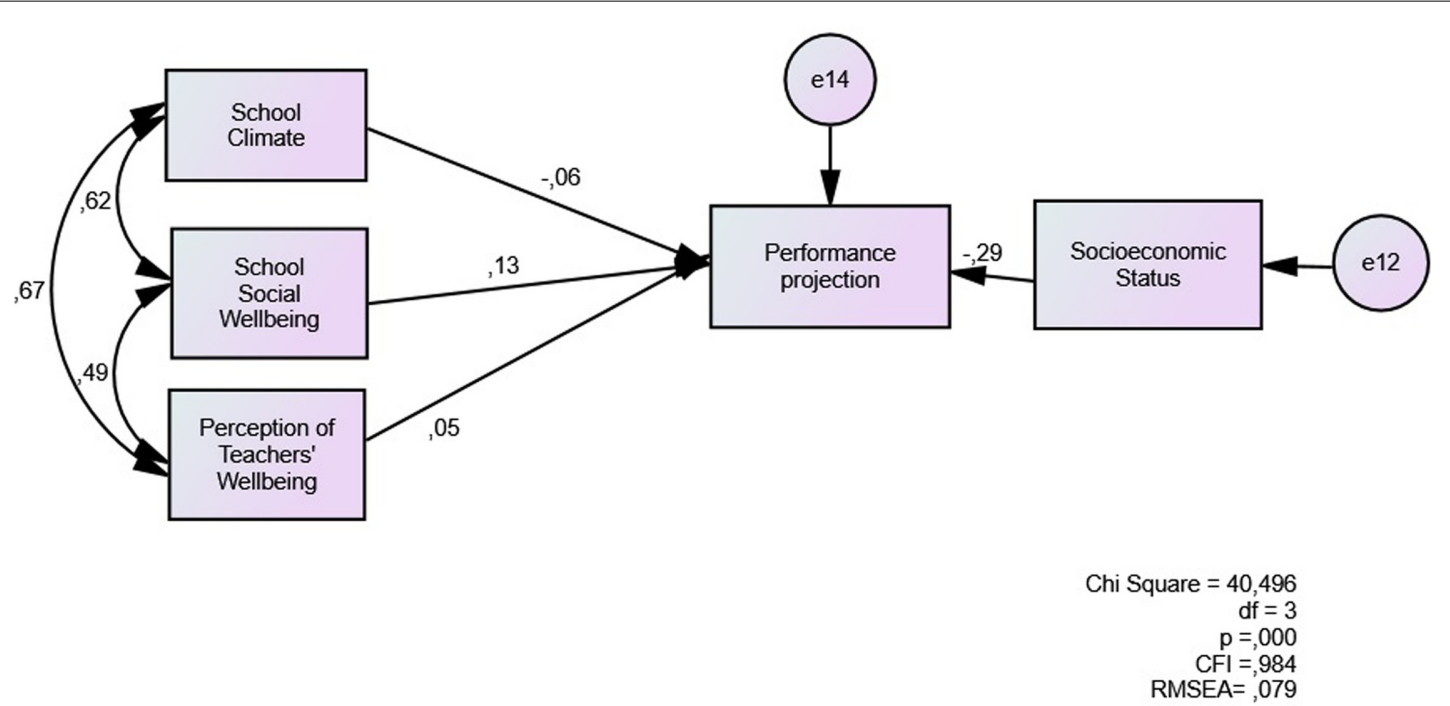

FIGURE 5 | Direct model of school-related evaluations as predictors of student academic performance.

a standard deviation, achievement measured in attendance and approval of the school year contributes 0.10 standard deviation. This relation is obtained by controlling the already known effect of SES of schools. On the other hand, when subjective wellbeing increases by one standard deviation, academic performance rises by 0.08 standard deviation. It also 


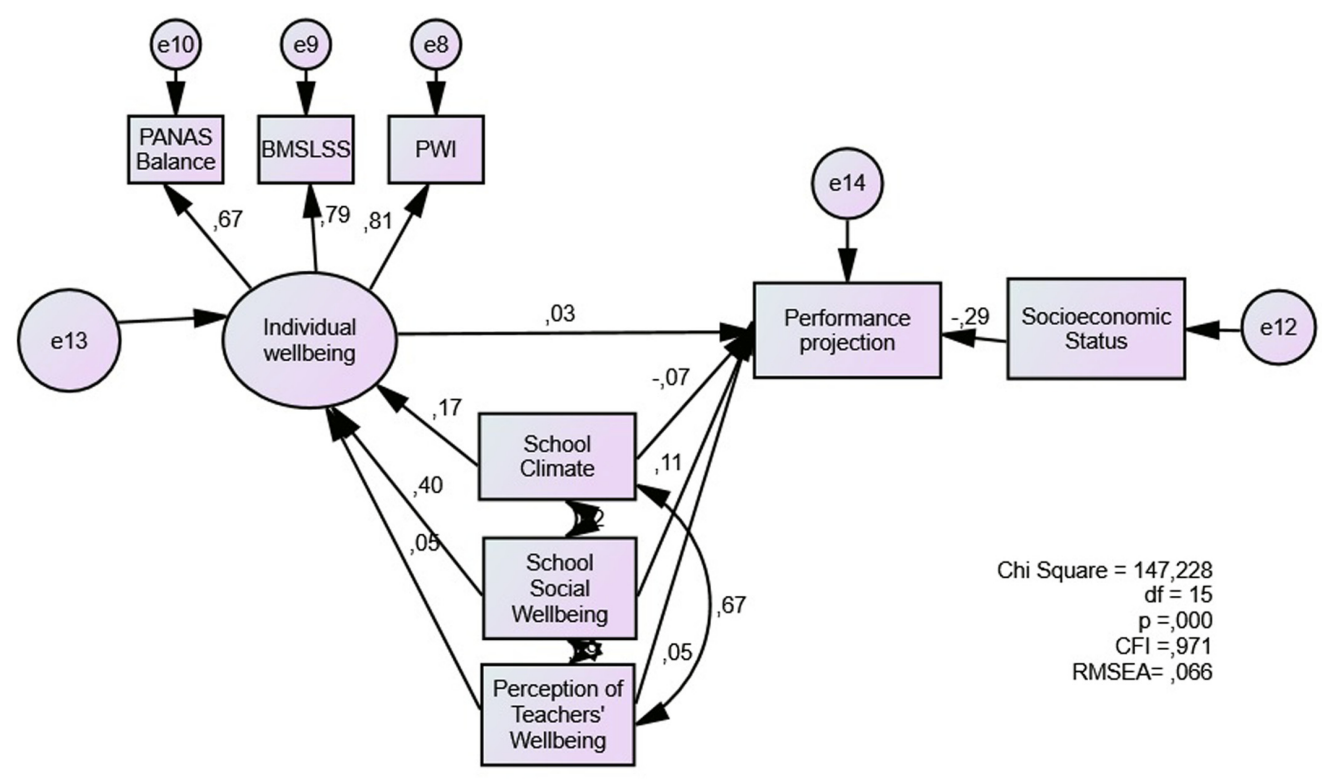

FIGURE 6 | Individual subjective wellbeing as a mediator of the association between school-related evaluations and student academic performance.

mediates the relationship between school social wellbeing and school climate with students' achievement. In the full model specification, perception of teachers' wellbeing presents a direct association with achievement, while school social wellbeing does the same with performance.

\section{DISCUSSION}

This study aimed to determine the relationship between high school students' individual wellbeing, school-related evaluations, academic achievement, and school performance. Findings support our initial hypotheses of positive associations between wellbeing measures and academic achievement and performance. Findings provide partial support for the mediating hypothesis of individual wellbeing on school-related evaluations. We found evidence for a partial mediation of individual wellbeing on the association between school social wellbeing and school climate with the outcome variables of school achievement.

Models reveal that the multidimensional scales of individual wellbeing allow the identification of effects of subjective wellbeing on academic achievement and student performance. The PWI and BMSLSS scales are theoretically complementary and increase the fit of the model for the determination of subjective wellbeing. Together with PANAS, they provide a global vision of individual subjective wellbeing.

The models also highlight the predicting role of evaluations made by children about the school on academic achievement and performance. These results support the results previously reported in the literature, although it is important to highlight the high correlation between the concepts school social wellbeing and school climate. This high association is a relevant point considering that school climate is a still a broad conceptual umbrella for several processes occurring in schools, whereas school social wellbeing represents a defined and clear concept rooted in the eudemonic tradition of wellbeing.

Individual wellbeing affects the relationship between school social wellbeing and school climate with the outcome variables of school achievement, meaning that both evaluations of school culture are mediated by the life outlook of adolescents. These variables are socio-affective variables embedded in the school context (Benbenishty and Astor, 2005; Espelage and Swearer, 2010), but are not regularly analyzed from the perspective of children and their general concerns. According to Casas et al. (2013), there is no other more direct and valid method to assess children's perspectives than turning directly to them. Children are key informants of their lives and relevant agents in providing data on the realities they experience. As we can see from our results, their individual wellbeing affects the way they experience school and how this experience translates into achievement.

Of course, our findings also highlight the role of schoolrelated evaluations which are not related to individual wellbeing: perceptions of teachers' wellbeing have a direct association with achievement, meaning that the dyadic relationship between teacher and student can have a greater influence than individual general concerns for student achievement. Regarding the estimation of academic performance, school social wellbeing is the best predictor, not being mediated by individual wellbeing.

Finally, SES is a relevant variable for the prediction of educational achievement and performance, confirming what has already been widely described in the Latin American literature (UNESCO, 2008, 2016; Valenzuela et al., 2014).

We have tested hypotheses regarding the direct effect of individual wellbeing on academic achievement and its mediating 
role on school-related evaluations. These results allow us to say with high confidence that individual wellbeing is a component that increases the probability of attending school and passing grades, as well as obtaining higher marks. Therefore, it is a protective factor, reducing the probability of dropout and school delay in adolescents.

However, further analyses of this relationship are needed to understand which underlying mechanisms, at the individual and collective level, would explain this influence on achievement and performance. We propose that improvement can be fomented through the promotion of positive mental health of the school community, without forgetting the role of individuals. Improving schools involves a healthy school environment with a high perception of school social wellbeing, fostering and supporting teacher-student relationships as well as boosting both students' and teachers' individual wellbeing (Wubbels, 2011; Wubbels et al., 2015).

\section{ETHICS STATEMENT}

This study was carried out in accordance with the recommendations of the National Commission of Science and Technology of Chile with written informed consent from all subjects. All subjects gave written informed consent in accordance with the Declaration of Helsinki. The protocol was approved by the ethics committee of Pontificia Universidad Católica de Valparaíso.

\section{REFERENCES}

Adelman, H. S., and Taylor, L. (1997). Addressing barriers to learning: beyond school-linked services and full service schools. Am. J. Orthopsychiat. 67, 408-442. doi: 10.1037/h0080243

Aguirre, M., Adasme, A., and Candia, C. (2009). Deserción escolar en Chile. Estudios de Economía Regional 2, 3-6.

Allen, J. P., Gregory, A., Mikami, A., Lun, J., Hamre, B., and Pianta, R. (2013). Observations of effective teacher-student interactions in secondary school classrooms: predicting student achievement with the classroom assessment scoring system-secondary. Schl. Psychol. Rev. 42, 76-98.

Ascorra, P., Arias, H., and Graff, C. (2003). La escuela como contexto de contención social y afectiva. Rev. Enfoques Educ. 5, 117-135.

Ascorra, P., and Crespo, N. (2004). La incidencia del rol docente en el desarrollo del conocimiento metacomprensivo. Psicoperspectivas 3, 23-32.

Assael, J., and Neumann, E. (1991). Clima Emocional del Aula. Santiago: PIIE.

Astor, R. A., Rosemond, M., Pitner, R. O., Marachi, R., and Benenishty, R. (2006). "An overview of best violence prevention practices in schools," in The School Services Sourcebook, eds C. Franklin, M. B. Harris, and P. A. Meares (New York, NY: Oxford University Press), 143-168.

Bassi, M., Busso M., and Muñoz, J. S. (2013). Is the glass half empty or half full? School enrollment, graduation, and dropout rates in Latin America. IDB Working Paper Series No. IDB-WP-462. Available at: http://ssrn.com/abstract= 2367706

Benbenishty, R., and Astor, R. A. (2005). School Violence in Context: Culture, Neighborhood, Family, School, and Gender. New York, NY: Oxford Press. doi: 10.1093/acprof:oso/9780195157802.001.0001

Bilbao, M., Torres-Vallejos, J., Ascorra, P., López, V., Páez, D., Oyanedel, J. C., et al. (2016). Propiedades psicométricas de la escala Índice de Bienestar Personal (PWI-SC) en adolescentes chilenos. Salud Soc. 7, 168-178. doi: 10.22199/ S07187475.2016.0002.00003

\section{AUTHOR CONTRIBUTIONS}

VL co-lead the research, drafted the first version of the manuscript and reviewed the final one. JO co-lead the research, ran the analyses and drafted the second version of the manuscript. $\mathrm{MB}$ directed the original research project, conducted a literature review, and commented on an earlier version of the manuscript. JT improved the literature review. DO and MM provided research assistance. PA and CC commented on an earlier version of the manuscript.

\section{FUNDING}

Funding was obtained from FONIDE grant 11242 from Ministerio de Educación de Chile, grant 1140960 from Fondo Nacional de Desarrollo Científico y Tecnológico (FONDECYT), and grants PIA CONICYT CIE160009 and PAI781403013 from the Chilean National Comission of Science and Technology (Comisión Nacional de Ciencia y Tecnología, CONICYT).

\section{ACKNOWLEDGMENTS}

The authors wish to thank the expert judges of FONIDE grant 114241, especially Dr. María Isidora Mena, for their suggestions on assessing students' perceptions of teacher's wellbeing at school. We also want to thank Ariela Parra and Ian Hearnden for English language editing of the final version of this article.

Blanco, A., and Valera, S. (2007). "Los fundamentos de la intervención psicosocial," in Intervención Psicosocial, Coord, eds A. Blanco and J. Rodríguez Marín (Madrid: Pearson), 1-59.

Bronfenbrenner, U. (1987). Ecología del Desarrollo Humano. Barcelona: Paidós.

Bronfenbrenner, U., and Morris, P. (2006). "The bioecological model of human development," in Handbook of child psychology, 6th Edn, eds W. Damon and R. Lerner (Hoboken, NJ: John Wiley and Sons), 793-828.

Buelga, S., Musitu, G., Murgui, S., and Pons, J. (2008). Reputation, loneliness, satisfaction with life and aggressive behavior in adolescence. Span. J. Psychol. 11, 192-200. doi: 10.1017/S1138741600004236

Byrne, B. M. (2009). Structural Equation Modeling with AMOS: Basic Concepts, Applications, and Programming. Boca Raton, FL: CRC Press.

Cairns, R. B., Cairns, B. D., and Neckerman, H. J. (1989). Early school dropout: configurations and determinants. Child Dev. 60, 1437-1452. doi: 10.2307/ 1130933

Cárdenas, M., Mejía, C., and Di Maro, V. (2008). Education and life satisfaction: perception or reality? Paper Presented at Understanding Quality of Life in Latin America and the Caribbean: A multidimensional Approach, Organized by the $I A D B$. Washington, DC: IADB.

Casas, F., and Bello, A. (2012). Calidad de Vida y Bienestar Infantil Subjetivo en España ¿Qué afecta al Bienestar de Niños y Niñas Españoles de $1^{\circ}$ de ESO? Madrid: UNICEF.

Casas, F., Bello, A., Gonzalez, M., and Aligue, M. (2013). Children's subjective well-being measured using a composite index: what impacts Spanish firstyear secondary education students' subjective well-being? Child Indic. Res. 6, 433-460. doi: 10.1007/s12187-013-9182-x

CASEN (2013). Resultados Encuesta Casen 2013. Santiago: Ministerio de Desarrollo Social.

CEPAL (2002). Panorama Social de América Latina 2001-2002. New York, NY: CEPAL. 
Cummins, R. A., Eckersley, R., Van Pallant, J., Vugt, J., and Misajon, R. (2003). Developing a national index of subjective wellbeing: the Australian unity wellbeing index. Soc. Indic. Res. 64, 159-190. doi: 10.1023/A:1024704320683

Davis, H. A. (2003). Conceptualising the role and influence of student-teacher relationships on children's social and cognitive development. Educ. Psychol. 38, 207-234. doi: 10.1207/S15326985EP3804_2

Diener, E. (2006). Guidelines for national indicators of subjective wellbeing and ill-being. J. Happiness Stud. 7, 397-404. doi: 10.1007/s10902-006-9000-y

Diener, E., Lucas, R. E., and Oishi, S. (2002). "Subjective well-being: the science of happiness and life satisfaction," in Handbook of Positive Psychology, eds C. R. Snyder and S. J. Lopez (Oxford: Oxford University Press), 63-73.

Diseth, A., Danielsen, A., and Samdal, O. (2012). A path analysis of basic need support, self-efficacy, achievement goals, life satisfaction and academic achievement level among secondary school students. Educ. Psychol. 32, 335-354. doi: 10.1080/01443410.2012.657159

Dwyer, M. (2008). Need for cognition, life satisfaction, and academic achievement. Episteme 3, 12-13. doi: 10.1186/1477-7525-11-46

Dwyer, T., Sallis, J. F., Blizzard, L., Lazarus, R., and Dean, K. (2001). Relation of academic performance to physical activity and fitness in children. Pediatr. Exerc. Sci. 13, 225-238. doi: 10.1123/pes.13.3.225

Espelage, D. L., and Swearer, S. M. (2010). “A social-ecological model for bullying prevention and intervention: understanding the impact of adults in the social ecology of youngsters," in Handbook of Bullying in Schools: An International Perspective, eds S. R. Jimerson, S. M. Swearer, and D. L. Espelage (New York, NY: Routledge), 61-72.

Espinoza, O., Castillo, D., González, L., and Santa Cruz, E. (2011). Deserción y abandono temporal en la Enseñanza Básica de la comuna de Cerro Navia: experiencias de los desertores y percepciones de los estudiantes vulnerables. Akademeia 2, 1-9.

Espinoza, O., Castillo, D., González, L. E., and Loyola, J. (2012). Factores familiares asociados a la deserción escolar en Chile. Rev. Cienc. Soc. 17, 136-150. doi: 10.4067/S0718-07052014000100006

Espinoza-Díaz, O., Castillo-Guajardo, D., González, L. E., Loyola-Campos, J., and Santa Cruz-Grau, E. (2014). Deserción escolar en Chile: un estudio de caso en relación con factores intraescolares. Educ. Educad. 17, 32-50. doi: 10.5294/edu. 2014.17.1.2

Fall, A. M., and Roberts, G. (2012). High school dropouts: interactions between social context, self-perceptions, school engagement, and student dropout. J. Adolesc. 35, 787-798. doi: 10.1016/j.adolescence.2011.11.004

Fan, W., and Wolters, C. (2012). School motivation and high school dropout: the mediating role of educational expectation. Br. J. Educ. Psychol. 84, 22-39. doi: 10.1111/bjep.12002

Ferrante, F. (2002). Education, aspirations and life satisfaction. Kyklos 62, 542-562. doi: 10.1111/j.1467-6435.2009.00450.x

Finn, J. D., and Rock, D. A. (1997). Academic success among students at risk for school failure. J. Appl. Psychol. 82, 221-234. doi: 10.1037/0021-9010.82. 2.221

Fraser, M. W. (1996). Aggressive behavior in childhood and early adolescence: an ecological-developmental perspective on youth violence. Soc. Work 41, 347-361.

Friedberg, R. D. (2015). Where's the Beef? Concrete elements when supervising cognitive-behavioral therapy with youth. J. Am. Acad. Child. Psy. 54, 527-531. doi: 10.1016/j.jaac.2015.03.020

García-Huidobro, J. E. (2000). "La deserción y el fracaso escolar," in Seminario Educación, Pobreza y Deserción Escolar, ed. UNICEF (Santiago: UNICEF), 61-69.

Gasper, J., DeLuca, S., and Estacion, A. (2012). Switching schools: revisiting the relationship between school mobility and high school dropout. Am. Educ. Res. J. 49, 487-519. doi: 10.3102/0002831211415250

Hamre, B. K., and Pianta, R. C. (2006). "Student-teacher relationships," in Children's Needs III: Development, Prevention, and Intervention, eds G. G. Bear and K. M. Minke (Bethesda, MD: National Association of School Psychologists), 59-72.

Havik, T., Bru, E., and Ertesvag, S. K. (2015). School factors associated with school refusal- and truancy-related reasons for school non-attendance. Soc. Psychol. Educ. 18, 221-240. doi: 10.1007/s11218-015-9293-y

Henry, K. L., Knight, K. E., and Thornberry, T. P. (2012). School disengagement as a predictor of dropout, delinquency, and problem substance use during adolescence and early adulthood. J. Youth Adolesc. 41, 156-166. doi: 10.1007/ s10964-011-9665-3

Herrera, M. E. (1999). Fracaso escolar, códigos y disciplina: una aproximación etnográfica. Última Década 10, 1-9.

Hirschi, A. (2009). Career adaptability development in adolescence: multiple predictors and effect on sense of power and life satisfaction. J. Vocat. Behav. 74, 145-155. doi: 10.1016/j.jvb.2009.01.002

Huebner, E. S., and Gilman, R. (2006). Students who like and dislike school. App. Res. Qual. Life 1, 139-150. doi: 10.1007/s11482-006-9001-3

Johnson, B. (2010). "Exploring and explicating the distinctive features of educational organizations: theories and theorizing," in Analyzing School Context: Influences of Principals and Teachers in the Service of Students, eds W. K. Hoy and M. DiPaola (Charlotte, NC: Information Age Publishing), 1-38.

Keyes, C. L. (1998). Social wellbeing. Soc. Psychol. Quart. 61, 121-140. doi: 10.2307/ 2787065

Keyes, C. L. (2006). Subjective wellbeing in mental health and human development research worldwide: an introduction. Soc. Indic. Res. 77, 1-10. doi: 10.1007/ s11205-005-5550-3

Keyes, C. L. (ed.) (2013). Mental Wellbeing. International Contributions to the Study of Positive Mental Health. Georgia: Springer.

Keyes, C. L., and Lopez, S. J. (2005). "Toward a science of mental health," in Handbook of Positive Psychology, eds C. R. Snyder and S. J. Lopez (Oxford: Oxford University Press), 45-59.

Keyes, C. L., and Shapiro, A. (2004). "Social wellbeing in the United States: a descriptive epidemiology," in How Healthy Are We?: A National Study of Wellbeing at Midlife, eds O. G. Brim, C. D. Ryff, and R. C. Kessler (Chicago, IL: University of Chicago Press), 350-372.

Khoury-Kassabri, M., Benbenishty, R., Astor, R. A., and Zeira, A. (2004). The contributions of community, family, and school variables to student victimization. Am. J. Comm. Psychol. 34, 187-204. doi: 10.1007/s10464-0047414-4

Kirkcaldy, B., Furnham, A., and Siefen, G. (2009). Intelligence and birth order among children and adolescents in psychiatric care. Schl. Psychol. Int. 30, 43-55. doi: $10.1177 / 0143034308101849$

Longobardi, C., Prino, L. E., Marengo, D., and Settanni, M. (2016). Student-teacher relationships as a protective factor for school adjustment during the transition from middle to high school. Front. Psychol. 7:1988. doi: 10.3389/fpsyg.2016. 01988

López, V., Bilbao, M. A., Ascorra, P., Moya Diez, I., and Morales, M. (2014). Escala de clima escolar: adaptación al español y validación en estudiantes chilenos. Univ. Psychol. 13, 1111-1122. doi: 10.11144/Javeriana.UPSY13-3.ecea

López, V., Bilbao, M. A., and Rodriguez, J. I. (2012). La sala de clases sí importa: incidencia del clima de aula sobre la percepción de intimidación y victimización entre escolares. Univ. Psychol. 11, 91-101.

López, V., Montecinos, C., Rodríguez, J. I., Calderón, A., and Contreras, J. F. (2011). "Enacting solidarity to address peer to peer aggression in schools," in Building Solidarity Across Communities of Difference in Education: International Perspectives, eds C. Sleeter and E. Soriano (New York, NY: Teachers College Press), 23-44.

López-Vargas, B. I., and Basto-Torrado, S. P. (2010). Desde las teoría implícitas a la docencia como práctica reflexiva. Rev. Educ. Educad. 13, 275-291.

MacKinnon, D. P., Lockwood, C. M., Hoffman, J. M., West, S. G., and Sheets, V. (2002). A comparison of methods to test mediation and other intervening variable effects. Psychol. Methods 7, 83-104. doi: 10.1037/1082-989X.7.1.83

McEvoy, A., and Welker, R. (2000). Antisocial behavior, academic failure, and school climate: a critical review. J. Emot. Behav. Disord. 8, 130-140. doi: $10.1177 / 106342660000800301$

$\mathrm{Na}, \mathrm{C}$. (2016). The consequences of school dropout among serious adolescent offenders: more offending? More arrest? Both? J. Res. Crime. Delinq. 54, 78-110. doi: $10.1177 / 0022427816664118$

Natvig, G. K., Albrektsen, G., and Qvarnstrøm, U. (2003). Associations between psychosocial factors and happiness among school adolescents. Int. J. Nurs. Pract. 9, 166-175. doi: 10.1046/j.1440-172X.2003.00419.x

Ning, B., Van Damme, L., Liu, H., Vanlaar, G., and Giele, S. (2013). Students' individual perceptions of school climate predict reading achievement. Shanghai. Int. J. School Ed. Psychol. 1, 188-198. doi: 10.1080/21683603.2013.821638

OECD (2011). Education At a Glance 2011: OECD Indicators. Paris: OECD Publishing. 
OECD (2013). Guidelines on Measuring Subjective Wellbeing. Paris: OECD Publishing.

Oyanedel, J. C., Alfaro, J., Varela, J., and Torres, J. (2014). ¿Qué afecta el Bienestar Subjetivo y la Calidad de Vida de las Niñas y Niños Chilenos? Resultados de la Encuesta Internacional sobre Bienestar Subjetivo Infantil. Santiago: LOM Ediciones.

Oyanedel, J. C. and Bazan, C. (2011). The effect of school violence on life satisfaction: an international comparative analysis. Paper Presented at the 5th World Conference on School Violence. Mendoza, Argentina.

Pasta, T., Mendola, M., Longobardi, C., Prino, L. E., and Gastaldi, F. G. M. (2013). Attribution style of children with and without specific learning disability. Electron. J. Res. Educ. Psychol. 11, 649-664. doi: 10.14204/ejrep.31.13064

Pianta, R. C., Hamre, B. K., and Allen, J. P. (2012). "Teacher-student relationships and engagement: conceptualizing, measuring, and improving the capacity of classroom interactions," in Handbook of Student Engagement, eds S. L. Christenson, A. L. Reschly, and C. Wylie (New York, NY: Springer), 365-386. doi: 10.1007/978-1-4614-2018-7_17

Pölkki, P. L., and Vornanen, R. H. (2015). Role and success of Finnish early childhood education and care in supporting child welfare clients: perspectives from parents and professionals. Early Child. Educ. J. 44, 581-594. doi: 10.1007/ s10643-015-0746-x

Prino, L. E., Pasta, T., Gastaldi, F. G. M., and Longobardi, C. (2016). The effect of autism spectrum disorders, down syndrome, specific learning disorders and hyperactivity and attention deficits on the student-teacher relationship. Electron. J. Res. Educ. Psychol 14, 89-106. doi: 10.14204/ejrep.38.15043

Putnam, R. (2001). Social capital: measurement and consequences. Can. J. Policy Res. 2, 41-51.

Quaas, C., Ascorra, P., and Bertoglia, L. (2005). Estrategias metacomprensivas lectoras y constructos asociados: en busca de una relación. Psicoperspectivas 4 , 77-90.

Quinn, P., and Duckworth, A. (2007). Happiness and academic achievement: evidence for reciprocal causality. Paper Presented at the American Psychological Society, Washington, DC.

Quiroga, C., Janosz, M., Bisset, S., and Morin, A. (2013). Early adolescent depression symptoms and school dropout: mediating processes involving self-reported academic competence and achievement. J. Educ. Psychol. 105, 552-560. doi: 10.1037/a0031524

Raczynski, D., and Muñoz, G. (2005). Efectividad Escolar y Cambio Educativo en Condiciones de Pobreza en Chile. Santiago: Ministerio de Educación.

Román, M. (2009). El fracaso escolar de jóvenes en la enseñanza media: ¿Quiénes y por qué abandonan definitivamente en el liceo en Chile? REICE. Rev. Iber. Sobre Calid. Efic. Cambio Educ. 7, 95-119.

Rumberger, R. W., and Rotermund, S. (2012). "The relationship between engagement and high school dropout," in Handbook of Research on Student Engagement, eds S. L. Christenson, A. L. Reschly, and C. Wylie (New York, NY: Springer), 491-513.

Ryff, C. D., and Singer, B. (1998). The contours of positive human health. Psychol. Inq. 9, 1-28. doi: 10.1207/s15327965pli0901_1

Saab, H., and Klinger, D. (2010). School differences in adolescent health and wellbeing: findings from the Canadian health behaviour in school-aged children study. Soc. Sci. Med. 70, 850-858. doi: 10.1016/j.socscimed.2009.11.012

Samdal, O., Nutbeam, D., Wold, B., and Kannas, L. (1998). Achieving health and educational goals through schools: a study of the importance of the school climate and students' satisfaction with school. Health Educ. Res. 13, 383-397. doi: 10.1093/her/13.3.383

Scherer, R., and Nilsen, T. (2016). "The relations among school climate, instructional quality, and achievement motivation in mathematics," in Teacher Quality, Instructional Quality and Student Outcomes, eds T. Nilsen and J. Gustafsson (Cham: Springer), 51-80. doi: 10.1007/978-3-319-41252-8_3

Seligson, J. L., Huebner, E. S., and Valois, R. F. (2003). Preliminary validation of the brief multidimensional student's life satisfaction scale. Soc. Indic. Res. 61, 121-145. doi: 10.1023/A:1021326822957

Sobel, M. E. (1982). Asymptotic confidence intervals for indirect effects in structural equation models. Sociol. Methodol. 13, 290-312. doi: 10.2307/270723

South, S. J., Haynie, D. L., and Bose, S. (2007). Student mobility and school dropout. Soc. Sci. Res. 36, 68-94. doi: 10.1016/j.ssresearch.2005.10.001
Strózik, D., Strózik, T., and Szwarc, K. (2016). The subjective well-being of school children. The first findings from the Children's Worlds study in Poland. Child Indic. Res. 9, 39-50. doi: 10.1007/s12187-015-9312-8

Suldo, S. M., Riley, K. N., and Shaffer, E. J. (2006). Academic correlates of children and adolescents' life satisfaction. Schl. Psychol. Int. 27, 567-582. doi: 10.1016/j. addbeh.2010.11.017

Thapa, A., Cohen, J., Guffey, S., and Higgins-D'Alessandro, A. (2013). A review of school climate research. Rev. Educ. Res. 83, 357-385. doi: 10.3102/ 0034654313483907

Tyler, J. H., and Lofstrom, M. (2009). Finishing high school: alternative pathways and dropout recovery. Future Child 19, 77-103. doi: 10.1353/foc. 0.0019

UNESCO (2008). Los Aprendizajes de los Estudiantes de America Latina y el Caribe. Availabele at: http://unesdoc.unesco.org/images/0016/001606/160659s.pdf

UNESCO (2016). Informe de Resultados TERCE: Tercer Estudio Regional Comparativo y Explicativo. Factores Asociados. Santiago: OREALC/UNESCO. Available at: http://unesdoc.unesco.org/images/0024/002435/243533s.pdf

Valenzuela, J. P., Bellei, C., and De Los Ríos, D. (2014). Socio-economic school segregation in a market-oriented educational system: the case of Chile. J. Educ. Policy 29, 217-241. doi: 10.1080/02680939.2013.806995

Vázquez, C., and Hervás, C. (eds). (2008). "Salud mental positiva: del síntoma al bienestar," in Psicología positiva aplicada (Bilbao: Desclee de Brower), 17-39.

Veltro, F., Ialenti, V., Iannone, C., Bonanni, E., and García, M. A. (2014). Promoting the psychological wellbeing of Italian youth: a pilot study of a high school mental health program. Health Promot. Pract. 16, 169-175. doi: 10.1177/ 1524839914533965

Wang, M., and Degol, J. (2016). School climate: a review of the construct, measurement, and impact on student outcomes. Educ. Psychol. Rev. 28, 315-352. doi: 10.1007/s10648-015-9319-1

Wang, M., and Fredricks, J. (2014). The reciprocal links between school engagement, youth problem behaviors, and school dropout during adolescence. Child Dev. 85, 722-737. doi: 10.1111/cdev.12138

Watson, D., Clark, L. A., and Tellegen, A. (1988). Development and validation of brief measures of positive and negative affect: the PANAS scales. J. Pers. Soc. Psychol. 54, 1063-1070. doi: 10.1037/0022-3514.54.6.1063

Wentzel, K. R. (1998). Social relationships and motivation in middle school: the role of parents, teachers, and peers. J. Educ. Psychol. 90, 202-209. doi: 10.1037/ 0022-0663.90.2.202

Werblow, J., Robinson, Q. L., and Duesbery, L. (2010). "Regardless of school size, school climate matters: how dimensions of school climate affect student dropout rate," in Analyzing School Contexts: Influences of Principals and Teachers in the Service of Students, eds W. K. Hoy and M. DiPaola (Charlotte, NC: Information Age Publishing), 191-208.

Wit, D. J., Karioja, K., Rye, B. J., and Shain, M. (2011). Perceptions of declining classmate and teacher support following the transition to high school: potential correlates of increasing student mental health difficulties. Psychol. Schl. 48, 556-572. doi: 10.1002/pits.20576

Wubbels, T. (2011). An international perspective on classroom management: what should prospective teachers learn? Teach. Educ. 22, 113-131. doi: 10.1080/ 10476210.2011.567838

Wubbels, T., Brekelmans, M., den Brok, P., Wijsman, L., Mainhart, T., and Van Tartwijk, J. (2015). “Teacher-student relationships and classroom management," in Handbook of Classroom Management, 2nd Edn, eds E. T. Emmer and E. J. Sabornie (New York, NY: Routledge), 363-385.

Conflict of Interest Statement: The authors declare that the research was conducted in the absence of any commercial or financial relationships that could be construed as a potential conflict of interest.

Copyright (c) 2017 López, Oyanedel, Bilbao, Torres, Oyarzún, Morales, Ascorra and Carrasco. This is an open-access article distributed under the terms of the Creative Commons Attribution License (CC BY). The use, distribution or reproduction in other forums is permitted, provided the original author(s) or licensor are credited and that the original publication in this journal is cited, in accordance with accepted academic practice. No use, distribution or reproduction is permitted which does not comply with these terms. 


\section{OPEN ACCESS}

Edited by:

Barbara McCombs, University of Denver, United States

Reviewed by:

Maria Joao Beja,

University of Madeira, Portugal

Luis J. Martín-Antón,

University of Valladolid, Spain

*Correspondence:

Ana M. Cristóvão

anamaria.cristovao@gmail.com

Specialty section:

This article was submitted to

Educational Psychology,

a section of the journal

Frontiers in Psychology

Received: 06 March 2017 Accepted: 16 October 2017 Published: 08 November 2017

Citation:

Cristóvão AM, Candeias AA and Verdasca J (2017) Social and

Emotional Learning and Academic Achievement in Portuguese Schools:

A Bibliometric Study.

Front. Psychol. 8:1913.

doi: 10.3389/fpsyg.2017.01913

\section{Social and Emotional Learning and Academic Achievement in Portuguese Schools: A Bibliometric Study}

\author{
Ana M. Cristóvão ${ }^{1 *}$, Adelinda A. Candeias ${ }^{1,2}$ and José Verdasca ${ }^{1,3}$ \\ ${ }^{1}$ Research Center in Education and Psychology, University of Évora, Évora, Portugal, ${ }^{2}$ Department of Psychology, School of \\ Social Sciences, University of Évora, Évora, Portugal, ${ }^{3}$ Department of Pedagogy and Education, School of Social Sciences, \\ University of Évora, Évora, Portugal
}

Social and Emotional Learning (SEL) is an educational movement that is gaining ground throughout the world. We can define SEL as the capacity to recognize and manage emotions, solve problems effectively, and establish positive relationships with others. Research has demonstrated the significant role of SEL in promoting healthy student development and academic achievement. Extensive research confirms that SEL competencies: can be taught, that they promote positive development and reduce problem behaviors, and that they improve students' academic achievement and citizenship. At the international level, several rigorous studies have identified programs and practices that promote SEL. In Portugal, however, no review has yet been published regarding the implementation of SEL programs. Such a study would elucidate the current panorama of SEL programs in Portugal. This study aims to identify research on SEL programs implemented in Portuguese schools and the relationship of those programs with academic achievement. To this end, we have consulted the following databases: Scientific Repository of Open Access of Portugal (RCAAP), Online Knowledge Library (b-on), and Web of Science (WoS). The criteria were: (a) all time frames; (b) publications in either Portuguese or English; (c) programs that developed socio-emotional competencies in Portuguese schools; (d) academic levels including elementary, middle, and high school and (e) students of regular education. Few publications on SEL programs implemented in Portugal were found, although the recent decade has witnessed an upsurge of interest in the topic, principally that arising from academic research.

Keywords: SEL programs, academic achievement, Portuguese schools, bibliometric study

\section{INTRODUCTION}

The twenty-first century challenge for educators, families, and community members is seeking to raise and educate children who are knowledgeable, responsible, caring, and socially competent. A key challenge for schools involves serving culturally diverse students with varied abilities and motivations for learning (Learning First Alliance, 2001). Times have changed. A few generations ago most children would spend only a few years in school. Schools' priority was teaching the traditional subjects, such as reading, writing, and arithmetic. Young people are now spending more 
years in school and are more exposed to issues of depression, social isolation, or other problems. This requires that they develop concentration, impulse control, and emotional regulation (Lopes and Salovey, 2004).

In the past two decades, research on educational outcomes has demonstrated the importance of positive social behaviors in fostering academic achievement (Blake et al., 2015). According to Greenberg et al. (2003), educators, parents, students, and other members of the educational community believe that today's school has to teach beyond basic skills (reading, writing, counting). Today's school must enhance students' socialemotional competence, character, health, and civic engagement (Greenberg et al., 2003, p. 466).

According to the World Economic Forum's Future of Jobs Report (World Economic Forum, 2016), emotional intelligence will be one of the top 10 job skills in 2020. The awareness that emotional intelligence is an important job skill, in some cases even surpassing technical ability, has been growing in recent years. In any case, we have come to the conclusion that the new generation of children needs something more. Every individual counts, and we will be doing a disservice to the children if we do not orient our educational practices to the individuality of each one.

Awareness of the importance of mental health has been growing worldwide. In Portugal, according to the report citing the First National Epidemiological Study of Mental Health published in 2013, psychiatric disturbances affect more than one fifth of the Portuguese population (Directorate-General for Health, 2013). Common mental disorders (such as depression) are one of the main causes of disability, as expressed, for example, by the high number of deaths and early retirements. According to the Portuguese Directorate-General of Health, common mental disorders are highly prevalent (annually $22.9 \%$, $42.7 \%$ throughout life). At the same time, Portugal has been the largest European consumer of benzodiazepines for years, with significant numbers of users of antidepressants and alcoholic beverages. Investigations reveal that some people who develop mental illness in adulthood have manifested signs or had critical episodes during childhood. Some mental illnesses cannot be avoided, but their impact can still be reduced and quality of life can be increased (Directorate-General of Health, 2017).

The National Coordination for Mental Health (2008) has made it a priority to implement mental health education programs including those to promote personal and social skills (Pinto and Raimundo, 2016). Behavioral, emotional, and mental health problems of school children and young people have been growing, significantly impacting school performance, obesity, and risk behaviors (Greenberg et al., 2003; Durlak et al., 2011). The mission of today's school must be reinvented in order to address these problems. In addition to its role in learning and academic performance, the school must actively participate in promoting students' lifelong mental health and well-being (Kickbush, 2012).

Social and Emotional Learning (SEL) is an educational movement gaining ground throughout the world. SEL can be defined as the capacity to recognize and manage emotions, solve problems effectively, and establish positive relationships with others (CASEL, 2003).
A study of the publications about SEL programs implemented in Portuguese schools should provide better understanding of the national panorama regarding the development of social and emotional skills. To this end, we carried out a bibliometric study. According to Archambault et al. (2009), the increased availability of statistics like bibliographic impact makes it increasingly important to understand how publication and citation activities can be included as part of a more holistic review of the literature. Zupic and Cater (2015) pointed out that bibliometric methods employ a quantitative approach for the description, evaluation, and monitoring of published research. They argue that these methods have the potential to introduce a systematic, transparent, and reproducible review process and thus improve the quality of reviews (Zupic and Cater, 2015, p. 430). According to Cortez (2011), the most relevant types of publications are books, theses, chapters of books, articles published in scientific journals, communications in conference proceedings, technical reports, pedagogical materials, white papers, and web pages. Each of these may or may not be subject to peer-review, and they may be national or international in scope (2011, p. 3).

Bibliometric studies enable us to identify published studies on SEL implementation in Portuguese schools, while also informing us about the scientific activity of researchers and universities.

\section{SOCIAL AND EMOTIONAL LEARNING-SEL}

Emotions can facilitate or impede children's academic engagement, commitment, and ultimate school success since relationships and emotional processes affect how and what we learn. Thus, schools and families must effectively address these aspects of the educational process for the benefit of all students (Elias et al., 1997).

In 1994 a group of professors, researchers and health care professionals held a meeting at the Fetzer Institute to reflect on how to improve students' social and emotional competences and school performance. The concept of SEL emerged from this meeting. It can be defined as a strategy to nurture students' social and emotional competences by way of explicit teaching. SEL uses a student-centered approach that encourages student participation in the learning process and in the development of analytical communication and collaborative behaviors (CASEL, 2012; Weissberg et al., 2015).

These participants created the Collaborative for Academic, Social, and Emotional Learning (CASEL), a nonprofit organization in Chicago which has been at the forefront of North American and international efforts to promote SEL. Founded by Daniel Goleman and Eileen Growald, CASEL's mission is to establish SEL as an essential part of education. "We envision the world where families, schools, and communities work together to support the healthy development of all children. All children will become engaged lifelong learners who are selfaware, who are caring and connected to others, and who make responsible decisions" (CASEL, 2003, p. 5). CASEL defines SEL as the process by which people develop their social and emotional 
competencies for "success in school and in the workplace, including the skills necessary to recognize and manage emotions, develop care, and concern for others, form positive relationships, make responsible decisions, and successfully handle the demands of growing up in today's complex society." (CASEL, 2012, p. 4). One of the most commonly used definitions is that of Elias et al. (1997). They see SEL as a process through which we learn to recognize and manage emotions, care about others, make good decisions, behave ethically and responsibly, develop positive relationships, and avoid negative behaviors.

The SEL approach defends that, as with academic skills, the development of social and emotional competencies must be accomplished through explicit instruction. According to Weissberg et al. (2015) one of the most prevalent SEL approaches "involves training teachers to deliver explicit lessons that teach social and emotional skills, then finding opportunities for students to reinforce their use throughout the day" (2015, p. 8 ). The development of social and emotional competences in the SEL approach occurs within and outside the classroom in a school context, but also at the family, community, and political levels (Weissberg et al., 2015). Teachers must be the engine that drives SEL programs. Recently, Schonert-Reicht Kimberly (2017) examined the role of teachers in implementing SEL programs and practices in schools and classrooms. The author concludes the success of SEL programs is directly related to teachers' beliefs and their well-being. Hence the importance of teacher training in SEL and the importance of explicitly promoting SEL in initial teacher training (Schonert-Reicht Kimberly, 2017).

SEL programming is based on understanding that many different kinds of problem behaviors are caused by the same or similar risk factors, and the best learning emerges from supportive relationships that make learning both challenging and meaningful (CASEL, 2003).

CASEL recommends that SEL Programs should have as direct targets five key competencies: (1) Competence in selfawareness - the ability to understand one's own emotions, personal goals, and values. This includes accurately assessing one's strengths and limitations and possessing a well-grounded sense of confidence and optimism. (2) Competencies in selfmanagement-the ability to regulate emotions and behaviors. This includes managing stress, controlling impulses, and setting and working toward achieving personal and academic goals. (3) Competence in social awareness-the ability to take the perspective of those from different cultures and backgrounds. (4) Competence in relationship skills-providing children with the tools they need to establish and maintain healthy and rewarding relationships. (5) Competencies in responsible decision making - the ability to consider ethical standards, safety concerns, and accurate behavioral norms for risky behaviors, to realistically evaluate the consequences of various actions, and to take the health and well-being of self and others into consideration (CASEL, 2003). These five CASEL competencies reflect intrapersonal and interpersonal domains (National Research Council, 2012). Self-awareness and self-management deal with issues within the intrapersonal domain, whereas social awareness and relationship skills are interpersonal. Responsible decision-making is both an individual and social process and therefore overlaps both domains (CASEL, 2012).

According to Brackett et al. (2016) a unified vision for SEL exists that promotes the children's fullest potential (socially, emotionally, and academically). They state that there are many ways to realize this vision "what makes each approach to SEL unique is the specific content it includes, how the presentation of content is sustained with quality within a school organization over time." (2016, p. 21).

Zins et al. present the essential characteristics of effective SEL programming. They posit that the most effective SEL efforts use comprehensive, multiyear, multicomponent approaches (Zins et al., 2004, p8). Successful programs must be carefully planned, and they must be both theory and research based. Students should be taught to apply SEL skills to daily life. Both the affective and social dimension of learning should be addressed. Initiatives should lead to coordinated, integrated and unified programming linked to academic outcomes. They should address key implementation factors to support effective social and emotional learning and development. Familycommunity partnerships should be nurtured and the design should include components aimed at continuous improvement, evaluation of outcomes, and dissemination (Zins et al., 2004, p. 10-11). For skills to become part of children's active repertoire, they need to be learned, supported, and, furthermore, they need to be valued in a range of contexts. Elias and colleagues present five main characteristics that contexts must have: (1) a school climate that articulates specific themes and values such as respect, responsibility and honesty, and conveys an overall sense of purpose for attending school; (2) explicit instruction and practice in skills for participatory competence; (3) developmentally appropriate instruction so as to promote health and prevent specific problems; (4) services that enhance students' coping skills and provide social support; and 5) widespread, systematic opportunities for positive contributory service (Elias et al., 2015, p. 35).

There are a large number of correlational and longitudinal studies that indicate that the development of socio-emotional competencies contributes to better psychosocial adjustment of students, and improved attitudes, academic and behavioral results (Weissberg et al., 2015).

Weissberg et al. (2015) conducted a pertinent discussion about the results of the most influential SEL studies. The first was the first comprehensive survey of existing school-based SEL programs, the Safe and Sound: An Educational Leader's Guide to Evidence-Based Social and Emotional Learning (SEL) Programs (CASEL, 2003). This publication was very important and became a popular source of information. It provided educators with practical information about procedural aspects and shared the outcomes of several SEL programs. In 2013 CASEL published Guide: Effective Social and Emotional Learning Programs-Preschool and Elementary School Edition. It was based on more rigorous research criteria than those used in 2003. This important guide focused on successful preschool and elementary 
school outcomes. Another important publication was that of Zins et al. (2004) Building Academic Success on Social and Emotional Learning: What Does the Research Say. This article reinforced the notion that SEL programs can improve students' success in school and in life. The last work was Durlak et al. (2011). It involved an important, large-scale meta-analysis of studies involving over 270,000 students and confirmed that SEL produces significant positive effects in different aspects of adjustment, including improvements in academic performance, SEL skills, prosocial behaviors, and attitudes toward self and others. In summary, Weissberg et al. concluded that "wellimplemented SEL programs are an evidence-based approach that not only improves student's academic, behavioral, and personal adjustment but also prevents some important negative outcomes" (Weissberg et al., 2015, p. 12-13).

In 2015 the Handbook of Social and Emotional Learning: Research and Practice edited by Durlak, Domitrovich, Weissberg, and Gullota was published. This comprehensive and definitive handbook is a testimony to the extraordinary SEL work over the last two decades. It covers all aspects of SEL research, practice, and policy. The conceptual and scientific underpinnings of SEL are reviewed and the approach's relationship to children's and adolescents' academic success and mental health is examined. In-depth analyses of SEL implementations and assessments in diverse educational settings are described including the roles of school- and district-level leadership, teacher training, and schoolfamily partnerships. This publication shows there is a large body of scientific evidence demonstrating the positive outcomes of SEL.

\section{SEL Programs and Academic Achievement}

Schools will be most successful in their educational mission when they integrate efforts to promote children's academic, social, and emotional learning (Elias et al., 1997). Social and emotional learning has a critical role in improving children's academic performance and lifelong learning. Researchers have demonstrated that SEL plays important roles in influencing nonacademic outcomes, but also has a critical role in improving children's academic performance and lifelong learning (Zins et al., 2004). Building Academic Success on Social and Emotional Learning edited by Zins et al. (2004) presents considerable evidence that SEL can not only improve students' social development and mental health but can strengthen their academic achievement. Figure 1 illustrates the connection between evidence-based SEL programming and better academic performance and success in school and in life.

In their words, this figure "indicates that SEL interventions and skill development should occur within a supportive learning environment (...) As a result, opportunities for reward are created and SEL competencies are developed and reinforced (...) The final outcome is improved performance in school and life" (Zins et al., 2004, p. 9). The authors call for consistent studies to demonstrate that socio-emotional skills improve academic performance (2004, p. 193).

Analyses of recent school-based prevention programs provide general agreement that some of these programs are effective in reducing maladaptive behaviors and improving school success (Durlak and Wells, 1997; Durlak et al., 2011). Payton et al. (2008) conducted three large-scale reviews (of 317 studies involving 324,303 children) on the impact of SEL on elementary and middle-school students. The reviews demonstrated gains of 1117 percentile points on achievement tests that demonstrated that SEL programs offer students a practical educational benefit. Durlak et al. (2011) conducted one meta-analysis of 213 schoolbased initiatives involving more than 270,000 students who participated in evidence-based SEL programs and it showed an 11 percentile-point gain in academic achievement compared to students who did not participate in SEL programs. These reviews showed improved classroom behavior, an increased ability to manage stress and depression, and better attitudes about themselves, others, and school for students who participated in SEL programs (Payton et al., 2008; Durlak et al., 2011).

CASEL has carried out an extensive body of rigorous research (including randomized control trials, longitudinal follow-ups, and multiple replications) that demonstrates that education that promotes SEL gets results and that teachers in all academic areas can effectively teach SEL (CASEL, 2016).

\section{SEL Programs in Portugal}

Most of the SEL studies have taken place in U.S. schools. Torrente et al. (2015) reviewed European SEL policy and found "an extremely diverse panorama in terms of the presence, progress, and origins of SEL and initiatives" (p. 569). They found that much progress is to be made in Portugal "in agreeing on its meaning and practical implications" (Menezes, 2003, p. 572). The first reference to social and emotional education in Portugal emerged only in 2011 (Faria, 2011).

The Foundation Law of the Educational System, Law $\mathrm{n}^{\circ}$ $86 / 1986$, the normative reference for educational policies that aim toward the development of education and the educational system, stipulated in article 50 that "the curricular organization of schools shall take into account, at both the horizontal and vertical levels, a well-balanced promotion of students' physical, motor, cognitive, affective, aesthetic, social, and moral development." In the 30 years following the 1986 law, Portuguese schools have experienced many reforms, both those instigated by various governments and others, to promote the issues of social and emotional development.

The specific promotion of social and emotional skills only began in the 1990s however, with the emergence of some intervention programs, often driven by local entities or associations. In 1997, the Ministry of Education published a pioneering program to boost social and emotional competencies, the Manual of the Program of Promotion and Education for Health. A decade of research on this program presented as principal vectors the importance of teacher training for the program's implementation, the usefulness of promoting these competences in school contexts, and a lack of preventative measures and the scarity of promotion of positive behaviors (Pinto and Raimundo, 2016).

According to Costa and Faria (2013) SEL in Portugal still has a long way to go toward its institutionalization in schools (2013, 


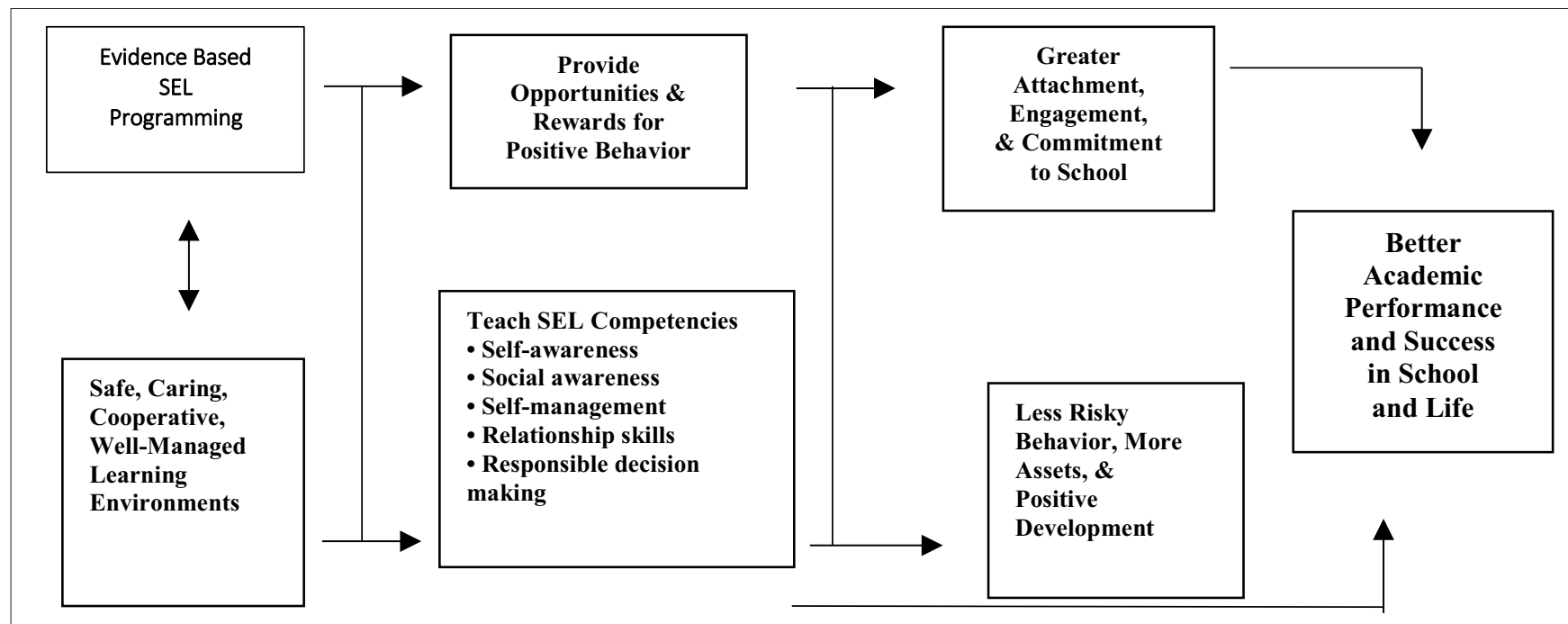

FIGURE 1 | Evidence-based SEL programming paths to success in school and in life by Zins et al. (2004).

p. 419). Recently, however, we have witnessed a rising interest in this question by the Portuguese government. In 2016, the Ministry of Health published the Manual for the Promotion of Social and Emotional Competencies in Schools. Its main objective was to serve as a pedagogical resource to facilitate the formation and implementation of a project promoting Mental Health in schools based on SEL programs (de Carvalho et al., 2017). To date, no data have been published regarding the implementation and effectiveness of this program.

In February 2017, the Portuguese government commissioned a national reference group to draw up a document entitled the "Profile of students dropping out of compulsory schooling" (Martins et al., 2017) with the following components: (a) a humanistic profile; (b) educating by teaching for practical achievement of learning; (c) making inclusion a requisite of education; (d) contributing to sustainable development; (e) educating by teaching with consistency and flexibility; (f) acting with adaptability and daring; g) guaranteeing stability; and (h) valorizing knowledge (Martins et al., 2017). The student profile in this document is based on a humanist profile which "means focusing on a person-centered society guided by the fundamental value of human dignity" (Martins et al., 2017, p. 6). The document described 10 key competencies that students must have at the end of compulsory schooling, and we highlight those of interpersonal relationships, personal development, and autonomy. Interpersonal relationship competencies relate to "interaction with others, which occurs in different social and emotional contexts. They allow us to recognize, express, and manage emotions, build relationships, set goals and respond to personal and social needs," (Martins et al., 2017, p. 15).

Personal development and autonomy skills concern the "process by which the student develops his capacity to integrate thought, emotion, and behavior, building self-confidence, motivation to learn, self-regulation, self-initiative, and informed decision-making, which enable a growing autonomy in the

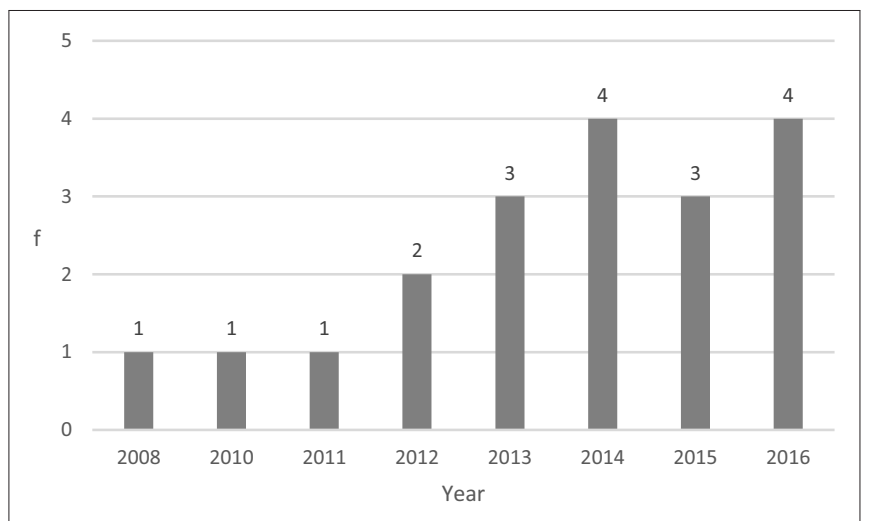

FIGURE 2 | Evolution of publications over time.

various dimensions of knowledge, know-how, know-how, and action" (Martins et al., 2017, p. 15).

A set of teaching initiatives decisive for the development of students' profiles were presented. We highlight: (a) purposefully and systematically encouraging activities inside and outside of the classroom that allow students to make choices, exchange points of view, solve problems and make value based decisions; (b) creating time and space within schools for students to act freely and responsibly; (c) when evaluating student learning, valorizing work arising from students' free initiative, and encouraging their positive actions within the school and the community (Martins et al., 2017, p. 18).

This document can be a lever for the School to develop a broader and holistic student development model that integrates young people's social and emotional development.

It is important to identify investigations that demonstrate the implementation of SEL programs in Portuguese schools and their relationship with school achievement, while also raising awareness within the educational community of good practices 
within the schools. To this end, we carried out a bibliometric study and a systematic review of the literature, looking for publications that cover the implementation of SEL programs and their relationship to academic performance.

\section{METHODS}

There is a need to analyze the effects of SEL programs on academic achievement (Durlak et al., 2011; CASEL, 2013). The lack of effectiveness studies of SEL programs in the Portuguese context was the springboard for this study, whose main purpose was to find SEL programs in Portuguese schools and whether relationships had been established between these programs and academic achievement. The following questions guided the review: (1) How many SEL projects exist in Portuguese schools? (2) Does Portuguese SEL mention the relationship to academic achievement?

To answer these questions we set the following objectives: (a) to identify the number of papers that looked at SEL programs in Portuguese schools; (b) to analyze when more publications took place; (c) to investigate publication type;

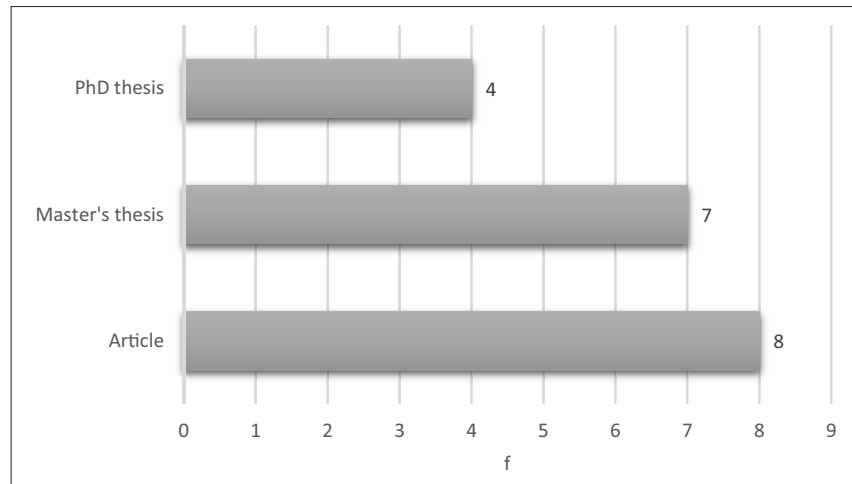

FIGURE 3 | Graph of the type of the publications. (d) to evaluate the geographical distribution of the selected documents; (e) to identify Portuguese SEL, in particular, the years of implementation and students involved, and (f) to gathering data about the relationship between SEL programs and academic achievement.

The methodological approach blended technical bibliometric and content analysis. The bibliometric analysis permitted us to identify trends in terms of the number of publications over time, main authors and works (Neely, 2005). Content analysis codified and analyzed the main themes in the literature (Bardin, 2008).

Data analysis was performed in two stages. Firstly, the primary data were treated, seeking to form a quantitative view of the publications, grouping them by year of publication and journal. The title and abstracts were copied to a database using Microsoft Excel 2013.

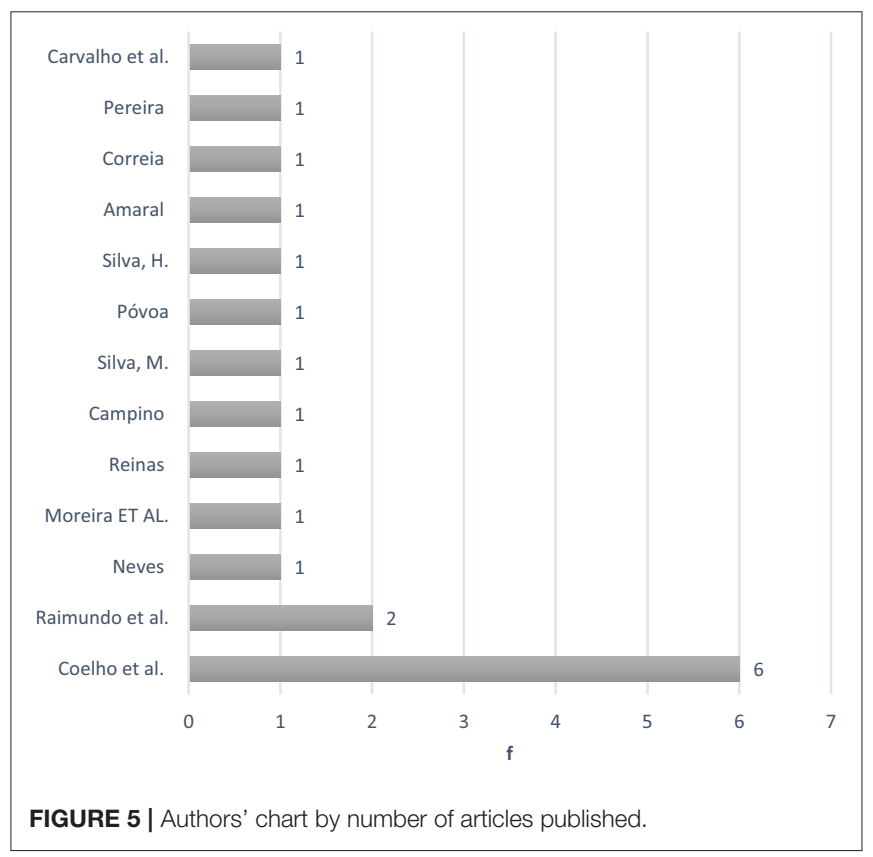

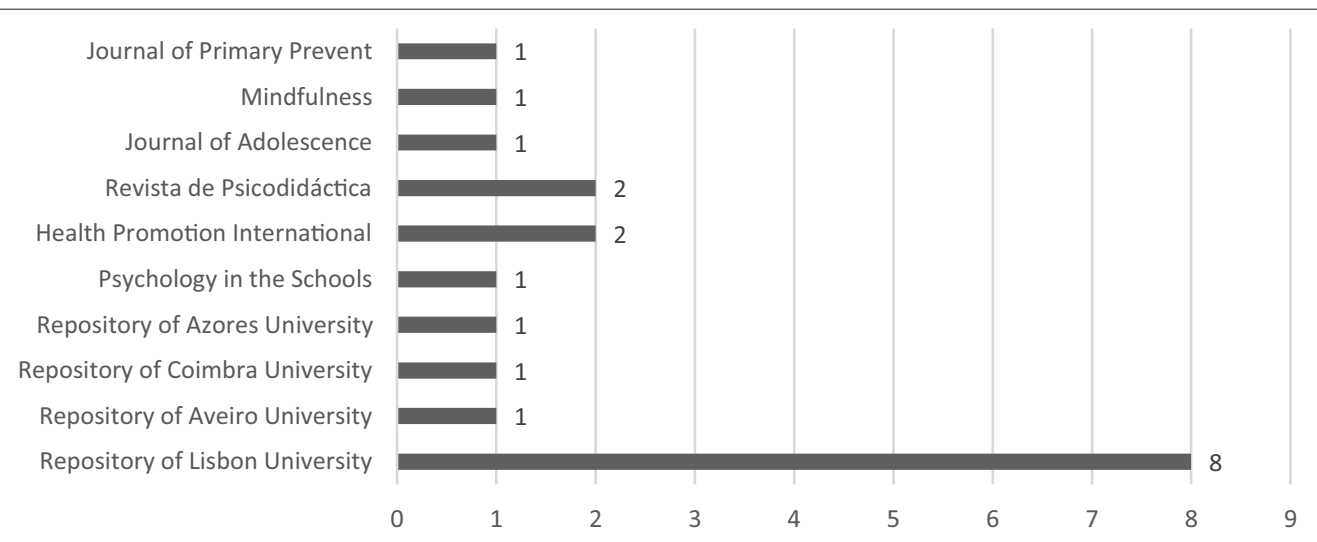

FIGURE 4 | Graph of the origin of the publications. 
TABLE 1 | Most cited articles.

\begin{tabular}{|c|c|c|c|}
\hline $\begin{array}{l}\text { Author and year of } \\
\text { publication }\end{array}$ & Journal & Title of article & Number of citations \\
\hline Moreira et al., 2010 & Health Promotion International & $\begin{array}{l}\text { Evaluation of a manual-based programme for the promotion of social } \\
\text { and emotional skills in elementary school children: results from a 4-year } \\
\text { study in Portugal }\end{array}$ & 11 \\
\hline Raimundo et al., 2013 & Psychology in the Schools & $\begin{array}{l}\text { The effects of a social-emotional learning program on elementary } \\
\text { school children: the role of pupils' characteristics }\end{array}$ & 4 \\
\hline Coelho et al., 2014 & Revista de Psicodidáctica & $\begin{array}{l}\text { The Impact of a School-Based Social and Emotional Learning Program } \\
\text { on the Self-Concept of Middle School Students }\end{array}$ & 8 \\
\hline Coelho et al., 2015a & Journal of Adolescence & $\begin{array}{l}\text { "Positive Attitude": A multilevel model analysis of the effectiveness of a } \\
\text { Social and Emotional Learning Program for Portuguese middle school } \\
\text { students }\end{array}$ & 2 \\
\hline Coelho et al., 2015b & Health Promotion International & $\begin{array}{l}\text { The impact of a Portuguese middle school social-emotional learning } \\
\text { program }\end{array}$ & 8 \\
\hline
\end{tabular}

Content analysis comprised the second stage. The articles were classified regarding the presence or not of data regarding the relationship between SEL programs and academic results.

\section{Procedure}

Three databases were thought to serve our goals: (1) Scientific Repository of Open Access of Portugal (RCAAP); (2) Online Knowledge Library (b-on), and (3) Web of Science (WoS). The Scientific Repository of Open Access of Portugal (RCAAP) database aims to collect, aggregate and index Open Access scientific contents from Portuguese institutional repositories. It is a single entry point for searching, discovering, and recalling thousands of scientific and scholarly publications, namely journal articles, conference papers, thesis, and dissertations, distributed by several Portuguese repositories. "Open Access" in Portugal consists of the free Internet publication of peer-reviewed journals, dissertations, thesis, conference communications and technical reports. According to the stipulated objectives, this database has proved to be the most complete. In the course of the investigation, we also searched the B-on databases and WoS database, as we are interested in knowing what was published internationally. The Online Library of Knowledge (bon) provides unlimited access to full texts from thousands of scientific journals and online e-books from some of the world's leading content providers. Web of Science is owned by Thomson Reuters, a database that provides access to more than 9,200 journal titles.

The following criteria guided the searches: (a) documents published through 2016; (b) English keywords Social and Emotional Learning; (c) Portuguese keywords with various synonyms (e.g., aprendizagem socioemocional; aprendizagem socio-emocional, aprendizagem social e emocional); (d) only SEL programs implemented in Portuguese schools; (e) school level [e.g., elementary, middle, and high school and (f) students of regular education].

The initial search produced 2,436 documents in the RCAAP, 311 in B-on and 9 in the WoS, resulting in a total of 2,756 documents, of which 556 were repeated, leaving a total of 2,200 works for analysis. Applying the inclusion criteria reduced the list to only 19 publications requiring deeper analysis.

\section{RESULTS}

The following section discusses the results of the analyses conducted from the sample obtained so that it is possible to have an overview of publications related to SEL programs implemented in Portuguese schools and their relation to academic performance.

In the initial analysis, we observed the number of publications that deal with SEL programs implemented in Portuguese schools. It is worth mentioning that there has been a growth in recent years (Figure 2). As Figure 2 illustrates, no publications dealing with Portugal pre-date 2008, although international SEL programs are over 20 years old. Most investigations have been published in the last 3 years $(n=11 ; 58 \%)$. It is worth highlighting how few studies there are in the literature regarding SEL implementation in Portugal.

Figure 3 shows the distribution of the research analyzed by the type of publication. Academic research (master's and Ph.D. theses) are most prominent $(n=11 ; 58 \%)$, with master's theses predominating $(n=7)$.

That data showed considerable dispersion among different authors and institutional affiliations as illustrated in Figures 4, 5.

Nineteen publications originated from 10 different sources. Figure 4 shows us that the University of Lisbon produced the most publications $(n=8)$ with Vitor Coelho having authored the largest number (Figure 5).

Table 1 illustrates the most often cited articles. Many publications provided no information about citations. Moreira et al. (2010) and Coelho et al. (2014, 2015a,b) were the most frequently cited, with 11 and 8 citations, respectively.

Regarding SEL Programs, the "Positive Attitude Program" has the most references $(n=6)$, followed by the "Slowly but steadily" $(n=3)$. It should also be mentioned that all the articles analyzed were published in international journals.

Table 2 illustrates the results of our content analysis.

The "Positive Attitude" SEL program of Vitor Coelho et al. involved the most students. Only four of the investigations dealt with fewer than 100 student SEL participants. It is also of interest that most of the SEL Programs were implemented in the district of Lisbon, with only two studies taking place in other locations. 


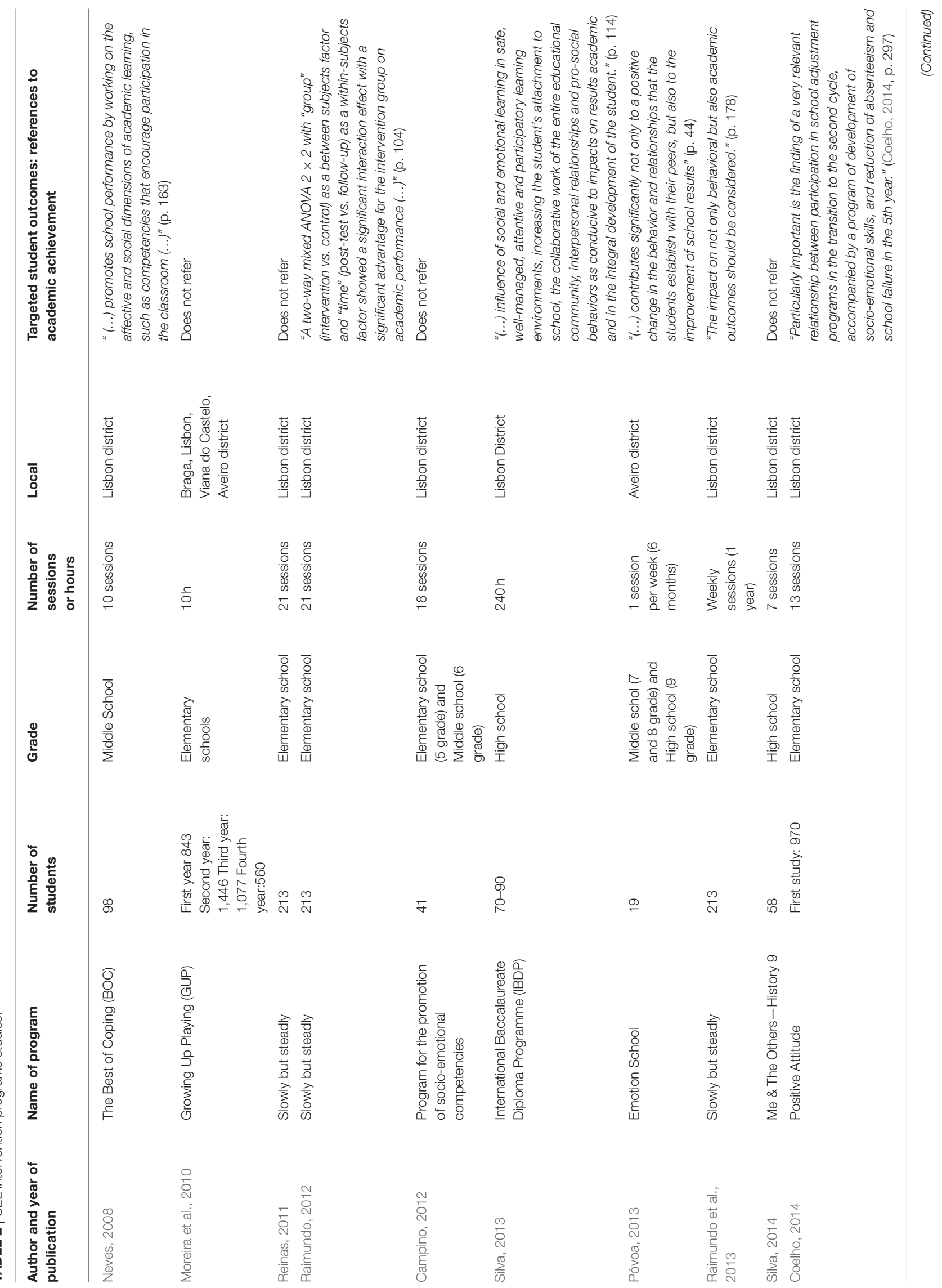




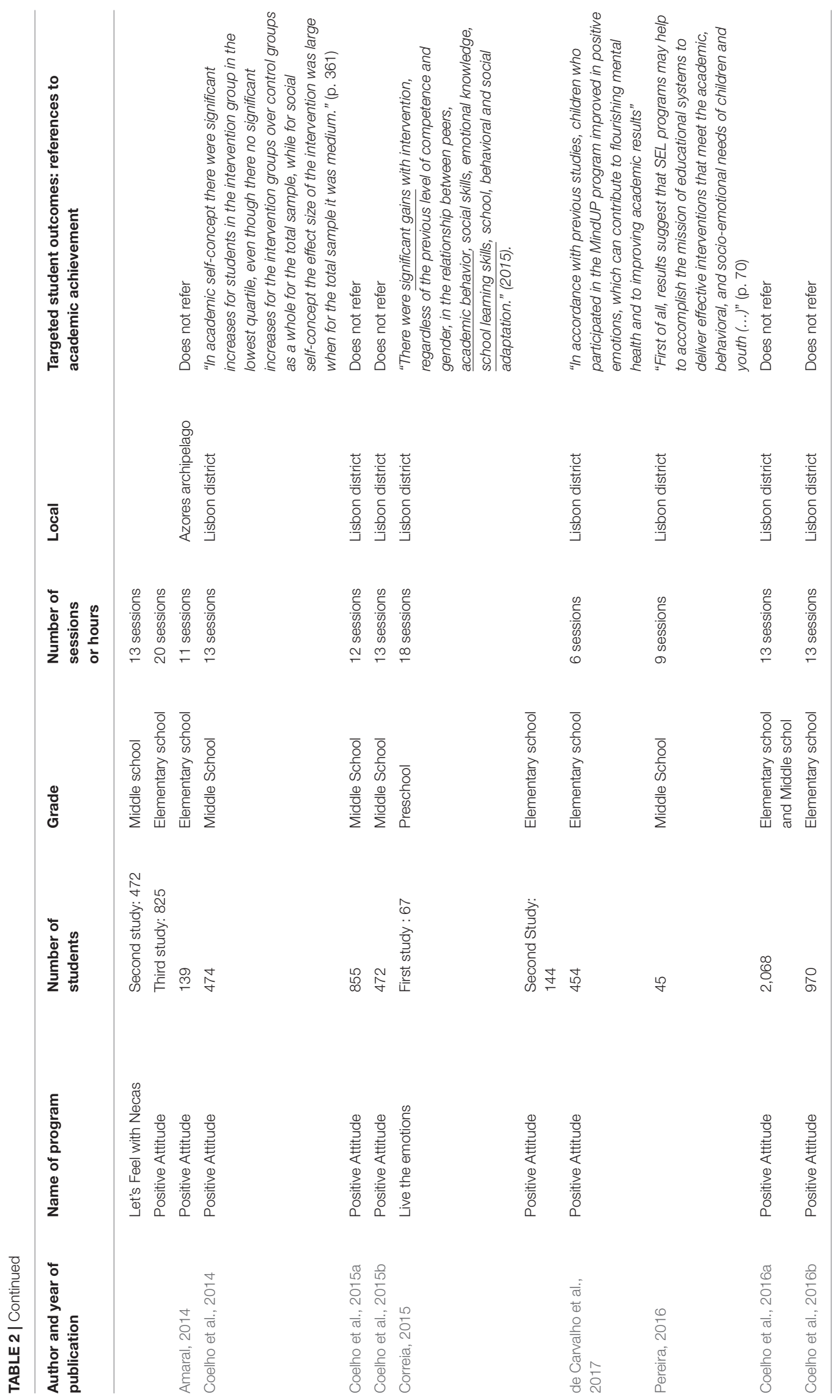


Finally, as Table 2 illustrates, most SEL Programs, with only two exceptions, refer to the relationship between programs and academic achievement. Although, the literature indicates that one of the results of the implementation of SEL Programs is the improvement of academic performance, in the studies analyzed only nine studies refer to this relationship.

\section{DISCUSSION}

The discussion around twenty-first century competencies has rekindled the debate about the importance of developing social and emotional competencies in our children and young people. The promotion of social and emotional competencies within the Portuguese educational context has seen advances and retreats. Costa and Faria's (2013) analysis clearly presents the introduction of disciplinary areas at certain times in the last 30 years (example: Project Area, Personal, and Social Development) and their exclusion. They see a preference for performanceoriented education vs. the integration of the personal and social competencies and the search for greater understanding of their contribution to preventing academic failure (Costa and Faria, 2013). They trace these changes to political changes within the Ministry of Education.

School culture must also be referred to, namely teacher resistance to innovative practices that might bring improvements to students and to the school environment. Santo and Alves (2015) affirm that resistance in schools is notorious oftentimes because of the "lack of commitment of the teachers and students, a latent conflict of dissatisfaction that does not allow a cooperative work that leads to the implementation of new practices inside and outside the classroom" (p. 1,061).

We are experiencing a special moment in Portugal, due to the extension of compulsory schooling to 12 years of schooling or 18 years of age, and this has brought various challenges to schools, teachers, and society as a whole. A 2014 study on the enlargement of schools concluded in part that "it is fundamental that the school prepares young people to overcome their difficulties autonomously" (Cid et al., 2014, p. 121).

The challenges of the twenty-first century on the one hand, on the other hand, the challenges of the Portuguese education reforms were the motto for the public discussion of the Profile of students at the end of compulsory schooling. According to Martins et al. (2017), the discussion is based on a "model of schooling oriented toward student learning, which aims at both individual qualification and democratic citizenship" (p. 10). This is an important moment in the Portuguese context that we believe may bring important changes regarding the promotion of citizenship skills in our students.

In conclusion, we defend the SEL approach aimed at developing five key competencies: self-awareness, social awareness, self-control, relational skills, and responsible decision making (CASEL, 2003). In our view, this is a promising approach to supporting students to deal adequately with the demands of today's society while also promoting greater school success.

\section{CONCLUSION}

This study identified a dearth of literature about the implementation of SEL programs in Portuguese schools. Only 17 publications met our research criteria, seven of which belonged $^{* * *}$ to a single SEL initiative, the Positive Attitude program. We therefore conclude that, in addition to the lack of research, there also is little diversity among SEL programs. The first publications only began to appear in 2008, although recent years have witnessed an increase. Due to the impact of developing students' socio-emotional competences their behavior and academic success, we argue that this issue should receive greater attention by Portuguese researchers. More investigation should be carried out and published and the flow of publications as well as their quality should be monitored. Other countries, such as the U.S.A. and Spain are much more productive in this respect (Torrente et al., 2015). Our review of the research identified that academic investigations (masters and doctoral theses) comprised the vast majority of the literature on this issue, which suggests that universities play an important role in disseminating the SEL methodology. However, we believe that, in addition to academic researchers, Portuguese schoolteachers should be encouraged to publish what is done within their schools to encourage socio-emotional competences. Knowledge should not be hidden behind school walls.

We concluded from our analysis that research on Portuguese SEL programs and their relationship with academic success is still quite dispersed, both in relation to publication vehicles and in relation to authors and works of reference.

This study further suggests the need for inservice training about this issue as well as the importance of preparing new teachers in SEL (Schonert-Reicht Kimberly, 2017). One study of this type is limited due to the source and availability of data. We faced the fact that our institution did not have access to all of the available data bases, nor were many publications available for consultation.

\section{AUTHOR CONTRIBUTIONS}

Conceptualization: AMC and AAC; Methodology: AMC and JV; Formal Analysis: JV; Investigation: AMC; Writing-Review and Editing: AMC and AAC; Supervision: AMC and JV.

\section{FUNDING}

This work was supported by Fundation Calouste Gulbenkian as part of the Project PMA-CEAG-XXI. AMC is supported by a PhD grant from Fundation Calouste Gulbenkian as part of the Project CEAG-XXI funded by the same institution. And AAC is supported by FCT: SFRH/BSAB/130560/2017.

\section{ACKNOWLEDGMENTS}

Portions of the present findings were obtained by AMC as a part of her $\mathrm{PhD}$ thesis. 


\section{REFERENCES}

Amaral, S. (2014). Promoting Emotional Regulation in Children in the First Cycle of Basic Education: A Program of Emotional and Social Competencies, Master thesis, Repository of Açores University.

Archambault, É., Campbell, D., Gingras, Y., and Larivière, V. (2009). Comparing bibliometric statistics obtained from the Web of science and scopus. J. Am. Soc. Inf. Sci. Technol. 60, 1320-1326. doi: 10.1002/asi.21062

Bardin, L. (2008). Content Analysis. Lisbon: Edições 70.

Blake, P., Piovesan, M., Montinari, N., Warneken, F., and Gino, F. (2015). Prosocial norms in the classroom: The role of self-regulation in following norms of giving. J. Econ. Behav. Organ. 115, 18-29. doi: 10.1016/j.jebo.2014.10.004

Brackett, M., Elbertson, N., and Rivers, S. (2016). "Applying theory the development of approaches to SEL," in Handbook of Social and Emotional Learning, eds J. A. Durlak, C. E. Domitrovich, R. P. Weissberg, and T. P. Gullota (New York, NY: Guilford Publications), 20-32.

Campino, S. (2012). Evaluation of the Process of Implementation of A Program to Promote Social and Emotional Competencies in the Transition from Preschool to 1st Year of Schooling. Master thesis, Repository of Lisbon University.

Cid, M., Verdasca, J., Oliveira, M., Borralho, A., Grácio, L., Chaleta, E., et al. (2014). The Scientific-Humanistic Courses And The Extension of Compulsory Schooling. Lisboa: DGE.

Coelho, V., Sousa, V., and Figueira, A. (2014). The impact of a school-based social and emotional learning program on the self-concept of middle school students. Revista de Psicodidáctica 19, 347-365. doi: 10.1387/RevPsicodidact.10714

Coelho, V., Marchante, M., and Sousa, V. (2015a). "Positive attitude": a multilevel model analysis of the effectiveness of a social and emotional learning program for portuguese middle school students. J. Adolesc. 43, 29-38. doi: 10.1016/j.adolescence.2015.05.009

Coelho, V., Sousa, V., Raimundo, R., and Figueira, A. (2015b). The impact of a Portuguese middle school social-emotional learning program. Health Prom. Int. 32, 292-300. doi: 10.1093/heapro/dav064

Coelho, V., Marchante, M., and Sousa, V. (2016a). Positive attitude program's impact upon self-concept across childhood and adolescence. Revista de Psicodidáctica 21, 261-280. doi: 10.1387/RevPsicodidact.15129

Coelho, V., Sousa, V., and Figueira, A. (2016b). The effectiveness of a portuguese elementary school social and emotional learning program. J. Prim. Prev. 37, 433-447. doi: 10.1007/s10935-016-0445-4

Coelho, V. (2014). Promotion of Success and School Adjustment: Studies on the Effectiveness and Effectiveness of Social-Emotional Development Programs for Students in Grades 4 to 9. Ph.D. thesis, Repository of Coimbra University.

Collaborative for Academic Social and Emotional Learning (CASEL) (2003). Safe and Soud: An Educational Leader's Guide to Evidence-Based Social and Emotional Learning (SEL) Programs. Chicago: Collaborative for Academic Social and Emotional Learning.

Collaborative for Academic Social and Emotional Learning (CASEL) (2012). Effective Social and Emotional Learning Programs: Preschool and Elementary School Edition. Available online at: http://casel.org/wp-content/uploads/2016/ 01/2013-casel-guide- $1 . p d f$

Collaborative for Academic Social and Emotional Learning (CASEL) (2013). Implementing Systemic District and School Social and Emotional Learning. (Chicago, IL).

Collaborative for Academic Social and Emotional Learning (CASEL) (2016). SEL Impact. Available online at: http://www.casel.org/impact/

Correia, K. (2015). Adaptation in the Transition from Preschool to 1st Year of Schooling: Design and Evaluation of the Effectiveness of An Intervention Program. Ph.D. thesis, Repository of Lisbon University.

Cortez, P. (2011). Some Scholarly Communication Guidelines: Teaching Report. Guimarães: Department of Information Systems of University of Minho. Avaiable online at: http://hdl.handle.net/1822/11599

Costa, A., and Faria, L. (2013). Aprendizagem social e emocional: reflexões sobre a teoria e a prática na escola portuguesa. Anál. Psicol. 31, 407-424. doi: 10.14417/ap.701

de Carvalho, J. S., Pinto, A. M., and Marôco, J. (2017). Results of a mindfulnessbased social-emotional learning program on portuguese elementary students and teachers: a quasi-experimental study. Mindfulness. 8, 337-350 doi: $10.1007 / \mathrm{s} 12671-016-0603-\mathrm{z}$
Directorate-General for Health (2013). Portugal Mental Health in Numbers: National Program for Mental Health. Lisbon: Directorate-General for Health.

Directorate-General of Health (2017). Why Talk About Mental Health? Available online at: https://www.dgs.pt/paginas-de-sistema/saude-de-a-a-z/programanacional-para-a-saude- mental/perguntas-e-respostas.aspx

Durlak, J., and Wells, A. (1997). Primary prevention mental health programs for children and adolescentes: a meta-analytic review. Am. J. Commun. Psychol. 25, 115-152. doi: 10.1023/A:1024654026646

Durlak, J., Weissberg, R., Dyminicki, A., Taylor, R., and Schellinger, K. (2011). The impact of enhancing students' social and emotional learning: a metaanalysis of school-based universal interventions. Child Dev. 82, 405-432. doi: 10.1111/j.1467-8624.2010.01564.x

Elias, M. J., Zins, J. E., Weissberg, R. P., Frey, K. S., Greenberg, M. T., Haynes, N. M., et al. (1997). Promoting Social and Emotional Learning: Guidelines for Educators. Alexandria, VA: Association for Supervision and Curriculum Development.

Elias, M., Leverett, L., Duffell, J., Humphrey, N., Stepney, C., and Ferrito, J. (2015). "Integrating SEL with related prevention and youth development approaches," in Handbook of Social and Emotional Learning, eds J. Durlak, C. Domitrovich, R. Weissberg, and T. Gullotta (New York, NY: The Guilford Press), 33-49.

Faria, L. (2011). "Social and emotional education in Portugal: Perspectives and prospects," in Social and Emotional Education: An International Analysis, ed Foundation Marcelino Botín (Spain: Santander), 153-187.

Greenberg, M. T., Weissberg, R. P., O’Brien, M. U., Zins, J. E., Fredericks, L., Resnik, H., et al. (2003). Enhancing school-based prevention and youth development through coordinated social and emotional learning. Am. Psychol. 58, 466-474. doi: 10.1037/0003-066X.58.6-7.466

Kickbush, I. (2012). Learning for Well-Being: A Policy Priority for Children and Youth in Europe. A Process for Change. Lisbon: Calouste Gulbenkian Foundation.

Learning First Alliance (2001). Every Child Learning: Safe and Supportive Schools. Washington, DC: Learning First Alliance.

Lopes, P., and Salovey, P. (2004). "Toward a broder education: social, emotional, and pratical skills," in Building Academic Success on Social and Emotional Learning: What Does the Research Say? eds J. Zins, R. Weissberg, M. Wang, and H. Walberg (New York, NY: Teacher College Press), 76-93.

Martins, G., Gomes, C., Brocardo, J., Pedroso, J., Carrilho, J., Ucha, L., et al. (2017). Profile of Students at the End of Compulsory Schooling. Available online at: http://dge.mec.pt/sites/default/files/Noticias_Imagens/perfil_do_aluno.pdf

Menezes, I. (2003). Civic education in Portugal: curricular evolutions in basic education. J. Soc. Sci. Educ. 2, 1-13. doi: 10.4119/UNIBI/jsse-v2-i2-474

Moreira, P. M., Crusellas, L., Sá, I., Gomes, P., and Matias, C. (2010). Evaluation of a manual-based programme for the promotion of social and emotional skills in elementary school children: results from a 4-year study in Portugal. Health Promot. Int. 25, 309-317.doi: 10.1093/heapro/ daq029

National Coordination for Mental Health (2008). National Mental Health Plan 2007-2016. Retrieved from the Website of the Office of the High Commissioner for Health. Available online at: http://www.adeb.pt/files/upload/paginas/Plano \%20Nacional\%20de\%20Saude\%20Mental.pdf

National Research Council (2012). Education for Life and Work: Developing Transferable Knowledge and Skills in the 21st Century. Washington, DC: The National Academies Press. doi: 10.17226/13398

Neely, A. (2005). The evolution of performance measurement research: developments in the last decade and a research agenda for the next. Int. J. Oper. Prod. Manag. 25, 1264-1277. doi: 10.1108/014435705106 33648

Neves, M. (2008). Promotion of Coping Skills in Students of the 3rd Cycle: an Exploratory Study. Master thesis, Available in Repository of Lisbon University.

Payton, J., Weissberg, R. P., Durlak, J. A., Dymnicki, A. B., Taylor, R. D., Schellinger, K. B., et al. (2008). The Positive Impact of Social and Emotional Learning for Kindergarten to Eighth-Grade Students: Findings from Three Scientific Reviews. Chicago, IL: Collaborative for Academic, Social, and Emotional Learning.

Pereira, N. (2016). "Experiencing Emotions": Planning and Evaluating an Apprenticeship Program Socio-Emotional with Educational Dance. Ph.D. thesis, Repository of Lisbon University. 
Pinto, A., and Raimundo, R. (2016). "Socio-emotional learning framework: evolution and challenges,"in Evaluation and Promotion of Socioemotional Skills in Portugal, eds A. Pinto and R. Raimundo (Lisboa: Coisas de Ler), 15-36.

Póvoa, D. (2013). Emotion School: Feelings and Emotions in Mediation of Behaviors. Master thesis, Repository of Aveiro University.

Raimundo, R. (2012). "Slowly but Steadily": Evaluation of the Effectiveness and Quality of the Implementation of A Program for the Promotion of Socioeconomic Competencies in Children. Ph.D. thesis, Available in Repository of Lisbon University.

Raimundo, R., Marques-Pinto, A., and Lima, M. L. (2013). The effects of a social-emotional learning program on elementary school children: the role of pupils' characteristics. Psychol. Schools 50, 165-180. doi: 10.1002/pits. 21667

Reinas, F. (2011). Evaluation of A Program to Promote Socio-Emotional Skills: Process Analysis of Negative Critical Incidents. Master thesis, Available in Repository of Lisbon University.

Santo, I., and Alves, J. (2015)." A new management model of schools: between the rhetoric change and the emptiness of consequences," in Proceedings Education, Territories and Human Development: Minutes of the First International Seminar, Available online at: http://repositorio.ucp.pt/bitstream/10400.14/19537/1/Um novo modelo de gestẽo das escolas entre a retórica da mudança e o vazio das consequências.PDF

Schonert-Reicht Kimberly (2017). Social and emotional learning and teachers. Future Children 27, 137-155.

Silva, M. (2013). IBDP (International Baccalaureate Diploma Program) and the Impact of CAS (Creativity, Action, Service) Activities on the Personal and Social Development of Students. Master thesis, Available in Repository of Lisbon University.

Silva, H. (2014). Study of the Effects of the Eu and o Others Program (History 9) on Institutionalized and Non-Institutionalized Adolescents. Master thesis, Available in Repository of Lisbon University.
Torrente, C., Alimchandani, A., and Aber, L. (2015). "International Perspectives on SEL," in Handbook of Social and Emotional Learning, eds J. Durlack, C. Domitrovich, R. Weissberg, and T. Gullota (New York, NY: The Guildford Press), 566-587.

Weissberg, R., Durlak, J., Domitrovich, C., and Gullotta, T. (2015). "Social and emotional learning: past, present, and future," in Handbook of Social and Emotional Learning, eds J. Durlak, C. Domitrovich, R. Weissberg and T. Gullotta (New York, NY: The Guilford Press), 3-19.

World Economic Forum (2016). The Future of Jobs Employment, Skills and Workforce Strategy for the Fourth Industrial Revolution. Global Challenge Insight Report.

Zins, J., Bloodworth, M., Weissberg, R., and Walberg, H., (2004). "The scientific base linking social and emotional learning to school success," in Building Academic Success on Social and Emotional Learning: What Does the Research Say? eds J. E. Zins, R. P. Weissberg, M. C. Wang, and H. J. Walberg (New York, NY: Teachers College Press), 3-22.

Zupic and Cater (2015) Bibliometric methods in management and organization. Organ. Res. Methods 18, 429-472. doi: 10.1177/10944281145 62629

Conflict of Interest Statement: The authors declare that the research was conducted in the absence of any commercial or financial relationships that could be construed as a potential conflict of interest.

Copyright (C) 2017 Cristóvão, Candeias and Verdasca. This is an open-access article distributed under the terms of the Creative Commons Attribution License (CC BY). The use, distribution or reproduction in other forums is permitted, provided the original author(s) or licensor are credited and that the original publication in this journal is cited, in accordance with accepted academic practice. No use, distribution or reproduction is permitted which does not comply with these terms. 
OPEN ACCESS

Edited by:

Edgar Galindo,

University of Évora, Portugal

Reviewed by:

Heldemerina Samutelela Pires,

University of Évora, Portugal

Evelyn Kroesbergen,

Utrecht University, Netherlands

Juan Luis Castejon,

University of Alicante, Spain

*Correspondence:

Lilia Marcelino

lilia.marcelino@gmail.com

Specialty section:

This article was submitted to

Educational Psychology,

a section of the journal

Frontiers in Psychology

Received: 24 February 2017 Accepted: 14 June 2017

Published: 30 June 2017

Citation:

Marcelino L, de Sousa Ó and Lopes A (2017) Predictive Relation

between Early Numerical

Competencies and Mathematics Achievement in First Grade

Portuguese Children.

Front. Psychol. 8:1103.

doi: 10.3389/fpsyg.2017.01103

\section{Predictive Relation between Early Numerical Competencies and Mathematics Achievement in First Grade Portuguese Children}

\author{
Lilia Marcelino $^{1 *}$, Óscar de Sousa ${ }^{1}$ and António Lopes ${ }^{2}$ \\ ${ }^{1}$ Center of Interdisciplinary Studies in Education and Development, Education Institute, Universidade Lusófona, Lisbon, \\ Portugal, ${ }^{2}$ Center of Studies in Cognitive Psychology and Learning, Faculty of Psychology, Universidade Lusófona, Lisbon, \\ Portugal
}

Early numerical competencies (ENC) (counting, number relations, and basic arithmetic operations) have a central position in the initial learning of mathematics, and their assessment is useful for predicting later mathematics achievement. Using a regression model, this study aims to analyze the correlational and predictive evidence between ENC and mathematics achievement in first grade Portuguese children $(n=123)$. The children's ENC were examined at the point of school entry. Three criterion groups (low, moderate, and high ENC) were formed based on the results of the early numerical brief screener and mathematics achievement measured at the end of first grade. The following hypotheses were tested: children who started first grade with low numerical competencies remained low mathematics achievement at the end of first grade; and children who started with high numerical competencies, finished the first grade with high mathematics achievement. The results showed that ENC contributed to a significant amount of explained variance in mathematics achievement at the end of the first grade. Children with low numerical competencies performed lower than children with moderate and high numerical competencies. Findings suggest that ENC are meaningful for predicting first-grade mathematics difficulties.

Keywords: early numerical competencies, mathematics achievement, grade 1, short-term longitudinal study, linear regression model

\section{INTRODUCTION}

Difficulties in mathematics are pervasive and can have lifelong consequences (Jordan, 2010). Androulla Vassiliou, Commissioner responsible for Education, Culture, Multilingualism and Youth, endorsed this argument saying that: "Competence in mathematics has been identified at $\mathrm{EU}$ level as one of the key competences for personal fulfillment, active citizenship, social inclusion and employability in the knowledge society of the 21st century. Concerns about low student performance, as revealed by international surveys, led to the adoption in 2009 of an EU-wide benchmark in basic skills" [Education, Audiovisual and Culture Executive Agency (EACEA P9 Eurydice), 2011, p.3].

Identifying these basic skills has been a mathematical cognition research concern for the past two decades, and some key findings relevant to later achievement in mathematics were pointed out 
by Alcock et al. (2016). For instance, longitudinal studies are necessary to investigate which early abilities predict later mathematics achievement, and it is crucial to map predictors of mathematical competence to develop valid and reliable measures and to design effective interventions. Screening and targeted intervention would allow young children at risk for failure in mathematics to be identified and supported at early ages (Jordan et al., 2010).

The present study attempts to contribute to this research which aims to analyze the correlation and predictive evidence between early numerical competencies (ENC) (which are pointed out as one of the foundations of mathematical competence) and mathematics achievement at the end of first grade. We expect to enhance the transcultural evidence and consistency of international studies that analyzed and verified the predictive relation between these two variables in different contexts, in this case, in the Portuguese setting.

Our study may not only contribute to the international literature, as mentioned above, but may also give theoretical support to national literature, due to the fact that the National Council of Education (Conselho National de Educação, 2015) reported the need for an early identification and intervention at the first signs of school failure, particularly in kindergarten and in the first years of schooling, to fight the national grade retention considered $10 \%$ in 2 nd grade, and to combat the difficulties that 4th grade students showed in mental calculation, in performing arithmetic operations, and in other mathematics areas, such as geometry.

In this paper, we refer to the ENC as a set of symbolic numerical abilities (also known as symbolic number sense) received from cultural and learning inputs, which may depend on the development and the integration of multiple basic cognitive abilities (Dehaene, 2011), such as working memory. Hornung et al. (2014) revealed that non-verbal number sense and working memory are central buildings blocks for developing ENC in kindergarten, and ENC is a key competence for first grade mathematics achievement.

Although there is no one definition of ENC, several researchers agree that this set of symbolic competencies in the 4to 6-year-old range refers to: (a) counting in a small set of objects; (b) number identification; (c) making relations about numbers (e.g., 4 is closer to 3 than to 6 ) and their magnitudes (e.g., 5 is more than 3); and (d) basic arithmetic operations, which means transforming sets of numbers by adding or taking away items (e.g., 3 and 2 makes 5, and taking away 2 from 5 is 3) (Griffin and Case, 1997; Gersten and Chard, 1999; Berch, 2005; Jordan et al., 2008).

\section{Counting}

To represent larger sets precisely, children need to learn how to count (Jordan and Levine, 2009). With the introduction of a verbal representation - the number word, counting is considered a symbolic numerical competence, which includes oral and object counting. Children can often count to 10 (reciting $1,2,3,4,5 \ldots)$, but they may not understand what numbers represent (Bermejo et al., 2004). To do so, children need to gradually bring meaning to counting (Dehaene, 2011). Meaning to counting signifies that numbers in the counting sequence have larger quantities than earlier numbers (e.g., n; n+1; $(n+1)$ +1 , etc.) and numbers have exact magnitudes (Sarnecka and Carey, 2008). For small sets (i.e., sets of 3 or less), children first map number words through subitization (Le Corre and Carey, 2007). For larger sets, counting is usually needed to determine the cardinal value. During preschool and kindergarten, most children learn to enumerate sets in a stable order (e.g.,1, 2, 3, $4,5)$ using one-to-one correspondence between the number and the object, and come to realize cardinality, which means that the last number indicates the number of objects in a set (Gelman and Gallistel, 1978). Understanding these counting principles allows children to enumerate any type of sets (e.g., heterogeneous or homogeneous) in any direction (e.g., left to right or right to left and so forth). Children also use meaning to counting to construct a linear representation of numerical magnitudes (also known as mental number line), which allows them to compare numbers, learn how to place values in our base-10 number system, and manipulate sets through addition and subtraction, with and without object representations (Levine et al., 1992).

\section{Number Identification}

Identifying numbers implies the ability to identify or recognize a number symbol (e.g., 13) or number symbols combined to represent any number (e.g., 128) presented as a visual stimulus. To answer the question "What number is this?" children must learn number-words using long-term memory.

\section{Comparing Numbers}

Comparing numbers on the most basic level implies that children look at two numbers (e.g., 4 and 9) and answer the question, "Which is bigger?"(9) or "Which is smaller?"(4). Preschool students, when presented with two non-symbolic sets for comparison, often do not count when comparing the two sets. Typically, students rely on visual (i.e., non-symbolic) inspection (Zhou, 2002). This helps students only for a while, generally when numbers are between 1 and 3, after which they rely more on the system of approximate magnitudes to make judgments of small quantities larger than 3 (Xu and Spelke, 2000), using the mechanism to represent approximate quantities. At 6 years of age, students integrate counting schemes that allow them to develop a numeric mental line (Siegler and Booth, 2004). It is this mental line that will give them better knowledge of "quantitative words" (Griffin, 2002), and to understand that the numbers themselves in this numerical sequence have distinct magnitudes numbers (e.g., 5 is a successor number and greater than 4 and predecessor number, less than 6). Understanding that numerical sequence is becoming larger and more inclusive than the preceding numbers, the student begins to command the identification of successor numbers and predecessors (Le Corre and Carey, 2007, Sarnecka and Carey, 2008). Students also need to discriminate and relate quantities using symbolic mathematical processes, such as the use of numerals and cardinal numbers. For instance, knowing that eight (8) is bigger $(>)$ than five (5), six (6) is smaller $(<)$ than nine (9), or that 5 is closer to 6 than to 7 (Case and Griffin, 1990). Studies with adults showed that students have an easier time discriminating between quantities that are much farther apart 
(e.g., 9 and 2) than those that are closer in magnitude (e.g., 9 and 8) (Murray and Mayer, 1988).

\section{Basic Arithmetic Operations}

Adequate counting, comparing, and symbol knowledge skills are necessary to carry out most addition and subtraction problems presented to students in early elementary school (Powell and Fuchs, 2012). To learn about the addition and subtraction (i.e., basic facts), students often work on simple problems with manipulatives. With practice, students rely less on manipulatives and more on their fingers for counting (Groen and Resnick, 1977). Because counting is often involved in solving basic addition and subtraction, counting skills are important (Baroody et al., 2009). Most of the time, young students use counting by ones as their default counting mechanism, and then counting by twos or utilizing subitizing skills (Camos, 2003). Students then move from counting to solving basic arithmetic operations using reasoning strategies (e.g., the friends of 10 's) or from memory (e.g., fact retrieval). Mastery of and fluency in numerical calculations (fact retrieval and computation fluency) is the end goal of basic arithmetic operations, and it is considered a necessary foundation at many levels - from solving simple word problems, to calculating with fractions, decimals and percentages, to solving algebraic equations or even to calculating with basic geometry (Jordan et al., 2007, 2008).

Some studies indicate that ENC, especially with respect to basic arithmetic operations, are closely tied to the mathematics curriculum in elementary school. For instance, the results of the Geary et al. (2000) study, showed that weak numerical competencies are associated with characteristics of mathematics learning difficulties, such as poor counting procedures, slow fact retrieval, and inaccurate computation. Therefore, inaccurate and dysfluent numerical calculation, considered a signature characteristic of students with learning difficulties in mathematics, is identified as a fundamental weakness in numerical competencies (Gersten et al., 2005; Jordan et al., 2008). Moreover, Locuniak and Jordan (2008) assessed ENC using symbolic and non-symbolic tasks in 198 kindergarten children, and again in second grade on a calculation fluency measure. Students scoring below the 25th percentile at the beginning of kindergarten were designated at risk for poor mathematics development. The results showed that approximately $52 \%$ of children with difficulties in fluency in numerical calculations were identified as at-risk students.

These findings suggested that ENC is a crucial predictor of early mathematics achievement. Children who started first grade with advanced ENC will consequently progress faster in arithmetic and generally in symbolic numerical tasks in the first grade (Bartelet et al., 2014). Hornung et al. (2014), using structural equation modeling and mediation analyses, suggested that ENC (verbal counting, dot counting, and Arabic number comparison, measured in kindergarten) is a critical mediator of the relationship between kindergarten non-symbolic domain-specific (i.e., approximate estimation of quantities) and domain-general (i.e., working memory) predictors and first grade mathematics achievement. They found that nonsymbolic domain-specific abilities and working memory turned out to be critical for ENC in kindergarten, but not for first grade mathematics achievement after ENC was taken into account. In line with these studies, Jordan et al. (2007) indicate that the development and performance of counting, number identification, number comparison and basic arithmetic operations in kindergarten children explain $66 \%$ of mathematics achievement at the end of first grade.

\section{Purpose and Research Questions}

The present study aims to understand to role of ENC in mathematics achievement in Portuguese first school children. The main purpose is to analyze the correlation and predictive evidence between ENC and mathematics achievement at the end of first grade. The following research questions were considered:

(1) What is the correlation between ENC and mathematics achievement at the end of first grade?;

(2) Do ENC at the point of school entry predict mathematics achievement at the end of first grade?;

(3) What is the relation between low, moderate, and high numerical competencies and mathematics achievement? In this research question, two hypotheses were tested: (a) children who started first grade with low numerical competencies remained low mathematics achievement at the end of first grade; (b) children who started with moderate numerical competencies, finished the first grade with moderate to higher gains on mathematics achievement; (c) children who started with high numerical competencies, finished the first grade with high mathematics achievement.

\section{MATERIALS AND METHODS}

The NSB - Number Sense Brief Screener (Jordan et al., 2008) was adapted to the Portuguese population $(n=2246)$, and psychometrics properties analyzed (Marcelino et al., 2012; Marcelino, 2015). Children were evaluated at the beginning of first grade (defined as a status point) and mathematics outcomes were obtained adding a formal mathematics achievement test (MSE - Math Summative Evaluation), the psychometric properties of which were also analyzed. Correlation and regression data analyses were used to evaluate the association between NSB and MSE.

Children were split into the low, middle, and high grounds based on the normative values of NSB. Children were assigned to the low numerical competence group (A) when they performed at or below the 25th percentile; average numerical competence (B) and high numerical competence (C) children's groups were defined as performing on the $25-75$ th range, and above the 75 th percentile, respectively.

\section{Participants}

The participants were children who, after kindergarten, attended the first grade (first year of formal schooling in Portugal) in four elementary public schools. The average age was $6.37(S D=0.74)$; 71 of the 123 students were boys and 52 were girls. All children were taught mathematics with the same formal curriculum mathematics contents. 
The public schools are located in a residential area of western Lisbon with different background characteristics concerning the level of education and socioeconomic level of the local population. The southern part has a family-unit urbanization with houses, where the level of education and the socioeconomic level is medium-high. The northern part has buildings (median five stories) with a medium to low socioeconomic level.

Among the demographic characteristics of the three working samples, Group C (high numerical competence) has more boys than girls, and the parents' education is higher when compared to Group A (low numerical competence).

The demographic information of the overall sample and the three working sample is portrayed in Table 1.

\section{Materials}

\section{Number Sense Brief Screener (NSB)}

The NSB is a shortened version (Jordan et al., 2008) of the Number Sense Battery developed by Jordan et al. (2006). It is a number sense assessment tool for identifying children at risk for mathematics difficulties. The items assess symbolic numerical competencies - counting knowledge and principles, number identification, number comparison, non-verbal calculation, story problems, and number combinations. The NSB can being applied to 4- to 6-year-old children. The total possible score on the NSB is 33 points in a dichotomous scale $(1=$ correct; $0=$ incorrect $)$. The NSB is reliable, with a Cronbach alpha of 0.84 at the beginning of first grade, with a raw score mean of 21.83 (Jordan et al., 2008, 2010).

The NSB raw score means for the Portuguese population is 22.87 points (Marcelino, 2015) (scale in the range 033). The psychometric analysis indicated that NSB is reliable with a coefficient Cronbach alpha of $0.87(n=2246)$ at the beginning of first grade. The measure shows homogeneity between items, with an acceptable item-total mean correlation of 0.69 .

The composite achievement score in NSB (NSB overall) was the combined raw scores for seven subtests assessing the following ENC:

TABLE 1 | Demographic information for participants.

\begin{tabular}{lrrrr}
\hline & NSB & Group A & Group B & Group C \\
\hline Gender & & & & \\
Male & 57.70 & 53.70 & 53.80 & 71.40 \\
Female & 42.30 & 46.30 & 46.20 & 28.60 \\
Parent's education & & & & \\
Primary education & 6.80 & 10.30 & 5.00 & 5.30 \\
Secondary education & 52.50 & 61.90 & 54.60 & 42.90 \\
Higher education & 40.70 & 27.80 & 40.40 & 51.80 \\
\hline
\end{tabular}

Each value corresponds to the value's percentage of the total. Parents' education level refers to primary (up to fourth grade), secondary (up to twelfth grade), and higher education (concluded). NSB, number sense brief screener overall; Group A, low numerical competence; Group B, moderate numerical competence; Group C, high numerical competence (C). NSB ( $n=123)$; Group A $(n=43)$; Group B $(n=52)$; Group C $(n=28)$.

\section{Counting (3 items)}

After the child finished counting a set of five stars, the examiner asked the following question: "How many stars were on the paper you just saw?" Counting sequence also included counting to 30 .

\section{Counting principles (4 items)}

To assess counting principles, children were asked to recognize correct, incorrect counts (e.g., counting the first object twice), and correct unusual counts (e.g., counting from right to left or counting the yellow dots first and the blue dots afterward).

\section{Number identification (4 items)}

Children were asked to name a visually presented number (e.g., 13) with the question "What number is this?"

\section{Number comparisons (7 items)}

Children were asked to make numerical magnitude judgments in three different ways: (a) given a number (e.g., 7), children were asked what number comes after the given number and what number comes two numbers after the given number; (b) given two numbers, children were asked to indicate which of two numbers was bigger or smaller; (c) and given three number (e.g., 6,2 , and 5), each placed on the point of an equilateral triangle, children also were asked to identify which number was closer to the target number.

\section{Non-verbal calculation (4 items)}

On non-verbal calculation (presence of objects but without verbal stimuli) the examiner showed a set of chips, covered them, and then performed the addition or subtraction transformation (by removing or adding chips). Children were then asked to indicate how many chips were then under the cover.

\section{Story problems (5 items)}

On story problems (objects referents with verbal stimuli), children were orally phrased to three addition and two subtraction story problems and asked to solve them (e.g., Jose has 3 cookies. Sarah gives him 2 more cookies. How many cookies does Jose have now?).

\section{Number combination (6 items)}

On number combination (no object referents with verbal stimuli), children were asked to solve four addition and two subtraction computations (e.g., How much is 3 and 2?).

\section{Mathematic Summative Evaluation (MSE)}

Achievement in mathematics was assessed using a formal Portuguese school evaluation of mathematics. The MSE was applied by teachers to measure mathematics achievement at the end of first grade in the classroom for $1 \mathrm{~h}$ and a half. The measure is based on 25 items. Results were normalized to a total of $100 \%$. The items included four subtests using the quantities 1 up to 99.

The composite achievement score (MSE overall) was the combined raw scores for subtests assessing counting and arithmetic operations, place value, applied problems and basic geometry.

The psychometric analysis showed that MSE is reliable with an internal-consistency reliability of $0.87(n=119)$. Subtests coefficients alpha were also analyzed, respectively, counting and 
operations ( $\alpha=0.729$ ), place value ( $\alpha=0.764$ ), applied problems ( $\alpha=0.804)$ and, forms and spatial $(\alpha=0.669)$. The measure shows homogeneity between items, with an acceptable item-total mean correlation of 0.71 .

\section{Counting and operations}

Children were asked to solve exercises concerning object counting to 10 , counting by fives up to 30 , counting money up to 10 (e.g., $1 €+2 €+5 €$ ), ordering numbers up to 99 , adding and subtracting facts up to 99 (e.g., $15+25=\ldots, 50-40=\ldots$ ) and missing values with addition facts (e.g., $80=40+\ldots$ ).

\section{Place value}

The tasks were related to units and tens identification with abacus and Cuisenaire rods models. Children also had to identify predecessor and successor numbers up to 99 (e.g., _ 49 _ ), and to identify several numbers on a number line (with interval from 10 to 90) partially filled with numbers.

\section{Applied problems}

Children were asked to solve three addition and subtraction word problems up to 50. Another word problem concerned the interpretation and counting data in a $2 \times 2$ table.

\section{Forms and spatial}

The tasks were related to geometry (e.g., to identify basic geometric figures), time (e.g., to identify the days of the week) and spatial sense (e.g., to design a symmetry figure).

\section{Procedure}

This study was carried out in accordance with the recommendations of the National Direction for Education with written informed consent to contact the national groups of schools. After one national group of schools with four primary public schools located in Lisbon had given permission to apply the present study, the sample were collected with the parents' written informed consent, with a notification that any elements of research will be covered by the anonymity of the participants.

Children were assessed individually with the NSB at the point of school entry by examiners who were fully trained in the testing procedures. The examiners were graduate students in Psychology and Education Sciences. Based on the NSB initial application protocol (Marcelino, 2015), the examiner read the questions to children individually while the children were seated next to him in a quiet room. Children's mathematics achievement was assessed at the end of first grade by teachers in the classroom using a mathematics achievement formal test (MSE).

\section{RESULTS}

\section{Correlation Evidence between Early Numerical Competencies and Mathematics Achievement}

To determine the association between ENC (assessed by NSB raw scores) and mathematics achievement (assessed by MSE raw scores), bivariate correlations were analyzed and are presented in
Table 2. The correlation between NSB overall and MSE overall was moderate, positive and statistically significant $(r=0.57)$. Between NSB overall and MSE subtests, all the correlations were also moderate, positive and statistically significant, with the highest correlation to be found in spatial and forms and counting and operations ( 0.50 and 0.50 , respectively).

Regarding the NSB subtests and MSE overall, number identification $(r=0.42)$, story problems $(r=0.50)$ and number combinations ( $r=0.49$ ) were the highest correlation found, with the lowest correlations being counting and principles $(r=0.10$ and $r=0.18$, respectively).

\section{Predictive Evidence of Early Numerical Competencies in Mathematics Achievement}

The main purpose of the study was to determine the contribution of the NSB in predicting mathematics achievement at the end of first grade. To accomplish this goal, students' scores on the NSB were regressed on the outcomes of ASM overall. As we are conducting a simple regression analysis on two variables which, on a first approach, are linearly dependent, the major assumptions concerns normality and homoscedasticity. In this regard, normality $\mathrm{P}-\mathrm{P}$ plots and Q-Q plots of the standardized residuals were conducted. Shapiro-Wilk test of normality of the standardized residuals reveals a significance of 0.043 which, per $s e$, does not represents a big "violation." On the other hand, the scatter-plot of the Standardized Residuals (Min. -2.20, Max. $1.85, M D=0.000, S D=1.000)$ vs. Standardized Predicted Value (Min. -2.21, Max. 1.71, $M D=0.000, S D=0.996$ ) is rather rectangular, indicating that behavior is not far from homoscedasticity. This is confirmed by the Breusch-Pagan test which gives $\chi^{2}(1)=3.247$ with a significance of 0.072 .

Table 3 presents the results for predicting on the MSE overall mathematics scores at the end of first grade. Results showed that the NSB was statistically significant to the prediction outcomes in MSE overall $(p<0.01)$. The NSB overall accounted for $33 \%$ of the variance in mathematics achievement scores.

Independent regressions of the different subareas of NSB vs. MSE were performed to recognize their relative importance on the prediction. Story problems $\left(R^{2}=0.25\right)$ and number combinations, $\left(R^{2}=0.24\right)$ accounted moderately for about $25 \%$ of the explained variance in MSE achievement. A stepwise regression analysis with all subareas of NSB showed that story problems by themselves accounted for $24.7 \%$ of the variance in mathematics achievement in first grade, and together with number identification accounted for $31 \%$. Individual subareas of the NSB, such as counting and counting principles are not statistically significant in predicting mathematics achievement $(p>0.05)$.

\section{Differences between NSB Achievement Groups and Mathematics Performance}

The differences between NSB outcomes groups (Group A, B, and $\mathrm{C}$; low, moderate, high numerical competencies) allow us to test if children who started first grade with low numerical 
TABLE 2 | Correlations between early numerical competencies and dependent variables.

\begin{tabular}{|c|c|c|c|c|c|}
\hline & MSE & co & Pv & Ap & FS \\
\hline NSB & $0.57^{* *}$ & $0.50^{* *}$ & $0.47^{* *}$ & $0.39^{* *}$ & $0.50^{* *}$ \\
\hline Counting & 0.10 & -0.03 & 0.07 & 0.08 & $0.19^{*}$ \\
\hline Counting principles & 0.18 & 0.18 & 0.10 & 0.12 & 0.13 \\
\hline Number identification & $0.42^{* *}$ & $0.36^{* *}$ & $0.34^{* *}$ & $0.32^{* *}$ & $0.28^{* *}$ \\
\hline Number comparisons & $0.37^{* *}$ & $0.35^{* *}$ & $0.32^{* *}$ & $0.24^{* *}$ & $0.34^{* *}$ \\
\hline Non-verbal calculation & $0.20 *$ & $0.18^{* *}$ & 0.12 & 0.12 & $0.22 *$ \\
\hline Story problems & $0.50^{* *}$ & $0.46^{* *}$ & $0.41^{* *}$ & $0.34^{* *}$ & $0.43^{* *}$ \\
\hline Number combinations & $0.49 * *$ & $0.39^{* *}$ & $0.42^{* *}$ & $0.34^{* *}$ & $0.47^{* *}$ \\
\hline
\end{tabular}

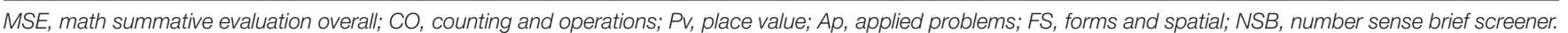
$n=118 .{ }^{*} p<0.05 .{ }^{* *} p<0.01$.

TABLE 3 | Variance explained and regression coefficients by early numerical competencies (assessed by NSB and subtests) in Mathematics Achievement (assessed by MSE).

\begin{tabular}{|c|c|c|c|c|c|}
\hline & $\mathbf{R}^{2}$ & B & Beta & $t$-value & $p$-value \\
\hline NSB & $0.33^{* *}$ & $2.16^{* *}$ & 0.57 & 7.53 & 0.00 \\
\hline Counting & 0.01 & 5.59 & 0.10 & 1.06 & 0.29 \\
\hline Counting principles & 0.03 & 5.73 & 0.18 & 1.96 & 0.05 \\
\hline Number identification & $0.17^{* *}$ & $6.99 * *$ & 0.42 & 4.94 & 0.01 \\
\hline Number comparisons & $0.14^{*}$ & $5.17^{*}$ & 0.37 & 4.32 & 0.02 \\
\hline Non-verbal calculation & $0.04^{*}$ & $5.77^{*}$ & 0.20 & 2.14 & 0.04 \\
\hline Story problems & $0.25^{* *}$ & $6.47^{* *}$ & 0.50 & 6.17 & 0.00 \\
\hline Number combinations & $0.24^{* *}$ & $4.87^{* *}$ & 0.49 & 6.01 & 0.00 \\
\hline
\end{tabular}

MSE, math summative evaluation; NSB, number sense brief screener overall. * $p<0.05,{ }^{* *} p<0.01$.

competencies remained low mathematics achievement at the end of first grade; and children who started with high numerical competencies finished the first grade with high mathematics achievement. Differences between NSB outcome groups were observed when mathematics achievements were measured at the end of first grade.

As data do not fit a normal distribution, a Kruskal-Wallis test was used to measure if differences between NSB groups' means were statistically significant. In this regard, we found significant group differences (A, B, and C) in mathematics achievement scores at the end of first grade, $\chi^{2}(2)=28.34$, $p<0.001$, with score means in MSE about 60\% (Group A), $72 \%$ (Group B), and $84 \%$ (Group C). Group A had the lowest mathematics means score, and Group $\mathrm{C}$ the highest in MSE overall and subareas. Group A was the only NSB group achievement who performed below in MSE overall and subareas (Table 4).

\section{DISCUSSION}

Early numerical competencies are considered a foundational domain-specific cognitive factor in the development of mathematical competence, allowing students to make connections with mathematical relationships, principles and procedures. Doing so, students can learn with success advanced mathematics (Gersten et al., 2005). Measuring ENC as early as possible is important in predicting later mathematics achievement, and can identify students at risk for having future mathematics difficulties (Jordan et al., 2007; Powell and Fuchs, 2012).

The main purpose of this study was to better understand the predictive relationship between early numerical competence (or number sense) and mathematics achievement in Portuguese students. Specifically, we attempted to predict achievement in mathematics at the end of first grade by measuring early number competencies at the point of entering school (i.e., prior of formal education). We used two measures: NSB Number Sense Brief Screener and MSE - Math Summative Evaluation in 123 children from an urban public-school setting.

The results indicated that numerical competencies (as assessed by NSB) had a moderate predictability for the performance of mathematics at the end of first year in Portuguese children. Jordan et al. (2007) found that the development and performance of counting, number identification, number relations and basic arithmetic operations in kindergarten children had a moderate to strong predictability of mathematics achievement at the end of first grade (Jordan et al., 2007, 2010, respectively). Our findings are in accordance with the results of Jordan and colleagues' studies concerning ENC as an important predictor of the achievement in mathematics, which supports transcultural evidence.

Our findings also show a positive, significant and moderate correlation between numerical competencies (as assessed by NSB) at the beginning of first grade, and the performance of mathematics at the end of first grade. The results indicated that basic arithmetic operations had the highest correlation with 
TABLE 4 | Mathematics achievement means score overall and subareas by NSB outcome groups.

\begin{tabular}{|c|c|c|c|c|}
\hline & NSB & Group A & Group B & Group C \\
\hline & $M D(D P)$ & $M D(D P)$ & $M D(D P)$ & $M D(D P)$ \\
\hline NSB & $22.42(05.83)$ & $15.35(02.93)$ & $23.80(02.35)$ & $29.60(01.63)$ \\
\hline MSE & 70.39 (21.39) & $57.49(23.01)$ & $71.66(19.53)$ & $83.63(10.55)$ \\
\hline Counting and operations & $16.86(05.84)$ & $14.05(05.71)$ & $16.96(05.22)$ & $21.16(03.31)$ \\
\hline Place value & $14.51(04.54)$ & $12.20(05.23)$ & $14.92(03.98)$ & $17.34(02.04)$ \\
\hline Applied problems & $18.84(10.00)$ & $14.79(10.87)$ & $19.18(09.36)$ & $24.82(06.01)$ \\
\hline Spatial and forms & $21.20(06.30)$ & $17.58(06.63)$ & $21.96(05.92)$ & $25.23(02.61)$ \\
\hline
\end{tabular}

MSE, math summative evaluation overall; SD, standard deviation, Group A ( $n=43$ ); Group B ( $n=52)$; Group $C$ ( $n=28$ ). NSB, number sense brief screener overall.

mathematics achievement when compared to other individual subareas of NSB.

Consistent with these findings, Jordan et al. (2006) found strong and significant correlations between basic arithmetic operations (number combinations and story problems) and mathematics achievement. Children developed an understanding of basic arithmetic operations and how they related to one another in the preschool years. Throughout the first year, children with low numerical competencies had difficulties in performing basic arithmetic operations involving addition and subtraction facts. Our results support other studies suggesting that weaknesses in numerical competencies, particularly those related to basic arithmetic operations, underlie most mathematical learning difficulties (e.g., Landerl et al., 2004; Gersten et al., 2005; Geary et al., 2007).

As stated by Baroody et al. (2009) fluency in basic arithmetic operations appears to begin with and grows out of number competencies. As they develop numerical competencies in preschool and elementary school, children acquire abilities to perform basic computations quickly and proficiently. If they show low numerical competencies at the beginning of school, their abilities to perform basic computations are at risk for failure.

Our results do not indicate that counting skills by themselves underlie mathematical difficulties. Noticeably, there is almost no difference in object counting tasks in the three different NSB achievement groups when compared to other mathematics contents tasks. Jordan et al. (2007) found that, apart from counting and principals, the remaining individual subareas of NSB had good predictability in mathematics achievement (assessed by the WJMath; McGrew and Woodcock, 2001), at the end of first grade. Although counting is a mathematical formal task highly correlated to arithmetic operations, by itself it does not appear to be a good predictor in mathematics achievement.

Related to the third research question, the results indicated that children who started first grade with low numerical competencies remained low mathematics achievement at the end of first grade; and children who started with moderate and high numerical competencies, finished the first grade with moderate and high mathematics achievement, respectively. The significant group differences found allow us to assume that ENC are important for setting learning trajectories in mathematics (Mazzocco and
Thompson, 2005; Jordan et al., 2007; Jordan and Levine, 2009).

\section{SUMMARY AND CONCLUDING DISCUSSION}

With the methodology herein presented (short-term longitudinal study) we can predict, in a reasonable way, that numeracy indicators as well as number identification, story problems and number combinations measured at the point of school entry, predict later mathematical performance, specifically at the end of first grade. As a final note, with this study we cannot state that the explained variance of mathematics achievement is a consequence of a single variable - the ENC -, but based on other works its importance may be assumed. For instance, Jordan et al. (2010), using the same measure with general predictors such as language, visual-spatial relations and working memory, found that ENC additionally contributed to the variance explained in first grade.

As the absence of control variables is one of the limitations of the present study, future studies should compare NSB with other ENC screening tools to measure concurrent analysis, with the purpose of producing a coherent and predictive model between ENC and mathematics achievement.

From a conceptual point of view, these findings support the studies of Jordan et al. (2010) related to the NSB as a reliable early screening tool for identifying children at risk for failure in mathematics. It also gives good transcultural evidence of the potential importance of NSB in a country other than the United States. More importantly, the results of this study give a practical support to designing and applying effective early intervention programs in children with mathematical learning difficulties.

As mathematical thinking invades the daily activities of a young child, and poor mathematics achievement has been shown to be a major influence during school-age years, this work can contribute to identify Portuguese children who are at risk for failure in mathematics. Another implication for educational practice draws attention to the importance of an ENC screening tool for use in schools, clinics and other educational settings, with the purpose of helping children build numerical competencies as early as possible, giving them the background they need to achieve in mathematics during the first years of schooling. 


\section{ETHICS STATEMENT}

We declare that this study was carried out in accordance with the recommendations of the committee ethic of the MIME - Monotorização de Inquéritos em Meio Escolar, Direção-Geral de Educação, Ministério da Educação [MIME - Monitoring of School-based Inquiries, GeneralDirection of Education, Ministry of Education] with written informed consent to be used for all students of first-grade public schools and with anonymous reporting procedures. We also declare that the parents or legal guardian's of all subjects gave written informed consent to carry out the current research in accordance with the Declaration of Helsinki. Finally, we state that the protocol was reviewed and approved by the Direção Geral da Educação.

\section{AUTHOR CONTRIBUTIONS}

Conceptualization: LM and ÓdS. Methodology: LM. Formal analyses: LM and AL. Writing-review and editing: LM, ÓdS, and AL.

\section{REFERENCES}

Alcock, L., Ansari, D., Batchelor, S., Bisson, M. J., Smedt, B., Gilmore, C., et al. (2016). Challenges in mathematical cognition: a collaboratively derived research agenda. J. Numer. Cogn. 2, 20-41. doi: 10.5964/jnc. v2i1.10

Baroody, A. J., Bajwa, N. P., and Eiland, M. (2009). Why can't Johnny remember the basic facts? Dev. Disabil. Res. Rev. 15, 69-79. doi: 10.1002/ddrr.45

Bartelet, D., Vaessen, A., Blomert, L., and Ansari, D. (2014). What basic number processing measures in kindergarten explain unique variablility in first-grade arithmetic proficiency? J. Exp. Child Psychol. 117, 12-28. doi: 10.1016/j.jecp. 2013.08.010

Berch, D. B. (2005). Making sense of number sense: implications for children with mathematical disability. J. Learn. Disabil 38, 333-339.

Bermejo, V., Morales, S., and deOsuna, J. G. (2004). Supporting children's development of cardinality understanding. Learn. Instr. 14, 381-398. doi: 10.1016/j.learninstruc.2004.06

Camos, V. (2003). Counting strategies from 5 years to adulthood: adaptation to structural features. Euro. J. Psychol. Edu. 18, 251-265. doi: 10.1007/BF03173247

Case, R., and Griffin, S. (1990). "Child cognitive development: the role of central conceptual structures in the development of scientific and social thought," in Developmental Psychology: Cognitive, Perceptuo-Motor and Psychological Perspective, ed. E. A. Hauert (Amsterdam: Elsevier), 193-230.

Conselho National de Educação (2015). Recomendações Sobre a Retenção Escolar no Ensino Básico e Secundário. [Recommendations for School Dropout in Elementary and Secondary Education]. Diário da República, 2. ${ }^{\mathrm{a}}$ série - N. ${ }^{\circ}$ 59 - 25 de Março de 2015. Recomendação n. ${ }^{\circ}$ 2/2015. Lisboa: Ministério da Educação e Ciência.

Dehaene, S. (2011). The Number Sense: How the Mind Creates Mathematics, Revised and Updated Edition. New York, NY: Oxford University Press.

Education, Audiovisual and Culture Executive Agency (EACEA P9 Eurydice) (2011). Mathematics in Education in Europe: Common Challenges and National Policies. Brussels: European Commission.

Geary, D. C., Hamson, C. O., and Hoard, M. K. (2000). Numerical and arithmetical cognition: a longitudinal study of process and concept deficits in children with learning disability. J. Exp. Child Psychol. 73, 236-263. doi: 10.1006/jecp.2000. 2561

Geary, D. C., Hoard, M. K., Byrd-Craven, J., Nugent, L., and Numtee, C. (2007). Cognitive mechanisms underlying achievement deficits in children with

\section{FUNDING}

This research did not receive any specific grant from funding agencies in the public, commercial, or non-profit sectors. The article's publication was supported by the Center of Interdisciplinary Studies in Education and Development (CeiED), Education Institute, Universidade Lusófona, a source with no involvement in the study design, data collection, analysis, data interpretation, or report writing, or in publication submission decisions. The first author completed this work with a doctoral grant supported by the Foundation for Science and Technology (Portugal).

\section{ACKNOWLEDGMENTS}

We wish to thank all participating children who made the study possible, and their parents. We also extend our thanks to the first-grade elementary school teachers for their assistance with the Mathematics Evaluation Assessment. Moreover, we thank the director of the group of schools, Ana Mafalda Manita, for allowing the application of this short-term longitudinal study in the elementary schools.

mathematical learning disability. Child Dev. 78, 1343-1359. doi: 10.1111/j.14678624.2007.01069

Gelman, R. E., and Gallistel, C. R. (1978). The Child's Understanding of Number. Cambridge, MA: Harvard University.

Gersten, R., and Chard, D. (1999). Number sense: rethinking arithmetic instruction for students with mathematical disabilities. J. Spec. Educ. 33, 18-28. doi: $10.1177 / 002246699903300102$

Gersten, R., Jordan, N. C., and Flojo, J. R. (2005). Early identification and interventions for students with mathematics difficulties. J. Learn. Disabil. 38, 293-304. doi: 10.1177/00222194050380040301

Griffin, S. (2002). "The development of math competence in the preschool and early school years: cognitive foundations and instructional strategies," in Mathematical Cognition, ed. J. Royer (Greenwich, CT: Information Age Publishing), 1-32.

Griffin, S., and Case, R. (1997). Re-thinking the primary school math curriculum: an approach based on cognitive science. Issues Educ. 3, 1-49.

Groen, G., and Resnick, L. B. (1977). Can preschool children invent addition algorithms? J. Educ. Psychol. 69, 645-652. doi: 10.1037/0022-0663.69. 6.645

Hornung, C., Schiltz, C., Brunner, M., and Martin, R. (2014). Predicting firstgrade mathematics achievement: the contributions of domain-general cognitive abilities, nonverbal number sense, and early number competence. Front. Psychol. 5:272. doi: 10.3389/fpsyg.2014.00272

Jordan, N. C. (2010). "Early predictors of mathematics achievement and mathematics learning difficulties," in Encyclopedia on Early Childhood Development, eds R. E. Tremblay, R. G. Barr, R. Peters, and M. Boivin (Montreal: Centre of Excellence for Early Childhood Development).

Jordan, N. C., Glutting, J., and Ramineni, C. (2008). "A numerical competencies assessment tool for identifying children at risk for mathematical difficulties," in Mathematical Difficulties: Psychology and Intervention, ed. A. Dowker (San Diego, CA: Academic Press), 45-58.

Jordan, N. C., Glutting, J., and Ramineni, C. (2010). The importance of number sense to mathematics achievement in first and third grades. Learn. Individ. Differ. 20, 82-88. doi: 10.1016/j.lindif.2009. 07.004

Jordan, N. C., Kaplan, D., Locuniak, M. N., and Ramineni, C. (2007). Predicting first-grade math achievement from developmental numerical competencies trajectories. Learn. Disabil. Res. Pract. 22, 36-46. doi: 10.1111/j.1540-5826.2007. 00229.x 
Jordan, N. C., Kaplan, D., Olah, L., and Locuniak, M. (2006). Number sense growth in kindergarten: a longitudinal investigation of children at risk for mathematics difficulties. Child Develop. 77, 153-175. doi: 10.1111/j.1467-8624.2006.00862

Jordan, N. C., and Levine, S. C. (2009). Socioeconomic variation, number competence, and mathematics learning difficulties in young children. Dev. Disabil. Res. Rev. 15, 60-68. doi: 10.1002/ddrr.46

Landerl, K., Bevan, A., and Butterworth, B. (2004). Developmental dyscalculia and basic numerical capacities: a study of 8-9-year-old students. Cognition 93, 99-125. doi: 10.1016/j.cognition.2003.11.004

Le Corre, M., and Carey, S. (2007). One, two, three, four, nothing more: an investigation of the conceptual sources of the verbal counting principles. Cognition 105, 395-438. doi: 10.1016/j.cognition.2006.10.005

Levine, S. C., Jordan, N. C., and Huttenlocher, J. (1992). Development of calculation abilities in young children. J. Exp. Child Psychol. 53, 72-103. doi: 10.1016/0193-3973(94)90014-0

Locuniak, M. N., and Jordan, N. C. (2008). Using kindergarten number sense to predict calculation fluency in second grade. J. Learn. Disabil. 41, 451-459. doi: $10.1177 / 0022219408321126$

Marcelino, L. (2015). Sentido de Número e Desempenho em Matemática: Identificação e Acompanhamento em Alunos do $1^{\circ}$ e $2^{\circ}$ ano de Escolaridade [Number Sense and Mathematics Achievement in 1st and 2nd Grade Students]. Lisboa: Universidade Lusófona.

Marcelino, L., de Sousa, O., Cruz, V., and Lopes, A. (2012). Multi-year longitudinal investigation of children's early mathematics development. Proc. Soc. Behav. Sci. 69, 1911-1920. doi: 10.1016/j.sbspro.2012.12.145

Mazzocco, M., and Thompson, R. E. (2005). Kindergarten predictors of math learning disability. Learn. Disabil. Res. Pract. 20, 142-155. doi: 10.1016/j.ridd. 2014.07.012

McGrew, K. S., and Woodcock, R. W. (2001). Woodcock-Johnson III. Itasca, IL: Riverside.
Murray, P. L., and Mayer, R. E. (1988). Preschool children's judgments of number magnitude. J. Educ. Psychol. 80, 206-209. doi: 10.1037/0022-0663.80.2.206

Powell, S. R., and Fuchs, L. S. (2012). Early numerical competencies and students with mathematics difficulty. Focus Except Child. 44, 1-16. PMID 23997274 ,

Sarnecka, B. W., and Carey, S. (2008). How counting represents number: what children must learn and when they learn it. Cognition 108, 662-674. doi: 10.1016/j.cognition.2008.05.007

Siegler, R. S., and Booth, J. L. (2004). Development of numerical estimati-on in young children. Child Dev. 75, 428-444. doi: 10.1111/j.1467-8624.2004.00684.x

$\mathrm{Xu}, \mathrm{F}$., and Spelke, E. S. (2000). Large number discrimination in 6month-old infants. Cognition 74, B1-B11. doi: 10.1016/S0010-0277(99) 00066-9

Zhou, X. (2002). Preschool children's use of counting to compare two sets in cardinal situations. Early Child. Dev. Care 172, 99-111. doi: 10.1080/ 03004430210889

Conflict of Interest Statement: The authors declare that the research was conducted in the absence of any commercial or financial relationships that could be construed as a potential conflict of interest.

The reviewer HSP and handling Editor declared their shared affiliation, and the handling Editor states that the process nevertheless met the standards of a fair and objective review.

Copyright (c) 2017 Marcelino, de Sousa and Lopes. This is an open-access article distributed under the terms of the Creative Commons Attribution License (CC BY). The use, distribution or reproduction in other forums is permitted, provided the original author(s) or licensor are credited and that the original publication in this journal is cited, in accordance with accepted academic practice. No use, distribution or reproduction is permitted which does not comply with these terms. 
OPEN ACCESS

Edited by: Ana Lucia Pereira,

Ponta Grossa State University, Brazi

Reviewed by:

Claudio Longobardi, University of Turin, Italy

Ove Edvard Hatlevik, Oslo and Akershus University College,

Norway

${ }^{*}$ Correspondence: Paulo N. Vilia

pnrcvv@gmail.com

Specialty section: This article was submitted to Educational Psychology, a section of the journal

Frontiers in Psychology

Received: 28 February 2017 Accepted: 09 June 2017

Published: 28 June 2017

Citation:

Vilia PN, Candeias AA, Neto AS,

Franco MS and Melo M (2017)

Academic Achievement

in Physics-Chemistry: The Predictive Effect of Attitudes and Reasoning Abilities. Front. Psychol. 8:1064 doi: 10.3389/fpsyg.2017.01064

\section{Academic Achievement in Physics-Chemistry: The Predictive Effect of Attitudes and Reasoning Abilities}

\author{
Paulo N. Vilia ${ }^{1 *}$, Adelinda A. Candeias ${ }^{2}$, António S. Neto ${ }^{1}$, Maria Da Glória S. Franco ${ }^{3}$ \\ and Madalena Melo ${ }^{4}$
}

\begin{abstract}
' School of Social Sciences and Centre for Studies in History and Philosophy of Science, University of Évora, Évora, Portugal, ${ }^{2}$ School of Social Sciences and Centre for Educational Research and Psychology, University of Évora, Évora, Portugal, ${ }^{3}$ Faculty of Arts and Humanities, University of Madeira, Funchal, Portugal, ${ }^{4}$ School of Social Sciences and Interdisciplinary Center for History, Culture and Societies, University of Évora, Évora, Portugal
\end{abstract}

Science education plays a critical role as political priority due to its fundamental importance in engaging students to pursue technological careers considered essential in modern societies, in order to face scientific development challenges. High-level achievement on science education and positive attitudes toward science constitutes a crucial challenge for formal education. Several studies indicate close relationships between students' attitudes, cognitive abilities, and academic achievement. The main purpose of this study is to analyze the impact of student's attitudes toward the school discipline of Physics and Chemistry and their reasoning abilities on academic achievement on that school subject, among Portuguese 9th grade students using the data collected during the Project Academic Performance and Development: a longitudinal study on the effects of school transitions in Portuguese students (PTDC/CPE-CED/104884/2008). The participants were 470 students (267 girls - 56.8\% and 203 boys $-43.2 \%$ ), aged $14-16$ years old ( $\mu=14.3 \pm 0.58$ ). The attitude data were collected using the Attitude toward Physics-Chemistry Questionnaire (ATPCQ) and, the Reasoning Test Battery (RTB) was used to assess the students reasoning abilities. Achievement was measured using the students' quarterly (9-week) grades in the physics and chemistry subject. The relationships between the attitude dimensions toward Physics-chemistry and the reasoning dimensions and achievement in each of the three school terms were assessed by multiple regression stepwise analyses and standardized regression coefficients ( $\beta$ ), calculated with IBM SPSS Statistics 21 software. Both variables studied proved to be significant predictor variables of school achievement. The models obtained from the use of both variables were always stronger accounting for higher proportions of student's grade variations. The results show that ATPCQ and RTB had a significantly positive relationship with student's achievement in Physics-chemistry, indicating that both attitudinal and cognitive variables should be taken into account on science education as well as in educative intervention.

Keywords: academic achievement, attitude, reasoning skills, physics education, chemistry education, high-school 


\section{INTRODUCTION}

In modern societies, science is increasingly a central aspect of our work and our everyday lives. Educators, policymakers, and researchers are focusing on ensuring that science education continues to help preparing future citizens scientifically literate and engaged prone to engage with science in their lives, allow the societies to meet and overcome the news challenges they are facing (Tytler, 2014).

Students' academic performance is a fundamental indicator to be taken into account when defining and planning educational intervention both at nationwide level (e.g., curriculum definition) and at classroom level (e.g., teaching strategy). However, although it is well established that academic performance is a complex and multivariate issue with numerous variables contributing simultaneously as predictors for its' explanation most researchers tend to analyze each variable separately (Ozel et al., 2013), preventing them from getting a full picture of the situation (Byrnes and Miller, 2007).

School and society, in general, tend to assign cognitive abilities the preponderant role when defining school curricula or when explaining and evaluating student's success or failure, although the importance of the affective domain in education is acknowledged for a long time. (Efklides, 2009; Kahveci, 2015). Newer approaches to the comprehension of learning processes include a broader range of relevant variables at the personal level such as metacognitive knowledge and skills, perceptions of how good is the performance in learning, attitudes, emotions, and motivation (Efklides, 2011). The relational aspects of school living, in particular the importance of positive and supportive teacher-student relationships is another area including relevant variables to understand achievement on students with both typical (Longobardi et al., 2016) and atypical development (Prino et al., 2016) These new set of variables are thought to play a relevant role in students' process of developing a meaningful understanding of scientific concepts (Nieswandt, 2007).

In this paper, we use a multivariate approach to analyze the contribution of both cognitive (measured through a battery of reasoning tests) and affective abilities (measured through an attitude questionnaire) as predictors of achievement in the subject of Physics-chemistry, among Portuguese 9th grade students.

The concept of "intelligence" can be considered as a complex ability to think, to infer, to understand, to solve new problems, to recognize and build structures, relationships and context meanings (Rindermann, 2007). In educational context this general ability to learn meanings and establish and implement relations in various performance situations assumes a particularly important role (Soares et al., 2015) since there is a broad consensus that academic achievement is statistically correlated with students' cognitive capabilities (Candeias et al., 2007; Deary et al., 2007), with general intelligence being considered the strongest predictor of scholastic achievement (Roth et al., 2015).
Intelligence tests are widely used by educational psychologists to help in the diagnostic and prognostic of students' cognitive capabilities and difficulties (Watkins et al., 2007) and also to provide students with self-information helping them in the vocational choices (Lemos et al., 2010). Intelligence test results are positively correlated with school grades and also exhibit good predictive abilities as predictors of school achievement (Deary et al., 2007). Some caution should nonetheless be exerted when analyzing these results once academic achievement cannot be exclusively explained by cognitive abilities or other personal variables (Byrnes and Miller, 2007; Lemos et al., 2008) and also because there are evidence that cognitive abilities are themselves shaped by educational experiences (Watkins et al., 2007; Lemos et al., 2008).

Roth et al. (2015) conducted a psychometric meta-analysis on the correlation between standardized intelligence and school grades including a total of 240 independent samples with over 100,000 participants and found a mean correlation of 0.54 in line with previous reviews (e.g., Sternberg et al., 2001) in their analysis the highest correlations values were attained when the tests used rely on both verbal and non-verbal indicators. Concerning school subjects, the highest correlations were found in the mathematicsscience subgroup followed by the language subgroup (Roth et al., 2015).

In Portugal, using the same battery of cognitive tests used in this paper - Reasoning Test Battery (RTB) developed by Almeida and Lemos (2006) and Lemos et al. (2010) refer results similar to Roth's with highest correlations found for the school subjects of Portuguese Language and Mathematics. The RTB version for the 9th grade consists of five tests allowing the assessment of five reasoning dimensions: numerical, verbal, spatial, abstract, and mechanical.

Despite the importance of the cognitive abilities, other personal variables namely in the affective domain, such as attitudes should also be considered since some studies suggest that attitudinal and motivational factors affect cognitive learning and, in this way, they contribute to improving our ability to explain and predict school achievement, as mentioned earlier.

In this study data from a questionnaire developed to measure the students' attitudes toward learning Physics-chemistry was used to assess the contribution of attitudinal variables in explaining school achievement in that school subject.

Students' attitudes toward science have received constant attention in the field of science education for several decades although the precise definition of attitude in this field of study is still a matter of debate, hindering the description and measurement of attitudes (Kind et al., 2007). In this study we will consider "attitudes toward science" in agreement with the definition proposed by Osborne et al. (2003): "feelings, beliefs, and values about an object that can be the enterprise of science, school science, the impact of science on society or scientists themselves" (p. 1053) (emphasis added).

When conducting research on the students' attitudes toward science two important clarifications should be made. First, it 
is important to distinguish between attitudes toward science in general and attitudes toward school science subjects or activities since it is the perceptions and feelings about the later that are more likely to influence students' learning and to be significant in determining their decisions about continuing to study sciences or to pursue future careers in this area (Nieswandt, 2005; Tytler and Osborne, 2012). Second, it is important to distinguish between attitudes toward school science and attitudes toward the various science school subjects, since considering attitudes toward the different science subjects in a unified way may cause biased results because students may have different attitudes toward each of them (Can and Boz, 2012).

In Portugal, compulsory education encompasses basic education and secondary education. Basic education lasts for 9 years and is divided into three cycles: the first corresponds to the first 4 years of schooling; the second comprises the next two and, the third that lasts for 3 years (7th to 9th) and corresponds to Lower Secondary Education. In these cycles, the disciplines and the curriculum are common to all students. Science education in the first and second cycles corresponds to a single, general, integrated subject area. In the third cycle science is taught as two separate subjects: Natural Science covering biology and geology themes and Physics and Chemistry, a single subject encompassing physics and chemistry topics. In the 9th year, to which the data used in this study refer, this subject includes concepts of chemistry like the Periodic Table, the basis of atomic structure or chemical bonding and physics themes such as forces, movement, and electricity.

Although physics and chemistry are the two science subjects toward which students' attitudes are more negative (Tytler and Osborne, 2012) the number of studies referring specifically to students' attitudes toward these school disciplines isn't very large (Kahveci, 2015). The published work on these subjects follows the general trend of school science attitudinal studies. Some examples are: the reduction in students' attitudes toward studying physical science in post-compulsory school levels (Tytler and Osborne, 2012), the gender gap between boys and girls attitudes toward learning chemistry (Cheung, 2009; Can and Boz, 2012) and toward physics (Atasoy et al., 2014), and the relation attitudes and achievement (Bennett, 2001; Salta and Tzougraki, 2004; Kan and Akbaş, 2006).

The "Attitude toward Physic-chemistry questionnaire" (ATPCQ) used in this study was developed by Neto et al. (2011) and assess four attitudinal dimensions: a positive emotions factor referring to the pleasant sensations aroused by studying or attending Physic-chemistry classes, a negative emotions factor relative to the disagreeable feelings induce by this school discipline, a competence factor associated with the capacity of being skilful or successful on this subject and the related activities and, finally utility factor concerning the perceived utility of Physics-chemistry for daily life (e.g., Neto et al., 2011).

The purpose of this study is to analyze the contribution of the five types of reasoning measured by the RTB, and the four attitudinal dimensions assessed by the Attitude toward Physicchemistry questionnaire, on the 9th grade Portuguese students' achievement in the Physics-chemistry, using correlational analysis and a multivariate approach based on multiple linear regressions.

\section{MATERIALS AND METHODS}

\section{Participants}

The data for this study were collected as a part of a larger research project - "Academic Performance and Development: a longitudinal study on the effects of school transitions in Portuguese student" (PTDC/CPE-CED/104884/2008), aimed at assessing the effects of numerous of variables on the achievement of Portuguese basic education students.

This study was conducted using the data collected on the 9th grade students, attending the discipline of Physics-chemistry from 10 Portuguese schools. Schools were selected to represent all three administrative, educational regions: North (3 schools), Center ( 3 schools), and South (3 schools) in mainland Portugal and the Azores (1 school). The sample consisted of 470 students (267 girls - 56.8\% and 203 boys $-43.2 \%$ ), representing approximately $0.5 \%$ of all 9 th grade Portuguese students. Table 1 shows the students' gender and age distribution by school zone.

\section{Instruments}

\section{Reasoning Test Battery (RTB)}

The RTB (Almeida and Lemos, 2006) is a set of tests aimed at assessing cognitive achievement considering both inductive reasoning, which is the apprehension of relations between elements, and deductive reasoning, i.e., the application of the inferred relations to new situations. Being originally based on the "Tests de Raisonnement Différentiel" (Meuris, 1969) it was developed and published in Portugal and Brazil (Almeida and Primi, 1996), and it's validated and assessed for Portuguese 5th to 12 th school year students.

The version for the 3 rd cycle (7th to 9th grades) of basic education includes five tests:

- Numerical reasoning test (NR), consists of 20 numerical linear or alternating sequences (test duration - $10 \mathrm{~min}$ );

- Verbal reasoning test (VR) formed by 25 analogies taking into account relationships between words (test duration $4 \mathrm{~min}$ );

- Spatial reasoning test (SR), composed of 20 series of linear or alternating cubes in motion (test duration - $9 \mathrm{~min}$ );

- Abstract reasoning test (AR), consists of 25 analogies involving figures without any apparent meaning (test duration - $5 \mathrm{~min}$ );

- Mechanical reasoning test (MR), presents 25 problems associated with everyday experiences, also covering basic knowledge of physics and mechanics (test duration $8 \mathrm{~min})$.

The tests were applied once in begging of the school year.

The results from different schools were statistically standardized (t-score standardization). 
TABLE 1 | Student gender and age distribution by school zone.

\begin{tabular}{|c|c|c|c|c|c|c|c|c|c|}
\hline \multirow[b]{3}{*}{ School zone } & \multicolumn{6}{|c|}{ Gender } & \multicolumn{3}{|c|}{ Age } \\
\hline & \multicolumn{2}{|c|}{ Female } & \multicolumn{2}{|c|}{ Male } & \multicolumn{2}{|c|}{ Total } & \multirow[b]{2}{*}{ Mean } & \multirow[b]{2}{*}{ Std. Dev. } & \multirow[b]{2}{*}{ Median } \\
\hline & Count & $\%$ & Count & $\%$ & Count & $\%$ & & & \\
\hline North (3 schools) & 97 & 36.3 & 73 & 36.0 & 170 & 36.2 & 14.18 & 0.44 & 14.0 \\
\hline Center (3 schools) & 65 & 24.3 & 39 & 19.2 & 104 & 22.1 & 14.31 & 0.54 & 14.0 \\
\hline South (3 schools) & 68 & 25.5 & 58 & 28.6 & 126 & 26.8 & 14.37 & 0.60 & 14.0 \\
\hline Azores (1 schools) & 37 & 13.9 & 33 & 16.3 & 70 & 14.9 & 14.66 & 0.76 & 14.0 \\
\hline Total & 267 & & 203 & & 470 & & 14.33 & 0.58 & 14.0 \\
\hline
\end{tabular}

Attitude toward Physics and Chemistry Questionnaire The "ATPCQ" used in this study was developed by Neto et al. (2011) considering that the construct "Attitude toward the Physics-chemistry school subject" has a threefold structure based on the classical three components of attitudes: the cognitive, the affective, and the behavioral (Eagly and Chaiken, 1993). However, subsequent factorial analysis of the version for the 3rd cycle of basic education revealed a four-factor structure (e.g., Neto et al., 2011):

- Positive emotions (6 items) includes items related to the agreeable attitudes evoked by studying or attending Physicchemistry classes.

- Negative emotions (6 items) contains items referring to adverse attitudes induced by this school subject.

- Competence (6 items) is made up of items associated attitudes on the ability to have good results or being skillful when solving problems or performing Physics-chemistry activities.

- Utility (4 items) refers to attitudes about the perceived utility of Physics-chemistry for daily life.

The Attitude toward Physics and Chemistry Questionnaire (ATPCQ) is composed of 22 items, with an answer scale of 4 point Likert type $(1=$ Strongly Disagree, $2=$ Disagree, $3=$ Agree, $4=$ Strongly Agree).

The questionnaires were applied once in begging of the school year in a single 15 -min session.

The results from different schools were statistically standardized (t-score standardization).

\section{Academic Achievement}

Academic achievement was assessed directly from the students' school grades at the end of each school term. These data, ranging from 1 to 5 , were provided by the schools.

The school grades were chosen to assess achievement due to the lack of national tests on this subject and also because these classifications can be directly related to the students' academic success (Lemos et al., 2008). According to Roth et al. (2015) school grades are a good measure of school achievement since they include information on scholastic performance over a wide period of time, and based on different sources such as participation in classes or written examinations. In this way they are less prone to error than specific school achievement tests, more subject to temporary mental states and the individual abilities of the examinees (e.g., written versus verbal performance).

\section{Procedure/Ethics Approval}

The surveys, both the RTB and the ATPCQ, were applied collectively in the classroom context, during class time in the presence of the researchers and the class teachers. Each student received a set of documents with a code number including a biographic form, a written informed consent form and the answer sheets for RTB and ATPCQ. Both questionnaires were applied in a single 60-75 min session beginning with RTB.

The participation was volunteer and anonymous. Written informed consent from the parents, authorization from the schools' directors and authorization from National Committee for the Protection of Data and from Committee for Monitoring Surveys in Schools from the Ministry of Education were obtained before the data collection. All data are confidential and anonymous.

\section{Data Normalization}

The raw data collected for all variables was submitted to a linear normalization procedure and transformed into $t$-scores, to allow easier comparison and eliminate some ambiguity resulting from differences between the various schools. T-score normalized scores express individual values distance to average in terms of the standard deviation of the distribution. The numerical relations among the normalized scores are exactly same as the raw values, and all the features of the original distribution remain in the distribution of normalized scores (Cohen et al., 2003). The conversion is calculated trough the formula $\mathrm{T}=50+$ $\frac{10(\mathrm{X}-\overline{\mathrm{X}})}{\mathrm{SD}}$, where $\mathrm{X}$ is the raw value, $\overline{\mathrm{X}}$ is the mean value and $\mathrm{SD}$ is the standard deviation. T-score normalization was originally proposed by W.A. McCall (1922 in Anastasi et al., 2000) and converts the raw data distribution into one with average $=50$ and standard deviation $=10$. To ensure the correctness of the procedure the mean and standard deviation of each variable were assessed after normalization.

\section{Data Analysis}

Using the normalized data, the existence of statistically significant correlations between the five RTB tests, the four dimensions of ATPCQ and the school grades in the 1st school term was 
assessed by determining the Pearson Correlation Coefficient (r). The strength of the correlations was classified according to the criteria proposed by Cohen (1988) in which a Pearson correlation value of $0.10-0.29$ is small, $0.30-0.49$ is medium, and $0.50-1.00$ is high. Stepwise multiple linear regressions were then performed to establish a multivariate model of the predictive power of the cognitive and attitudinal data collected on the Physicschemistry school grades. Standardized versions of the regressions' B coefficients ( $\beta$-values) were determined since they provide a measure of the unique explanatory power of the independent variables relative to one another.

This analytical procedure was repeated with the 2nd and 3rd term school grades to determine the stability of both the correlations and the predictive model throughout the year.

For all the multiple linear regressions, independence of residuals was verified by a Durbin-Watson statistic between 1 and 2 . Homoscedasticity was verified by visual inspection of plots of studentized residuals versus unstandardized predicted values for each school term. The absence of multicollinearity, as assessed by tolerance values greater than 0.2 . The existence of occurring outliers, high leverage points or highly influential points were tested and the occurring studentized deleted residuals greater than \pm 3 standard deviations, leverage values greater than 0.2 , and values for Cook's distance above 1, were eliminated and the regressions were re-calculated. The assumption of normality was as assessed by inspection of Q-Q plots for each school term.

All the statistical procedures and tests were conducted using the IBM SPSS Statistics 22 software package.

\section{RESULTS}

The correlation analysis between the five RTB tests and Physicschemistry grades in the 1 st school term showed that all the RTB test results were positively and statistically correlated with achievement in Physics-chemistry (Table 2). Verbal and numerical reasoning presented the higher correlations $(r=0.36$ and $r=0.33$, respectively), though moderate according with Cohen (1988) classification, followed by spatial and abstract reasoning ( $r=0.28$ and $r=0.25$, respectively) and mechanical reasoning $(r=0.17)$, weak according to Cohen (1988) classification.
The correlation coefficients between the ATPCQ dimensions and the Physics-chemistry grades in the 1st school term were positive and statistically significant for competence, utility and positive emotions and statistically significant but negative for negative emotions. According with Cohen (1988) classification, the correlations with school grades were moderate for both competence and negative emotions ( $r=0.48$ and $r=-0.32$, respectively) and weak for utility $(r=0.18)$ and positive emotions $(r=0.11)$ (Table 3).

The data assumptions for conducting multiple linear regression were tested as described in the "Materials and Methods" section. Independence of residuals was verified by a Durbin-Watson statistic of 1.88. Data showed homoscedasticity and there were no evidences of multicollinearity. The occurring outliers, high leverage points or highly influential points were eliminated and the regression was re-calculated. The residuals' normal distribution was verified by inspection of Q-Q plot.

The multiple linear regression model obtained for the 1 st term explained $46 \%$ of the variance in the Physic-chemistry grades. The competence $(\beta=0.38)$ and negative emotions $(\beta=-0.28)$ dimensions of the attitudes toward Physics-chemistry and verbal reasoning $(\beta=0.24)$ were the three largest single significant predictors, with $\beta$-value for the negative emotions being negative as expected. The numeric components of reasoning and the utility dimension of attitudes were the other two other variables occurring as significant predictors although with $\beta$-values lower than 0.18 (Table 4).

Considering now the analysis conducted for the 2nd and 3rd school terms, the correlations between each of the five RTB tests and Physics-chemistry grades in both school terms were always positive and statistically significant, with similar values to those found in the 1st term. The order of relevance was also always the same with verbal reasoning presenting the higher correlation values followed by numerical, spatial, abstract, and mechanical reasoning. Although varying very little, all the RTB tests, exhibited the same pattern of variation increasing from the 1 st to the 2 nd terms and decreasing again in the 3 rd (Table 2).

Correlation coefficients between ATPCQ dimensions and Physics-chemistry grades in the 2nd and 3rd school terms are shown in Table 3 . The correlation values were always positive and

TABLE 2 | Correlation coefficients between Reasoning Test Battery (RTB) tests and Physics and Chemistry grades.

\begin{tabular}{|c|c|c|c|c|c|c|}
\hline & & RTB NR & RTB VR & RTB SR & RTB AR & RTB MR \\
\hline \multirow[t]{3}{*}{ 1st term } & Pearson correlation & $0.333^{* *}$ & $0.359 * *$ & $0.285^{* *}$ & $0.251^{* *}$ & $0.173^{* *}$ \\
\hline & Sig. (2-tailed) & 0.000 & 0.000 & 0.000 & 0.000 & 0.000 \\
\hline & $N$ & 466 & 469 & 469 & 469 & 469 \\
\hline \multirow[t]{3}{*}{ 2nd term } & Pearson correlation & $0.368^{* *}$ & $0.368^{* *}$ & $0.301^{* *}$ & $0.303^{* *}$ & $0.206^{* *}$ \\
\hline & Sig. (2-tailed) & 0.000 & 0.000 & 0.000 & 0.000 & 0.000 \\
\hline & $N$ & 467 & 470 & 470 & 470 & 470 \\
\hline \multirow[t]{3}{*}{ 3rd term } & Pearson correlation & $0.307^{* *}$ & $0.350^{* *}$ & $0.276^{* *}$ & $0.241^{* *}$ & $0.173^{* *}$ \\
\hline & Sig. (2-tailed) & 0.000 & 0.000 & 0.000 & 0.000 & 0.001 \\
\hline & $N$ & 451 & 454 & 454 & 454 & 454 \\
\hline
\end{tabular}

**Correlation is significant at the 0.01 level (2-tailed). 
TABLE 3 | Correlation coefficients between ATPQC dimensions and Physics-chemistry grades.

\begin{tabular}{|c|c|c|c|c|c|}
\hline & & $\begin{array}{l}\text { Positive } \\
\text { emotions }\end{array}$ & $\begin{array}{l}\text { Negative } \\
\text { emotions }\end{array}$ & Competence & Utility \\
\hline \multirow[t]{3}{*}{ 1st term } & Pearson correlation & $0.106^{*}$ & $-0.323^{* *}$ & $0.476^{* *}$ & $0.176^{* *}$ \\
\hline & Sig. (2-tailed) & 0.030 & 0.000 & 0.000 & 0.000 \\
\hline & $N$ & 420 & 420 & 420 & 420 \\
\hline \multirow[t]{3}{*}{ 2nd term } & Pearson correlation & 0.085 & $-0.350 * *$ & $0.466^{*}$ & $0.142^{* *}$ \\
\hline & Sig. (2-tailed) & 0.082 & 0.000 & 0.000 & 0.003 \\
\hline & $N$ & 421 & 421 & 421 & 421 \\
\hline \multirow[t]{3}{*}{ 3rd term } & Pearson correlation & $0.137^{*}$ & $-0.353^{* *}$ & $0.453^{* *}$ & $0.180^{* *}$ \\
\hline & Sig. (2-tailed) & 0.006 & 0.000 & 0.000 & 0.000 \\
\hline & $N$ & 407 & 407 & 407 & 407 \\
\hline
\end{tabular}

*Correlation is significant at the 0.05 level (2-tailed). **Correlation is significant at the 0.01 level (2-tailed).

TABLE 4 | Summary of stepwise multiple regression analysis between RTB and ATPC and Physics and Chemistry 1st term grades.

\begin{tabular}{lrcrrr}
\hline & $\boldsymbol{B}$ & Std. Error & $\boldsymbol{\beta}$ & $\boldsymbol{t}$ & $\boldsymbol{S}$ Sig. \\
\hline Intercept & 17.222 & 3.759 & & 4.582 & 0.000 \\
Competence & 0.374 & 0.038 & 0.377 & 9.888 & 0.000 \\
Negative emotions & 0.245 & 0.040 & 0.239 & 6.184 & 0.000 \\
RTB - Verbal & -0.275 & 0.036 & -0.275 & -7.535 & 0.000 \\
RTB - Numeric & 0.171 & 0.039 & 0.174 & 4.382 & 0.000 \\
Utility & 0.144 & 0.036 & 0.145 & 4.008 & 0.000 \\
\hline
\end{tabular}

$r^{2}=0.481 ;$ Adjst. $r^{2}=0.461 ; F(5,410)=71.64 ; p<0.001$.

statistically significant for competence and utility, and statistically significant but negative for negative emotions. For the positive emotions dimension, correlations were always positive but were only statistically significant in the 3rd term. The $r$-values and the relative order of importance of the four ATPCQ dimensions correlations with school grades in the 2nd and 3rd terms were similar to the ones observed in the 1st term and, in the same way as RTB tests correlations, the variation between the three school terms were very small for each of the four ATPCQ dimensions (Table 3).

The data assumptions for performing the multiple linear regressions for the 2 nd and 3rd terms were tested in the same way as for the 1st semester with the Durbin-Watson statistic being 1.81 and 1.13, respectively. Data showed homoscedasticity, there were no evidences of multicollinearity and the occurring outliers, high leverage points or highly influential points were eliminated and the regressions were re-calculated. The residuals' normal distribution was verified by inspection of Q-Q plot.

The amount of explained variance was 49 and $41 \%$, respectively, in the 2 nd and 3 rd terms. The five most relevant statistically significant predictors occurring in both terms were the same as in the 1 st term with $\beta$-values also very similar to those found for the 1st term (Tables 5, 6). In this way, the competence dimension of attitudes continued to be the most important predictor ( $\beta=0.34$ in both terms) followed by the negative emotions dimension of attitudes $(\beta=-0.27$ in both terms) and by verbal reasoning $(\beta=0.23$ and 0.21 in 2 nd and
TABLE 5 | Summary of stepwise multiple regression analysis between RTB and ATPC and Physics and Chemistry 2nd term grades.

\begin{tabular}{lrcrcr}
\hline & $\boldsymbol{B}$ & Std. Error & $\boldsymbol{\beta}$ & $\boldsymbol{t}$ & Sig. \\
\hline Intercept & 16.222 & 4.073 & & 3.983 & 0.000 \\
Competence & 0.346 & 0.038 & 0.344 & 9.013 & 0.000 \\
Negative emotions & -0.272 & 0.038 & -0.269 & -7.230 & 0.000 \\
RTB - Verbal & 0.236 & 0.040 & 0.227 & 5.819 & 0.000 \\
RTB - Numeric & 0.180 & 0.041 & 0.180 & 4.387 & 0.000 \\
Utility & 0.092 & 0.037 & 0.091 & 2.510 & 0.012 \\
RTB - Abstract & 0.095 & 0.042 & 0.092 & 2.300 & 0.022
\end{tabular}

$r^{2}=0.500 ;$ Adjst. $r^{2}=0.492 ; F(6,407)=67.73 ; p<0.001$.

TABLE 6 | Summary of stepwise multiple regression analysis between RTB and ATPC and Physics and Chemistry 3rd term grades.

\begin{tabular}{lccccc}
\hline & $\boldsymbol{B}$ & Std. Error & $\boldsymbol{\beta}$ & $\boldsymbol{t}$ & \multicolumn{1}{c}{ Sig. } \\
\hline Intercept & 16.779 & 4.515 & & 3.716 & 0.000 \\
Competence & 0.347 & 0.041 & 0.342 & 8.483 & 0.000 \\
Negative emotions & -0.279 & 0.040 & -0.271 & -6.990 & 0.000 \\
RTB - Verbal & 0.221 & 0.043 & 0.214 & 5.171 & 0.000 \\
Utility & 0.139 & 0.040 & 0.135 & 3.507 & 0.001 \\
RTB - Numeric & 0.143 & 0.042 & 0.142 & 3.374 & 0.001 \\
Positive emotions & 0.093 & 0.039 & 0.092 & 2.406 & 0.017 \\
\hline
\end{tabular}

$r^{2}=0.419 ;$ Adjst. $r^{2}=0.410 ; F(6,397)=47.62 ; p<0.001$.

3rd term, respectively). Numerical reasoning and utility were the two other significant predictors in both terms with $\beta$-values lower than 0.18 . The abstract component of reasoning and the positive emotions dimension of attitudes occurred as statistically significant predictors in the 2 nd and 3 rd terms, respectively, but in both cases with a very low $\beta$-value of 0.092 .

As a summary, our results show that the correlation pattern between both the cognitive and attitudinal variables studied and the Physic-chemistry school grades was very similar in all three school terms, with very small changes in the correlation values of all the variables and with the same order of importance occurring in each of the three school terms. The same happened with the predictive models obtained from the multiple linear regressions, where similar amounts of explained variance and the same five principal predictors emerged for the three school terms.

The presence of the positive emotions and the abstract reasoning as significant predictors only in one school term and with relatively weak values, and the fact that two components reasoning (spatial and mechanical) never occurred as significant predictors, were unexpected and deserve a special reference.

\section{DISCUSSION AND CONCLUSION}

The purpose of this study was assessing the contribution of reasoning abilities and attitudes toward the Physicschemistry discipline on predicting student's achievement using a multivariate approach, and the analysis of our results indicates that both affective and cognitive variables are relevant predictors of school performance in that school subject. In fact, both the 
results of the correlation analysis, with statistically significant values occurring for all variables, and the results of the multiple regressions, with the presence of affective and cognitive variables as predictors in the models for all the three school terms, confirm the initial assertion that that school achievement is best predicted when using a multivariate approach including both cognitive and affective variables.

These results are in agreement with others [e.g., Byrnes and Miller (2007) and Lawrenz et al. (2009)] published on this subject both for school science in general and for specific school subjects in particular. Byrnes and Miller (2007) analyzed science achievement in a large sample of 10th to 12th grade North American students using a new framework that stresses the importance of examining a large number of factors in the same study. The variables present in the predictive model include socio-economic status, previous science achievement or "feeling efficacious about graduating high school." Lawrenz et al. (2009) investigated the variables affecting the physics achievement of 3000 U.S. students, half of which from the 9 th grade. The study included different student and teacher/classroom level variables and the final models included, at the student level, variables such as previous knowledge, gender, ethnicity and students' attitude.

A relevant outcome of our study is the stability of the results throughout the three school terms since it reinforces the confidence in the model obtained as hypothesized initially. In fact, the correlation values found for each reasoning ability and each attitudinal dimension, are similar in all school terms, both concerning the absolute value and the relative order of importance. A parallel situation occurred with the results of the multiple linear regressions, where the significant predictors and their relative order of importance were, in general, the same in each of the three school terms.

Although the study design, with only one data collection for the reasoning abilities and the student's attitudes, doesn't allow drawing conclusions about the variation throughout the academic year, the constancy in the results, can also be indicative of the immutability in the student's school grades over the course of the school year. This may be a matter of concern since it might indicate the school's incapacity to improve the student's results and should, therefore, be addressed in future studies.

Considering now in more detail the results of the different analysis conducted, our results show that correlations between the various reasoning abilities assessed by the five RTB tests and Physics-chemistry grades were always statistically significant with values ranging $0.37-0.17$. This range of values is somewhat lower than others reported in the literature where 0.5 is considered the average value (Deary et al., 2007; Lemos et al., 2010; Roth et al., 2015), but are comparable to the results reported for 9th grade Portuguese students by Soares et al. (2015) in a study using the same battery of reasoning tests and the science school grades, where the correlations varied between 0.22 and 0.46 .

Regarding each of the different reasoning tests, verbal and numeric reasoning always showed the higher correlations with school grades, which is in line with other studies conducted in Portugal using the same tests (Lemos et al., 2010; Soares et al., 2015). The nature of the abilities assessed by these two tests - language knowledge and basic mathematical skill, and their close relation with school learnings, is suggested by the authors as a possible reason for the relative higher importance of these two tests. Roth et al. (2015) found a similar result in their meta-analysis with the verbal reasoning tests presenting the higher correlations with school grades, and offer a closely related explanation when they stress the importance of verbal abilities for the successful participation in class activities and in written examinations, which in turn are fundamental in establishing school grades.

The comparatively lower correlations for spatial, abstract and particularly for mechanical reasoning may be somewhat unexpected, considering the nature of the school subject studied Physics-chemistry, but are similar to the results found in other studies using this battery of tests (Lemos et al., 2010; Soares et al., 2015). Our results are also in accordance with several others presented by Hegarty (2014) who reviewed the published work on this topic. In her review, Hegarty (2014) refers various studies presenting significant correlations, with values comparable to ours, between achievement in physics and chemistry school subjects and spatial reasoning abilities.

The correlations between the four ATPCQ dimensions and the Physics-chemistry grades were also all statistically significant except for the positive emotions dimension in the 2nd term. As stated earlier, the values for each dimension were similar in all the three school terms and were moderate and positive for competence $(0.45<r<0.48)$, moderate and negative for negative emotions $(-0.32<r<-0.35)$, and positive and weak in the cases of utility $(0.14<r<0.18)$ and positive emotions $(0.09<r<0.14)$. These results are in agreement with previous studies, referring the existence of statistically significant correlations between the attitudes toward the school disciplines of physics and chemistry and achievement. Kingir and Aydemir (2012) in a study with 81,11 th grade Turkish students found a correlation of 0.52 between attitude toward chemistry and school grades. Salta and Tzougraki (2004) examining a sample of 567 11th grade Greek students and also report moderate to low correlations $(0.24<r<0.41$ for the different subscales) between attitude toward chemistry and achievement. The differences between their subscales and the ones found in our questionnaire hinder direct comparisons, however, their "importance" subscale ( $r=0.24)$ may be comparable to our "utility" dimension and both present similar correlation values. Analyzing the correlations between students' attitudes toward physics measured through various attitudinal scales Awodun et al. (2014), in their study with senior secondary Nigerian students, obtained a significant correlation of 0.48 and Vahedi and Yari (2014) reported a 0.27 correlation for Iranian high-school students. Veloo et al. (2015) found significant correlations of 0.24 and 0.19 for the "Interest toward Physics" and "Attitude toward difficulty in Physics" subscales, respectively, but didn't obtain a significant correlation for "Attitude toward the importance of Physics" subscale. Chang and Cheng (2008) also reported a moderate correlation between achievement in physics $(r=0.33)$ and chemistry $(r=32)$ and a measure of self-confidence and interest in science for a sample of 11th grade Taiwanese students. Baran and Maskan (2011) in a study with 396 high-school Turkish students on the relationship 
between science self-concept and achievement on physics found a significant correlation $(r=0.169)$ between the subscale "interest in science" and physics grades.

To conclude the analysis of the correlations between the four ATPCQ dimensions and the Physics-chemistry grades, we would like to draw attention to the fact that the dimensions "positive emotions" and "utility" have very low correlation values, always less than half of those observed for the other two attitudinal dimensions. This results, although not unexpected [e.g., Cheung (2009) for Hong Kong or Can and Boz (2012) for Tukey], are worth mention because they lead us to question the efficacy of school educational intervention both in promoting positive attitudes toward science and in guaranteeing that students understand the usefulness and applicability of what is taught.

In what concerns the stepwise multiple linear regressions performed to assess the predictive power of the cognitive and attitudinal variables studied on the Physics-chemistry achievement our models explain $41-49 \%$ of the variance in school grades. The majority of comparable studies found in the bibliographic research report, values of explained variance lower than ours, normally around or below 20\%. Acar et al. (2015) using a sample of 8th grade Turkish students and multiple regression methods, obtained a model explaining $19 \%$ of the variance on the scores of a conceptual knowledge test with topics of physics. Prior knowledge, scientific reasoning and utility value of science were the significant predictors. Also in Turkey and also using multiple regressions, Kan and Akbaş (2006) found that $10 \%$ of total variance in the achievement score of chemistry could be explained by the attitudes of students' toward the chemistry course and that an additional $2 \%$ variance was explained by including students' self-efficacy in the model. Lawrenz et al. (2009) using hierarchical linear modeling on a sample of 9th grade North American students, obtained a model explaining $19 \%$ of the variance in a physics achievement test. Attitude toward physics, prior knowledge, and mathematics achievement were the most important predictors included in the model. In addition, Awodun et al. (2014) using multiple regression, report a final model that explains $81 \%$ of physics achievement variance of senior Nigerian high-school students, with attitude to physics, study habits and interest in physics as the three most relevant predictors.

\section{REFERENCES}

Acar, Ö., Türkmen, L., and Bilgin, A. (2015). Examination of gender differences on cognitive and motivational factors that influence 8th graders' science achievement in turkey. Eur. J. Math. Sci. Technol. Educ. 11, 1027-1040. doi: 10.12973/eurasia.2015.1372a

Almeida, L. S., and Primi, R. (1996). Bateria de Provas de Raciocinio (BPR 5). Braga: Instituto de Educação e Psicologia.

Almeida, L. S., and Lemos, G. (2006). Bateria de Provas de Raciocínio: Manual Técnico. Braga: Centro de Investigação em Psicologia.

Anastasi, A., Urbina, S., and Veronese, M. A. V. (2000). Testagem psicológica. Porto Alegre: Artmed Editora.

Atasoy, Ş., Ergin, S., and Şen, A. I. (2014). The effects of peer instruction method on attitudes of 9th grade students towards physics course. Eur. J. Phys. Chem. Educ. 6, 88-98. doi: 10.12973/ejpce.2014.00072a
The results of our study confirm the relevance of using multivariate approaches when assessing students' achievement and point the way for future research. The small number of variables used might be considered as a limitation of this work but simultaneously reveal the direction for future studies. We intend to expand our analysis with other potentially relevant variables such as previous knowledge or school-related variables like teaching methods or classroom environment. Another limitation of this study is the data collection design. Future research could include two moments of data collection for attitudes and cognitive abilities one in the beginning and other at the end of the academic year, which will allow a more thorough assessment of the effect of school educational intervention in these areas.

\section{AUTHOR CONTRIBUTIONS}

Conceptualization: PV, AC, and AN; Methodology: PV, AC, and MM; Formal analysis: AN; Investigation: MF and MM; Writingreview and editing: $\mathrm{PV}$ and $\mathrm{AC}$; Supervision: AN.

\section{FUNDING}

This research did not receive any specific grant from funding agencies in the public, commercial, or non-profit sectors. The articles' publication was supported by the Project "Academic Performance and Development: a longitudinal study on the effects of school transitions in Portuguese student" with public funding from Fundação para a Ciência e Tecnologia (FCT) (PTDC/CPE-CED/104884/2008) and University of Évora, a source with no involvement in study design, data collection, analysis, data interpretation, or report writing and neither in publication submission decisions. The first author completed this work with the support of the FCT (SFRH/BD/90575/2012).

\section{ACKNOWLEDGMENT}

Portions of the present findings were obtained by PV (2016) as a part of his Ph.D. thesis.

Awodun, A. O., Oni, S. A., and Aladejana, A. L. (2014). Students' variables as predictor of secondary school students' performance in physics. Int. J. Sci. Res. 4, 541-545.

Baran, M., and Maskan, A. K. (2011). A study of relationships between academic self concepts, some selected variables and physics course achievement. Int. J. Educ. 3, doi: 10.5296/ije.v3i1.586

Bennett, J. (2001). The development and use of an instrument to assess students' attitude to the study of chemistry. Int. J. Sci. Educ. 23, 833-845. doi: 10.1080/ 09500690010006554

Byrnes, J. P., and Miller, D. C. (2007). The relative importance of predictors of math and science achievement: an opportunity-propensity analysis. Contemp. Educ. Psychol. 32, 599-629. doi: 10.1016/j.cedpsych.2006. 09.002

Can, H. B., and Boz, Y. (2012). A cross-age study on high school students attitudes toward chemistry. Int. J. New Trends Educ. Implic. 3, 82-89. 
Candeias, A., Rosário, A., Almeida, L., and Guisande, M. (2007). Bateria de provas de raciocínio diferencial: suporte à sua utilização em orientação vocacional. Rev. Port. Pedagog. 41, 143-156.

Chang, C.-Y., and Cheng, W.-Y. (2008). Science achievement and students' selfconfidence and interest in science: a taiwanese representative sample study. Int. J. Sci. Educ. 30, 1183-1200. doi: 10.1080/09500690701435384

Cheung, D. (2009). Students' attitudes toward chemistry lessons: the interaction effect between grade level and gender. Res. Sci. Educ. 39, 75-91. doi: 10.1007/ s11165-007-9075-4

Cohen, J. (1988). Statistical Power Analysis for the Behavioral Sciences. Hillsdale, NJ: L. Erlbaum Associates.

Cohen, J., Cohen, P., West, S. G., and Aiken, L. S. (2003). Applied Multiple Regression/correlation Analysis for the Behavioral Sciences. 3rd Edn. Mahwah, NJ: Lawrence Erlbaum Associates.

Deary, I. J., Strand, S., Smith, P., and Fernandes, C. (2007). Intelligence and educational achievement. Intelligence 35, 13-21. doi: 10.1016/j.intell.2006. 02.001

Eagly, A. H., and Chaiken, S. (1993). "Process theories of attitude formation and change: the elaboration likelihood and heuristic-systematic models," in The Psychology of Attitudes, eds A. H. Eagly and S. Chaiken (Fort Worth, TX: Harcourt Brace Jovanovich College Publishers), 305-349.

Efklides, A. (2009). The role of metacognitive experiences in the learning process. Psicothema 21, 76-82.

Efklides, A. (2011). Interactions of metacognition with motivation and affect in self-regulated learning: the masrl model. Educ. Psychol. 46, 6-25. doi: 10.1080/ 00461520.2011 .538645

Hegarty, M. (2014). Spatial thinking in undergraduate science education. Spat. Cogn. Comput. 14, 142-167. doi: 10.1080/13875868.2014.889696

Kahveci, A. (2015). Assessing high school students' attitudes toward chemistry with a shortened semantic differential. Chem. Educ. Res. Pract. 16, 283-292. doi: 10.1039/C4RP00186A

Kan, A., and Akbaş, A. (2006). Affective factors that influence chemistry achievement (attitude and self efficacy) and the power of these factors to predict chemistry achievement-I. J. Turk. Sci. Educ. 3, 76-85.

Kind, P., Jones, K., and Barmby, P. (2007). Developing attitudes towards science measures. Int. J. Sci. Educ. 29, 871-893. doi: 10.1080/095006906009 09091

Kingir, S., and Aydemir, N. (2012). An investigation of the relationships among 11 th grade students' attitudes toward chemistry, metacognition and chemistry achievement. Gazi Univ. J. Gazi Educ. Faculty 32, 823-842. doi: 10.17152/gefd. 48837

Lawrenz, F., Wood, N. B., Kirchhoff, A., Kim, N. K., and Eisenkraft, A. (2009). Variables affecting physics achievement. J. Res. Sci. Teach. 46, 961-976. doi: 10.1002/tea.20292

Lemos, G., Almeida, L. S., Guisande, M. A., and Primi, R. (2008). Inteligência e rendimento escolar: análise da sua relação ao longo da escolaridade. Rev. Port. Educ. 21, 83-99.

Lemos, G. C., Almeida, L. S., Guisande, M. A., Barca, A., Primi, R., Martinho, G., and Fortes, I. (2010). Inteligência e rendimento escolar: contingências de um relacionamento menos óbvio no final da adolescência. Rev. Galego-Port. Psicol. Educ. 18, 163-167.

Longobardi, C., Prino, L. E., Marengo, D., and Settanni, M. (2016). Student-teacher relationships as a protective factor for school adjustment during the transition from middle to high school. Front. Psychol. 7:1988. doi: 10.3389/fpsyg.2016. 01988

Meuris, G. (1969). Tests de Raisonnement Différentiel. Bruxelles: Editest.

Neto, A., Candeias, A., Pomar, C., Costa, P., Oliveira, M., Silva, S., et al. (2011). "Questionários de atitudes face à língua portuguesa (QAFLP), matemática (QAFM), ciências da natureza (QAFCdN), ciências naturais (QAFCN) e ciências físico-químicas ( $\mathrm{qafcfq}$ ) em alunos portugueses do ensino básico: estudo psicométrico," in Proceedings of the XI Congreso Internacional GalegoPortugués de Psicopedagoxía (Coruña: Universidade da Coruña).

Nieswandt, M. (2005). "Attitudes toward science: a review of the field," in Beyond Cartesian Dualism, eds W. W. Cobern, K. Tobin, H. Brown-Acquay, M. Espinet, G. Irzik, O. Jegede, et al. (Dordrecht: Springer), 41-52. doi: 10.1007/1-40203808-9_4

Nieswandt, M. (2007). Student affect and conceptual understanding in learning chemistry. J. Res. Sci. Teach. 44, 908-937. doi: 10.1002/tea.20169

Osborne, J., Simon, S., and Collins, S. (2003). Attitudes towards science: a review of the literature and its implications. Int. J. Sci. Educ. 25, 1049-1079. doi: 10.1080/0950069032000032199

Ozel, M., Caglak, S., and Erdogan, M. (2013). Are affective factors a good predictor of science achievement? Examining the role of affective factors based on PISA 2006. Learn. Ind. Diff. 24, 73-82. doi: 10.1016/j.lindif.2012. 09.006

Prino, L. E., Pasta, T., Gastaldi, F., and Longobardi, C. (2016). The effect of autism spectrum disorders, down syndrome, specific learning disorders and hyperactivity and attention deficits on the student-teacher relationship. Electron. J. Res. Educ. Psychol. 14, 89-106. doi: 10.14204/ejrep.38.15043

Rindermann, H. (2007). The big g-factor of national cognitive ability. Eur. J. Pers. 21, 767-787. doi: 10.1002/per.658

Roth, B., Becker, N., Romeyke, S., Schäfer, S., Domnick, F., and Spinath, F. M. (2015). Intelligence and school grades: a meta-analysis. Intelligence 53, 118-137. doi: 10.1016/j.intell.2015.09.002

Salta, K., and Tzougraki, C. (2004). Attitudes toward chemistry among 11th grade students in high schools in Greece. Sci. Educ. 88, 535-547. doi: 10.1002/sce. 10134

Soares, D. L., Lemos, G. C., Primi, R., and Almeida, L. S. (2015). The relationship between intelligence and academic achievement throughout middle school: the role of students' prior academic performance. Learn. Ind. Diff. 41, 73-78. doi: 10.1016/j.lindif.2015.02.005

Sternberg, R. J., Grigorenko, E., and Bundy, D. A. (2001). The predictive value of IQ. Merrill-Palmer Q. 47, 1-41. doi: 10.1353/mpq.2001.0005

Tytler, R. (2014). “Attitudes, identity, and aspirations toward science," in Handbook of Research in Science Education, eds N. G. Lederman and S. K. Abell (New York, NY: Routledge), 82-103.

Tytler, R., and Osborne, J. (2012). "Student attitudes and aspirations towards science," in Second International Handbook of Science Education, eds B. J. Fraser, K. Tobin, and C. J. McRobbie (Dordrecht: Springer), 597-625. doi: 10.1007/ 978-1-4020-9041-7_41

Vahedi, S., and Yari, M. (2014). Role of cognitive and emotional factors on educational achievement among high school students in physics. Eur. Online J. Nat. Soc. Sci. 3, 572-579.

Veloo, A., Nor, R., and Khalid, R. (2015). Attitude towards physics and additional mathematics achievement towards physics achievement. Int. Educ. Stud. 8, 35-43. doi: 10.5539/ies.v8n3p35

Watkins, M. W., Lei, P.-W., and Canivez, G. L. (2007). Psychometric intelligence and achievement: a cross-lagged panel analysis. Intelligence 35, 59-68. doi: 10.1016/j.intell.2006.04.005

Conflict of Interest Statement: The authors declare that the research was conducted in the absence of any commercial or financial relationships that could be construed as a potential conflict of interest.

Copyright (c) 2017 Vilia, Candeias, Neto, Franco and Melo. This is an open-access article distributed under the terms of the Creative Commons Attribution License (CC BY). The use, distribution or reproduction in other forums is permitted, provided the original author(s) or licensor are credited and that the original publication in this journal is cited, in accordance with accepted academic practice. No use, distribution or reproduction is permitted which does not comply with these terms. 
OPEN ACCESS

Edited by:

Jesus de la Fuente,

University of Almería, Spain

Reviewed by:

Yuejin Xu,

Murray State University, United States Javier Fiz Pérez,

European University of Rome, Italy

*Correspondence: Heldemerina S. Pires hsp@uevora.pt

Specialty section:

This article was submitted to Educational Psychology, a section of the journal

Frontiers in Psychology

Received: 28 February 2017 Accepted: 01 September 2017

Published: 19 September 2017

Citation:

Pires HS, Candeias AA, Grácio L,

Galindo E and Melo M (2017)

The Influence of Family Support According to Gender

in the Portuguese Language Course Achievement. Front. Psychol. 8:1610. doi: 10.3389/fpsyg.2017.01610

\section{The Influence of Family Support According to Gender in the Portuguese Language Course Achievement}

\author{
Heldemerina S. Pires ${ }^{1,2 *}$, Adelinda A. Candeias ${ }^{1,2}$, Luísa Grácio ${ }^{1,2}$, Edgar Galindo ${ }^{1,2}$ and \\ Madalena Melo 1,3
}

\begin{abstract}
${ }^{1}$ Department of Psychology, School of Social Sciences, University of Évora, Évora, Portugal, ${ }^{2}$ Center for Research in Education and Psychology, University of Évora, Évora, Portugal, ${ }^{3}$ Interdisciplinary Center for History, Culture and Societies, University of Évora, Évora, Portugal
\end{abstract}

Several factors like pupils' characteristics, school conditions and family context have been pointed out in the literature as being linked to academic achievement. Regarding the latter, family socio-economic status and parental support have been identified as determining variables on success at school. The current study analyses the influence of family support on the achievement of school children in their native language [Portuguese language course (PLC)]. Participants were 885 students attending PLC on basic and secondary schools (6th and 9th school grades) (ISCED 1); 418 boys and 467 girls, ranged between 10 and 18 years of age $(M=12.99)$. School achievement was assessed using year-end classifications in PLC. Family support was assessed using the Family Support-Context Variables Questionnaire. A regression analysis showed that students' perception about instrumental and affective family support in school life was positively related to their Portuguese grades. However, different predictive values were revealed according to gender. Girls' Portuguese languge couse classification seemed to depend on affective variables like their perception of affective parental support and affective attitudes toward the PLC, while boys' results seemed to be influenced by instrumental variables, such as the perception of instrumental support from parents and boys' attitudes toward the utility of learning Portuguese language. These results supported those of other studies, showing the need to take gender differences into account in educational interventions, especially during early adolescence. In conclusion, the study shows an influence of parental support on PLC achievement. Such influence differs according to gender, with girls being more sensitive to the affective dimension of parental support and boys to the instrumental one.

Keywords: achievement, Portuguese language course, family support, gender differences, attitudes

\section{INTRODUCTION}

Children's school achievement may be influenced by a variety of individual and environmental factors (Kerr, 2014). Several authors point to the fact that academic achievement is determined by students' personal factors, family aspects and characteristics of the school (González-Pienda et al., 2002; Jeynes, 2007; Blondal and Adalbjarnardottir, 2009; Fan and Williams, 2010; Karibayeva and Bogar, 2014; Kerr, 2014). The current view of school achievement and failure emphasizes the role 
of the environment as a determining factor in children's achievement. Consequently, academic success has been studied not only from the point of view of individual characteristics, but also as a function of environmental variables, according to the ecological model of Bronfenbrenner (1979) that points to reciprocal influences among the various systems, namely family and school, in our case.

School achievement has been analyzed as a function of individual variables, like gender (King, 2016), academic selfconcept (e.g., Chen et al., 2013), pupils' perception of parental attitudes (e.g., Peixoto and Carvalho, 2009), children's emotions (e.g., Valiente et al., 2012), and diverse motivational (e.g., Wigfield et al., 2015) and cognitive (Dent and Koenka, 2016) dimensions.

In respect to environmental factors, relevant studies have analyzed the relationships between academic achievement and the school system, including variables like teachers' attitudes toward gender and race (Zusho et al., 2016), relationships between teachers (Dodge et al., 2003; Gauvain, 2016; Hanish et al., 2016), and pupil-teacher relationships (Montague and Rinaldi, 2001; Gregory and Korth, 2016; Wubbels et al., 2016). Other authors, such as Brown (2009), have analyzed the relevance of more general factors like social economic status/SES for school achievement. Finally, a set of studies has analyzed the relevance of family characteristics for school achievement and failure (Kurdek and Sinclair, 2001; Abbott, 2012; Karibayeva and Bogar, 2014; Castro et al., 2015), particularly parental support (Baker et al., 2001; Dearing et al., 2004; Goodall and Montgomery, 2014; Bazán and Castellanos, 2015; You et al., 2016). The current study focuses precisely on this latter factor, namely, the influence of family support on achievement in a specific subject, Portuguese as a native language.

At an individual level, the mastery of language is considered key to general learning and specifically to the learning of a range of school subjects. It has been seen as a pre-condition for learning in general and, especially, for reading, writing and maths (Poe et al., 2004). Language problems can have immediate negative consequences for children's progress at school and may hinder the subsequent acquisition of important adult life skills and integration into society (European Parliament, 2006). On the other hand, the native language is also a part of individuals' personal identity and a direct cultural expression (Mateus, 2011). In the school setting, language learning (Portuguese language, in the current study) has a central role in the curriculum. It is the basis for learning the content of other school subjects, as it serves as a transversal skill for all disciplines (Costa et al., 2000). The mastery of one's native language is considered a general skill for the development of the individual in society (Valadares, 2003; Figel, 2007; Organisation for Economic Cooperation, and Development [OECD], 2012; Organisation for Economic Co-operation and Development [OECD], 2014).

The family has been identified as a major environmental influence (Holloway and Jonas, 2016), determining school achievement of children and adolescents (Claes et al., 2003; Abbott, 2012; Bazán and Castellanos, 2015). Some studies show that parents involved in school positively influence the achievement of their children, i.e., the pupils show more commitment to school tasks and their dropout levels are lower
(Jeynes, 2007; Park and Holloway, 2013). Also, children and adolescents living in a supportive family context normally have more parental help in school tasks (Alves-Martins and Peixoto, 2000; Alves-Martins et al., 2002). In general terms, good academic achievement is associated with respectful, stable, balanced families (Alvarenga and Piccinini, 2002). Parental affective and material support increases both school adjustment and the motivation of students and leads to better levels of school achievement (McGrath and Repetti, 2000; Ryan and Patrick, 2001).

According to Chowa et al. (2013), parental support has mediating effects on the attitudes of children toward school. Moreover, it fosters adaptive academic practices and transmits positive information about school. However, the effect of parental involvement depends on its type. Parental involvement at home (e.g., homework support, talking to their child about what they learned in school) is positively associated with children's achievement in the native language (English, in this case) and maths (with a smaller size effect). On the other hand, parental involvement in school (e.g., parents' attendance at meetings with teachers, participation in school events) is negatively associated with school achievement, namely in maths and English classifications (Chowa et al., 2013). The authors suggest that such negative relationship may be due to the fact that greater involvement of parents can be a result of being called to school due to pupil's problems (children's low achievement leads to an increase in parental involvement). However, Wilder (2014), based on a meta-synthesis of meta-analyses on the effects of parental involvement in academic achievement, finds a positive relationship between involvement (regardless of their definition) and academic outcomes.

The main goal of the current study is to analyze the influence of parental support on the achievement of school children in a specific subject, Portuguese language course (PLC) native language. Year-end classifications in PLC were also looked in relation to the type of parental support (affective or instrumental), student attitudes (motivation, affect, and utility) toward PLC and, finally, the students' age and gender.

\section{MATERIALS AND METHODS}

\section{Participants}

Participants were 885 students attending 6th and 9th school grades, International Standard Classification of Education (ISCED 1) in four Portuguese regions (23.8\% in the north; $19.7 \%$ in the center; $18.0 \%$ in Lisbon region; $17.4 \%$ in the Alentejo; 13.6\% Algarve; and 7.3\% Azores). 467 (52.8\%) were girls and 418 (47.2\%) boys, and they ranged between 10 and 18 years of age $(M=12.99 ; S D=1.63)$.

\section{Instruments}

The Questionnaire of Contextual variables - Family Support (QCV-FS; Pires et al., 2013) comprised 13 items measuring parental support. The format was a four-category Likert-type ranging from strongly agree (four points) to strongly disagree (one point). The QCV-FS items are organized into two dimensions: 
(i) Affective support (seven items) - e.g., My family helps me to feel better when I am worried.

(ii) Instrumental support (six items) - e.g., My family goes over my school results with me.

These two dimensions account for $57.8 \%$ of the total variance. The internal consistency analyzed by Alfa Cronbach measured 0.911 for the global tool, 0.884 for affective support, and 0.816 for the instrumental.

The Attitude toward Portuguese Language Course Questionnaire (ATPCQ, Neto et al., 2011) comprised 17 items, each answered in a four-category Likert-type response format ranging from strongly agree (four point) to strongly disagree (one point). The negatively worded items were reversely scored, leading to the self-perception and appreciation of the student as a person and as a student. These items are organized into three dimensions:

(i) Motivation (four items) - e.g., I feel enthusiastic when I go to Portuguese language classes.

(ii) Affection (seven items) - e.g., The discipline of Portuguese makes me feel insecure.

(iii) Utility (six items) - e.g., The Portuguese language is useful for my life.

The items from the second dimension were negative, so we proceeded to recodify them so that they appear to be positive in the data analysis and could be analyzed as positive feelings about learning the Portuguese language.

These three dimensions explained $60 \%$ of the variance, with a Cronbach Alpha of 0.90 (Neto et al., 2011).

Portuguese language course achievement was measured by the year-end school classifications in a quantitative scale from 1 to 5 . The classifications at 6 th and 9th school grades are comparable because it is a unique measurement scale and each value has the same meaning ( 1 is a bad classification; 5 a very good classification). Year-end classifications are the weighted result of the school internal classification and the classification of national examinations. In the case of Portugal, it is important to mention that there is a national curriculum for every school year that is followed by all schools. The school grades were selected to measure achievement because they include information about school classification over a long period of time, and based on different sources of data, as participation in classes or written assessment, as some authors defend (Lemos et al., 2008; Roth et al., 2015).

\section{Procedure}

This study is part of a larger project entitled: "School Income and Development" (RED). Firstly, we collected the authorizations to carry out the study from the Portuguese Commission for Data Protection, the Committee for Monitoring Surveys in Schools from the Portuguese Ministry of Education, and the principals of all participating schools. Students' parents and the students themselves gave authorization as well. After the authorizations were granted, we applied the QCV-FS and the ATPCQ in a single, 40-min session during class time. In each session, the project was presented and all ethical and confidentiality conditions were carried out to safeguard data collection.

\section{Data Analysis}

All the statistical procedures and tests were conducted using the IBM SPSS Statistics for Windows (version 21). A descriptive analysis of the sample's characteristics was carried out. The missing values in QCV-FS and ATPCQ were replaced by the mean value obtained for all the participants with valid answers (Cuesta et al., 2013).

In our study there are no missing data on the variable "Classification in Portuguese Language Course Classifications," but we accept cases with a maximum of three missing data in the questionnaires: QCV-FS and ATPCQ because in this questionnaire the participants had a list of items to answer. Those items are integrated in a factorial dimension with content convergence. So, we decided to accept the cases with one, two or three missing data and replace exactly these missing data by the mean value of the item obtained for all the participants with valid answers. We chose that procedure of replacing the missing data based in authors such as Peugh and Enders (2004) and Cuesta et al. (2013) because they show that this procedure is more precise and maintains the factorial structure of the questionnaires.

\section{RESULTS}

\section{Correlations among Variables and Rationale for Regression Models}

Correlations among the study variables are given in Table $\mathbf{1}$. The results showed positive and significant correlations $(p<0.01)$,

TABLE 1 | Descriptive statistics and Zero-order correlation among study variables.

\begin{tabular}{|c|c|c|c|c|c|c|c|c|}
\hline Variable & Mean (SD) & 1 & 2 & 3 & 4 & 5 & 6 & 7 \\
\hline (1) Student age & $12.99(0.06)$ & - & $-0.149 * *$ & $-0.406^{* *}$ & $0.075^{*}$ & $-0.191^{* *}$ & $-0.206^{* *}$ & $-0.125^{* *}$ \\
\hline (2) Classifications in PLC & $3.23(0.03)$ & & - & $0.123^{* *}$ & $0.134^{* *}$ & $0.173^{* *}$ & $0.137^{* *}$ & $0.173^{* *}$ \\
\hline (3) Attitude - motivation & $1.88(0.02)$ & & & - & $0.159^{* *}$ & $0.542^{* *}$ & $0.287^{* *}$ & $0.229 * *$ \\
\hline (4) Attitude - affective & $2.16(0.02)$ & & & & - & $0.341^{* *}$ & 0.042 & $0.143^{* *}$ \\
\hline (5) Attitude - utility & $2.52(0.02)$ & & & & & - & $0.272^{* *}$ & $0.331^{* *}$ \\
\hline (6) Family support affective & $2.27(0.01)$ & & & & & & - & $0.626^{* *}$ \\
\hline (7) Family support instrumental & $2.24(0.01)$ & & & & & & & - \\
\hline
\end{tabular}

$N=(885) ; * p<0.05 ; * * p<0.01$. 
between the perception of family support - affective $(r=0.137)$ and family support - instrumental $(r=0.173)$ and the PLC classifications as well as between $(r=0.123)$, Attitude - affective $(r=0.134)$ and Attitude - utility $(r=0.173)$ and PLC classifications.

Parental support - Affective $(r=-0.206)$ and instrumental $(r=-0.125)$ were negatively correlated $(p<0.01)$ with students' age. Classifications at PLC $(r=-0.149)$, the attitudes motivation $(r=-0.406)$ and utility $(r=-0.191)$ also correlated negatively with age. Thus, as students got older, not only did their academic achievement in PLC diminish, but there was also a fall in both their perception of affective and instrumental parental support as well as in their motivational and instrumental attitudes toward the language. On the other hand, perceptions of family support correlated positively, if weakly, with PLC and the latter with the attitudes toward the language.

The perception of family support - affective, was strongly and positively related to the perception of family support instrumental $(r=0.626)$, that is, when the students felt affectively supported, they also perceived instrumental support from the parents. On the other hand, attitudes toward the PLC in the motivational, affective and instrumental (utility) dimensions correlated positively and significantly $(p<0.01)$. The motivational attitudes were related not only to the affective attitudes $(r=0.159)$ but also with the instrumental ones $(r=0.542)$; the affective and instrumental attitudes also correlated with each other $(r=0.341)$.

The perception of family support-affective correlated positively with motivational $(r=0.287)$ and instrumental ( $r=0.272)$ attitudes toward the PLC. As far as the perception of instrumental support was concerned, there was also a positive correlation with all attitudinal dimensions: motivation ( $r=0.229)$, affect $(r=0.143)$, and utility $(r=0.331)$.

There were statistically significant differences $(p<0.001)$ between boys and girls in their classifications in the PLC. Girls also demonstrated higher levels of positive attitudes toward PLC than boys in both the affective $(t=6.39) ;(t=4.65)$ and instrumental dimensions $(t=3.92)$.

These results led us to examine the predictive power of perceptions of family support, and of attitudinal and developmental variables (age) relative to PLC classifications. Thus, we tested a global model to evaluate the predictive power of these variables on students' PLC classifications (Table 2). Given the mean differences according to gender, different regression models were also tested for boys and girls (Tables 3, 4). These models were intended to verify if there were different explanatory patterns for boys and girls in the perception of family support, attitudes, and age in predicting PLC classifications.

As can be seen (Table 2), in the general model (with a global predictive value of $9.5 \%$ ), gender is the most important predictive variable $(4.3 \%)$, followed by the perception of family supportinstrumental $(2.5 \%)$, age $(1.9 \%)$ and attitudinal dimensionaffective $(0.8 \%)$.

There were also gender differences in the predictor variables (Tables 3, 4).

Thus, in girls, the variables with the greatest impact on classification in PLC (with a global predictive value of $4.1 \%$ ) were: age $(2.2 \%)$, affective attitudes $(1.1 \%)$ and perception of parental affective support $(0.8 \%)$.

For boys, the predictive variables with the greatest impact (with a global predictive value of $7.1 \%$ ) were instrumental parental support (4.9\%), instrumental attitudes toward PLC (1.6\%) and age $(0.6 \%)$.

\section{DISCUSSION}

The current study analyzes the influence of parental support on the achievement of school children in a specific subject: Portuguese as a native language. The relationships between the year-end Portuguese grade, the type of parental support (affective or instrumental), students' attitudes (motivation, affect, and utility) toward the subject and the age and gender of students were also analyzed. Results showed that perceptions of parental support, age and favorable student's attitudes correlated positively with classifications in PLC. Significant positive correlations $(p<0.01)$ were found between the perception of instrumental and affective parental support and classifications in PLC, as well as between the three dimensions of attitudes (motivation, affect, and utility) and language performance. Table 1 shows that perception of affective parental support correlated positively with motivational and utility attitudes to the PLC as well as with marks in Portuguese language. On the other hand, perception of instrumental parental support correlated positively with the three dimensions of attitudes (utility, affect, and motivation). These results point to the existence of reciprocal influences among those variables, where parental support seems to be a variable with multidimensional influence and that has an important impact on PLC classifications and consequently on achievement. These findings support those of other researchers (Malecki and Demaray, 2003; Ratelle et al., 2005; Chowa et al., 2013; Karbach et al., 2013; Wilder, 2014; Castro et al., 2015; Song et al., 2015; King, 2016; Arens and Jude, 2017).

The current results also supported those of other studies (e.g., Martin and Steinbeck, 2017) showing that motivation played an important role in performance, since low motivation is associated with low achievement and high motivation to high performance. The variable affect also demonstrated a previously identified (see Williams et al., 2005; Rogaten et al., 2013), narrow link with motivation and performance. Positive emotions were seen to support academic achievement, when mediated by self-regulated learning and motivation (Mega et al., 2014). It must be pointed out, however, that, in spite of finding positive correlations, the results also revealed a parallel decrease of motivation and PLC classifications with increasing student's age. These results coincided with those of Mucherah and Ambrose-Stahl (2014) and Martin and Steinbeck (2017) who found a decrease in motivational levels of students in puberty, as did Bozack (2011), who mentioned teachers' difficulty in motivating students at that age. In the current study, the motivational decrease is associated with a fall in performance, a fact which corresponds with Martin and Steinbeck (2017) results, pointing to a mutual influence between the variables. 
TABLE 2 | Summary of stepwise multiple regression analysis predicting academic classification in PLC.

\begin{tabular}{|c|c|c|c|c|c|}
\hline Model & $B$ & $S E$ & $\beta$ & $t$ & Significance \\
\hline Intercept & 3.546 & 0.326 & & 10.889 & 0.000 \\
\hline Gender & -0.314 & 0.052 & -0.195 & -6.005 & 0.000 \\
\hline Family support - instrumental & 0.340 & 0.086 & 0.129 & 3.962 & 0.000 \\
\hline Age & -0.074 & 0.016 & -0.149 & -4.592 & 0.000 \\
\hline Attitude - affective & 0.159 & 0.054 & 0.097 & 2.956 & 0.003 \\
\hline
\end{tabular}

$r^{2}=0.099 ; r^{2}=0.095 ; F(4.880)=24.066 ; p<0.001$

TABLE 3 | Summary of stepwise multiple regression analysis predicting girls' PLC classifications.

\begin{tabular}{|c|c|c|c|c|c|}
\hline Model & $B$ & SE & $\beta$ & $t$ & Significance \\
\hline Intercept & 3.460 & 0.441 & & 7.846 & 0.000 \\
\hline Age & -0.080 & 0.024 & -0.158 & -3.388 & 0.001 \\
\hline Attitude - affective & 0.201 & 0.081 & 0.114 & 2.484 & 0.013 \\
\hline Family support -affective & 0.233 & 0.106 & 0.101 & 2.188 & 0.029 \\
\hline
\end{tabular}

$r^{2}=0.047 ; r^{2}=0.041 ; F(3.466)=7.642 ; p<0.001$.

TABLE 4 | Summary of stepwise multiple regression analysis predicting boys' PLC classifications.

\begin{tabular}{|c|c|c|c|c|c|}
\hline Model & $B$ & SE & $\beta$ & $t$ & Significance \\
\hline Intercept & 2.340 & 0.462 & & 5.063 & 0.000 \\
\hline Family support - instrumental & 0.385 & 0.129 & 0.155 & 2.979 & 0.003 \\
\hline Attitude - utility & 0.180 & 0.079 & 0.122 & 2.285 & 0.023 \\
\hline Age & -0.045 & 0.023 & -0.099 & -1.980 & 0.048 \\
\hline
\end{tabular}

$r^{2}=0.078 ; r^{2}=0.071 ; F(3.414)=11.673 ; p<0.001$

It is verified that affective and instrumental parental support has a significant negative correlation $(p<0.01)$ with age. The significant negative correlation between the perception of parental support and age means that, as age increases, a decline in the amount of parental support is perceived. At this stage of development, adolescents generally experience increasing autonomy from their parents in favor of greater peer-to-peer communication/attachment, a fact which may be influencing the perception of decreased parental support (Song et al., 2015). Nevertheless, in our findings, parental support is (albeit slightly) associated with good classifications in PLC, even if students report falling support. This fact seems to demonstrate, once again, the importance of parental support.

An analysis of age pointed out a significantly negative correlation $(p<0.01)$ between PLC classifications and the motivational and utilitarian attitudes toward the language. There were also significant differences in language grades by gender, with girls having higher means. This has been confirmed by other studies (e.g., King, 2016) that showed better achievement for girls.

In the current study, the gender difference became more noticeable when examining its predictive power. These results allowed us to confirm the existence of different predictive patterns in relation to PLC classifications according to gender. Thus, for girls, academic achievement in PLC was predicted by age, affective attitudes and the perception of parental affective support. In boys, the predictable variables were, in order of importance, perceptions of parental instrumental support, instrumental attitudes toward the PLC and, finally, age. These results clearly supported the findings that language classifications were influenced by variables of a different nature in boys and girls. On the one hand, girls appeared to be more susceptible to the influence of affective variables (perception of parental affective support and affective attitudes). On the other, boys appeared to be more sensitive to the influence of instrumental variables (perception of parental instrumental support and instrumental attitudes). The students' age for both genders served as a negative predictor of classification in PLC. This result refers to the influence of developmental variables on academic achievement and has been supported by other research (e.g., Martin and Steinbeck, 2017) showing a link between puberty (developmental variable) and decreasing academic achievement.

It is important to highlight that, for boys, instrumentality has special importance in the perception of parental support, as well as in attitudes. Parental instrumental support (e.g., encouragement, appreciation of value, discussion about the marks) is recognized and valued, influencing boys' achievement in PLC and it is also linked to the perception of the subject's utility. There was some consistency in these results because, in some situations, instrumental support was driven by other reasons (Morelli et al., 2015). For girls, the affective dimension was of special importance. PLC classifications was mainly associated with the affective components of parental support (e.g., encouragement, respect, understanding) of the attitudinal dimensions (e.g., insecurity, unpleasant feeling). Studies (e.g., 
Morelli et al., 2015) suggest that, in some cases, emotional support and instrumental support are linked. Nevertheless, there are also differences between the two types of support in individuals. In the present study, this link was demonstrated by a positive correlation between the perceptions of parental affective and instrumental support. This means that when students felt affectionately supported, they also perceived instrumental support from their parents $(r=0.626)$. According to Ratelle et al. (2005), perceptions of parental involvement and emotional support play a specific role in predicting the student's performance. Furthermore, these perceptions are especially correlated with language performance, particularly regarding the native language. In agreement with Porumbu and Necşoi (2013), there was a consistent link between the student's academic achievement and variables associated with parents' support of their children's school life. Khajehpoura and Ghazvini (2011) also demonstrated that when parents are encouraged to support their children's school life, children's grades definitely improve. According to Porumbu and Necşoi (2013), these data suggest that schools have to review their practices of involving parents in the communication between school and family. Moreover, parents should be aided in developing the necessary skills for supporting their children. This need is reinforced by the evidence of the differential effects of parental support on children's results (Chowa et al., 2013; Karbach et al., 2013).

\section{CONCLUSION}

The current results allow us to conclude that parental support influences PLC achievement. This influence is differentiated according to gender, with girls being more sensitive to the affective dimension of parental support and boys to the instrumental one.

In general, these results have some practical implications related to the implementation and use of differentiated strategies in the fight against school failure. It is suggested that strategies must be differentiated at the level of educational practice. Several suggestions follow: (i) In the family context, parental practical support should be differentiated by gender: instrumental parental support in boys and affective support in girls. However, it is important to point out that there is an influence between the affective and instrumental supports, since in some situations the instrumental support is accompanied by affective support and

\section{REFERENCES}

Abbott, K. P. (2012). The Influence of the Family on Adolescent Academic Achievement. Doctoral Dissertation, University of Iowa, Iowa City, IA.

Alvarenga, P., and Piccinini, C. (2002). Práticas educativas maternas e problemas de comportamento em pré-adolescentes. Psicologia 14, 449-460.

Alves-Martins, M., and Peixoto, F. (2000). Self-esteem, social identity and social achievement in adolescence. Psychology 7, 278-289.

Alves-Martins, M., Peixoto, F., Gouveia, M., Amaral, V., and Pedro, I. (2002). Self esteem and academic achievement among adolescents. Educ. Psychol. 22, 51-62. doi: 10.1080/01443410120101242 both establish a relationship with effects on well-being (Arens and Jude, 2017) Thus, the affective support provided by instrumental support can generate positive effects that, in addition to improvements in performance, may have implications for the students' well-being and mental health. (ii) Communication and connection between the school and the family should promote and encourage parents to monitor children's school life. (iii) Age (relative to puberty) is a developmental variable with negative influence on motivation both in boys and in girls and both (pre/post puberty and motivation) are predictors of academic achievement (Martin and Steinbeck, 2017). So, since motivational difficulties are more present in older, post-puberty students (Martin and Steinbeck, 2017), it is important that strategies for improving motivation and school achievement also take this factor into consideration.

\section{AUTHOR CONTRIBUTIONS}

Conceptualization: HP and AC; methodology: AC; formal analysis: $\mathrm{AC}$ and $\mathrm{MM}$; investigation: $\mathrm{HP}$ and $\mathrm{LG}$; wrote the manuscript: HP, MM, LG, and AC; reviewed, and edited the manuscript: EG, LG, and MM; supervision: EG.

\section{FUNDING}

This research did not receive any grants from funding agencies in the public, commercial, or non-profit sectors. Publication was supported by the RED-Rendimento Escolar e Desenvolvimento a research project financed by the Portuguese government FCT- Fundação para a Ciência e Tecnologia (PTDC/CPECED/104884/2008) and this paper is financed with National Funds through FCT - Foundation for Science and Technology, within the scope of the project Center for Research in Education and Psychology-(CIEP)-UID/CED/04312/2016 and the School of Social Science (ECS) of the University of Évora. Neither funding entity participated in any way in the study design, data analysis, or write up, nor in decisions regarding submission for publication.

\section{ACKNOWLEDGMENT}

Technical writing-review was carried out by Maria Isabel Mira and Kathryn Gray Craven.

Arens, A., and Jude, N. (2017). Parental involvement and student achievement in two language domains: indirect relations and generalizability across migration status. Learn. Individ. Differ. 53, 145-155. doi: 10.1016/j.lindif.2016.12.001

Baker, L., Mackler, K., Sonnenschein, S., and Serpell, R. (2001). Parents' interactions with their first -grade children during storybook reading and relations with subsequent home reading activity and reading achievement. J. Sch. Psychol. 39, 415-438. doi: 10.1016/S0022-4405(01)00082-6

Bazán, A., and Castellanos, D. (2015). Parents' support and achievement in a Mexican elementary school: child's perception and parents' self-evaluation. Int. J. Psychol. Stud. 7, 59-69. doi: 10.1016/j.bbr.2016.10.020

Blondal, K. S., and Adalbjarnardottir, S. (2009). Parenting practices and school dropout: a longitudinal study. Adolescence 44, 729-749. 
Bozack, A. (2011). Reading between the lines: motives, beliefs and achievement in adolescent boys. High Sch. J. 94, 58-76. doi: 10.1353/hsj.2011.0001

Bronfenbrenner, U. (1979). The Ecology of Human Development. Cambridge: Harvard University Press.

Brown, E. D. (2009). Persistence in the face of academic challenge for economically disadvantaged children. J. Early Child Res. 7, 173-184. doi: 10. 1177/1476718X09102650

Castro, M., Exposito-Casas, E., Lopez-Martin, E., Lizasoain, L., NavarroAsencio, E., and Gaviria, J. (2015). Parental involvement on student academic achievement: a meta- analysis. Educ. Res. Rev. 14, 33-46. doi: 10.1016/j.edurev. 2015.01.002

Chen, S.-K., Yeh, Y.-C., Hwang, F.-M., and Lin, S. S. J. (2013). The relationship between academic self-concept and achievement: a multicohort-multioccasion study. Learn. Individ. Differ. 23, 172-178. doi: 10.1016/j.lindif.2012.07.021

Chowa, G., Masa, R., and Tucker, J. (2013). The effects of parental involvement on academic performance of Ghanaian youth: testing measurement and relationships using structural equation modeling. Child Youth Serv. Rev. 35, 2020-2030. doi: 10.1016/j.childyouth.2013.09.009

Claes, M., Lacourse, E., Bouchard, C., and Perucchini, P. (2003). Parental practices in late adolescence, a comparison in three countries: Canada, France and Italy. J. Adolesc. 26, 387-399. doi: 10.1016/S0140-1971(03)00035-6

Costa, A. F., Ávila, P., Gomes, M. C., and Sebastião, J. (2000). Literacia: Problemática e Estudos (Relatório de Investigação). Lisboa: CIES-ISCTE.

Cuesta, M., Fonseca-Pedrero, E., Vallejo, G., and Muñiz, J. (2013). Datos perdidos y propiedades psicométricas en los tests de personalidade. Anal. Psicol. 29, 285-292. doi: 10.6018/analesps.29.1.137901

Dearing, E., McCartney, K., Weiss, H. B., Kreider, H., and Simpkins, S. (2004). The promotive effects of family educational involvement for low -income children's literacy. J. Sch. Psychol. 42, 445-460. doi: 10.1016/j.jsp.2004.07.002

Dent, A. L., and Koenka, A. C. (2016). The relation between self-regulated learning and academic achievement across childhood and adolescence: a meta-analysis. Educ. Psychol. Rev. 28, 425-474. doi: 10.1007/s10648-015-9320-8

Dodge, K. A., Lansford, J. E., Burks, V. S., Bates, J. E., Pettit, G. S., Fontaine, R., et al. (2003). Peer rejection and social information processing factors in the development of aggressive behavior problems in children. Child Dev. 74, 374-393. doi: 10.1111/1467-8624.7402004

European Parliament (2006). Recommendation of the European Parliament and of the Council of 18 December 2006 on key competences for lifelong learning (2006/962 / EC). Off. J. Eur. Union 49, 18-20.

Fan, W., and Williams, C. M. (2010). The effects of parental involvement on students' academic self-efficacy, engagement and intrinsic motivation. Educ. Psychol. 30, 53-74. doi: 10.1080/01443410903353302

Figel, J. (2007). Competências Essenciais Para a Aprendizagem ao Longo da Vida: Quadro de Referência Europeu. Luxemburgo: Serviço das Publicações Oficiais das Comunidades Europeias.

Gauvain, M. (2016). "Peer contributions to cognitive development," in Handbook of Social Influences in School Contexts. Social-Emotional, Motivation, and Cognitive Outcomes, eds K. R. Wentzel and G. B. Ramani (New York, NY: Routledge), 80-95.

González-Pienda, J. A., Núñez, J. C., González-Pumariega, S., Álvarez, L., Roces, C., and García, M. (2002). A structural equation model of parental involvement, motivational and aptitudinal characteristics, and academic achievement. J. Exp. Educ. 70, 257-287. doi: 10.1080/00220970209599509

Goodall, J., and Montgomery, C. (2014). Parental involvement to parental engagement: a continuum. Educ. Rev. 66, 399-410. doi: 10.1080/00131911.2013. 781576

Gregory, A., and Korth, J. (2016). "Teacher-student relationships and behavioral engagement in the classroom," in Handbook of Social Influences in School Contexts. Social-Emotional, Motivation, and Cognitive Outcomes, eds K. R. Wentzel and G. B. Ramani (New York, NY: Routledge), 178-191.

Hanish, L. D., Martin, C. L., Miller, C. F., Fabes, R. A., Delay, D., and Updegraff, K. A. (2016). "Social harmony in schools: a framework for understanding peer experiences and their effects," in Handbook of Social Influences in School Contexts. Social-Emotional, Motivation, and Cognitive Outcomes, eds K. R. Wentzel and G. B. Ramani (New York, NY: Routledge), 48-62.

Holloway, S. D., and Jonas, M. (2016). "Families, culture and schooling: a critical review of theory and research," in Handbook of Social Influences in School Contexts. Social-Emotional, Motivation, and Cognitive Outcomes, eds K. R. Wentzel and G. B. Ramani (New York, NY: Routledge), 258-272.

Jeynes, W. H. (2007). The relationship between parental involvement and urban secondary school student academic achievement: a meta-analysis. Urban Educ. 42, 82-110. doi: $10.1177 / 0042085906293818$

Karbach, J., Gottschling, J., Spengler, M., Hegewald, K., and Spinath, F. (2013). Parental involvement and general cognitive ability as predictors of domainspecific academic achievement in early adolescence. Learn. Instr. 23, 43-51. doi: 10.1016/j.learninstruc.2012.09.004

Karibayeva, A., and Bogar, Y. (2014). To what extent does parents' involvement in middle school influence children's educational progress? Proc. Soc. Behav. Sci. 152, 529-533. doi: 10.1016/j.sbspro.2014.09.222

Kerr, R. W. (2014). The Relationship between Family, Personal, and School Variables and the Math Achievement of Elementary Students. Doctoral Dissertation, Walden University, $l$ Minneapolis, MN.

Khajehpoura, M., and Ghazvini, S. (2011). The role of parental involvement affect in children's academic performance. Proc. Soc. Behav. Sci. 15, 1204-1208. doi: 10.1016/j.sbspro.2011.03.263

King, R. B. (2016). Gender differences in motivation, engagement and achievement are related to students' perceptions of peer-but not of parent or teacherattitudes toward school. Learn. Individ. Differ. 52, 60-71. doi: 10.1016/j.lindif. 2016.10.006

Kurdek, L. A., and Sinclair, R. J. (2001). Predicting reading and mathematics achievement in fourth -grade children from kindergarten readiness scores. J. Educ. Psychol. 93, 451-455. doi: 10.1037/0022-0663.93.3.451

Lemos, G. C., Almeida, L. S., Guisande, M. A., and Primi, R. (2008). Inteligência e rendimento escolar: análise da sua relação ao longo da escolaridade. Rev. Portug. Educ. 21, 83-99.

Malecki, C. K., and Demaray, M. K. (2003). What type of support do they need? Investigating student adjustment as related to emotional, informational, appraisal, and instrumental support. Sch. Psychol. Q. 18, 231-252. doi: 10.1521/ scpq.18.3.231.22576

Martin, A. J., and Steinbeck, K. (2017). The role of puberty in students' academic motivation and achievement. Learn. Individ. Differ. 53, 37-46. doi: 10.1016/j. lindif.2016.11.003

Mateus, M. H. (2011). Diversidade linguística na escola Portuguesa. Rev. Lusófona Educ. 18, 13-24.

McGrath, E., and Repetti, R. (2000). Mother's and father's attitudes toward their children's academic performance and children's perceptions of their academic competence. J. Youth Adolesc. 29, 713-723. doi: 10.1023/A:1026460 007421

Mega, C., Ronconi, L., and De Beni, R. (2014). What makes a good student? How emotions, self-regulated learning, and motivation contribute to academic achievement. J. Educ. Psychol. 106, 121-131. doi: 10.1037/ a0033546

Montague, M., and Rinaldi, C. (2001). Classroom dynamics and children at risk: a follow -up. Learn. Disabil. Q. 24, 75-83. doi: 10.1002/ab.21613

Morelli, S., Lee, I. A., Arnn, M., and Zaki, J. (2015). Emotional and instrumental support provision interact to predict well-being. Emotion 15, 484-493. doi: $10.1037 / \mathrm{emo} 0000084$

Mucherah, W. M., and Ambrose-Stahl, D. A. (2014). Relation of reading motivation to reading achievement in seventh-grade students from Kenya and the United States. Int. Pers. Psychol. 3, 154-166. doi: 10.1037/ipp0 000012

Neto, A., Candeias, A., Pomar, C., Costa, P., Oliveira, M., Silva, S., et al. (2011). Questionários de atitudes face à língua portuguesa (QAFLP), matemática (QAFM), ciências da natureza (QAFCdN), ciências naturais (QAFCN) e ciências físico-químicas (QAFCFQ) em alunos portugueses do ensino básico: estudo psicométrico. Paper Presented at XI Congresso Internacional Galego Portugués de Psicopedagoxía, (Corunha: University of Corunha).

Organisation for Economic Co-operation, and Development [OECD] (2012). Education at a Glance 2012: OECD Indicators. Paris: OECD Publishing.

Organisation for Economic Co-operation and Development [OECD] (2014). PISA 2012 Results: What Students know and can do - Student Performance in Mathematics, Reading and Science, Vol. 1. Paris: OECD Publishing.

Park, S., and Holloway, S. (2013). No Parent Left Behind: Predicting parental involvement in adolescents' education within a sociodemographically diverse population. J. Educ. Res. 106, 105-119. doi: 10.1080/00220671.2012.667012 
Peixoto, F., and Carvalho, R. (2009). “Students' perceptions of parental attitudes toward academic achievement effects on motivation, self-concept and school achievement," in Contemporary Motivation Research: From Global to Local Perspectives, eds M. Wosnitza, S. Karabenick, A. Efklides, and P. Nenniger (Göttingen: Hogrefe Huber), 279-297.

Peugh, J. L., and Enders, C. K. (2004). Missing data in educational research: a review of reporting practices and suggestions for improvement. Rev. Educ. Res. 74, 525-556. doi: 10.3102/00346543074004525

Pires, H., Candeias, A., Rebelo, N., Varelas, D., and Diniz, A. M. (2013). "Socioemotional competences in Portuguese youngsters: developing of assessment tools for parents," in Poster presented at InPACT -International Psychological Applications Conference and Trends, Madrid.

Poe, M. D., Burchinal, M. R., and Roberts, J. E. (2004). Early language and the development of children's reading skills. J. Sch. Psychol. 42, 315-332. doi: 10. 1016/j.jsp.2004.06.001

Porumbu, D., and Necşoi, V. (2013). Relationship between parental involvement/ attitude and children's school achievements. Proc. Soc. Behav. Sci. 76, 706-710. doi: 10.1016/j.sbspro.2013.04.191

Ratelle, C. F., Larose, S., Guay, F., and Senécal, C. (2005). Perceptions of parental involvement and support as predictors of college students' persistence in a science curriculum. J. Fam. Psychol. 19, 286-293. doi: 10.1037/0893-3200. 19.2.286

Rogaten, J., Moneta, G., and Spada, M. (2013). Academic performance as a function of approaches to studying and affect in studying. J. Happiness Stud. 14, 1751-1763. doi: 10.1007/s10902-012-9408-5

Roth, B., Becker, N., Romeyke, S., Schäfer, S., Domnick, F., and Spinath, F. M. (2015). Intelligence and school grades: a meta-analysis. Intelligence 53, 118-137. doi: 10.1016/j.intell.2015.09.002

Ryan, A., and Patrick, H. (2001). The classroom social environment and changes in adolescents' motivation and engagement during middle school. Am. Educ. Res. J. 38, 437-460. doi: 10.3102/00028312038002437

Song, J., Bong, M., Lee, K., and Kim, S. (2015). Longitudinal investigation into the role of perceived social support in adolescents' academic motivation and achievement. J. Educ. Psychol. 107, 821-841. doi: 10.1037/edu0000016

Valadares, L. M. (2003). Transversalidade da Língua Portuguesa. Lisbon: Edições ASA.
Valiente, C., Swanson, J., and Eisenberg, N. (2012). Linking students' emotions and academic achievement: when and why emotions matter. Child Dev. Perspect. 6, 129-135. doi: 10.1111/j.1750-8606.2011.00192.x

Wigfield, A., Muenks, K., and Rosenzweig, E. Q. (2015). “Children's achievement motivation in school," in The Routledge International Handbook of Social Psychology of the Classroom, eds C. M. Rubies Davies, J. M. Stephens, and P. Watson (New York, NY: Routledge), 9-20.

Wilder, S. (2014). Effects of parental involvement on academic achievement: a meta- synthesis. Educ. Rev. 66, 377-397. doi: 10.1080/00131911.2013. 780009

Williams, T., Williams, K., Kastberg, D., and Jocelyn, L. (2005). Achievement and affect in OECD nations. Oxford Rev. Educ. 31, 517-545. doi: 10.1080/ 03054980500355427

Wubbels, T., Brekelmans, M., Mainhard, T., Den Brok, P., and Van Tartwijk, J. (2016). "Teacher-student relationships and student achievement," in Handbook of Social Influences in School Contexts," eds K. R. Wentzel and G. B. Ramani (New York, NY: Routledge), 127-142.

You, S., Lim, S., No, U., and Dang, M. (2016). Multidimensional aspects of parental involvement in Korean adolescents' schooling: a mediating role of general and domain- specific self-efficacy. Educ. Psychol. 36, 916-934. doi: 10.1080/ 01443410.2015.1025705

Zusho, A., Daddino, J., and García, C. B. (2016). "Culture, race, ethnicity, and motivation," in Handbook of Social Influences in School Contexts. SocialEmotional, Motivation, and Cognitive Outcomes, eds K. R. Wentzel and G. B. Ramani (New York, NY: Routledge), 273-292.

Conflict of Interest Statement: The authors declare that the research was conducted in the absence of any commercial or financial relationships that could be construed as a potential conflict of interest.

Copyright () 2017 Pires, Candeias, Grácio, Galindo and Melo. This is an open-access article distributed under the terms of the Creative Commons Attribution License (CC BY). The use, distribution or reproduction in other forums is permitted, provided the original author(s) or licensor are credited and that the original publication in this journal is cited, in accordance with accepted academic practice. No use, distribution or reproduction is permitted which does not comply with these terms. 
OPEN ACCESS

Edited by:

Puri Checa,

University of Cádiz, Spain

Reviewed by:

Leandro S. Almeida,

University of Minho, Portugal

Juan Luis Castejon,

University of Alicante, Spain

${ }^{*}$ Correspondence:

Miguel A. Carbonero carboner@psi.uva.es Luis J. Martín-Antón

limanton@psi.uva.es

Specialty section: This article was submitted to Educational Psychology, a section of the journal

Frontiers in Psychology

Received: 29 January 2017 Accepted: 02 May 2017

Published: 22 May 2017

Citation:

Carbonero MA, Martín-Antón LJ

Otero L and Monsalvo E (2017)

Program to Promote Personal

and Social Responsibility

in the Secondary Classroom.

Front. Psychol. 8:809.

doi: 10.3389/fpsyg.2017.00809

\section{Program to Promote Personal and Social Responsibility in the Secondary Classroom}

\author{
Miguel A. Carbonero ${ }^{1 *}$, Luis J. Martín-Antón ${ }^{1 *}$, Lourdes Otero ${ }^{2}$ and Eugenio Monsalvo ${ }^{3}$ \\ ${ }^{1}$ Department of Psychology, Excellence Research Group GR179 Educational Psychology, University of Valladolid, Valladolid, \\ Spain, ${ }^{2}$ Department of Philosophy, University of Valladolid, Valladolid, Spain, ${ }^{3}$ Instituto de Enseñanza Secundaria Delicias, \\ Junta de Castilla y León, Valladolid, Spain
}

The performance of school children has been studied by considering partial relationships between several personal variables such as the link between cognition and motivation. However, contextual variables, such as a child's willingness to accept social responsibility, also influence students' social and academic performance. Thus, students with greater responsibility have a better attitude toward their studies, resulting in higher academic achievement. This 2-year study aims to reveal to what extent an intervention program affects student performance and is based on the Theory of Positive Action among young people proposed by Don Hellison and the Theory of Reasoned Action by Fishbein and Ajzen. The program focuses on positive influences on social and personal responsibility, taking into consideration parental styles, gender, and academic performance. The program was a part of the educational curricula in participating schools and it targeted four main areas: (a) teaching units using academic texts about social responsibility, (b) student training in mediation processes, (c) teacher training, and (d) family training and involvement. A total of 271 students took part from first and second year of Secondary Education (12-14 years old). The experimental group was made up of 132 students while the remaining 139 formed the control group. All participants completed the Assessment Scale of Social Responsibility Attitudes in Secondary Education and the Parent-Adolescent Communication Scale. Results show that students in the experimental group performed significantly better than those in the control group. Additionally, the issue of social responsibility seems to be related to commitment, self-discipline and perseverance. Regarding gender, males appear to score higher in the factor for well-mannered, friendly and tidy. Finally, a positive relationship has been identified between social responsibility attitudes and parenting with an open communicational style. This paper discusses the results so that schools can include programs aimed at improving social and personal responsibility.

Keywords: social responsibility attitudes, personal attitudes, reasoned-action, mentoring, secondary education

\section{INTRODUCTION}

Responsibility is the ability that people possess to respond effectively and adequately toward their behaviors, in a way that the person adjusts to those norms that set all social behaviors (Barberá, 2001). Schools and families are expected to be responsible for educating students in this value (Ochs and Izquierdo, 2009; Paradise and De Haan, 2009; Wood et al., 2009; Maliki et al., 2010; 
Thomas, 2011; Wray-Lake and Syvertsen, 2011; Salusky et al., 2014). In the school and education system, any pedagogical methods will depend on what philosophical and psychological conceptions are used, whereas the promotion of personal and social responsibility in the family will depend on the style of parenting.

From a philosophical point of view, responsibility should be approached as a primary value as Ingarden (1959) suggested. In this view, responsibility would be thought of as a value with a universal and necessary cognitive base, or as a value dependent on cultural conditions and historical facts such as Aristotle and the Hermeneutic Philosophy propose. In line with this author's approach, responsibility does not relate to knowledge but is rather a characteristic that embodies certain actions. These actions or behaviors could be described as deliberate acts that are carried out using adequate and correct tools in order to achieve aims that, in certain situations, are considered appropriate and correct. Taking this approach into consideration, a person acquires responsibility by the internalization of external norms, along with an adequate development of their cognitive and evaluative ability (Barberá, 2001). The latter capability relates to the theoretical perspective of practical reason rather than theoretical reason, as stated by several authors (Gadamer, 2006; Gadamer and DaVia, 2015). This research follows such an approach. To be precise, it considers the concept of responsibility from Ricoeur's theoretical line along with the Theory of Narrative Hermeneutics (Ricoeur, 2012; Savage, 2015). According to Ricoeur, people's narratives prefigure their idea about the world. Considered from this perspective, when people read, they do not only configure the sense of the novels or texts, but they project and imagine their future behavior when similar situations appear in their lives. Therefore, in certain situations, novels could be thought of as "labs to take ethical decisions.' This drives us to form our own idea of the world and the values that help us to define it, which means our vision of the world and the values that help us to define it. Furthermore, this philosophical theory is closely related to Seligman's proposal about Positive Psychology (Seligman and Csikszentmihalyi, 2000; Seligman et al., 2005; Seligman, 2012) and its 'character strengths' (Seligman and Petterson, 2004), where happiness is considered to be a concept that helps to give sense to life.

From a psychological standpoint, the Theory of Moral Development (Kohlberg et al., 1984) and the Theory of Moral Socialization (Hoffman, 2000, 2001) have so far been the main approaches in the area. These theoretical approaches follow different principles. While the Theory of Moral Development is based on Cognitive Psychology proposed by Piaget, the Theory of Moral Socialization takes its principles from the Psychology of Learning. In the first approach, moral development implies a continuous construction of morality (Colby and Kohlberg, 1987), meaning that the person who has achieved an internal or autonomous orientation has a mature comprehension of moral norms and values. Seen from Learning Psychology, moral development would be the transfer of moral norms and values from the society to the child.

From an anthropological point of view, studies carried out by Ochs and Izquierdo (2009), which look at how children give explanations to their families about their daily activities in four different cultures, identify three observed situations when acquiring personal autonomy through the activities of responsibility offered by their parents. The first dimension is social awareness, the second dimension in social sensitivity, and the third dimension, self-sufficiency. Similar studies have been conducted in different countries and cultures such as Nigeria (Maliki et al., 2010), Norway (Bjerke, 2011), Vietnam (Zaharim et al., 2013), and Peru (Paradise and De Haan, 2009; Ames, 2013).

Another psychological approach stems from Symbolic Interaction Theory (SIT, Beranek and Butler, 2006). This theory explains the formation of responsibility taking into consideration the idea that people have a concept of themselves in relation to the interaction with the image that they receive from others. These studies complement the research carried out by Cook and Douglas (1998) who stated that symbolism in the acquisition of responsibility by children consisted in satisfying their role as children, while at the same time keeping their sense of self. Parents act as helpers establishing expectations of each member of the family in order to make the family work. These expectations are transmitted to the school, which makes the teachers behave like parents. These studies confirmed the conclusions obtained by Such and Walker (2004), who suggested that responsibility is a key concept in policy and public debate on the lives of children and their families. On the one hand, parents help children to take responsibility for their welfare and, on the other, children and young people are frequently blamed and punished for "irresponsible" or antisocial behavior. Such and Walker (2004) conclude that from the point of view of children we must make a distinction between 'doing things in a responsible way' and 'doing responsible things.' Doing things in a responsible way (meaning with common sense, maturity, and trust) would be a way of accessing more responsible things (choosing when and how to do homework, staying alone at home, etc.). For many children, this means "power and autonomy" (Such and Walker, 2004, p. 240). Lister (2008) confirms these findings by adding the need adults have for "acceptance of the child as a responsible human being," within the social community where he or she lives. Nevertheless, this acceptance would partly depend on the ability of the child to demonstrate their capability to do things in a responsible manner. The combination of being responsible and doing things in a responsible way is the idea that has led other authors (Ochs and Izquierdo, 2009; Thomas, 2011) to propose a theoretical approach toward the acquisition of autonomy and responsibility that could be framed within Self-Determination Theory (STD, Deci and Ryan, 2000, 2012). This theory states that there are three basic psychological needs (competence, autonomy, and relationship with others) whose satisfaction increases intrinsic motivation and personal well-being (Huertas, 2012; Ames, 2013; Menéndez-Santurio and Fernández-Río, 2016). Autonomy refers to the willingness to experience the self as an agent, as the initiator of one's own behaviors, being the origin of the perception or the source one's own actions (Deci and Ryan, 2000). The relationship with others or Relatedness, refers to the desire to feel connected with others loving and caring, and being loved and cared for (Deci and Ryan, 2000; Menéndez-Santurio and Fernández-Río, 2016). Competence is the need to feel effective when interacting with 
the environment or, as Deci and Ryan (2000) and Raimundi and Molina (2015) propose, the idea of experiencing opportunities by applying or expressing one's own capacities. This theory links with the approach of Positive Action by young people whose maximum proponent was Hellison (1995, 2003, 2011).

Taking into consideration the approach of Positive Action Theory among young people (Seligman and Csikszentmihalyi, 2000; Lomas et al., 2016; Pawelski, 2016), various intervention programs have emerged over the last few decades which start by considering sports or physical activity as a way to achieve the objective of improving the personal and social development of teenagers thought to be 'at risk' (Escartí et al., 2010a,b). Although the aims and effectiveness of the programs have been varied, most of them have centered on increasing participants' moral reasoning, attributions, self-concept, self-perception of efficiency, and the understanding of other people's worlds. The Teaching Personal and Social Responsibility Model (Hellison, 2003) program is one of the most consistent. The model has been adjusted and applied in physical education classes in many countries (Hellison et al., 2000), including Spain (Escartí et al., 2013; Martinez et al., 2016).

Fishbein and Ajzen $(1974,1975,1980)$ made an important contribution to the study of human behavior when they proposed the theory of reasoned action. Its importance is due to the complete research model that takes into account factors that are usually considered separately in other theories. Beliefs, for instance, are seen as behavioral aspects when they are specific for each subject or as regulations when they are considered relevant to groups and belonging. Other issues would be: attitudes are subjective standards, social norms or, in other words, objective dimensions of our normative beliefs, and intention toward the realization of a behavior. Alonso-Arroyo (2014) uses these factors to carry out research among second- and third-year students in secondary education (13-15 years). Similarly, Monsalvo (2012, 2013) ran a study with students during early years and elementary education, using methods that consider those four dimensions of action defined previously (beliefs, attitudes, social norms, intention) and applying them to the teaching units in the classroom in collaboration with the tutors. Results have led other authors (Carbonero et al., 2015) to analyze differences between academic performance and attitudes of personal and social responsibility within students of primary education.

In the recent years, new programs have appeared within the Spanish education system that attempt to work on the acquisition of habits of responsible education. Of note among them is the Botín Foundation's project aimed at responsible education, specifically its Life and Values in Education program (LIVE Project; Argos et al., 2011; Melero and Palomera, 2011), and Prevent in Order to Live (POL) program. Both schemes are part of the line of work on responsible education that the Botín Foundation has applied among students in primary and secondary education.

A child's style of moral behavior can be explained by taking their family background and home environment into consideration. The style of responsibility depends on the observation of others' moral behavior, especially after observing the way their parents behave. Traditionally, family socialization has been considered an important factor of children's psychosocial wellbeing and a basic theoretical construct in order to understand adjusted and adapted behaviors within society (Musitu and García, 2016). The evaluation of the process of socialization requires a theoretical perspective that conceptualizes how parents can influence their children. Some authors (Brody and Shaffer, 1982; Bandura, 2001; Diaz and Eisenberg, 2015) underline the role that parents play, as they act as a model of prosocial behavior and as models of moral restriction. In fact, studies have found evidence that those people who have observed prosocial models tend to be more prosocial than those who have never been exposed to them (López-Pérez et al., 2016). In addition, some studies have shown children whose parents have given them everything they ask for tend to yield more easily than children who are not exposed to this type of model (Brody and Shaffer, 1982). As a result it could be thought that the role model that a young person receives from their parents during childhood until preadolescence is fundamental and would orient a child's moral behavior.

\section{AIMS OF THIS STUDY}

The previous section introduced different programs that aim to work on attitudes of personal and social responsibility at school. Additionally, the role that family plays as a model for the acquisition of attitudes of this type has been discussed. Nevertheless, with the school setting in mind, there are other factors that can complete the process of acquiring personal and social responsibility, such as the importance of peers in the classroom. In this sense, responsibility explained through short stories can help emphasize the learning of moral judgment. Likewise, it is thought that tutorial action programs, coexistence plans, and schemes to promote reading might help to develop moral judgment among students. All of these share the idea of education in emotional judgment (Wray-Lake and Syvertsen, 2011) in order to strengthen character (Seligman and Petterson, 2004), which this research intends to study in the reading of short stories and folktales.

Specifically, this study aims to test the effectiveness of systematic training in social responsibility, involving different members of the educational community. In particular, it attempts to discover: (a) if the program produces significant improvements in social responsibility factors, as well as the reasoned action descriptors; (b) if, after applying the program, there are differences in the changes in social responsibility and reasoned action between males and females, (c) whether or not there is a relationship between factors of social responsibility or the descriptors of the reasoned action and parenting styles.

\section{MATERIALS AND METHODS}

\section{Participants}

A total of 271 students (144 males and 127 females) in the first and second years of secondary education (12-14 years) from three different schools took part in the study. One school was 
randomly assigned as the experimental group and the other two as the control. Each class was taken to be a natural group, which meant that 132 students were assigned to the experimental group and 139 students belonged to the control group. All three schools are in urban areas and have intake from families from middle-range socioeconomic groups. The percentage of children coming from other countries was similar for all three schools (from 6 to 8\%), mainly from Morocco, Rumania, and Ecuador. The demographic characteristics of all students were similar (see Table 1). Specifically, gender distribution was equally distributed (53\% males in the experimental group and 52\% in the control group). The students were grouped in the range of 12-14 years corresponding to the age of the academic level.

The study was conducted in accordance with the 1964 Helsinki declaration and its later amendments or comparable ethical standards, with the approval of the management boards of the schools. Ethical approval was not required for this study in accordance with the national and institutional requirements.
Participation in the study was voluntary. Written informed consent was obtained from the parents/legal guardians of all participants.

\section{Measures}

\section{Assessment Scale of Social Responsibility Attitudes in Secondary Education (Otero, 2015)}

This scale measures several aspects of social responsibility of students in compulsory secondary education. A five-option Likert scale was used, which ranged from 1 (not/never) to 5 (yes/always). The survey had a total of 35 items grouped into ten factors that account for $55 \%$ of total variance, and the reliability indices in the study were $0.53<\alpha<0.79$. These factors are: (a) Respectful with the Context (five items, $\alpha=0.54$ ), (b) Friendly and Willing to Help (four items, $\alpha=0.69$ ), (c) Self-discipline and Perseverance (seven items, $\alpha=0.70$ ), (d) Acceptance of Errors (two items, $\alpha=0.79$ ), (e) Well-mannered, Friendly and Tidy (three items, $\alpha=0.55$ ), (f) Commitment (four items, $\alpha=0.64$ ),

TABLE 1 | Demographic characteristics of participants $(N=271)$.

\begin{tabular}{|c|c|c|c|c|}
\hline \multirow[b]{2}{*}{ Characteristic } & \multicolumn{2}{|c|}{ Experimental group ${ }^{a}$} & \multicolumn{2}{|c|}{ Control group ${ }^{b}$} \\
\hline & $n$ & $\%$ & $n$ & $\%$ \\
\hline \multicolumn{5}{|l|}{ Gender } \\
\hline Male & 71 & 54 & 73 & 52 \\
\hline Female & 61 & 46 & 66 & 48 \\
\hline \multicolumn{5}{|l|}{ Age at time of survey (years) } \\
\hline 11 & 4 & 3 & 4 & 3 \\
\hline 12 & 56 & 43 & 28 & 20 \\
\hline 13 & 54 & 41 & 66 & 48 \\
\hline 14 & 16 & 12 & 31 & 22 \\
\hline 15 & 2 & 1 & 10 & 7 \\
\hline \multicolumn{5}{|l|}{ Number of brothers } \\
\hline One & 32 & 24 & 30 & 22 \\
\hline Two & 77 & 59 & 77 & 55 \\
\hline Three & 19 & 14 & 20 & 14 \\
\hline Four & 4 & 3 & 7 & 5 \\
\hline Five or more & - & - & 5 & 4 \\
\hline \multicolumn{5}{|l|}{ Family unit } \\
\hline Father and mother & 105 & 79 & 125 & 90 \\
\hline Mother & 23 & 17 & 10 & 7 \\
\hline Others & 2 & 2 & 3 & 2 \\
\hline Don't know/don't answer & 2 & 2 & 1 & 1 \\
\hline \multicolumn{5}{|c|}{ Father's highest education level completed } \\
\hline Elementary school & 36 & 27 & 32 & 23 \\
\hline Junior high school & 35 & 27 & 52 & 37 \\
\hline High school & 27 & 20 & 33 & 24 \\
\hline Bachelor's degree or above & 33 & 25 & 22 & 16 \\
\hline Don't know & 1 & 1 & - & - \\
\hline \multicolumn{5}{|c|}{ Mother's highest education level completed } \\
\hline Elementary school & 42 & 32 & 17 & 12 \\
\hline Junior high school & 39 & 29 & 51 & 37 \\
\hline High school & 17 & 13 & 31 & 22 \\
\hline Bachelor's degree or above & 34 & 26 & 40 & 29 \\
\hline
\end{tabular}

$\mathrm{a}_{n}=132 ; \mathrm{b} n=139$. 
(g) Obedience (two items, $\alpha=0.78$ ), (h) Consistent, Prudent, and Self-controlled (four items, $\alpha=0.53$ ), (i) Parents as Model of Socially Responsible Behavior (two items, $\alpha=0.72$ ), and (j) Parents as Model of Perseverance (two items, $\alpha=0.72$ ).

Bearing in mind the criteria established by the theory of reasoned action and the contributions from Otero (2015), this scale also measures six descriptors of reasoned action while working with the program: (a) Beliefs (three items, $\alpha=0.65$ ), (b) Attitudes (six items, $\alpha=0.72$ ), (c) Standards (nine items, $\alpha=0.78$ ), (d) Intentions (seven items, $\alpha=0.78$ ), (e) Habits (four items, $\alpha=0.61$ ), and (f) Models (seven items, $\alpha=0.67$ ).

\section{Parent-Adolescent Communication Scale (PACS, Barnes and Olson, 1982; Translated by Musitu et al., 2001)}

The questionnaire has two scales aimed at teenagers and measures communication between children and mother, and children and father. Each scale has 20 items in a Likert-type format with five values: from 1 (never) to 5 (always). In the Spanish version, the scale shows a structure of three factors for mothers and fathers separately: (a) Open Communication (11 items, $\alpha=0.87$ ). (b) Offensive Communication (4 items, $\alpha=0.76$ ), and (c) Avoidant Communication (5 items, $\alpha=0.75$ ).

\section{Procedure}

In order to carry out the research inside a school, it was mandatory to obtain permission from the school and the educational authorities, as well as the informed consent from all the families. The study was conducted over a full 2year period. The educational material was prepared during the first year: the team selected all the stories and created the reading plan and the working plan to develop beliefs, attitudes, norms, intentions, habits, and models. During the second year, the responsibility attitudes questionnaire and family communication questionnaire were applied, and individualized student monitoring was designed, with mentoring sessions in order to train students and their families. Finally, the application of the questionnaires and the evaluation of the interviews that tutors conducted with their students took place at the beginning and at the end of the academic year. The educational program follows the methodology proposed in the theory of reasoned action (Fishbein and Ajzen, 1975), and Otero's (2015) proposal was added to it, including habits and models to work with the students (see Table 2).

In order to work with beliefs, a teaching program called "Playing to think: emotional judgment and good decisions" was developed (See Appendix, Table A1). It consists of 14 teaching units, each focussing on one story. The 14 stories were selected from a total of 71 taken from the traditional literature bearing in mind the students' age range. The selection criteria were: (a) teachers' preferences, (b) stories that work on several factors of social responsibility, (c) well-known authors from universal or children's literature or traditional tales, and (d) stories known and adapted by students' families in workshops for parents held at the school. Each story begins with a series of features that explain or define descriptors of responsibility that the program intends to work on. Secondly, there was a statement of the objectives of those elements that involve not only reasoned action (such as beliefs, rules, and attitudes) but also habits and models (for instance, emotional issues such as identification with the characters leading to the projection of the elements as those involved in intentions). After that, several activities were presented. These activities comprised a series of questions seeking reader identification with the main character in the story (describing). Furthermore, the plot and all the conflicts that appear in the story were turned into a moral laboratory (narrating). This was an opportunity for the children to test their decisions, and learn to take responsibility about their possible consequences (projecting). All teaching units ended with selfassessment: the student's self-reflection and self-recognition in story, enhancing the narrative reflection that is suggested in the introduction section. All questions refer to a student's prosocial,

TABLE 2 | Characteristics and structure of the program.

\begin{tabular}{|c|c|c|}
\hline Objective & Recipients & Procedure \\
\hline \multicolumn{3}{|l|}{ Standards } \\
\hline Standards & Students & - Self-evaluation about your responsibility social applied in mentoring individualized \\
\hline Attitudes & Students & Mediator-lector student participates in: \\
\hline \multirow[t]{2}{*}{ Intentions } & & - Leading sessions with the didactic units \\
\hline & & - Blogs \\
\hline Models & Faculty & Training courses: \\
\hline \multicolumn{3}{|l|}{ Habits } \\
\hline & & $\begin{array}{l}\text { - The student as mediator-lector and its role for the integration of the Plan de Fomento de la Lectura } \\
\text { (PFL, in English, Reading Promotion Plan) and Plan de Convivencia (in English, Coexistence Plan) }\end{array}$ \\
\hline
\end{tabular}


emotional, and cognitive aspects. This program includes a guide for the teacher who applies it.

Personal interviews were used by the tutors to work with the students on the norms. Tutors were suitably trained to work on the program. Orientation sessions prepared them to develop, implement, and monitor the program. An observation questionnaire was developed for each student to fill out while s/he was individually tutored and it was followed up over the whole course by the tutor with the approval of the parents.

In order to work with attitudes and intentions, the figure of the mediator-instructor student was created. These students worked on collaboration in implementing the program, especially when designing and applying activities related to social responsibility and those based on the theme of the stories that students were working on. The main objective was to identify whether or not students choose the beliefs of the people closest to them when there is a conflict between their behavioral beliefs, their convictions, the stories they work with and the beliefs assigned to those significant others (parents, teachers), as stated by Fishbein and Ajzen's (1975) model.

The only way to avoid this dissonance was through individualized tutoring, as mentioned above, but also through the peer group. In this case the role of the mediator-instructor was highly relevant, due to their role as a guide and as a leader to follow up the teaching unit activities about the stories. The mediator-instructor student was trained to acquire communicational skills such as dialog and peaceful resolution of conflicts. Therefore, the role of the mediator-instructor student was closely related to the students mediating coexistence. The coexistence plan included a group of training activities for the mediator students that could also be used with their mediatorinstructor peers.
Tutors and parents were trained to work with the models and habits. Tutors were trained at meetings with the School counselor and parents attended sessions of the 'parents' school' held at the experimental group's center to work on the main issue of the value of responsibility.

\section{Data Analysis}

To assess the effectiveness of the program, we calculated the differences between the scores from the pretest and the posttest measures in the control and the experimental group. For paired comparisons, the $t$-test for two independent groups was used, including Cohen's $d$ effect size (Cohen, 1988), considering: $d=0.20$ small, $d=0.50$ medium, and $d=0.80$ large effect size. For this purpose, we used the statistical package IBM SPSS Statistics, version 23 (2015). All statistical analyses used showed a 95\% confidence level. The Pearson correlation coefficient was used in order to measure strength of linear correlation between the variables of parental styles and the statements issued by the students about the benefits that they believe the program has as result.

\section{RESULTS}

\section{Effects of Applying the Educational Program}

Taking into consideration the factors of social responsibility, scores in all variables are higher in the experimental group than in the control group (see Table 3), an independent-samples $t$-test indicated scores in self-discipline were significantly higher for the experimental group $(M=-0.06, S D=2.90)$ than for the control group $(M=-2.29, S D=6.83), t(269)=3.46, p=0.001$, with a

TABLE 3 | Differences the pretest to the posttest measures when evaluating social responsibility and descriptors of the action reasoned between the experimental group and the control group.

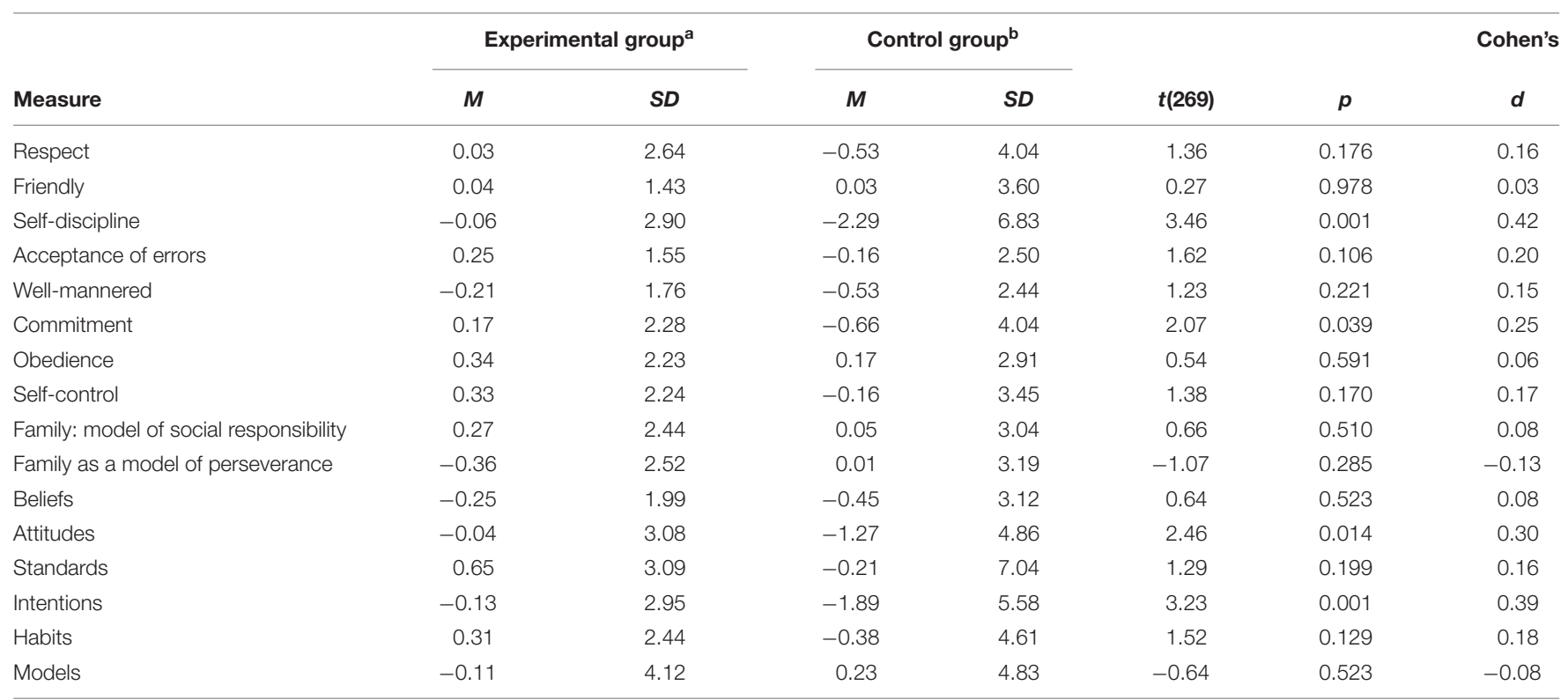

$\mathrm{a}_{n}=132 ;{ }^{\mathrm{b}} n=139$. 
size of low effect $d=0.42$. It has been observed that scores from the experimental group are kept at the initial levels, while the scores from the control group decrease considerably. A similar effect has been observed with the Commitment factor, with higher scores for the experimental group $(M=0.17, S D=2.28)$ than the control group $(M=-0.66, S D=4.04), t(269)=2.07$, $p=0.039$, also with a low effect size, $d=0.25$.

Additionally, the gains in the descriptors of reasoned action are higher in the experimental group when compared with the control group. An independent-samples $t$-test indicated that scores in attitudes were significantly higher for the experimental group $(M=-0.04, S D=3.08)$ than for the control group $(M=-1.27, S D=4.86), t(269)=2.46, p=0.014$, with a low effect size, $d=0.30$. A similar effect has been identified with the intentions factor, with higher scores for the experimental group $(M=-0.13, S D=2.95)$ when compared to the control group $(M=-1.89, S D=5.58), t(269)=3.23, p=0.001$, also with a low effect size, $d=0.39$. Regarding the other variables, there is no other significant difference.

It is interesting to discover whether or not there are differences between genders in the level of social responsibility after being involved in the educational program (see Table 4). Such differences exist in the factor of Well-mannered, Friendly and Tidy, with higher scores for males $(M=0.09, S D=1.54)$ in comparison with females $(M=-0.54, S D=1.96), t(130)=-2.02$, $p=0.045$, with a low effect size, $d=-0.35$. There is no difference between males and females within the descriptors of reasoned action.

\section{Relationship with Parenting Styles}

It has been observed that an open parental style is more positively correlated with variables of personal and social responsibility (see
Table 5). It should be pointed out that there is high and positive correlation between respect for a mother's open parental style, $r(130)=0.42, p<0.001$, in comparison with a father's style, $r(130)=0.40, p<0.001$, self-discipline and a father's open style, $r(130)=0.40, p<0.001$, and commitment to a father's open style, $r(130)=0.40, p<0.001$. On the other hand, although to a lesser extent, respect also positively correlates with an offensive parental style, both for the mother, $r(130)=0.30, p<0.01$, and for the father, $r(130)=0.21, p<0.05$. Finally, it should be noted that there is a positive correlation between being friendly and an avoidant maternal style, $r(130)=0.19, p<0.05$.

As with the factors of social responsibility, the open parental style positively correlates with the descriptors of reasoned action, except with the factor of beliefs. Worth noting is the high and positive correlation between a father's open style and standards, $r(130)=0.37, p<0.001$, and a mother's open style and intentions, $r(130)=0.33, p<0.001$, a father's open style and intentions, $r(130)=0.35, p<0.001$, a mother's open style and habits, $r(130)=0.37, p<0.001$, and a father's open style and habits, $r(130)=0.37, p<0.001$. With less intensity, however, there is a positive correlation between a mother's offensive style and rules, $r(130)=0.21, p<0.05$. On the other hand, a relationship seems to exist between the offensive parental style and habits, since a positive correlation between an offensive mother's style and habits, $r(130)=0.25$, $p<0.01$, has been identified, as well as a relationship between an offensive father's style and habits, $r(130)=0.19, p<0.05$. A similar effect appears between avoidant parental style and intentions. An avoidant mother's style positively correlates with intentions, $r(130)=0.21, p<0.05$, and an avoidant father's style also positively correlates with intentions, $r(130)=0.24$, $p<0.05$.

TABLE 4 | Differences in the pretest to the posttest measures when evaluating social responsibility and descriptors of the action reasoned among male and female within the experimental group.

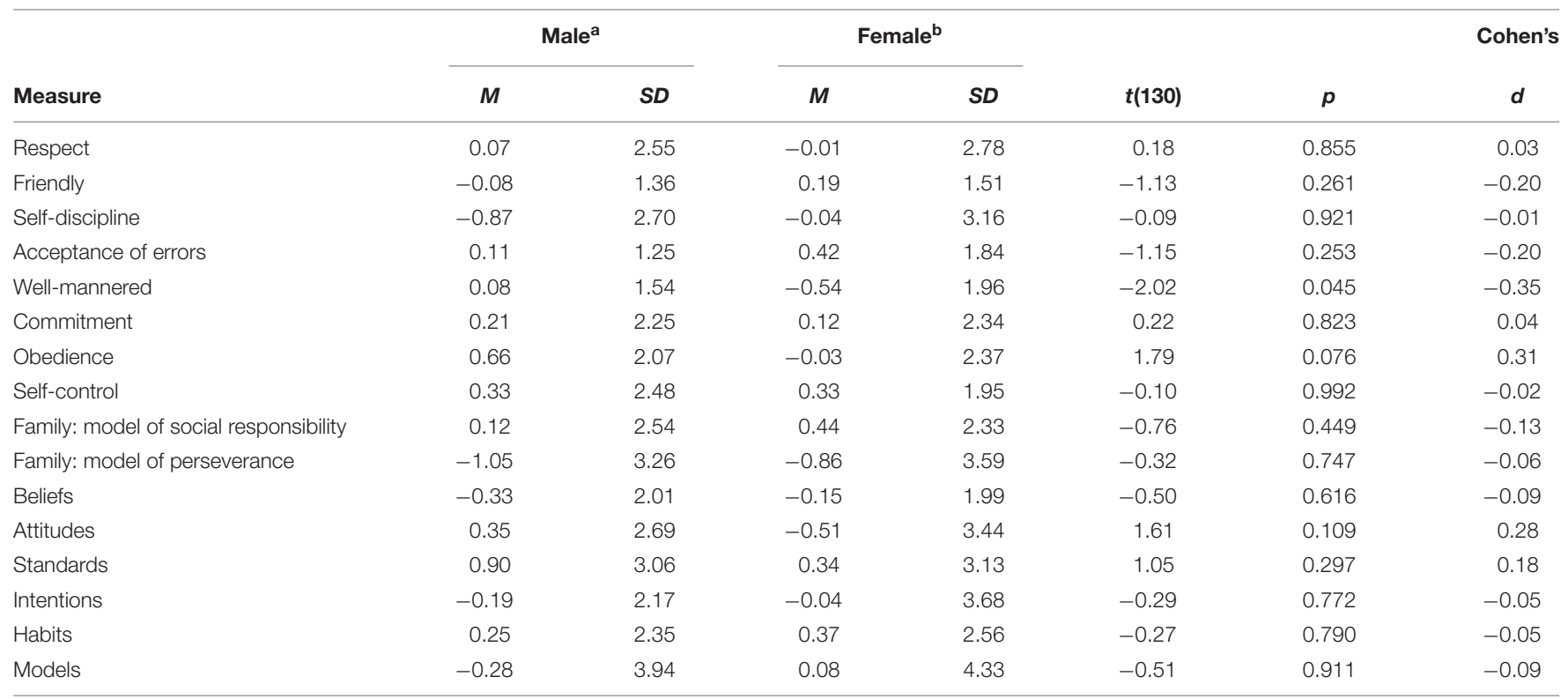

$\mathrm{a}_{n}=71 ; \mathrm{b}^{\mathrm{b}}=61$. 


\section{Assessment of the Program}

Students positively assessed the intervention program. Overall, their opinions are that the program: (a) has improved their social responsibility, (b) they like those peers who are more polite, (c) teachers appreciate that their own behavior is friendlier, (d) participants feel they will be more steadfast and committed when behaving and doing their tasks, (e) they feel that they pay more attention and are more engaged, (f) they believe their parents have seen them improving in coexistence, (g) they believe that they have had an overall improvement in all aspects of their lives, (h) they dislike it when teachers argue, and (i) they have improved in order and organization, which is the most valued claim among the students from the experimental group. The majority of these statements positively correlated with aspects that have been trained in the program (see Table 6). Intentions correlated with most of the above statements. On the other hand, it should be highlighted that there is a high correlation between perseverance and intentions, $r(130)=0.45, p<0.001$, perseverance and models, $r(130)=0.39, p<0.001$, and being more attentive and committed with habits, $r(130)=0.38, p<0.001$.

\section{DISCUSSION}

This research studied the effectiveness of a program for improving attitudes of personal and social responsibility in the first and second year of secondary education, using individualized sessions and taking into account gender, parental styles, and personal relationships. Students who have followed the program show higher scores in most of the analyzed variables when compared to those that have not been involved. It has also been observed that in two of the reasoned action descriptors they scored significantly higher. Additionally, participants obtained significant scores in those factors of social responsibility related with commitment, self-discipline, and perseverance.

Along similar lines, Deci and Ryan (2000) argue that at this age intrinsic motivation is still in the acquisition process. As a result, teenagers continue depending on their models, especially regarding habits and intentions. However, these intentions are the result of acceptance of the standards of their peers and not their attitudes and acceptance of standards internalized by them. In fact, obedience toward their parents is shown in order to

TABLE 5 | Significant correlation factors of social responsibility, descriptors of the action reasoned and parental styles.

\begin{tabular}{|c|c|c|c|c|c|c|}
\hline Measure & Mother open & Mother offensive & Mother avoidant & Father open & Father offensive & Father avoidant \\
\hline Respect & $0.42^{* * *}$ & $0.30^{* *}$ & -0.09 & $0.40^{* * *}$ & $0.21^{*}$ & -0.07 \\
\hline Friendly & 0.10 & -0.06 & $0.19^{*}$ & 0.08 & 0.01 & 0.12 \\
\hline Self-discipline & $0.31^{* * *}$ & $0.23^{*}$ & 0.03 & $0.40^{* * *}$ & -0.17 & 0.05 \\
\hline Acceptance of errors & $0.34^{* * *}$ & - & 0.11 & $0.33^{* *}$ & -0.09 & 0.14 \\
\hline Well-mannered & 0.10 & 0.06 & 0.14 & 0.12 & 0.09 & 0.10 \\
\hline Commitment & $0.23 *$ & -0.17 & 0.09 & $0.40^{* * *}$ & -0.10 & 0.09 \\
\hline Obedience & 0.09 & -0.12 & 0.08 & $0.29^{* * *}$ & 0.02 & 0.07 \\
\hline Self-control & $0.22 *$ & -0.10 & 0.18 & $0.21^{*}$ & -0.08 & 0.09 \\
\hline Family: model of social responsibility & 0.02 & 0.05 & 0.06 & 0.16 & 0.13 & -0.02 \\
\hline Family: model of perseverance & 0.17 & -0.05 & -0.06 & 0.14 & 0.03 & -0.02 \\
\hline Beliefs & 0.15 & -0.13 & 0.14 & 0.12 & -0.09 & 0.09 \\
\hline Attitudes & $0.22 *$ & -0.07 & 0.11 & $0.23^{*}$ & -0.03 & 0.07 \\
\hline Standards & $0.25^{* *}$ & $0.21^{*}$ & 0.03 & $0.37^{* * *}$ & -0.05 & 0.02 \\
\hline Intentions & $0.33^{* * *}$ & -0.13 & $0.21 *$ & $0.35^{* * *}$ & -0.02 & $0.24 *$ \\
\hline Habits & $0.37^{* * *}$ & $0.25^{* *}$ & -0.09 & $0.37^{* * *}$ & $0.19^{*}$ & -0.09 \\
\hline Models & $0.22 *$ & -0.11 & 0.00 & $0.34^{* * *}$ & -0.01 & -0.02 \\
\hline
\end{tabular}

${ }^{*} p<0.05, * * p<0.01,{ }^{* * *} p<0.001$.

TABLE 6 | Significant correlations of students' claims about the benefits of the program and the descriptors of the action reasoned.

\begin{tabular}{|c|c|c|c|c|c|c|}
\hline Measure & Beliefs & Attitudes & Standards & Intentions & Habits & Models \\
\hline Improving responsibility & 0.06 & 0.09 & 0.06 & $0.21^{*}$ & $0.34^{* *}$ & $0.29^{* *}$ \\
\hline Preference for kind classmates & 0.17 & $0.22^{*}$ & $0.21^{*}$ & $0.36^{* * *}$ & 0.16 & 0.06 \\
\hline Teachers who appreciate to be friendly & 0.08 & $0.22 *$ & $0.27^{* *}$ & $0.35^{* * *}$ & $0.21^{*}$ & $0.27^{* *}$ \\
\hline You will be more persistent & $0.23^{*}$ & $0.30^{* *}$ & 0.16 & $0.45^{* * *}$ & $0.31^{* *}$ & $0.39^{* * *}$ \\
\hline More attentive and committed & 0.03 & $0.21^{*}$ & 0.08 & $0.26^{* *}$ & $0.38^{* * *}$ & 0.05 \\
\hline Your father have seen you improving in coexistence & 0.13 & 0.17 & 0.09 & $0.22^{*}$ & $0.23^{*}$ & $0.25^{* *}$ \\
\hline Your mother have seen you improving in coexistence & 0.13 & $0.20^{*}$ & 0.13 & $0.38 * * *$ & $0.29 * *$ & $0.22^{*}$ \\
\hline You think that you have generally improved & 0.09 & 0.05 & 0.08 & 0.16 & 0.14 & $0.20^{*}$ \\
\hline You hate teachers who argue & $0.19^{*}$ & 0.16 & 0.01 & 0.13 & 0.05 & 0.00 \\
\hline You have improved in organization and order & $0.29^{* *}$ & $0.32^{* *}$ & 0.17 & $0.28^{* *}$ & $0.27^{* *}$ & $0.22 *$ \\
\hline
\end{tabular}

${ }^{*} p<0.05,{ }^{* *} p<0.01,{ }^{* * *} p<0.001$. 
avoid parental dissatisfaction. It can be concluded that during the ages studied (12-14 years old) students are still in the process of acquiring autonomy, meaning that in this period students are still understanding that their responsibility is based on obedience and reliability with their figures of attachment, and not on criteria of autonomy and/or self-efficacy.

Several studies have obtained similar results and conclusions, such as research conducted by Maliki et al. (2010), WrayLake and Syvertsen (2011), and Salusky et al. (2014) who interviewed teenagers regarding their responsibility criteria. The majority of participants said that they meet the standards because they consider it necessary for coexistence. However, other participants pointed out that they do so by obligation and to avoid punishment. Considering these ideas, the definition of the concept of responsibility for these teenagers seems to be associated with compliance. In a similar vein, Alonso-Arroyo's (2014) study with 14- to 16-year-old students aimed to rate the effectiveness of a volunteering program and concludes that there is no improvement in participants' altruistic attitudes.

In this regard, the anthropological studies conducted by Ochs and Izquierdo (2009) and Ochs (2011) find that children's participation in domestic activities not only provides practical skills, but also promotes moral responsibility, thus creating social awareness, responsiveness to the needs of others and selfsufficiency. In terms of moral development, the cultures observed by these researchers had already acquired personal and social responsibility at the age of 12 years. Such moral awareness creates in children a sense of belonging to the group in which they are involved, which in turn was expressed in a shared identity. Participation in domestic activities allows their relationship and identification with the family and the community (Paradise and De Haan, 2009) to be strengthened. Child participation in these activities was associated with their general well-being and a sense of identity within their social group, which helps to understand the positive opinions about work observed among the children taking part in the research (Ames, 2013).

It might be that the problem facing our society is linked to our culture, in which children increasingly delay the acquisition of attitudes of responsibility related with autonomy and social solidarity. This might be the result of a sense of overprotection and avoiding or not giving them domestic responsibilities as individuals. Awareness of the idea of the needs of others (Peters, 2015; Caba-Collado et al., 2016; Menéndez-Santurio and Fernández-Río, 2016) and involvement in meeting them creates awareness of belonging and therefore moral awareness, which according to recent evolutionary studies seems to be changing (Galo, 2016; Medina-Vicent, 2016). In this regard, the program presented here seems to promote, through fiction, identification with the needs of others and thus promote moral responsibility and social consciousness. In addition, training in decisionmaking and in the projection of consequences generates selfmotivation, confidence in one's own capacity of response to other people's needs and the independence of our moral judgments. One of the limitations of the present research lies in transferring the skills to real life and for specific tasks.

Taking the gender variable into consideration, higher scores have been identified among males after completing the program. However, these significant statistical differences are observed only in the social responsibility factor when related with being well-mannered, friendly and tidy. The results of the LIVE Project (Argos et al., 2011; Melero and Palomera, 2011) show greater efficiency within males, especially concerning the emotional aspects and assertiveness. Nevertheless, other research highlights higher scores among females in autonomy and responsibility when compared to males (Martinek et al., 2006; Monsalvo, 2012; Alonso-Arroyo, 2014).

In terms of communicative styles, the results show that an open parental style, both from the mother and the father, positively correlates with improvements in personal and social responsibility within students in the experimental group. Their moral autonomy and prosocial behaviors are clearly improved according to the judgments issued by the students; this is in line with results from Diaz and Eisenberg (2015) and Musitu and García (2016) when studying the acquisition of this process. Furthermore, these variables validate the model and habits variable, introduced as a contribution from this study in the reasoned action methodology (Otero, 2015). However, there is also a relationship that should not be forgotten: the link between respect and offensive parental style, possibly due to a low degree of personal autonomy, which is still in its development phase.

\section{CONCLUSION, LIMITATIONS, AND FUTURE DIRECTIONS}

Considering the results, it can be concluded that effort focussed on improving personal and social responsibility, in the individualized action of the tutor, has been beneficial for students in the first two courses of secondary education. Students suggest that they have improved significantly in responsibility skills due to the program model they have been involved in. The most significant results are identified among the variables of self-discipline, commitment, attitudes, intentions, and are closely related to an open parental style.

This transversal study focuses on a specific evolutionary period, which on one hand represents a limitation, but on the other helps to make the results more understandable. If students belonged to higher courses, results might be different, especially regarding obedience and respect given their higher degree of autonomy, which would reduce them being associated to the familiar environment, and/or to greater self-reliance. Consequently, it would be convenient to study another age range to complement the one studied here, and carry out longitudinal studies that allow the evolution of social and personal responsibility to be observed.

Additionally, the action of the tutors has been effective according to students' self-reports. The instruction process should be applied repeatedly, aiming to improve the model and the habits. In subsequent research it would be interesting to collect reports from tutors about how students improve in terms of responsibility when applying the program. These observed-reports would complement the results of the students' 
self-reports. Similarly it would be suitable to study in depth the influence of gender as a factor of personal and social responsibility and the reasoned action descriptors. It is understood that variables of socio-emotional development might condition its acquisition, but no study investigates this aspect. Consequently, there is a need for more studies that investigate emotions, with the emotional trials. In this regard, new measurements that study the relations between self-assessment and teaching units, as well as other kinds of reports should be used. It is also necessary to take a more detailed look at the model and how social responsibility is measured so that the questionnaire includes more reliable indices. In addition, systematic coaching and ongoing monitoring by tutors at this level is also a pending task. The task of the teacher or tutor has been especially well valued by students. Teachers should improve the orientations toward better emotional judgment among students, and, additionally, they should offer feedback regarding their students and provide them with proposals in order to solve any difficulties that might arise. All this would

\section{REFERENCES}

Alonso-Arroyo, F. (2014). Adquisición de actitudes de responsabilidad social a través de un programa de promoción de voluntariado [Acquisition of Social Responsibility Attitudes through a Volunteer Promotion Program]. Doctoral dissertation, Universidad de Valencia, Valencia.

Ames, P. (2013). Learning to be responsible: young children transitions outside school. Learn. Cult. Soc. Interact. 2, 143-154. doi: 10.1016/j.lcsi.2013. 04.002

Argos, J., Ezquerra, P., Sierra, J. M. O., and Blanco, L. S. (2011). Evaluación Pedagógica del Proyecto VyvE [Pedagogical Evaluation of LiVE Project]. Santander: Fundación Botín.

Bandura, A. (2001). Social cognitive theory of mass communication. Media Psychol. 3, 265-299. doi: 10.1207/S1532785XMEP0303_03

Barnes, H. L., and Olson, D. H. (1982). "Parent-adolescent communication scale," in Family Inventories: Inventories Used in a National Survey of Families Across the Family Life Cycle, eds D. H. Olson, H. I. McCubbin, H. Barnes, A. Larsen, M. Muxen, and M. Wilson (St. Paul, MN: Family Social Science, University of Minnesota), 33-48.

Barberá, V. (2001). La Responsabilidad: Cómo Educar en la Responsabilidad [Responsibility. How to Educate in Responsibility]. Madrid: Santillana.

Beranek, N., and Butler, M. (2006). Responsibility: Where Does Generation Y Stand? Journal of Student Research. Available at: http://www.uwstout.edu/rs/students/ journal_student_research.cfm

Bjerke, H. (2011). Children as' differently equal 'responsible beings: Norwegian children's views of responsibility. Childhood 18, 67-80. doi: 10.1177/ 0907568210371987

Brody, G. H., and Shaffer, D. R. (1982). Contributions of parents and peers to children's moral socialization. Dev. Rev. 2, 31-75. doi: 10.1016/0273-2297(82) 90003-X

Caba-Collado, M. A., López-Atxurra, R., and Bobowik, M. (2016). Social responsibility at school and peer aggression. Rev. Educ. 374, 187-210. doi: 10.4438/1988-592X-RE-2016-374-331

Carbonero, M. A., Martín-Antón, L. J., Monsalvo, E., and Valdivieso, J. A. (2015). School performance and personal attitudes and social responsibility in preadolescent students. Ann. Psychol. 31, 990-999. doi: 10.6018/analesps.31.3. 181161

Cohen, J. (1988). Statistical Power Analysis for the Behavioral Sciences. Hillsdale, NJ: LEA.

Colby, A., and Kohlberg, L. (1987). The Measurement of Moral Judgment: Theoretical Foundations and Research Validation, Vol. 1. New York, NY: Cambridge University Press. mean intensive training for tutors, which should be integrated within the schedule for organizing and designing the school curriculum. Similarly, it should be pointed out that the training should not only be for the staff in charge of implementing the program, but for the entire educational community and their families.

\section{AUTHOR CONTRIBUTIONS}

All authors made substantial contribution to the theoretical framework, design, data collection or interpretation of this study. All authors approved the final manuscript as submitted.

\section{ACKNOWLEDGMENT}

We want to thank to students, family, teachers and school managers for their collaboration.

Cook, W., and Douglas, E. (1998). The looking-glass self in family context: a social relations analysis. J. Fam. Psychol. 12, 299-309. doi: 10.1037/0893-3200.12.3.299

Deci, E. L., and Ryan, R. M. (2000). The "what" and "why" of goal pursuits: human needs and the self-determination of behavior. Psychol. Inq. 11, 227-268. doi: 10.1207/S15327965PLI1104_01

Deci, E. L., and Ryan, R. M. (2012). "Self-determination theory," in Handbook of Theories of Social Psychology, eds P. A. M. Van Lange, A. W. Kruglanski, and E. T. Higgins (Thousand Oaks, CA: Sage), 416-437. doi: 10.4135/ 9781446201022

Diaz, A., and Eisenberg, N. (2015). The process of emotion regulation is different from individual differences in emotion regulation: conceptual arguments and a focus on individual differences. Psychol. Inq. 26, 37-47. doi: 10.1080/1047840X. 2015.959094

Escartí, A., Gutiérrez, M., Pascual, C., and Llopis, R. (2010a). Implementation of the personal and social responsibility. Int. J. Psychol. Psychol. Ther. 10, 387-402.

Escartí, A., Gutiérrez, M., Pascual, C., and Marín, D. (2010b). Application of Hellison's teaching personal and social responsibility model. Span. J. Psychol. 13, 667-676. doi: 10.1017/S113874160000233X

Escartí, A., Gutiérrez, M., Pascual, C., and Wright, P. (2013). Observación de las estrategias que emplean los profesores de educación física para enseñar responsabilidad personal y social [Observation of the strategies that physical education teachers use to teach personal and social responsibility]. Rev. Psicol. Deporte 22, 159-166.

Fishbein, M., and Ajzen, I. (1974). Attitudes towards objects as predictors of single and multiple behavioral criteria. Psychol. Rev. 81, 59-74. doi: 10.1037/h0035872

Fishbein, M., and Ajzen, I. (1975). Belief, Attitude, Intention and Behavior. An Introduction to Theory and Research. Reading, MA: Addison-Wesley.

Fishbein, M., and Ajzen, I. (1980). Understanding Attitudes and Predicting Social Behavior. New Jersey, NJ: Prentice-Hall.

Gadamer, H. G. (2006). Estética y Hermenéutica [Aesthetics and Hermeneutics]. Madrid: Tecnos.

Gadamer, H. G., and DaVia, C. (2015). The Socratic question and Aristotle. Cont. Philos. Rev. 48, 95-102. doi: 10.1007/s11007-014-9312-2

Galo, J. P. E. (2016). Pedagogía crítica como medio para desarrollar la autonomía moral [Critical pedagogy as a mean to develop moral autonomy]. Revista Latinoamericana de Derechos Humanos 27, 57-73. doi: 10.15359/rldh.27-1.3

Hellison, D. (1995). Teaching Responsibility through Physical Activity. Champaign, IL: Human Kinetics.

Hellison, D. (2003). "Teaching personal and social responsibility in physical education," in Students Learning in Physical Education: Applying Research to Enhance Instruction, eds S. J. Silverman and C. Ennis (Champaign, IL: Human Kinetics), 269-286. 
Hellison, D. (2011). Teaching Personal and Social Responsibility through Physical Activity. Champaign, IL: Human Kinetics.

Hellison, D., Cuttford, N., Kallusky, J., Martinek, T., Parker, M., and Stiehl, J. (2000). Youth Development and Physical Activity. Linking Universities and Communities. Champaign, IL: Human Kinetics.

Hoffman, M. L. (2000). Empathy and Moral Development: Implications for Caring and Justice. New York, NY: Cambridge University Press.

Hoffman, M. L. (2001). "A comprehensive theory of prosocial moral development," in Constructive and Destructive Behavior, eds D. Stipek and A. Bohart (Washington, DC: American Psychological Association), 61-86.

Huertas, J. A. (2012). Los efectos de los afectos en la motivación y la autorregulación [Affect impact on motivation and self-regulation]. Cienc. Psicol. 6, 45-55. doi: 10.22235/cp.v6i1.62

Ingarden, R. (1959). For Roman Ingarden: Nine Essays in Phenomenology. New York, NY: Springer Science \& Business Media.

Kohlberg, L., Levine, C., and Hewer, A. (1984). "The current formulation of the theory," in Essays on Moral Development: Psychology of Moral Development, Vol. II, ed. L. Kohlberg (San Francisco, CA: Harper and Row), 219-319.

Lister, R. (2008). "Unpacking children's citizenship," in Children and Citizenship, eds A. Invernizzi and J. Williams (London: Sage), 9-19.

Lomas, T., Ivtzan, I., and Yong, C. Y. (2016). Mindful living in older age: a pilot study of a brief, community-based, positive aging intervention. Mindfulness 7, 630-641. doi: 10.1007/s12671-016-0498-8

López-Pérez, B., Sanchez, J., and Parkinson, B. (2016). Perceived effects of other people's emotion regulation on their vicarious emotional response. Motiv. Emot. 41, 113-121. doi: 10.1007/s11031-016-9585-3

Maliki, A. E., Asain, E. S., and Kebbi, J. (2010). Background variables, social responsibility and academic achievement among Secondary school students in Bayelsa State of Nigeria. Stud. Home Comm. Sci. 4, 27-32.

Martinek, T., Rodríguez, P., Ruiz, L. M., Schilling, T., Durán, L. J., and Jiménez, P. (2006). El proyecto esfuerzo: un modelo para el desarrollo de la responsabilidad personal y social a través del deporte [Project Effort. A model for the development of social and personal responsibility through sport]. Rev. Educ. 143, 933-958.

Martinez, B. J. S. A., Mármol, A. G., Valenzuela, A. V., de la Cruz Sánchez, E., and Suárez, A. D. (2016). El Modelo de responsabilidad personal y social a través del deporte como propuesta metodológica para la educación en valores en adolescentes [Personal and social responsibility model through Sport as methodological proposal for adolescents education in values]. Espiral 18, 16-26.

Medina-Vicent, M. (2016). La ética del cuidado y Carol Gilligan: una crítica a la teoría del desarrollo moral de Kohlberg para la definición de un nivel moral postconvencional contextualista [The ethics of care and Carol Gilligan: a critique of Kohlberg's theory of moral development for the definition of a post-conventional contextualist moral level]. Daimon 67, 83-98. doi: 10.6018/ daimon/199701

Melero, M. A., and Palomera, R. (2011). Evaluación Psicológica del Proyecto VyvE [Psychological Evaluation of LiVE Project]. Santander: Fundación Botín.

Menéndez-Santurio, J. I., and Fernández-Río, J. (2016). Violence, responsibility, friendship and basic psychological needs: effects of a sport education and teaching for personal and social responsibility program. Rev. Psicodidac. 21, 245-260. doi: 10.1387/RevPsicodidact.15269

Monsalvo, E. (2012). Adquisición de Actitudes de Responsabilidad en la Educación Infantil: Evolución y Actividades de Apoyo Educativo [Acquisition of Attitudes of Responsibility in Early Childhood Education: Evolution and Educational Support Activities]. Saarbrücken: Editorial Académica Española.

Monsalvo, E. (2013). Las Actitudes de Responsabilidad en Alumnos de Educación Primaria: Trabajo en su Adesarrollo y Adquisición [Attitudes of Responsibility in Primary Education Students: Development and Acquisition]. Saarbrücken: Editorial Academia Española.

Musitu, G., Buelga, S., Lila, M., and Cava, M. J. (2001). Familia y Adolescencia [Family and Adolescence]. Madrid: Síntesis.

Musitu, G., and García, F. (2016). La evaluación de la socialización familiar: ESPA29 [Evaluation of family socialization: ESPA29]. Padres Maestros 367, 60-66. doi: 10.14422/pym.i367.y2016.011
Ochs, E. (2011). "Narrative in everyday life," in Discourse Studies: A Multidisciplinary Introduction, ed. T. A. Van Dijk (London: Sage), 64-68.

Ochs, E., and Izquierdo, C. (2009). Responsibility in childhood: three developmental trajectories. J. Soc. Psychol. Anthropol. 37, 391-413. doi: 10.1111/j.1548-1352.2009.01066.x

Otero, M. (2015). La Responsabilidad Narrativa: Adquisición en Alumnos de Educación Secundaria Obligatoria [Narrative Responsibility: Acquisition in Students of Secondary Education]. Doctoral dissertation, Universidad de Valladolid, Valladolid.

Paradise, R., and De Haan, M. (2009). Responsibility and reciprocity: social organization of Mazahua Learning practices. Anthropol. Educ. Q. 40, 187-204. doi: $10.1111 / j .1548-1492.2009 .01035 . x$

Pawelski, J. O. (2016). Defining the 'positive' in positive psychology: Part I. A descriptive analysis. J. Posit. Psychol. 11, 339-356. doi: 10.1080/17439760. 2015.1137627

Peters, R. S. (2015). Moral Development and Moral Education. Abingdon, UK: Routledge.

Raimundi, M. J., and Molina, M. F. (2015). La promoción de desafíos por parte de los padres: construcción de una escala para su evaluación [Promoting challenges for parents: building a scale for evaluation]. Rev. Interam. Psicol. 49, 272-284. Retrieved from https://journal.sipsych.org

Ricoeur, P. (2012). On Psychoanalysis. Cambridge: Polity Press.

Salusky, I., Larson, R. W., Griffith, A., Wu, J., Raffaelli, M., Sugimura, N., et al. (2014). How adolescents develop responsibility: What can be learned from youth programs? J. Res. Adolesc. 24, 417-430. doi: 10.1111/jora.12118

Savage, R. W. (ed.). (2015). Paul Ricoeur in the Age of Hermeneutical Reason: Poetics, Praxis, and Critique. Lanham, MD: Lexington Books.

Seligman, M. E. (2012). Flourish: A Visionary New Understanding of Happiness and Well-Being. New York, NY: Simon and Schuster.

Seligman, M. E., and Csikszentmihalyi, M. (2000). Positive psychology: an introduction. Am. Psychol. 55, 5-14. doi: 10.1037/0003-066X.55.1.5

Seligman, M. E., and Petterson, C. (2004). Character Strengths and Virtues: A Handbook and Classification. Oxford: Oxford University Press.

Seligman, M. E., Steen, T. A., Park, N., and Peterson, C. (2005). Positive psychology progress: empirical validation of interventions. Am. Psychol. 60, 410-421. doi: 10.1037/0003-066X.60.5.410

Such, E., and Walker, R. (2004). Being responsible and responsible beings: children's understanding of responsibility. Child. Soc. 18, 231-242. doi: 10.1002/ chi.795

Thomas, R. (2011). Autonomy, Responsibility, and Families: Connections, Questions, and Complexities. Conference held in the 12th International Conference on Theory of Education. Barcelona, Spain. Available at: http://www. cite2011.com/Ponencias/RThomas.pdf

Wood, D., Larson, R. W., and Brown, J. R. (2009). How adolescents come to see themselves as more responsible through participation in youth programs. Child Dev. 80, 295-309. doi: 10.1111/j.1467-8624.2008.01260.x

Wray-Lake, L., and Syvertsen, A. K. (2011). The developmental roots of social responsibility in childhood and adolescence. New Dir. Child Adolesc. Dev. 134, 11-25. doi: 10.1002/cd.308

Zaharim, N. M., Hao, N. K., and Van Son, H. (2013). The concept of responsibilities among 5th grade students from ethnic minority groups in Vietnam. Asian Soc. Sci. 9, 99-106. doi: 10.5539/ass.v9n9p99

Conflict of Interest Statement: The authors declare that the research was conducted in the absence of any commercial or financial relationships that could be construed as a potential conflict of interest.

Copyright () 2017 Carbonero, Martín-Antón, Otero and Monsalvo. This is an openaccess article distributed under the terms of the Creative Commons Attribution License (CC BY). The use, distribution or reproduction in other forums is permitted, provided the original author(s) or licensor are credited and that the original publication in this journal is cited, in accordance with accepted academic practice. No use, distribution or reproduction is permitted which does not comply with these terms. 


\section{APPENDIX}

TABLE A1 | Structure, traits of personality and social responsibility factors worked with the training program: Let's play to think: the emotional judgment and good decisions.

\begin{tabular}{|c|c|c|}
\hline Unit & Traits of responsibility & Factors \\
\hline I am Sam & $\begin{array}{l}\text { (1) Expectative from parents and children, (2) parents as model of social responsibility, (3) parent } \\
\text { models of perseverance and self-discipline. }\end{array}$ & F9 and F10 \\
\hline The day of the responsibility & (1) Respect toward nature and classroom materials., (2) respect at home. & F1 \\
\hline The box of chocolates & $\begin{array}{l}\text { (1) Empathy and "listening," (2) Fellowship, (3) get along with adults, (4) be collaborative, (5) capacity } \\
\text { for coexistence. }\end{array}$ & $\mathrm{F} 2$ \\
\hline The disobedient Prince & $\begin{array}{l}\text { (1) Homework done, clean notebook, complete, etc. (2) attention to the teacher, punctuality, (3) } \\
\text { participation in housework. }\end{array}$ & F3 and F7 \\
\hline The village of unclean people & (1) Civility and personal hygiene, (2) Organization and order. & F5 \\
\hline The child and the bomb & $\begin{array}{l}\text { (1) Self-attribution od errors and acceptation of its consequences with self-criticism, (2) consistent, } \\
\text { prudent and self-control. }\end{array}$ & F4 and F8 \\
\hline A girl very superior & (1) Honesty, (2) assist and collaborate with coworkers, (3) generosity, against selfishness. & F6 \\
\hline A very busy parents & $\begin{array}{l}\text { (1) A model of social responsibility and perseverance is a model of parents dedicated to their } \\
\text { children. }\end{array}$ & $\mathrm{F} 9$ and $\mathrm{F} 10$ \\
\hline Household tasks & (1) Respect in the family context, (2) order in the family context. & $\mathrm{F} 1$ \\
\hline The last leaf & (1) Well-mannered, (2) be friendly and be ready to the support and to collaborate. & $\mathrm{F} 2$ \\
\hline The messed fairy & $\begin{array}{l}\text { (1) Friendliness and well-mannered, (2) order the tasks and homework; (3) collaboration in the } \\
\text { household tasks. }\end{array}$ & F5 \\
\hline The Gnome & $\begin{array}{l}\text { (1) Being self-disciplined and constant worker, (2) bring the made activities, clean notebook, full, } \\
\text { etc., (3) record in the Studio, (4) obedience; (5) comply with what it promises. }\end{array}$ & F3 and F7 \\
\hline The king who makes deserts & $\begin{array}{l}\text { (1) The importance of controlling own emotions, (2) the importance of accepting errors, (3) justice as } \\
\text { a commitment to each other. }\end{array}$ & F4 and F6 \\
\hline Lost in the forest & $\begin{array}{l}\text { (1) Self-evaluation and recognition of errors to amend them, (2) learn to control temper tantrums } \\
\text { and mood, (3) value patience as a way to achieve our goals and enhance friendship. }\end{array}$ & F8 \\
\hline
\end{tabular}

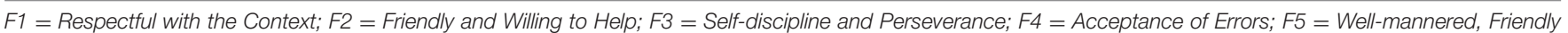

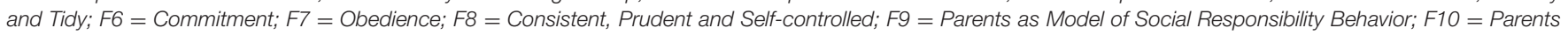
as Model of Perseverance. 
OPEN ACCESS

Edited by:

Puri Checa,

University of Granada, Spain

Reviewed by:

Milagros Damián Díaz,

Universidad Nacional Autónoma de

México, Mexico

Luis J. Martín-Antón,

University of Valladolid, Spain

Maria Da Glória Salazar D'Eça Costa

Franco,

University of Madeira, Portugal

*Correspondence: Edgar Galindo

edgar_galindo@hotmail.com

Specialty section: This article was submitted to Educational Psychology, a section of the journal

Frontiers in Psychology

Received: 24 January 2017 Accepted: 15 March 2018

Published: 29 May 2018

Citation:

Galindo E, Candeias AA, Pires HS,

Grácio L and Stück M (2018)

Behavioral Skills Training in

Portuguese Children With School Failure Problems.

Front. Psychol. 9:437. doi: 10.3389/fpsyg.2018.00437

\section{Behavioral Skills Training in Portuguese Children With School Failure Problems}

\author{
Edgar Galindo ${ }^{1 *}$, Adelinda A. Candeias ${ }^{1}$, Heldemerina S. Pires ${ }^{1}$, Luísa Grácio ${ }^{1}$ and \\ Marcus Stück ${ }^{2}$
}

${ }^{1}$ Centro de Investigação em Educação e Psicologia, Departamento de Psicologia, Universidade de Evora, Evora, Portugal, ${ }^{2}$ Department of Childhood Pedagogy, DPFA Hochschule Sachsen, University of Applied Sciences, Leipzig, Germany

This paper postulates that psychology can make an important contribution at an individual level to help children with school failure problems in a context where too little applied research has been conducted on the instructional needs of these children. Some data are analyzed, revealing that, despite some progress, school failure is still a main educational problem in many countries. In this study, Behavioral Skills Training (BST) was applied in Portugal to train children with school failure difficulties. BST is a method based on Applied Behavior Analysis, a teaching package consisting of a combination of behavioral techniques: instructions, modeling, rehearsal, and feedback. Two empirical studies are presented. Their main purpose was to develop behavioral diagnostic and training techniques to teach lacking skills. School success was defined in terms of a set of skills proposed by teachers and school failure as a lack of one or more of these skills. The main instrument was a package of training programs to be applied in three areas: basic behavior (precurrents), academic behavior, or social behavior. The second instrument is a package of check-lists, aimed to determine the level of performance of the child in an area. This check-list was applied before (pre-test) and after (post-test) training. In the first study, 16, 7- to 8-year old children were trained. They were attending the second or third grades and having academic difficulties of different origins. The effects of the training programs are evaluated in terms of percentage of attained objectives, comparing a pre- and a post-test. The results showed an increase in correct responses after training in all cases. To provide a sounder demonstration of the efficacy of the training programs, a second study was carried out using a quasi-experimental design. A multiple baseline design was applied to three 10- to 11-year-old children, referred by teachers because of learning difficulties in the fourth grade. Results showed few performance changes without training. Increases in behavior following BST were evident in all cases, indicating that training generated improvement in all three children. In both studies, comparable results occurred across students, demonstrating replication of the effects of the training programs.

Keywords: school failure, academic behavior, applied behavior analysis, behavioral skills training, educational psychology 


\section{INTRODUCTION}

There are several definitions of school failure. Fernandez Enguita et al. (2010, p. 18) propose one, which is adequate to our purposes:

... school failure is the situation of the student who, in trying to achieve the minimum objectives set forth by the institution, (...) fails to do so and withdraws after having been categorized as a failure...

Nevertheless, in this article a pragmatic working definition has been chosen: children with school failure are those referred by the teachers because they have repeated grades at least once or because they are currently at risk of having to repeat a grade.

School failure is a main educational problem in Portugal. Recent data by the European Commission/Directorate-General for Education and Culture (EC DGEC) (2016, p. 39) show that Portugal has one of the highest rates of early school leaving (as measured by the number of individuals 18-24 years of age that did not finish school and do not attend school for each 100 individuals of the same age). The Portuguese figure of $14 \%$ compares to $3 \%$ in Croatia and $11 \%$ percent across the UE. In spite of improvements since 2005, early school leaving is still a main problem in Portugal. Fourteen 14\% of people between 18 and 24 years who have not finished have, nevertheless, quit attending.

These data do not address the reasons behind the phenomenon. Yet, it might be supposed that at least $14 \%$ of children had some kind of academic problem at an early school age. Dropping out of school is largely determined by school failure in primary school (Justino et al., 2014, p. 54).

There are several types of school failure in Portugal: early school leaving, successive failure leading to a gap between grade and the chronological age of children (rate of retention), and dropping out of primary schooling (10-15 years). Table 1 compares some aspects of the problem in Portugal and other European countries for 2009. At the primary school level (ISCED 1) Portugal had by far the greatest proportion of pupils repeating at least once year of primary education, (22.4\%), vs. $12.2 \%$ for the next highest, Spain, and 7.7\% for the European mean. This means that, in Portugal, 22.4\% of children between 6 and 12 years have some kind of learning problems at school.

Additional data show an urgent need for intervention in the early school years, such as Portuguese sources (Gabinete de Estatística e Planeamento da Educação, 2010, p. 18) that point out that the yearly rate of retention and dropouts at basic school in 2008 was 7.6 for ISCED 1 (grades one to four) in 2008. These data

TABLE 1 | Proportion of 15 years old pupils who had repeated at least once in primary education (ISCED level 1) in 2009, a selection of some countries (Adapted from Eurydice, 2011, p. 36).

\begin{tabular}{llllllllll}
\hline EU-27 & BG & CZ & DK & DE & FR & ES & IT & AT & PT \\
\hline 7.7 & 2.7 & 2.1 & 3.6 & 9.2 & 17.8 & 12.2 & 1.0 & 4.9 & 22.4 \\
\hline
\end{tabular}

EU, European Union; BG, Bulgaria; CZ, Czech Republic; DK, Denmark; DE, Germany; FR, France; ES, Spain; It, Italy; AT, Austria; PT, Portugal. show significant improvement from 1999 to 2008, as retention and dropout rates fell from 12.1 to $7.6 \%$. Nevertheless, the rate remains significantly high, since it means that, in the first three grades, $7.6 \%$ of children either drop out of school or do not pass to the next school year.

The Organization for Economic Cooperation and Development [OECD] (see OECD, 2010), the European Union and international educational agencies identified the problem many years ago. A set of causes and recommendations for fighting school failure were proposed.

Commonly cited causes included cognitive deficiencies of children, unstable family environments (conflicts, divorce, parental disorders), socioeconomic issues such as low SES (poverty or social exclusion), and then, inadequate quality or functioning of the educational system (bad teaching methods, faulty school organization, or unorganized curricula; WebsterStratton et al., 2008). The failure of any one child is most likely the result not of one factor but rather the interaction of many, as in the case of the children participating in this study. However, from the point of view of treatment, the cause of school failure is not especially pertinent. It is urgent to find intervention strategies able to cope with the problem independently of the cause.

Scientists have proposed several strategies to deal with the problem, such as increased preschool education, adapting schools to children's needs and possibilities, preparing more and better teachers and specialists, innovating teaching and evaluation methods, improving relations between school and the social environment or between schools and families (Carbonero et al., 2017), and applying personalized teaching methods, according to specific needs and characteristics of each child (Marchesi and Hernández Gil, 2003). This last proposal is the basis of our work. At an individual level, the one main task of psychology is to develop differential teaching methods to be applied as early as possible. On the other hand, very little applied research has been conducted on the instructional needs of these children. Poche et al. (1981, p. 323) observed that "Students with learning disabilities who experience difficulties in mathematics are frequently taught multiplication facts using the same procedures and sequences that are used with students without difficulties, that is, repetition drills..." This also appears to be true for children with problems of school failure, who are frequently taught reading, writing and arithmetic with the same methodology that has failed to work in the past.

\section{Applied Behavior Analysis and Behavioral Skills Training}

Applied Behavior Analysis (ABA), also called Behavior Modification, is the applied part of the Experimental Analysis of Behavior, based on the principles of conditioning as they were defined originally by I. P. Pavlov and B. F. Skinner. ABA techniques have proved to be useful tools for coping with a broad range of behavior problems. A great deal of research is available about the application of $\mathrm{ABA}$ to the training and rehabilitation of people with different kinds of learning difficulties. Authors like Whitman et al. (1971) came up with this process while training mentally retarded children in 
instructions following, imitation, selfcare, eating, verbal, and social behavior. Since then, behavioral programs have been applied successfully to train people with intellectual disabilities in academic skills such as reading (Saunders et al., 2003) and using computers (Jerome et al., 2007). Another example has been training people with hearing and visual impairments (Green et al., 2005; Toussaint and Tiger, 2010), and others with autism (Axe and Sainato, 2010; Rodriguez-Medina et al., 2016) or with learning disabilities (Wood et al., 1998; Levingston et al., 2009). The analysis of school failure has accompanied this development. Adelman and Taylor (1993) analyzed the problems of learning at school, including the types, causes and consequences of these problems as well as some proposed solutions, emphasizing the use of behavioral techniques. Hallahan et al. (1999) and Wallace et al. (1992) analyzed the causes of school failure, pointing to individual, family and school system factors, in much the same way. This work also identified a very important cause of individual school failure, namely, the absence of antecedent behaviors, such as language, social and cognitive repertoires, which are a prerequisite for the learning of reading, writing, and arithmetic. Research in other countries has confirmed the importance of those cognitive, behavioral, verbal, or social pre-academic competencies for the learning of reading, writing, and arithmetic in the early school years (Carroll et al., 2003; Neef et al., 2003; DiLalla et al., 2004; Leppänen et al., 2004; Connor et al., 2005; Guevara and Macotela, 2006).

Behavior Skills Training (BST) is based on Applied Behavior Analysis, which can be used to teach a wide variety of important skills to individuals of different ages and difficulties. Actually, it is a teaching package bringing behavioral techniques together which have been used for many years to train disadvantaged or disabled children, school children or adults. It is "an effective training package that consists of instructions, modeling, rehearsal, and feedback" (Ward-Horner and Sturmey, 2012, p. 75). Instructions consist of explaining how to carry out a determined task. During modeling, the task is demonstrated by the trainer while the trainee observes. Next, the trainee practices the task. A good chain of responses is reinforced, and errors are corrected in the last, or feedback, phase.

As mentioned above, the components of BST have been in used independently or together by behavior analysts since the 1970s. Nevertheless, the term was first used by Sarokoff and Sturmey (2004).

In recent decades, several researchers have used the four components of BST without using the term. Danish et al. (1976) outlined components of a "skills training" in a course of helping relationships, which were: (1) identifying behavior objectives; (2) practicing skills; (3) group discussion; (4) understanding the reason for using the skills; (5) presenting the skills; (6) active participation by trainees; (7) modeling of techniques; and (8) immediate feedback. Evidently, these eight steps are quite similar to BST. At that time, the authors described the existence of "skills training groups" that focused on teaching skills required to implement specific behaviors. In a program for parents, Gordon and Davidson (1981) applied a "behavior skills training" containing the elements of: (1) training parents to focus on observable behavior; (2) teaching parents concepts of learning theory; and (3) helping parents to apply the concepts when working with their children. Although the "behavior skills training" in these papers differs slightly from that of the BTS in ABA research, it is an important antecedent to the current behavior principles.

Other training packages contain all of the components of BST without labeling it as such. Bornstein et al. (1977) used all of the components of BST to train four non-assertive children in skills such as eye contact, loudness of speech, speech duration, and requests for new behavior. Children learned all behaviors with good results in generalization and maintenance. Minkin et al. (1976) also used the components of BST to teach a social skill, showing the effectiveness of instructions, modeling, rehearsal, and feedback to increase assertive conversational skills and general social conversation skills. Wurtele et al. (1989) used the components of BST to teach sexual abuse prevention skills to children.

Some studies have analyzed the effects of the individual components of BST, and have demonstrated the importance all four steps. In this line, Yeaton and Bailey (1983) applied a package to train guards about how to teach children to cross the street; they then analyzed the effectiveness of the different steps. They found that the rehearsal, feedback and praise components were necessary to produce effective behavioral change, while isolated components were not so effective. In a study of the prevention of child molestation, Poche et al. (1981) used modeling, rehearsal, and social reinforcement to teach children how to correct verbal and motor responses. The results revealed the success of modeling and rehearsal, when used together. Parsons and Reid (1995) used instructions, role-plays, and feedback to train supervisors. They found that staff skill performance endured as a result of feedback.

Since then, several researchers have successfully used BST to teach children a variety of skills. Johnson et al. (2005) examined successfully the effectiveness of individual behavioral skills training in teaching 13 preschool children abduction prevention skills in naturalistic settings. All the children maintained the skills in the 2-week and 1-month follow-ups. Similar results were obtained by Miltenberger et al. (2009) and Pan-Skadden et al. (2009). Homlitas et al. (2014) evaluated the effectiveness of a behavioral skills training package to teach the picture exchange communication system (PECS) to teachers employed at a therapeutic center for children with autism. Similar results were obtained by Barnes et al. (2011), Gianoumis et al. (2012), and Nigro-Bruzzi and Sturmey (2010) with children with autism. Seiverling et al. (2012) used successfully a package of BST to teach parents of 3 children with autism to apply a treatment for food selectivity. Results were reflected in increases in children food acceptance and decreases in disruptive behavior. Similar results were obtained by Mueller et al. (2003). Miles and Wilder (2009) applied BST to increase correct implementation of guided compliance by caregivers of 3 children with autism who exhibited noncompliance. The skills were successfully trained and they were exhibited in different settings 3-6 weeks after training ended. 
Galindo et al. (2013) and Galindo (2009) applied ABA techniques to train children with intellectual, sensorial, social, and academic deficiencies. These works are the direct antecedents of the current project. The current study extends BST research to students experiencing school failure, adapts the procedures to children at educational risk, and evaluates the intervention with a multiple baseline.

\section{The Present Study}

The current research on school failure was carried out in two different phases. The first interventions were carried out in low income, public elementary schools surrounding Lisbon. Participating children were often victims of social exclusion, i.e., members of ethnic minorities or living in extreme poverty. In one case, the parents were often absent. Data from this period have been published (Galindo, 2015). The second phase began in 2013 and applied the same package of Behavioral Skills Training to another type of child, residents of the Alentejo, a disadvantaged region of Portugal. Results of this second intervention are analyzed below. Nevertheless, a global explanation of the intervention strategies in both phases will be given, in order to provide a clearer image of the field.

The main goal of these studies was to develop behavioral diagnostic and training techniques to teach academic and social skills to children with school failure problems. School success was defined as a set of skills proposed by teachers. School failure was then understood as a lack of one or more of these skills. The skills to be mastered by a single child were defined in terms of behavioral objectives, according to the expectations of the teacher. The nature, scope and probable origins of the child's academic problems were extremely varied.

The specific goals of these interventions were:

1) To develop behavioral diagnostic techniques based on school defined skills for elementary school (ISCED 1) in Portugal.

2) To develop skill-based training programs.

On the basis of a precise description of the problems of each child, one (or more) intervention program(s) was specifically tailored for that learner, following the logic of Behavioral Skills Training. A token economy was introduced to motivate children (Ayllon and Azrin, 1968), i.e., children earned points through good responses. The points were then exchanged for privileges chosen by the children (for instance, playing with the teacher).

Three main areas of intervention were defined on the basis of preliminary observations of academic problems at school:

1) Basic behavior. Pre-current behaviors, i.e., social and preacademic skills that constitute the basis for learning other skills.

2) Academic behavior. Portuguese reading and writing, arithmetic, and the environment (social studies and science).

3) Social behavior. Social skills for proper school functioning.

Children referred to the program by teachers for having school failure problems were evaluated and trained on an individual basis by specially trained psychology or special education students (tutors). These tutors mentored one child during a semester (15-16 weeks) and worked with them for 2-4h a week at school. All skills training programs had the same structure (see Table 2), including a pre and a post-test. Consequently, results were evaluated mainly by comparing the percentage of skills which were defined in terms of attained objectives in pre- and post-tests. However, training time was also taken into account.

The training programs were highly varied, since the nature of target skills was widely different. For example, "reading" means recognizing letters for one child, but spelling words for another one. This means leads to wide variation in the reading intervention for each child under the same label. Additionally, some children received training in one subject, some in two, some in three, and so on. Training duration also varied. The data comparing pre and post-test measures showed a positive effect in most cases but, evidently, a sounder demonstration of the efficacy of the program was necessary.

Consequently, a study was carried out with a quasiexperimental, multiple baseline design in order to reinforce the scientific bases of the skills training programs. Data from this study suggested that the progress by participant children was the result of the intervention programs rather than other factors (Galindo, 2015). A replication of this study will be presented below.

\section{TABLE 2 | Program to recognize letters.}

\section{General Objective}

The child must be able to recognize all letters of the Portuguese alphabet

Specific objectives

The child must be able to identify and reproduce the sound of all alphabet letters

$$
\text { handwritten, lower case letter }
$$

handwritten, capital letters

print, lower case letters and print, capital letters

\section{Definition}

A response is correct if the child

\section{identifies a letter presented by the tutor}

reproduces the sound of a letter presented by the tutor

\section{Precurrents}

Basic repertoires and language without articulation problems

Materials

Cards with letters (see Table 3)

Place

Working room or classroom

Procedure

Pre-test: All letters are presented

Training: A package of instructions, modeling, rehearsal, and feedback handwritten, lower case letters

handwritten, capital letters

print, lower case letters

print, capital letters

The child must be able to respond correctly, without help, to the same question in five successive trials

Post-test: All letters are presented

Training has been successful if the child attains at least $80 \%$ of correct responses 


\section{TRAINING CHILDREN WITH SCHOOL FAILURE PROBLEMS IN THE ALENTEJO: STUDY 1}

An average of 14 children was trained every semester between 2013 and 2016. In the following description, only data from one semester (2013-2014) is analyzed.

\section{Materials and Methods Participants and Setting}

Sixteen children aged seven to eight in the second and third grades were referred to the program due to academic problems (see Table 4). All of them were at risk of failing the school year. They had similar SES, as they belonged to the lower middle class of a small Portuguese town. The causes of their problems were difficult to determine. Nevertheless, according to their teachers, family problems (like divorce or separation of the parents) were often present. The training took place at a public elementary school in Evora, a small city in the Alentejo region. Sessions were conducted at tables located in school corners.

\section{Instruments}

The main instrument is a package of behaviorally designed training programs to be applied in three areas, namely, basic behavior (precurrent), academic behavior (subjects of Portuguese ISCED 1), or social behavior (see Tables 2, 3). Every program was designed to solve a specific problem (writing, spelling, articulation, etc.). Tutors are explicitly instructed to develop their own programs on the basis of the pre-existing musters (Galindo, 2015). Nevertheless, all programs had the same structure: (1) a general objective, (2) skills defined in terms of specific objectives (a set of correct responses to be given by the child), (3) a definition of the previous skills necessary to learn the new skill (precurrents), (4) a pre-test (\% of attained

TABLE 3 | Check list: recognizing letters.

Objective
The child must identify the letters presented by the tutor
Place
Workspace or classroom
Material
Cards with letters
cards with all handwritten, lower case letters
cards with all handwritten, capital letters
cards with all printed, lower case letters
cards with all printed, capital letters
Procedure
The tutor says "we are going to play cards; I will show you four cards with letters
and you must put your finger on the letter I am looking for"
Cards are chosen randomly
All letters must be shown
The child must identify the letter in <5s
A training is necessary if the child obtains less than $80 \%$ of correct responses.
In such a case, a more precise evaluation of the errors is necessary

objectives/correct responses), (5) a training package based on instructions, modeling, rehearsal, and feedback, (6) a post-test (\% of attained objectives/correct responses). The specific objectives of the program are defined in terms of responses given by a specific child. Every program has a set of previously established correct responses Evaluation of the efficacy of the program was carried out by comparing the percentage of attained objectives before (pre-test) and after training (post-test).

The second instrument is a package of behaviorally designed check-lists (Galindo, 2015) intended to determine the level of performance of the child in an area, i.e., basic behavior, academic behavior, and social behavior. Every list was designed by the tutor to evaluate a specific skill of the child (e.g., their articulation problems). Nevertheless, every check-list had the same structure (see Table 3).

\section{Procedure}

Before any contact with children, written informed consent was obtained from the parents. Before the assessment period, children were informed of the nature of the intervention and were told that the programs were expected to help them in their school subjects. Behavioral Skills Training was applied by ABA trained Psychology students (tutors) for $2 \mathrm{~h}$ a week (2 sessions $\times 1 \mathrm{~h}$ ) during a semester (15 weeks). Each tutor took on a child and worked with them throughout the intervention. Before the training began, the tutors gathered all the information they could about their child. Existing and non-existing skills, as well as the possible aims of the intervention were defined together with the teacher. The first week served for the tutors to get acquainted with the child, and the tutor then applied a set of check-lists to identify as precisely as possible the specific problems of the child in each subject. All information was used to elaborate a hierarchy of problems. On this basis, an intervention strategy was designed, elaborating specific training programs for the child. The specific objectives of the program were the goals of the intervention. The percentage of correct responses in a given program attained before and after intervention are the main data. The child must attain at least $80 \%$ of correct responses in a given program. During intervention, the tutor would collect the children from the classroom and work with them in another room for an hour, always in coordination with the teacher. An intervention might last a few weeks or the whole semester, depending on the children's needs. A post-test was carried out following the training.

\section{Results}

Table 4 shows a list of participants, the pre-test and post-test results and the number of sessions (including testing). Ten children (three girls and seven boys) were 7 years old and were in second grade. Five students (two girls and four boys) were eight and attended the third school year. They were trained mainly in school subjects like reading, writing, arithmetic, and environment, but some of them received additional training in precurrent behaviors like language (articulation), fine motor skills and good classroom social behavior (sitting in the chair and/or concentration). The objective of sitting in the chair for 
TABLE 4 | Study 1. Children at ISCED 1 trained in the period 2013-2014.

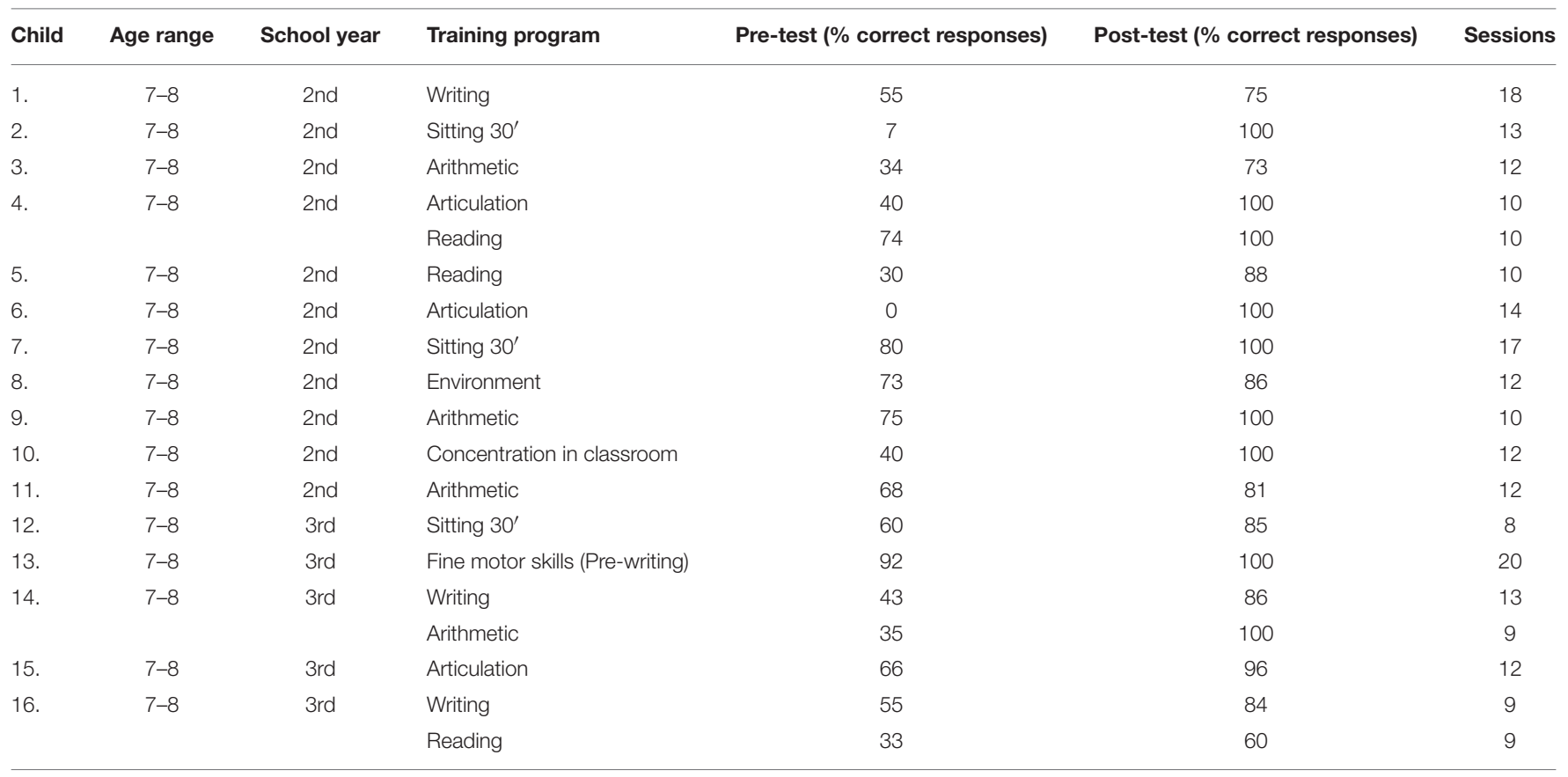

The table shows training programs applied to every child, the results obtained before (pre-test) and after training (post-test), as well as the number of sessions. 1 session $=1 \mathrm{~h}$.

30 min was defined by the teacher as good enough to work in the classroom.

Children 4, 14, and 16 were trained in two programs, the others in only one. Most of the children attained more than $80 \%$ of correct responses by the end of the training. Exceptions were children 1,3 , and 16 , who were not able to complete the program before the end of the semester. Child 1 was trained in writing. She improved from 55 to $75 \%$ correct responses in 18 sessions $(18 \mathrm{~h})$, even though failing to achieve the target $80 \%$. Child 2 was referred because of hyperactivity in the classroom. He was trained to sit still for $30 \mathrm{~min}$ while concentrating on a task and he advanced from $7 \%(2.1 \mathrm{~min})$ to $100 \%(30 \mathrm{~min})$ in 13 sessions $(13 \mathrm{~h})$. Child 3 received math training. He advanced from 34 to $73 \%$ in 12 sessions $(12 \mathrm{~h})$. Child 4 was referred because of reading problems. Our evaluation showed a language problem. Consequently, he was trained first in articulation, where he advanced from 40 to $100 \%$ in 10 sessions $(10 \mathrm{~h})$ and then in reading, where he advanced from 74 to $100 \%$ in 10 sessions $(10 \mathrm{~h})$. Child 5 was trained in reading and he advanced from 30 to $100 \%$ of correct responses in 10 sessions $(10 \mathrm{~h})$. Child 6 also received reading training. A detailed assessment revealed language problems and he was trained in articulation, whereupon he advanced from 0 to $100 \%$ correct responses in 14 sessions $(14 \mathrm{~h})$. Reading training was planned for the following semester. Child 7 was referred because of hyperactivity. Detailed observations revealed he could sit $24 \mathrm{~min}$ (80\%). Nevertheless, he was trained in sitting and concentration, and managed to attain $100 \%$ (30 min) in 17 sessions. Child 8 was trained in environment (Natural Sciences) and she improved from 73 to $86 \%$ correct responses in 12 sessions. Child 9 was trained in math and increased from 75 to $100 \%$ in 10 sessions ( $10 \mathrm{~h})$.
Child 10 was referred because of "lack of attention and disruptive behavior" in the classroom. Our observations revealed he could work without distraction $12 \mathrm{~min}$ (40\%). Consequently, he was trained to concentrate on a task without getting distracted during $30 \mathrm{~min}$, advancing to $100 \%$ (30 min) in 12 sessions ( $12 \mathrm{~h}$ ). Child 11 received math training; he improved from 68 to $81 \%$ correct responses in 12 sessions $(12 \mathrm{~h})$. Child 12 was referred because of hyperactivity. Our observations showed he could sit on his chair for $18 \mathrm{~min}(60 \%)$. After 8 sessions, he was able to sit and concentrate on his work for almost $26 \mathrm{~min}$ (85\%). Child 13 was already in the 3 rd grade, but she could not hold her pen properly and had problems completing writing tasks. Our observations revealed she had few motor skills problems, but they were enough to slow her writing. She received fine motor skills training consisting of pre-writing exercises and advanced from 92 to $100 \%$ of correct responses in 20 sessions $(20 \mathrm{~h})$. Child 14 had problems with writing and math. It was decided to prioritize math and he received 13 training sessions $(13 \mathrm{~h})$ and improved from 43 to $86 \%$ of correct answers. He also received math training, where he advanced from 35 to $100 \%$ correct responses in 9 sessions ( $9 \mathrm{~h}$ ). Child 15 was referred due to reading difficulties. Further analysis revealed an articulation problem and he received 12 training sessions, advancing from 66 to $96 \%$. Child 16 had problems with reading and writing. The tutor decided to start with writing and the child advanced from 55 to $84 \%$ in 9 sessions. It was considered a good result and a training program in reading was applied, where he advanced from 33 to $60 \%$ in 9 sessions.

A comparison of pre- and post-test results showed an increase in correct responses following training in all cases. The number of sessions necessary to train a skill is highly variable, ranging from 8 to 20 sessions. For instance, articulation problems were solved 
in 10 sessions (child 4), in 14 sessions (child 6), or in 9 sessions (child 16).

An independent-samples $t$-test was run. It showed there are no outliers in the data, i.e., the results of children's performances were normally distributed, as assessed by Shapiro-Wilks test $(p>$ 0.05 ). Additionally, a paired-sample $t$-test was run to determine if there were significant differences in the performance of children before training (pre-test) and after training (post-test). Table 5 shows that there was an increase in the mean values (39.31 points more) and a greater homogeneity in post-test results (less dispersion in Student deviation). A statistically significant difference in mean values was also found $(t=-5.72, p>0.000)$. Therefore, it is possible to say the increase in the performance of children was with $99 \%$ probability a result of the training programs.

\section{Discussion}

The data show the positive and negative aspects of the training programs. On one hand, it seems that all training programs (independently of the problem treated) led to increased correct responses in all children (independently of gender or age), in a relatively short time (8-20 h of training). In other words, every child managed to quickly learn a previously lacking skill. It seems then that the strategy used to identify the lacking skills and to train the identified skills produced an overall positive change in children's behavior. Teachers' subjective opinions confirmed this supposition. Nevertheless, in at least two cases, the teacher complained the children were "behaving better" but lacked any obvious improvements in academic performance. This is probably due to the fact that teachers were more focused on concrete results in academic subjects and were not accustomed to paying attention to precurrent skills like sitting still, concentration, articulation, or fine motor skills. These results coincide thoroughly with results of other interventions carried out with the same instruments, strategies, and procedures in other settings (Galindo, 2015).

On the other hand, the possibility should be considered that the children's improvements were not the result of the applied training, but of the work performed by teachers or due to the natural maturation process. It is still necessary to demonstrate that the positive behaviors were the direct result of the applied training programs.

Methodologically, these training programs represent a problem because it is difficult to compare a collection of such different cases since each child had a special problem and the training program was tailored for them.

TABLE 5 | Study 1. A comparison of the performance of children before training (pre-test) and after training (post-test).

\begin{tabular}{lccccccc}
\hline & N & Mean & $\begin{array}{c}\text { Student } \\
\text { deviation }\end{array}$ & $\begin{array}{c}\text { Difference } \\
\text { mean }\end{array}$ & T & df & $\begin{array}{c}\text { Sig. } \\
\text { (2-tailed) }\end{array}$ \\
\hline Pre-test & 16 & 51.2500 & 25.57212 & 39.31 & 25.57212 & 25.57212 & 25.57212 \\
Post-test 16 & 90.5625 & 10.65813 & & & &
\end{tabular}

In the next study, a quasi-experimental multiple baseline design (Johnston and Pennypacker, 2009) was applied in an attempt to resolve this issue. In a former work (Galindo, 2015), the successive application of the variable training to four children seemed to confirm that the results were caused by the intervention programs. In the following study, a replication of that work is carried out.

\section{TRAINING CHILDREN WITH SCHOOL FAILURE PROBLEMS IN ALENTEJO: STUDY 2}

\section{Materials and Methods Participants and Setting}

Three 10- to 11-year-old fourth graders were referred to the program because of academic problems. They had a similar SES, as they belonged to the lower middle class of a Portuguese village. The causes of their problems were not determined, but at least one had family problems (separation of the parents). They were selected according to the following criteria: (1) they belonged to an average Portuguese family without a history of immigration; (2) they had failed at least one grade; (3) they had no reports of intellectual incapacity; (4) they had been referred by the teacher because of similar academic problems; and (5) they had taken part without success in other programs for children at educational risk.

Child A, a girl aged 10, had repeated the 3rd grade and was at risk of failing again. According to her teacher, she had difficulties understanding texts and verbal instructions (comprehension) and a lack of concentration skills and motivation. As a consequence, she had problems in math, environment and Portuguese (reading and writing).

Child B, a boy of 11 , had repeated the 3rd grade. He had had delayed language development and behavioral (emotional) problems since his parents had divorced, and had been treated by a speech therapist and a psychologist. According to his teacher, he was disorganized, had difficulties concentrating on tasks, language problems, hyperactivity, and a lack of motivation. $\mathrm{He}$ had comprehension problems, poor spelling (orthography) and other writing problems.

Child C, a boy, aged 10, had suffered a health problem with secondary effects on his motor skills, as well as having moved house and school several times. He had repeated the last preschool year because of a lack of the necessary skills. According to his teacher, he presented oppositional behaviors, concentration problems and lack of motivation, and was consequently experiencing difficulties in all subjects. Regarding Portuguese reading and writing, he committed numerous and varied spelling errors.

The institution was a public elementary school situated in Arraiolos, a village in the Alentejo with retention rates higher than average in Portugal (Direção-Geral de Estatísticas da Educação e Ciência (DGEEC), 2014). It was a mixed class, where 18 children in the 2 nd ( 7 students) and the 4 th grades (11 students) were taught together. Obviously, having students from two different courses in the same class can influence the 
development of student learning. Most of the children had already repeated a grade. Training sessions were conducted at a table in a separate room of the school.

\section{Instruments and Materials}

The main instrument relied on three behaviorally designed training programs to be applied in verbal comprehension (VC), reading $(\mathrm{R})$, and spelling/orthography $(\mathrm{O})$. The programs were designed to solve the specific problems of the three children according to a set of objectives set by the teacher. All programs had the structure explained in Study 1: (1) general objective, (2) specific objectives, (3) definition of precurrents, (4) pre-test, (5) training packaged based on instructions, modeling, rehearsal, and feedback, and (6) post-test. A first difference with respect to programs applied in Study 1 related to the content: all skills were defined according to the handbooks and materials of the 4th grade. A second difference was that the same program was applied to all three children.

The second instrument, a package of behaviorally designed check-lists aimed to assess the level of performance of the child in a determined area were also applied, following the same explained strategies.

\section{Procedure}

The assessment began once parents gave written informed consent and the children were in agreement. Each child was evaluated according to the previously described strategy. It was verified that all three children had roughly the same academic problems. After assessment, Behavioral Skills Training was applied to the three children by an ABA trained tutor for $3 \mathrm{~h}$ a week ( 2 sessions $\times 1 \frac{1 / 2}{h}$ ) during 21 weeks. The tutor took charge of all 3 children and worked with them from the beginning to the end of intervention. Procedures were applied following the same lines of Study 1. All information gathered was used to design training programs for the children, according to a set of objectives set by the teachers. The target skills, defined as specific objectives, were the goal of the intervention. The percentage of correct responses in a given program attained before (pre-test) and after training (post-test) were the main data.

A multiple baseline design across subjects was used to evaluate the effects of the training problems, much in the way as that used by authors treating similar problems (Wood et al., 1998; Levingston et al., 2009; Krohn et al., 2012). In the current study, the package training as independent variable was applied successively to all three children.

A baseline assessment (BL) based on the application of the training programs pre-test for $\mathrm{VC}, \mathrm{R}$, and $\mathrm{O}$ was conducted in week 1 (BL1), week 5 (BL2), and week 9 (BL3). The final post-test assessment (FA) was conducted in week 21. Following baseline assessment, all children received training consisting of multiple baseline. Training was then applied to the three children (see Figure 1). They were assigned randomly to one of 3 different training conditions:

CONDITION A: Child A was evaluated once before training (BL1). She then received 19 weeks of training and a final assessment (FA) was carried out in week 21.
CONDITION B: Child B was evaluated twice without training in weeks 1 (BL1) and 5 (BL2), and he was then trained for 15 weeks and a final assessment (FA) was performed in week 21 .

CONDITION C: Child $C$ was evaluated three times without training in weeks 1 (BL1), 5 (BL2), and 9 (BL3). He then received training for 11 weeks and a final assessment (FA) was made on week 21 .

\section{Results}

The results of the multiple baseline analysis for all three children participating in Study 2 are presented in Figure 1. Children A, B and $C$ were trained in 3 subjects (verbal comprehension, reading, and spelling/orthography), but the onset of training was different for every child. Assessments were carried out in weeks 1, 5, 9, and 21. The percentage of correct responses attained by each child in every assessment is shown. Child A was evaluated once before training in week 1 (BL1) and once after 19 weeks training (FA). Child B was evaluated twice without training in weeks 1 (BL1) and 5 (BL2) and once after 15 weeks training (FA). Child C was evaluated three times without training in week 1 (BL1), week 5 (BL2), and week 9 (BL3) and once after 11 weeks' training (FA).

Overall, changes in all 3 children after training were evident. The most obvious took place in reading, where all three children attained $100 \%$ of correct responses in FA (week 21). An analysis of the individual results reveals other positive changes.

Child A showed clear increases from BL1 (week 1) to FA (week 21 ), advancing from 60 to $90 \%$ of correct responses in verbal comprehension, from 75 to $100 \%$ in reading, and from 73 to $89 \%$ in spelling (orthography). This improved performance seemed to have occurred in 19 weeks of training, i.e., $57 \mathrm{~h}$.

Child B was evaluated without training in week 1 (BL1) and week 5 (BL2). Starting in week 6 , a training procedure was applied for 15 weeks. The final evaluation (FA) was carried out in week 21. A comparison between BL 1 (week 1) and BL2 (week 5 ) showed little change. Indeed, change was negative, with the percentage of correct responses decreasing from 60 to $50 \%$ in verbal comprehension, from 65 to $64 \%$ in reading and from 63 to $62 \%$ in spelling (orthography). In other words, the child seemed to have gotten worse during training. On the contrary, a comparison of last BL2 (week 5) with FA (week 21) showed great increases, from 50 to $90 \%$ in verbal comprehension, from 64 to $100 \%$ in reading, and from 62 to $77 \%$ in spelling. This child's improvement seems to have occurred in a period of 15 weeks, i.e., $45 \mathrm{~h}$.

Child C was evaluated without training in week 1 (BL1), week 5 (BL2), and week 9 (BL3); he was then trained for 11 weeks. A last evaluation (FA) was performed after training, in week 21. A comparison of BL1 (week 1) with BL2 (week 5) shows an increase of correct responses in verbal comprehension (from 60 to $70 \%$ ), but decreases in reading and spelling/orthography (from 58 to $56 \%$ in both cases). A comparison of BL2 (week 5) with BL3 (week 9) shows a decrease from 70 to $60 \%$ in verbal comprehension, and slight increases in reading (from 56 to $58 \%$ ) and spelling (from 56 to $60 \%$ ). A comparison of BL1 (week 1) with BL3 (week 5) revealed that the student obtained the same values for verbal comprehension $(60 \%)$ and reading (58\%) and advanced slightly in spelling (from 58 to 


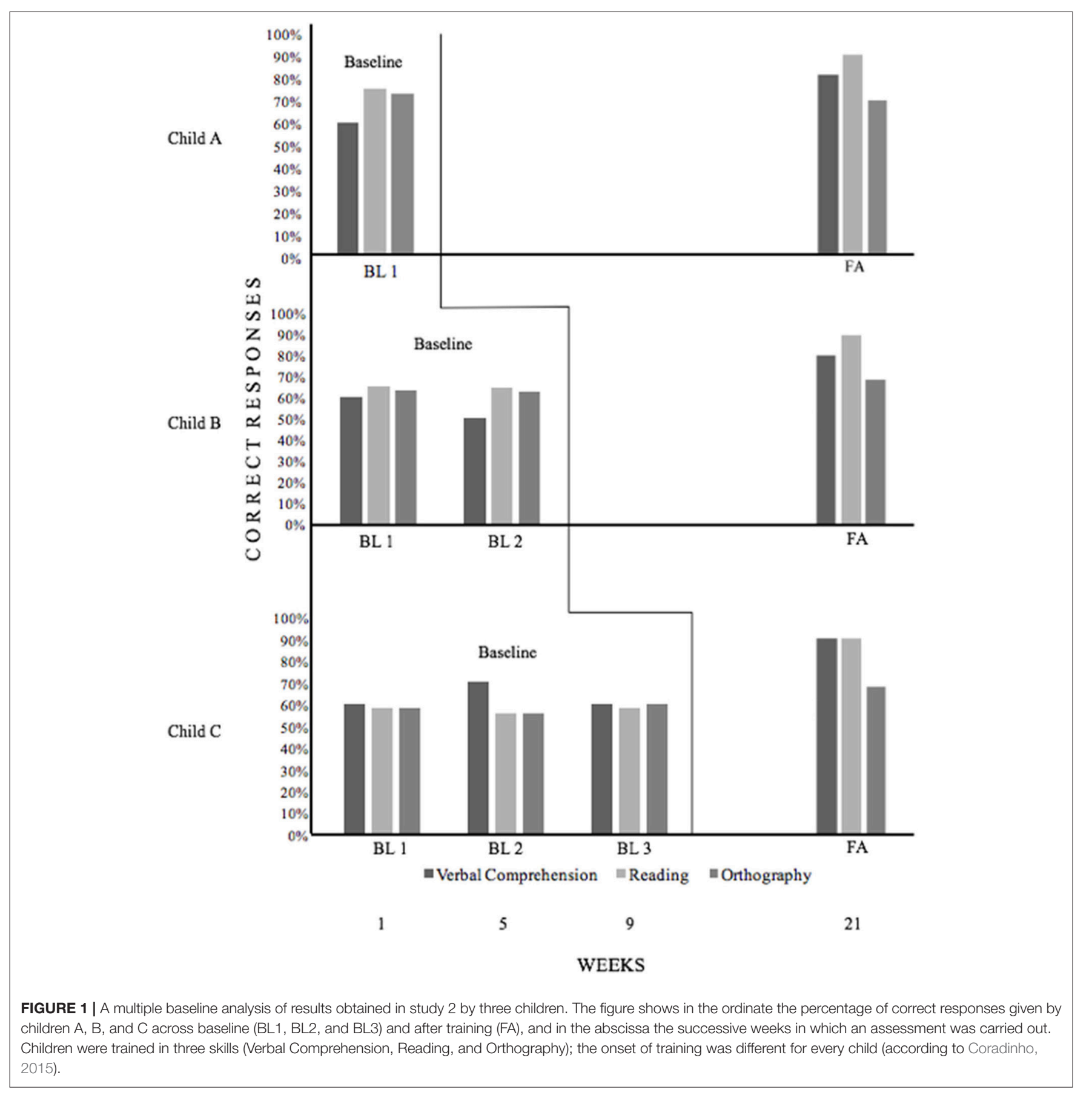

$60 \%$ ). Finally, a comparison of BL3 (week 9) with FA (week 21) showed considerable increases in verbal comprehension (from 60 to $100 \%$ ) and in reading (from 60 to $100 \%$ ) and a modest increase in spelling (from 60 to $75 \%$ ). This child's improved performance seems to have occurred with 11 weeks' training, i.e., $33 \mathrm{~h}$.

\section{Discussion}

These data seem to show that increases in positive responses occur consistently after training. Improvements without training were rare, but they did occur, such as, with child B (from week 1 to 5 in verbal comprehension), showing that positive changes can also result from other variables (probably the teaching at school). Nevertheless, decreases of correct responses occurred frequently without training, for instance with child B from BL1 to BL2 in all programs, revealing that regular teaching at school does not seem to improve these children's results and that a lack of systematic training might produce negative changes. The results of this study suggest that there was little change in children's performance following normal school activities (without training). When changes did occur, they were small and performance decreases 
were more common than increases. On the other hand, increases in academic and pre-academic behavior following the Behavioral Skills Training were evident in all cases and in all subjects. The following introduction of treatment resulted in considerable increases over baseline levels. These changes were obtained without corresponding changes in untreated baselines. The results of this multiple baseline analysis indicate that training generated improvement in all three children. It effectively enhanced performance in verbal comprehension, reading and spelling. All three children showed an obvious increase in the percentage of correct responses following the application of the training programs. This is to say that the multiple baseline analysis indicated that changes from baseline levels occurred only when training was directed to a specific child. The extent of the changes in the targeted child provides strong support for the effectiveness of the training package used. These results coincide with data obtained by Galindo (2015) with a similar quasi-experimental design, applying the same teaching strategies to students of a different environment, namely, children of a very low SES living in the slums of a big city, with problems of marginalization due to poverty or ethnic origins. In the Alentejo, these children were not living in conditions of exclusion. Their school failure problems coincided with family difficulties (Child B) or with health problems (Child C) or had no identifiable origin (Child A). In both multiple baseline studies, comparable results occurred across students, demonstrating the replication of the effects of the training programs.

\section{GENERAL DISCUSSION AND CONCLUSIONS}

The results from both of the current studies show an apparent improvement of all children following Behavioral Skills Training. It seems that the observed advanced resulted from the intervention programs and not daily classroom teaching. These results confirm earlier findings (Galindo, 2008, 2013, 2015) and coincide with those of authors working in the same line in different countries (Carroll et al., 2003; DiLalla et al., 2004; Leppänen et al., 2004; Connor et al., 2005; Guevara and Macotela, 2006), especially in relation to the kinds of behavioral repertoires that should be addressed in the case of school failure, i.e., not only academic, but also precurrent behaviors.

"Precurrent behaviors are those that increase the effectiveness of a subsequent (current) behavior in obtaining a reinforce." (Polson and Parsons, 1994, as cited by Levingston et al., 2009, p. 361). These behaviors are skills that are essential, as they form the basis for learning other skills. Many children fail to learn reading and writing for one of the following reasons: because they cannot discriminate forms and colors; or they lack motor coordination; or they have problems in verbal behavior. A lack of just one precurrent skill can have devastating consequences in the acquisition of reading, writing, or arithmetic. That is also the conclusion of Levingston et al. (2009) and Neef et al. (2003) in the teaching of arithmetic. Academic behavior is the main concern of teachers and scientists interested in school failure. Now, it is essential to define precisely, for each case, what the teacher is expecting and what the child can actually do. Social skills must be an integral part of any intervention. Many children with school failure problems also have behavioral problems and it is difficult to say if one is a cause or a consequence of the other. In either case, in order to solve academic failure, you might have to work simultaneously with social and academic skills (Monjas et al., 2014).

A word about the motivational is necessary. Most children with these kinds of problems do not want to learn. It is necessary to create a motivational system. A token economy seems to be the best solution.

In general terms, teachers reported significant positive changes in the children's behavior at school. Nevertheless, some complained that no changes were evident in academic behavior. It must be recognized that the developmental aims of the child and the academic aims of the teacher do not necessarily coincide.

It is difficult to determine the exact causes of the problems addressed, but all children belonged to a low SES and many had bad family relationships (parents in conflict or in a process of separation) or former health problems, or all those combined. Finding possible causes in the past development or in the present situation is always possible, but most of the time it is impossible to identify clearly the cause of school failure in individual cases. It seems that the individual problems of a child are a result of a set of bad coincidences at an important stage of development: the child missed the chance to learn the expected thing at the right moment for some reason and is not able to learn it later for other reasons. It is important to develop effective training procedures, independently of the factors causing the problem. Our results seem to show that programs of this kind can be applied successfully at school in order to train these kinds of skills, whose absence causes academic difficulties. Nevertheless, the present study is only a first contribution toward resolving school failure, for the following reasons:

1) Solving some academic problems still does not mean that the child will be successful. Additional training in other areas might be necessary.

2) More research on the long-term effects of these training programs is needed.

3) It is necessary to work with other problems at different school years.

4) It is necessary to work not only on the cognitive, but also the emotional problems of children with school failure.

5) A long-term observation of trained children is necessary.

6) It is necessary to develop more economic procedures to train children.

Although in this study the number of participants was relatively small, these ABA techniques already have a long history of success in training of people with intellectual, sensorial, physical, and social incapacities. Thus, it is not surprising to find they can be adapted to train children at educational risk. The current studies have demonstrated that BST techniques can be successfully applied to train children with problems of school failure. It has also been shown that a multiple baseline design can be a good choice for demonstrating the effects of training on a varied set of students. A further development of these training programs might constitute a sound psychological contribution to solving school failure as a social problem. 


\section{ETHICS STATEMENT}

This research was carried on in the frame of an agreement between University of Evora (signed by Vice-Reitor Paulo Quaresma) and Malagueira School Group (signed by Diretora Isabel Gomes) and approved by an Ethic Commission of the University of Evora (President Prof. Armando Raimundo). Written informed consent was obtained from the parents of the participants.

\section{AUTHOR CONTRIBUTIONS}

EG and AC: Conceptualization; EG: Methodology; MS: Formal analysis and supervision; HP and LG: Investigation; AC: Writingreview and editing.

\section{REFERENCES}

Adelman, H. S., and Taylor, L. (1993). Learning Problems and Learning Disabilities: Moving Forward. Pacific Grove, CA: Brooks/Cole Publishing Company.

Axe, J. B., and Sainato, D. M. (2010). Matrix training of preliteracy skills with preschoolers with autism. J. Appl. Behav. Anal. 43, 635-652. doi: 10.1901/jaba.2010.43-635

Ayllon, T., and Azrin, N. H. (1968). The Token Economy: A Motivational System for Therapy and Rehabilitation. Englewood Cliffs, NJ: Prentice Hall.

Barnes, C. S., Dunning, J. L., and Rehfedlt, R. A. (2011). An evaluation of strategies for training staff to implement the picture exchange communication system. Res. Autism Spectr. Disord. 5. 1574-1583. doi: 10.1016/j.rasd.2011.03.003

Bornstein, M. R., Bellack, A. S., and Hersen, M. (1977). Social-skills training for unassertive children: a multiple-baseline analysis. J. Appl. Behav. Anal. 10, 183-195. doi: 10.1901/jaba.1977.10-183

Carbonero, M. A., Martin, L. J., Otero, L., and Monsalvo, E. (2017). Program to promote personal and social responsibility in the secondary classroom. Front. Psychol. 8:809. doi: 10.3389/fpsyg.2017.00809.

Carroll, J. M., Snowling, M. J., Hulme, C., and Stevenson, J. (2003). The development of phonological awareness in preschool children. Dev. Psychol. 39, 913-923. doi: 10.1037/0012-1649.39.5.913

Connor, C. M., Son, S., Hindman, A. H., and Morrison, F. J. (2005). Teacher qualifications, classroom practices, family characteristics and preschool experience: complex effects on first graders vocabulary and early reading outcomes. J. School Psychol. 43, 343-375. doi: 10.1016/j.jsp.2005. 06.001

Coradinho, H. I. F. (2015). O Insucesso Escolar - Da Avaliação à Intervenção Cognitivo- Comportamental (School failure: From evaluation to intervention). Master's thesis, University of Evora, Evora.

Danish, S. J., D'Augelli, A. R., and Brock, G. W. (1976). An evaluation of helping skills training: effects on helpers' verbal responses. J. Couns. Psychol. 23, 259-265. doi: 10.1037/0022-0167.23.3.259

DiLalla, L. F., Marcus, J. L., and Wright-Phillips, M. V. (2004). Longitudinal effects of preschool behavioral styles on early adolescent school performance. J. School Psychol. 42, 385-401. doi: 10.1016/j.jsp.2004.05.002

Direção-Geral de Estatísticas da Educação e Ciência (DGEEC) (2014). Regiões em Números 2012/2013 - Volume IV - Alentejo (Regions in numbers 2012/2013 - Volume IV-Alentejo). Lisboa: DGEEC. Available online at: http://www.dgeec.mec.pt/np4/96/\%7B\$clientServletPath\%7D/ ?newsId=145\&fileName=ReN_Vol_IV_Alentejo_1213.pdf

European Commission/Directorate-General for Education and Culture (EC DGEC) (2016). Education and Training Monitor 2016. Brussels: EC DGCEC.

Eurydice (2011). Grade Retention during Compulsory Education in Europe: Regulations and Statistics. Brussels: Education, Audiovisual and Culture Executive Agency.

\section{FUNDING}

This research did not receive any grants from funding agencies in the public, commercial, or non-profit sectors. Publication is financed with National Funds through FCT - Foundation for Science and Technology, within the scope of the project Center for Research in Education and Psychology-(CIEP)UID/CED/04312/2016 and the School of Social Science (ECS) of the University of Évora. Neither funding entity participated in any way in the study design, data analysis, or write up, nor in decisions regarding submission for publication.

\section{ACKNOWLEDGMENTS}

Portions of the present findings were obtained by Coradinho (2015) as a part of her Master's thesis.

Fernandez Enguita, M., Mena Martinez, L., and Riviere Gomez, J. (2010). School Failure and Dropouts in Spain. Madrid: Fundación "La Caixa". Available online at: https://multimedia.caixabank.es/lacaixa/ondemand/obrasocial/pdf/ estudiossociales/vol29_en.pdf

Gabinete de Estatística e Planeamento da Educação (2010). Perfil do Aluno 2008-2009. (Profile of School Children 2008-2009). Available online at: http:// www.dgeec.mec.pt/np4/97/\%7B \protect \T1\textdollarclientServletPath\%7D/? newsId=147\&fileName=Perfil_Aluno_2008_09.pdf

Galindo, E. (2008). Treatment of school failure with behavioral techniques. Int. J. Psychol. 43, 568-568. doi: 10.1080/00207594.2008.10108486

Galindo, E. (ed.). (2009). Psicología y Educación Especial (Psychology and Special Education) 2nd Edn. Mexico: Ed. Trillas.

Galindo, E. (2013). "Intervenção cognitivo-comportamental em casos de insucesso escolar (Cognitive-behavioural intervention in cases of school failure) [DVD]," in Atas do XII Congresso Internacional Galego-Português de Psicopedagogia (Braga: Universidade do Minho, Setembro de 2013).

Galindo, E. (2015). Tratamento do Insucesso Escolar com Técnicas da Psicología: Manual Prático (Treatment of School Failure With Techniques of Psychology: A Practical Handbook). Lisboa: Livros Horizonte.

Galindo, E., Galguera, M. I., Taracena, E., and Hinojosa, G. (2013). La Modificación de Conducta en la Educación Especial. Diagnóstico y Programas (Behavior Modification in Special Education: Diagnosis and Programs) 4th Edn. Mexico: Editorial Trillas.

Gianoumis, S., Seiverling, L., and Sturmey, P. (2012). The effects of behavior skills training on correct teacher implementation of natural language paradigm teaching skills and child behavior. Behav. Interv. 27, 57-74. doi: 10.1002/bin. 1334

Gordon, S. B., and Davidson, H. (1981). "Behavioral parent training," in Handbook of Family Therapy, eds A. S. Gurman and D. P. Kniskern (New York, NY: Brunner/Mazel), 517-555.

Green, C. W., Reid, D. H., Rollyson, J. H., and Passante, S. C. (2005). An enriched teaching program for reducing resistance and indices of unhappiness among individuals with profound multiple disabilities. J. Appl. Behav. Anal. 38, 221-233. doi: 10.1901/jaba.2005.4-04

Guevara, Y., and Macotela, S. (2006). Evaluación del avance académico en alumnos de primer grado (Evaluating academic advances in first grade school children). Rev. Mexicana Anál. Conduc. 32, 129-153.

Hallahan, D., Kauffman, J., and Lloyd, J. W. (1999). Introduction to Learning Disabilities. Boston, MA: Allyn and Bacon.

Homlitas, C., Rosales, R., and Candel, L. (2014). A further evaluation of behavior skills training for implementation of the picture exchange communication system. J. Appl. Behav. Anal. 47, 198-203. doi: 10.1002/jaba.99

Jerome, J., Frantino, E. P., and Sturmey, P. (2007). The effects of errorless learning and backward chaining on the acquisition of internet skills in 
adults with developmental disabilities. J. Appl. Behav. Anal. 40, 185-189. doi: 10.1901/jaba.2007.41-06

Johnson, B. M., Miltenberger, R. G., Egemo-Helm, K., Jostad, C. M., Flessner, C., and Getheridge, B. (2005). Evaluation of behavior skills training for teaching abduction prevention skills to young children. J. Appl. Behav. Anal. 38, 67-78. doi: 10.1901/jaba.2005.26-04

Johnston, J. M., and Pennypacker, H. S. (2009). Strategies and Tactics of Behavioral Research. New York, NY: Routledge.

Justino, D., Pascueiro, L., Franco, L., Santos, R., Almeida, S., and Batista, S. (2014). Atlas da Educação. Contextos Sociais e Locais do Sucesso e Insucesso. Portugal 1991-2012 (Atlas of Education. Social and Local Contexts of Success and Failure. Portugal 1991-2012). Lisboa: CESNOVA- EPIS.

Krohn, K. R., Skinner, C. H., Fuller, E. J., and Greear, C. (2012). Using a taped intervention to improve kindergarten students' number identification. J. Appl. Behav. Anal. 45, 437-441. doi: 10.1901/jaba.2012.45-437

Leppänen, U., Niemi, P., Aunola, K., and Nurmi, J. E. (2004). Development of reading skills among preschool and primary school pupils. Read. Res. Quat. 39, 72-93. doi: 10.1598/RRQ.39.1.5

Levingston, H. B., Neef, N. A., and Cihon, T. M. (2009). The effects of teaching precurrent behaviors on children's solution of multiplication and division word problems. J. Appl. Behav. Anal. 42, 361-367. doi: 10.1901/jaba.2009.42-361

Marchesi, A., and Hernández Gil, C. (eds.). (2003). El Fracaso Escolar. Una Perspectiva Internacional. (School Failure: An International Perspective). Madrid: Alianza Ed.

Miles, N. I., and Wilder, D. A. (2009). Effects of behavioral skills training on caregiver implementation of guided compliance. J. Appl. Behav. Anal. 42, 405-410. doi: 10.1901/jaba.2009.42-405

Miltenberger, R., Gross, A., Knudson, P., Bosch, A., Jostad, C., and Breitwieser, C. B. (2009). Evaluating behavioral skills training with and without simulated in situ training for teaching safety skills to children. Educ. Treat. Child. 32, 63-75. doi: 10.1353 /etc. 0.0049

Minkin, N., Braukmann, C. J., Minkin, B. L., Timbers, G. D., Timbers, B. J., Fixsen, D. I., et al. (1976). The social validation and training of conversational skills. J. Appl. Behav. Anal. 9, 127-139. doi: 10.1901/jaba.1976.9-127

Monjas, M. I., Martin, M. J., Garcia-Bacete, F. J., and Sanchiz, M. L. (2014). Rejection and victimization among first graders primary school with education support needs. Anal. Psicol. 30, 499-511. doi: 10.6018/analesps.30.2.158211

Mueller, M. M., Piazza, C. C., Moore, J. W., Kelley, M. E., Bethke, S. A., Pruett, A. E., et al. (2003). Training parents to implement pediatric feeding protocols. J. Appl. Behav. Anal. 36, 545-562. doi: 10.1901/jaba.2003.36-545

Neef, N. A., Nelles, D. E., Iwata, B. A., and Page, T. J. (2003). Analysis of precurrent skills in solving mathematics story problems. J. Appl. Behav. Anal. 36, 21-33. doi: 10.1901/jaba.2003.36-21

Nigro-Bruzzi, D., and Sturmey, P. (2010). The effects of behavioral skills training on mand training by staff and unprompted vocal mands by children. J. Appl. Behav. Anal. 43, 757-761. doi: 10.1901/jaba.2010.43-757

Organization for Economic Co-operation and Development (OECD) (2010). Overcoming Failure at Schoo: Policies That Work. Paris: OECD.

Pan-Skadden, J., Wilder, D. A., Sparling, J., Severtson, E., Donaldson, J., Postma, N., et al. (2009). The use of behavior skills training and in-situ training to teach children to solicit help when lost: a preliminary investigation. Educ. Treat. Child. 32, 359-370. doi: 10.1353/etc.0.0063

Parsons, M. B., and Reid, D. H. (1995). Training residential supervisors to provide feedback for maintaining staff teaching skills with people who have severe disabilities. J. Appl. Behav. Anal. 28, 317-322. doi: 10.1901/jaba.1995. 28-317
Poche, C., Brouwer, R., and Swearinegen, M. (1981). Teaching selfprotection to young children. J. Appl. Behav. Anal. 14, 169-175. doi: 10.1901/jaba.1981.14-169

Polson, D. A. D., and Parsons, J. A. (1994). Precurrent contingencies: Behavior reinforced by altering reinforcement probability for other behavior. J. Exp. Anal. Behav. 61, 427-439. doi: 10.1901/jeab.1994.61-427

Rodriguez-Medina, J., Martin, L. J., Carbonero, M. A., and Ovejero, A. (2016) Peer-mediated intervention for the development of social interaction skills in high-functioning autism spectrum disorder: a pilot study. Front. Psychol. 7:1986. doi: 10.3389/fpsyg.2016.01986

Sarokoff, R. A., and Sturmey, P. (2004). The effects of behavioral skills training on staff implementation of discrete-trial teaching. J. Appl. Behav. Anal. 37, 535-538. doi: 10.1901/jaba.2004.37-535

Saunders, K. J., O' Donnell, J., Vaidya, M., and Williams, D. C. (2003). Recombinative generalization of within-syllable units in non-reading adults with mental retardation. J. Appl. Behav. Anal. 36, 95-99. doi: 10.1901/jaba.2003.36-95

Seiverling, L., Williams, K., Sturmey, P., and Hart, S. (2012). Effects of behavioral skills training on parental treatment of children's food selectivity. J. Appl. Behav. Anal. 45, 197-203. doi: 10.1901/jaba.2012.45-197

Toussaint, K. A., and Tiger, J. H. (2010). Teaching early braille literacy skills within a stimulus equivalence paradigm to children with degenerative visual impairments. J. Appl. Behav. Anal. 43, 181-194. doi: 10.1901/jaba.2010.43-181

Wallace, G., Larsen, S., and Elksnin, L. (1992). Educational Assessment of Learning Problems. Boston, MA: Allyn and Bacon.

Ward-Horner, J., and Sturmey, P. (2012). Component analysis of behavior skills training in functional analysis. Behav. Interv. 27, 75-92. doi: 10.1002/bin.1339

Webster-Stratton, C., Reid, M. J., University of, W. A., and Stoolmiller, M. (2008). Preventing conduct problems and improving school readiness: evaluation of the incredible years teacher and child training programs in high-risk schools. J. Child Psychol. Psychiatry 49, 471-488. doi: 10.1111/j.1469-7610.2007. 01861.x

Whitman, T. L., Zakaras, M., and Chardos, S. (1971). Effects of reinforcement and guidance procedures on instruction-following behavior of severely retarded children. J. Appl. Behav. Anal. 4, 283-290. doi: 10.1901/jaba.1971.4-283

Wood, D. K., Frank, A. R., and Wacker, D. P. (1998). Teaching multiplication facts to students with learning disabilities. J. Appl. Behav. Anal. 31, 323-338. doi: 10.1901/jaba.1998.31-323

Wurtele, S. K., Kast, L. C., Miller-Perrin, C. L., and Kondrick, P. A. (1989). Comparison of programs for teaching personal safety skills to preschoolers. J. Consult. Clin. Psychol. 57, 505-511. doi: 10.1037/0022-006X.57.4.505

Yeaton, W. H., and Bailey, J. S. (1983). Utilization analysis of pedestrian safety training program. J. Appl. Behav. Anal. 16, 203-216. doi: 10.1901/jaba.1983.16-203

Conflict of Interest Statement: The authors declare that the research was conducted in the absence of any commercial or financial relationships that could be construed as a potential conflict of interest.

Copyright (c) 2018 Galindo, Candeias, Pires, Grácio and Stück. This is an open-access article distributed under the terms of the Creative Commons Attribution License (CC $B Y)$. The use, distribution or reproduction in other forums is permitted, provided the original author(s) and the copyright owner are credited and that the original publication in this journal is cited, in accordance with accepted academic practice. No use, distribution or reproduction is permitted which does not comply with these terms. 


\title{
A National Early Intervention System as a Strategy to Promote Inclusion and Academic Achievement in Portugal
}

\author{
Vitor Franco ${ }^{1,2 *}$, Madalena Melo 1,3, Graça Santos ${ }^{1,2}$, Ana Apolónio ${ }^{4}$ and Leonor Amaral5 \\ ${ }^{1}$ Department of Psychology, University of Évora, Évora, Portugal, ${ }^{2}$ Research Center for Education and Psychology, \\ University of Évora, Évora, Portugal, ${ }^{3}$ Interdisciplinary Center for History, Culture and Societies, University of Évora, Évora, \\ Portugal, ${ }^{4}$ Associação Portuguesa de Pais e Amigos do Cidadão Deficiente Mental, Évora, Portugal, ${ }^{5}$ ISPA-Instituto \\ Universitário, Lisbon, Portugal
}

OPEN ACCESS

Edited by: Edgar Galindo,

University of Évora, Portugal

Reviewed by:

Maria Joao Beja,

University of Madeira, Portugal

Jose-Maria Roman,

University of Valladolid, Spain

*Correspondence:

Vitor Franco

vfranco@uevora.pt

Specialty section: This article was submitted to Educational Psychology, a section of the journal

Frontiers in Psychology

Received: 10 February 2017 Accepted: 21 June 2017 Published: 05 July 2017

Citation:

Franco V, Melo M, Santos G, Apolónio A and Amaral L (2017) A National Early Intervention System as a Strategy to Promote Inclusion

and Academic Achievement in Portugal. Front. Psychol. 8:1137. doi: 10.3389/fpsyg.2017.01137
Early intervention with children at risk or facing developmental problems is a practice defined by three fundamental characteristics: being family-centered, being based on the community and on the child's life context, and being conducted by a team with transdisciplinary practice. In this paper we wish to present how the SNIPINational System of Early Intervention, implemented in Portugal over the past 15 years, contributes to promote maximum development and the full inclusion of children up to 6 years of age and works to prevent school failure. The SNIPI covers the entire territory and intends to respond to the needs of children with developmental disorders or those in at risk situations. This community-based early intervention model is linked to the health, education and social care systems, involving the three responsible Ministries. In the present community case study, we present the implementation of this program in the Alentejo region, involving 31 local teams and almost 2500 children. Through the regional structure's reports and the responses of parents and professionals in impact studies, we demonstrate how the system is established and how it tackles school failure and improves the educational inclusion of these children. The impact of this Early Intervention model has been significant not only on children's developmental outcomes, but also for the health, education and social care professionals who work in a transdisciplinary perspective, as well as for the families who became more skilled at evaluating the children's needs and the support provided. This approach to implementing a familycentered Early Intervention program can contribute to full inclusion. It facilitates the transition to schooling based on a non-discriminatory approach and educational achievement by aiding development and an adapted contextualization in pre-school education. This program system introduces significant innovation within the framework of existing educational policies that promote development and inclusion, and has therefore earned the interest of the scientific community and policy-makers alike. It has been possible to implement some of principles already studied but it had never been tested. The Early Intervention program in Alentejo, as part of the SNIPI, can be an example of good practices, with its own characteristics that allowed to create a network of integrated and comprehensive responses to the needs of the population in this region. 


\section{INTRODUCTION: A COMMUNITY BASED MODEL OF EARLY INTERVENTION IN PORTUGAL}

\section{Historical Perspective}

In recent years, Portugal has implemented a National System for Early Intervention (SNIPI) has been implemented. This system covers the entire territory and is intended to respond to the needs of the children with disabilities or at serious risk of developmental delay.

This Early Intervention community based model has, as its first fundamental and innovative feature, the articulation between health, education and social security services, and it is supported by a specific legal framework (DecretoLei 281/2009, 2009) resultant from the work of three Ministries.

Usually, care for children with developmental disorders is distributed between three institutions: The Ministry of Social Security is responsible for rehabilitation institutions and organizations working with people with disabilities; The Ministry of Health oversees therapeutic and clinical interventions; and the Ministry of Education safeguards children's educational needs. Each of these fields has its own methodologies and emphases and all tended to work separately and without major articulation in the past.

The care of children with developmental disorders has progressed in Portugal, as in other countries, since the 1970s with the emergence of expert centers and non-governmental associations. These tried to address the needs of specific groups of children or people with disabilities or some other issues such as intellectual disabilities, cerebral palsy, etc. Later, more alternatives emerged (catering to the children under the age of six) and some of them reflected an effort to combine different fields, in particular health, education and social security.

Prior to the aforementioned regulatory legislation, a dispatch issued by the Government in 1999 (Despacho Conjunto $891 / 99$, 1999) supported more or less the responses already in place throughout the country. These alternatives included the traditional approaches with regards to rehabilitation and reduction of problematics hinging on isolated measures: therapy and special education. All of these interventions focused on the problem and on the child.

The publication of these regulations constituted a fundamental landmark in Early Intervention in Portugal. This new legislation has determined the implementation of a national system, within the framework of a privileged partnership between the three subscribing Ministries, Education, Health and Labor and Solidarity, with the involvement of the NGO's, legally defined as support entities of the Local Intervention Teams (LIT).

The legal framework of these teams was enacted through the conclusion of cooperation agreements. The concerted action of all these entities gave body to and framed the constitution of multidisciplinary teams. The aim was to provide direct support to children and their families in the context of their daily lives and with the involvement of the community.
For the first time, a type of organization and methodology was defined: A community-centered workgroup based on the capabilities and functioning of the different contexts of the child's life, and a family-centered intervention methodology.

This organizational system met some implementation difficulties at a national level, but has since matured in some regions where it was possible to create the network of teams that were able to test the feasibility and effectiveness of a nation-wide project.

After a lengthy review process, new legislation (DecretoLei 281/2009, 2009) created the National System of Early Intervention (SNIPI) and provided the tools for its implementation throughout the national territory. This legislation preserved the principles of the previous law and reinforced the role of health services in early detection and referral of children with developmental disorders or at risk of serious delay.

\section{The Structure of the National Early Intervention System (SNIPI)}

At the present, the National Early Intervention System is in place across the country, with some small discrepancies in the coverage and even in the operation mode. The SNIPI has a central structure, which is national and which articulates the general policies of operations, involving representatives of the three Ministries involved. There are intermediate structures (regional level) that ensure the implementation of these policies on the ground and provide coordination and supervision of local team's operations.

At the base of this pyramid, we find LIT which are composed of professionals from different fields. They provide the interventions with families and children, and the coordination with other services and institutions. Some fundamental structural principles are assumed as the basis for professional training and the production of guidelines (Carvalho et al., 2016). Three fundamental premises are emphasized: working with a family centered perspective, this model has to be based on the community and on the child's contexts, and the interventions have to be conducted by a transdisciplinary team (Guralnick, 2005).

The local teams and the system itself, have as guiding aims for the interventions, to promote the maximum development and also the maximum inclusion of children up to the age of 6 . When, at this age, children enter in Basic schooling (which is always done in mainstream schools) is expected that those whose development is altered or threatened will have better success because of the work already developed by early intervention.

\section{EARLY INTERVENTION AND PREVENTION OF EDUCATIONAL FAILURE}

The entry into compulsory Basic education represents an important challenge, for any child and family, one sometimes experienced with contradictory feelings. Research has shown 
that the process of transition to formal schooling implies the involvement of the educational agents (i.e., families, teachers, staff) and the interaction between the various organizational contexts of the mesosystem (Bronfenbrenner and Morris, 2006) in order to enable a smooth transition that encourages the development of the child and their sense of belonging to school (O’Kane, 2016).

In the case of children with developmental problems, issues related to the transition to formal education systems (kindergarten, school) are particularly important (Barnes-Holmes et al., 2013), especially regarding school readiness (UNICEF, 2012). But school readiness does not concern simply the child; it involves three interrelated dimensions: (a) ready children; (b) ready schools; and (c) ready families. "Children, schools and families are considered ready when they have gained the competencies and skills required to interface with other dimensions and support smooth transitions" (UNICEF, 2012, p. 3).

As systematically and clearly demonstrated by research, inclusive educational settings give children with special educational needs (SENs) greater academic and social gains.

There are several educational transitions throughout the child's life, beginning with the passage from the family context (home) to the nursery or kindergarten (including changes of setting in the preschool context: micro-transitions). But the transition to the school context represents the most important educational transition in the child's life (O'Kane, 2015). Many studies show that positive transition experiences are predictors of better social, emotional, and educational outcomes (Peters, 2010; Sayers et al., 2012; O’Kane, 2015).

The transition to school of children with SENs is particularly stressful for families (Peters, 2010; Barnes-Holmes et al., 2013), in particular due to concerns toward non-continuity of specialized support.

In the case of the national Early Intervention system, these concerns also seem to make sense. Indeed, this system promotes the mutual collaboration between families and technicians for the integral development of the child. By age 6, the child is integrated in a system that is family-centered and community-based.

The Early Intervention teams prepare the transition to preschool and their path in the kindergarten is followed attentively in close cooperation with the families in order to meet any potential emergent needs of the children.

In most cases, SNIPI teams and families are actively engaged in the child's process of transition of the child to preschool, planning and establishing effective communication with kindergartens and clarifying the roles of the various educational agents, which is a practice that promotes the development of the child and his educational and social success (Peters, 2010; Burgon and Walker, 2013; Ministry of Education, 2014).

The entry into primary school, however, implies more profound changes, both in the expectations of the child's roles (Bronfenbrenner, 1979) and in the demands of the context itself. Firstly, because the focus is more now on the child and less on the family, as well as on an individual educational plan. But secondly, because entry into formal schooling usually implies a change in child support services; they are now under the responsibility of special educational services (Ministry of Education), which represents a fundamental change regarding the philosophy of Early Intervention approaches.

These changes are accompanied by major concerns of the families, not only regarding the school readiness of their children (UNICEF, 2012), but particularly with regards to potential social relationships in which they may be involved. The issue of child social relationships appears to be one of the main concerns of the families related with their children's entrance to school (Burgon and Walker, 2013; Ministry of Education, 2013).

Early intervention contributes meaningfully to positive educational transitions, emphasizing collaborative work between all participants involved in the development of the child, reducing risk factors for the child (or increasing the child's ability to cope with these risk factors), and promoting their mental health an essential condition to increase the welfare, the possibilities of educational success, and the healthy development of children with SENs (Dunst, 2002; Hirst et al., 2011).

\section{COMMUNITY CASE STUDY: EARLY INTERVENTION NETWORK IN ALENTEJO}

\section{The Early Intervention System in Alentejo}

In order to highlight the impact of the Early Intervention System, we can look at how this network has been established in one of the first regions that successfully implemented this system.

Alentejo is the largest region of Portugal occupying one third of the national territory, including most of the south of the country. It consists of 3 districts, and part of another, for a total of 47 counties. The average population density is 23,4 inhabitants per $\mathrm{Km}^{2}$, the lowest in the country and one of the lowest in Europe.

The settlement is mostly concentrated around the district capitals (Évora, Beja and Portalegre) with a significant part of the rural population living in geographical and social isolation. High percentages of aging populations and low school enrollment rates are both present.

In 2015, there were 189 residents aged 65 and over for every 100 under 15 years, which is considerably higher than the national averages.

In Alentejo, the current organization of Early Intervention services began in 2001 with the constitution of the regional and district coordination teams and an initial survey of needs, which led to the construction of a network of county-based teams, including a few isolated teams already working in disabilitylinked institutions.

In 2002 there were 15 teams, supporting a total of 605 children with developmental problems and, in the years to follow, the number of children supported by Early Childhood Intervention teams significantly increased as this network spread throughout the region. Nowadays, there are 31 LIT that support the needs of children and families in Alentejo, according with the actual legislation (Decreto-Lei 281/2009, 2009), that enforces the national system. 


\section{The Current Early Intervention Network}

The current network is organized in a decentralized structure, with three levels of geographic organization depending on a Subcommission of Regional Coordination, which responds to the Commission of National Coordination and assures the management of the necessary resources for the implementation of the system in the region, in accordance with a national plan of action. The LIT have a multidisciplinary makeup. Each team has childhood educators, psychologists, social workers, physical, occupational and speech therapists, and sometimes doctors and nurses, in a total of nearly 300 professionals.

The system also includes 29 NGO's that ensure the legal framework for the teams through the celebration of Cooperation Agreements with the three responsible Ministries.

In 2015, 2471 children under the age of 6 years were supported in Alentejo (SNIPI-National System of Early Intervention, 2016): $60 \%$ of which had a developmental delay without known etiology, $18 \%$ were diagnosed with a specific condition or disability, and in $22 \%$ cases some development risk factors were identified.

The current model of early childhood intervention requires that the support be provided in the child's natural setting, with the active participation of parents and principal caregivers, in a partnership based on a trusting and close relationship. During $2015,14 \%$ of the children received support exclusively at home, $37 \%$ in the educational setting (kindergarten) and $41 \%$ benefited from the support in a mixed setting, that is, at home and at the kindergarten. In $8 \%$ of cases it was necessary to resort to another context of intervention, such as primary healthcare facilities and other specialized centers (SNIPI-National System of Early Intervention, 2016).

\section{Main Concepts and Framework}

The evolution in the structure of the SNIPI was accompanied by a conceptual modification. Early Intervention is defined as a measure of integrative support the aim of which is to develop specific actions of a preventive nature in the field of education; health and social security for children from 0 to 6 years, with disabilities, developmental delay or with serious risk of developing handicaps, and their families (Decreto-Lei 281/2009, 2009).

This care system should take into account a perspective of intervention in children's natural settings of life and to actively involve the principal caregivers, as developmental enhancers, in order to promote social inclusion.

The underlying Early Intervention concept, which has changed over time and according to the prevailing paradigms relating to child support and disability, relies on three fundamental pillars.

Firstly, Early Intervention recognizes the contributions of the neurosciences and the advances of knowledge of brain functions, including the cerebral plasticity (Johnston et al., 2001) as the ability of the brain to remodel according the experiences of life. The malleability and the fast maturation of the central nervous system of the newborn allows acting on possible injuries or disorders, in order to prevent future follow-ups, but it also means that, in situations of risk, the harmful stimuli have a greater impact in the development than in older children, due to the same plasticity. This can lead to a timely intervention (Shonkoff, 2010; Shonkoff and Levitt, 2010).

The knowledge resulting from the studies about child development, enhances the importance of the early times of life for the establishment of future skills, with a special emphasis on the mother-infant relationship and attachment as a secure base from which the child explores the world and acquires developmental skills. The transactional approach to development (Sameroff, 1983, 2010; Sameroff and Mackenzie, 2003) has been especially important in the field of early intervention. Research has equally shown children's precocious abilities to establish relationships to be crucial to their development. This perspective justifies an intervention focused on the family.

Bioecological contributions and perspectives are equally important (Bronfenbrenner, 1979; Bronfenbrenner and Morris, 2006) and enhance the systemic importance of life contexts in the promotion of development. Hence the support should be geared at strengthening the abilities needed for the child to reach autonomy and social inclusion (Guralnick, 2008, 2011).

SNIPI constructs its theoretical framework on the evidencebased research (Shonkoff, 2010) and presents itself as an intervention framework that whilst representing an investment, is a more effective application of resources with a improved development quality, thereby avoiding higher costs in the future (Guralnick and Conlon, 2007).

\section{Innovative Aspects of the Program}

This regional program presents innovative aspects which have led to a successful outcomes, more so than in other regions of the country, where the implementation has been much more difficult. The recognition that the needs of children with development disorders can only be fully evaluated, interpreted and tackled within the family and social setting the development takes place, implies community actions and with them the involvement of all local and broader resources throughout the region. Proximity solutions allowed a significant reduction of the children and families transport costs, which were almost entirely supported by the health system.

Furthermore, this program allowed a reduction in social and economic costs for families, given the presence of professionals in their home settings. At present, teams have cars, acquired by the Regional Health Administration of Alentejo, with community co-financing resources, which facilitates professional visits, and children and family travel, mainly in situations of great geographic isolation.

Building strong partnerships enabled creating adequate responses to the needs of children and families, with the involvement of the regional administrations of health services, education and social security. The articulation of these services has further developed the program and the monitoring of responses in order to reduce imbalances and avoid overlaps.

Other partnerships have been established with the secondary healthcare system, particularly with several hospitals that have ensured the support and the monitoring of children in pediatric subspecialties. 
The articulation with higher education institutions, which ensures the program's theoretical and scientific support, was promoted, as well as with the Schools of Education of Portalegre, Beja and the Department of Psychology of Évora University. These institutions organize training and research activities on a regular basis.

At a local level, working groups promote combined efforts to ensure several services that ensure answers to families' needs. At present, the program counts on the collaboration of 217 services: local authorities, health centers, schools, local social action services, other Social Solidarity institutions, security forces, volunteer firefighters, commissions for the protection of children, local development associations, amongst others.

Health services, especially family doctors, play an important role by signaling problematic situations and providing quick referral. Many early intervention teams are based in the health centers and this facilitates the articulation and the interconnection between the services and promotes early detection of developmental disorders.

All this networking increases the ability to provide solutions for complex problems inside the community, problems that go beyond the sectorial fields of education, health and social action, but which require integrated approaches/responses.

\section{Network Impact: Children, Families and Community}

The theoretical framework that supports the early intervention network emphasizes that it can obtain several types of results. At the development level, it aims to optimize the use of brain plasticity and the children's developmental potential, reducing the secondary effects of chronic disease and other disabilities. It promotes and reinforces attachment as a determinant factor in development, minimizes the negative influence of risk factors, and strengthens as well as enhances the child's ability to live in society. This prepares the children for the entry and progression in the education system from the age of 6.

For the family, it reinforces appropriate patterns of interaction and parental skills, helping to reduce family stress brought on by the situation. It also allows for the strengthening of formal and informal networks of social support for the family and can help reduce elements of social exclusion.

At the community level, it also plays an important role by promoting the articulation between services and bringing them closer to the target population, increasing quality and making resources more cost effective. Finally, it promotes social inclusion, because the different partners are focused on problemsolving.

A study carried out to evaluate the effective impact of the Early Intervention network in the Alentejo (Franco and Apolónio, 2008) has equally shown the effectiveness of its accomplishments:

(A) There is an effective strengthening of the role of health centers in the detection, signaling and referral of cases and an increase in the skills of health professionals in the assessment of development disorders. The impact on the detection and referral of cases to LIT and on the beginning of the intervention by those professionals is especially important as it has significantly reduced the age of diagnosis and the onset of the intervention.

(B) Early Intervention teams are an important element of the families' social support networks, being in many cases considered the most important element.

(C) Creation of the early intervention network had a strong impact on the activity of systems and services resulted in modifications in the practices of its professionals. With the increase of family centered work and a transdisciplinary functioning, professionals identified a strong impact on activity and services systems and a change in their own practices.

(D) Families found out a positive impact on children's development and on being more responsive to their needs.

The Early Intervention program in Alentejo, as part of the SNIPI, can be an example of good practices, with its own characteristics that allowed the creation of a regional network of integrated and comprehensive responses to the needs of the population. Its innovative character has been recognized, nationally and internationally, by being awarded two prizes. In October 2009, the program won the 2nd Prize of Good Health Practices in the context of their participation in the "Award for good practices on fairness, effectiveness and efficiency in health," awarded by APDH/HOPE \& FIH, with Novartis Oncology support. In 2010, this same program was distinguished by WHO - World Health Organization with the United Arab Emirates Foundation Prize for Health, for the contribution to the development of health in Portugal. These distinctions reinforced the importance of the work already done and the necessary commitment to reinforce the positive aspects and overcoming constraints that still exist, in order to expand this model across the country.

\section{CONCLUSION}

By looking at how children who receive early intervention find themselves in a better position to face the challenges of schooling and by evaluating the impact of the early intervention network at the level of the educational system, we confirm that:

(a) Children with developmental or educational problems need to receive support from a team of early intervention, with an effective network coverage;

(b) Kindergarten teachers who integrate these teams are experienced professionals. Most of them possess a specialized course, and all of whom have some experience in the field of early intervention (Dunst, 2009). They also consider themselves to be well-informed about early intervention (its theoretical foundations as well as its practices) and believe they have think they have increased their knowledge about development problems;

(c) Most of the teachers working in kindergarten classrooms do not possess any training in early intervention. However, their level of information about the early intervention system is high: they know how the network works, how to contact the LIT, and have in fact an effective contact with it and they know how to use the referral process; 
(d) Each teacher works with a considerable number of children and families (about 10), and most of the children are aged from 3 - to 5-years-old. There seems to be a good margin of progression in early intervention, and the number of children under 3 years is increasing;

(e) Children go to early intervention mainly as a result of being at risk situations because of family and social factors. Disability cases, or cases of severe developmental delays cases are significantly less. It is therefore important to:

- Define coherent methods to establish diagnosis or characterization of situations;

- Make a more specific characterization of children;

- Differentiate developmental aspects, for example, language skills, that requires working at the educational level from disabilities or to situations where pathology is present (Franco and Apolónio, 2011).

(f) The transition to elementary school is a very sensitive aspect, and includes the monitoring of other entities responsible for the protection of the child as well as for the social support to the family;

(g) Teachers recognize their practices reflect changes due to the work within the Early Intervention System. The bigger the use of specific assessment tools and intervention planning strategies, the more relevant change is brought on as result, empowering teachers ability to assess the needs of the child and the family and to promote changes in their own contexts. More than $80 \%$ of interventions are made at the child's or in the kindergarten/nursery, twice a week or once a week (with a duration of over an hour each).

(h) The intervention of the teachers is no longer focused only on the child, but also on their parents, on other teachers inside the kindergarten and even on other professionals the child works with. The family-centered intervention is considered one of the most significant benefits brought to the practice of these early intervention teachers, such as the ability to recognize the strengths and capabilities of the child and his family. Their work with families is mainly providing information, referrals and counseling, in the context of a close relationship. The

\section{REFERENCES}

Barnes-Holmes, Y., Scanlon, G., Desmond, D., Shevlin, M., and Vahey, N. (2013). A Study of Transition from Primary to Post-Primary School for Pupils with Special Educational Needs. County Meath: National Council for Special Education.

Bronfenbrenner, U. (1979). The Ecology of Human Development. Cambridge, MA: Harvard University Press.

Bronfenbrenner, U., and Morris, P. A. (2006). "The bioecological model of human development," in Handbook of Child Psychology: Theoretical Models of Human Development, 6th Edn, Vol. 1, eds W. Damon and R. M. Lerner (Hoboken, NJ: Wiley), 793-828. doi: 10.1002/9780470147658.chpsy0114

Burgon, J., and Walker, J. (2013). Successful Transitions from Early Intervention to School-Age Special Education Services. Wellington: New Zealand Council for Educational Research.

Carvalho, L., Almeida, I. C., Felgueiras, I., Leitão, S., Boavida, J., and Franco, V. (2016). Práticas Recomendadas em Intervenção Precoce na Infância: Um Guia para Profissionais. Coimbra: ANIP.

Decreto-Lei 281/2009 (2009). Diário da República, $1 .^{a}$ série - n. ${ }^{o} 193$ - 6.10.2009. Lisboa: Ministérios do Trabalho e Solidariedade Social, da Educação e da Saúde. transdisciplinary perspective is enhanced and hones skills such as the ability to spot difficulties shown by the children.

A global network operation contributes to:

(a) Inclusion: facilitating the transition, based on a non-discriminatory approach and that repudiates exclusion. On the contrary, the child receives care and support in a specific setting and the family assumes the center stage in this interventions.

(b) Educational achievement: by strengthening the development, and an adapted contextualization in pre-school education. That can also be possible because the children go to school with an effective screen of their developmental needs as well as the level of support necessary for each of them.

Consequently the system introduces major innovation within the framework of educational policies that promote development and inclusion, which has deserved the interest of the scientific community and of policy makers. It has been possible to implement some of principles already studied but it had never been tested at this level. It must be said that, for their implementation they require a proper educational policy context.

\section{AUTHOR CONTRIBUTIONS}

VF: Conception and design, manuscript preparation, and final approval of the version to be published. MM: Contributions to the conception of the work and drafting of the work. GS: Contributions to the design of the work, critical revision, and final approval of the version to be published. AA: Study design and data collection. LA: Study design, data collection, and final revision.

\section{FUNDING}

This paper was financed with National Funds through FCT Foundation for Science and Technology, within the scope of the project CIEP-UID/CED/04312/2016.

Despacho Conjunto 891/99 (1999). De 19 de Outubro, Orientações Reguladoras da Intervenção Precoce para Crianças com Deficiência ou em Risco de Atraso Grave do Desenvolvimento e Suas Famílias. Ministérios da Educação, da Saúde e do Trabalho e da Solidariedade. Diário da República, $2^{a}$ série. Lisboa: Ministérios da Educação, da Saúde e do Trabalho e Solidariedade Social.

Dunst, C. J. (2002). Family-centered practices: birth to high school. J. Spec. Educ. 36, 139-147. doi: 10.1177/00224669020360030401

Dunst, C. J. (2009). Implications of evidence-based practices for personnel preparation development in early intervention. Infants Young Child. 22, 44-53. doi: 10.1097/01.IYC.0000343336.34528.ea

Franco, V., and Apolónio, A. M. (2008). Evaluation of Early Intervention Impact in Alentejo. Évora: ARS.

Franco, V., and Apolónio, A. M. (2011). "Impacto da intervenção precoce no sistema educativo no alentejo," in Escola(s) do Alentejo: Um Mapa do Que se Aprende no Sul de Portugal, ed. B. NICO (Évora: Ed. Pedagogo), 316-323.

Guralnick, M. (2005). Early intervention for children with intellectual disabilities: current knowledge and future prospects. J. Appl. Res. Intellect. Disabil. 18, 313-324. doi: 10.1111/j.1468-3148.2005.00270.x 
Guralnick, M. J. (2008). International perspectives on early intervention: a search for common ground. J. Early Interv. 30, 90-101. doi: 10.1177/ 1053815107313483

Guralnick, M. J. (2011). Why early intervention works? A systems perspective. Infants Young Child. 24, 6-28. doi: 10.1097/IYC.0b013e3182002cfe

Guralnick, M. J., and Conlon, C. (2007). "Early intervention," in Children with Disabilities, eds M. Batshaw, L. Pelligrino, and N. Roizen (Baltimore, MD: Paul H. Brooks), 511-521.

Hirst, M., Jervis, N., Visagie, K., Sojo, V., and Cavanagh, S. (2011). Transition to Primary School: A Review of the Literature. Canberra, ACT: Commonwealth of Australia.

Johnston, M. V., Nishimura, A., Harum, K., Pekar, J., and Blue, M. W. (2001). Sculpting the developing brain. Adv. Pediatr. 48, 1-38.

Ministry of Education (2013). Transitions from Early Intervention to School-Age Special Education Services - An Overview of the Literature. Wellington: Ministry of Education.

Ministry of Education (2014). Transition to School: Guidelines for Early Intervention Providers. Wellington: Ministry of Education, New Zealand.

O'Kane, M. (2015). Multiple transitions. Paper Presented at the Symposium Early Educational Alignment: Reflecting on Curriculum and Pedagogy, Dublin.

O'Kane, M. (2016). Transition from Preschool to Primary School. Dublin: National Council for Curriculum and Assessment.

Peters, S. (2010). Literature Review: Transition from Early Childhood Education to School. Wellington: Ministry of Education.

Sameroff, A. J. (1983). "Developmental systems: contexts an evolution," in Handbook of Child Psychology: Theoretical Models of Human Development, Vol. 1, ed. P. H. Mussen (New York, NY: John Wiley \& Sons), 238-249.

Sameroff, A. J. (2010). A unified theory of development: a dialectic integration of nature and nurture. Child Dev. 81, 6-22. doi: 10.1111/j.1467-8624.2009. 01378.x
Sameroff, A. J., and Mackenzie, M. J. (2003). A quarter century of the transitional model of child development: How things have changed? Zero Three 24, 14-22.

Sayers, M., West, S., Lorains, J., Laidlaw, B., Moore, T. G., and Robinson, R. (2012). Starting school: a pivotal life transition for children and their families. Fam. Matters 90, 45-56.

Shonkoff, J. P. (2010). Building a new biodevelopmental framework to guide the future of early childhood policy. Child Dev. 81, 357-367. doi: 10.1111/j.14678624.2009.01399.x

Shonkoff, J. P., and Levitt, P. (2010). The neuroscience and the future of early intervention policy: moving from why to what and how. Neuron 67, 689-691. doi: 10.1016/j.neuron.2010.08.032

SNIPI- National System of Early Intervention (2016). Relatório de Actividades 2015- Subcomissão de Coordenação Regional do Alentejo. Évora: Subcomissão de Coordenação Regional do Alentejo.

UNICEF (2012). School Readiness and Transitions. New York, NY: UNICEF.

Conflict of Interest Statement: The handling Editor declared a shared affiliation, though no other collaboration, with several of the authors VF, MM, GS, and states that the process nevertheless met the standards of a fair and objective review.

The other authors declare that the research was conducted in the absence of any commercial or financial relationships that could be construed as a potential conflict of interest.

Copyright (C) 2017 Franco, Melo, Santos, Apolónio and Amaral. This is an open-access article distributed under the terms of the Creative Commons Attribution License (CC BY). The use, distribution or reproduction in other forums is permitted, provided the original author(s) or licensor are credited and that the original publication in this journal is cited, in accordance with accepted academic practice. No use, distribution or reproduction is permitted which does not comply with these terms. 


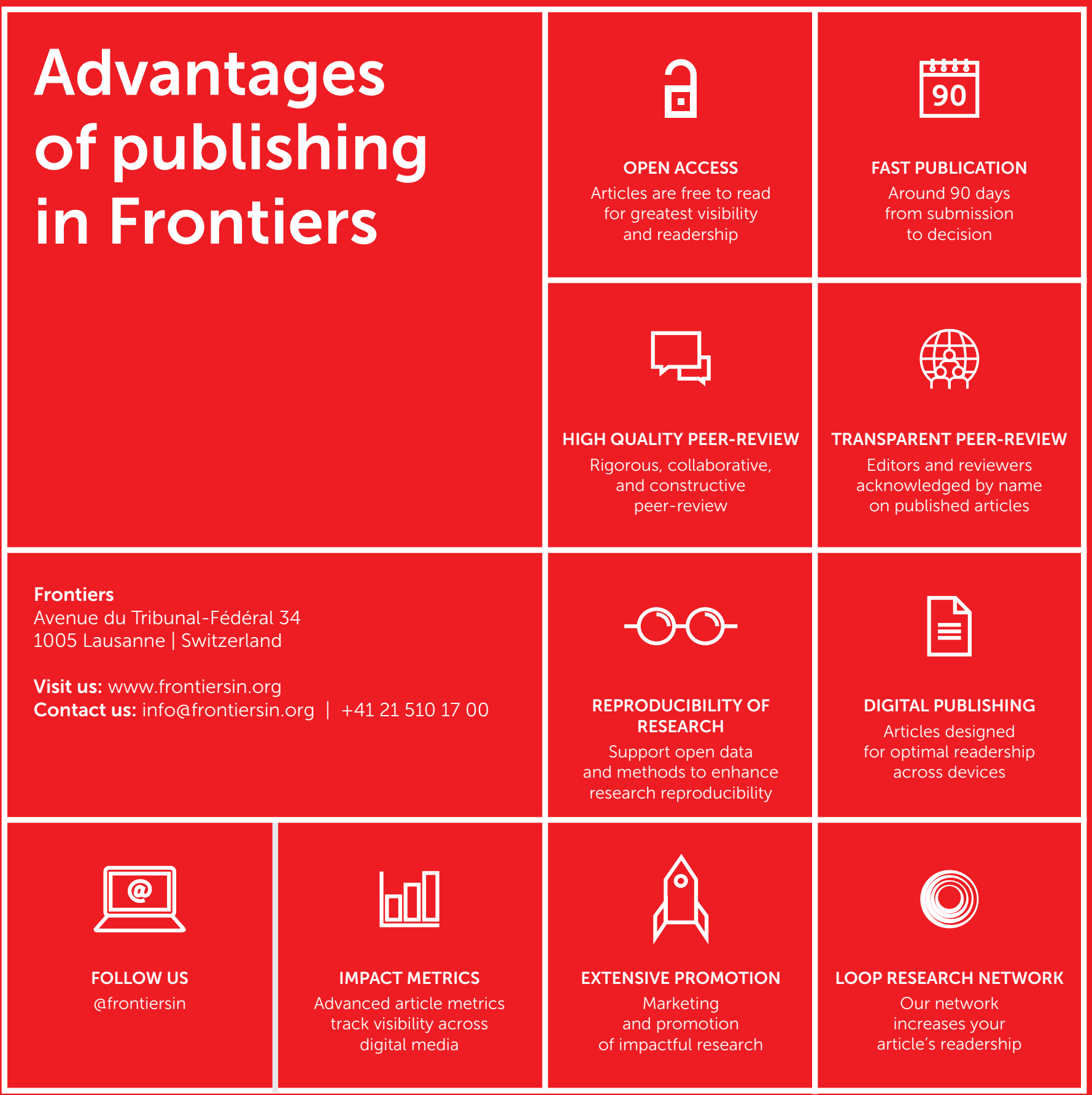

